University of Rhode Island

DigitalCommons@URI

Open Access Dissertations

1985

\title{
An Investigation of the Effect of Some Formulation and Manufacturing Variables on the Wet Granulation Process
}

Sambasiva Rao Ghanta

University of Rhode Island

Follow this and additional works at: https://digitalcommons.uri.edu/oa_diss

\section{Recommended Citation}

Ghanta, Sambasiva Rao, "An Investigation of the Effect of Some Formulation and Manufacturing Variables on the Wet Granulation Process" (1985). Open Access Dissertations. Paper 458.

https://digitalcommons.uri.edu/oa_diss/458

This Dissertation is brought to you for free and open access by DigitalCommons@URI. It has been accepted for inclusion in Open Access Dissertations by an authorized administrator of DigitalCommons@URI. For more information, please contact digitalcommons-group@uri.edu. 
AN INVESTIGATION OF THE EFFECT OF SOME FORMULATION

AND MANUFACTURING VARIABLES ON THE WET GRANULATION PROCESS

BY

SAMBASIVA RAO GHANTA

A DISSERTATION SUBMITTED IN PARTIAL FULFILLMENT OF

THE REQUIREMENTS FOR THE DEGREE OF

DOCTOR OF PHILOSOPHY

IN

PHARMACEUTICAL SCIENCES

UNIVERSITY OF RHODE ISLAND

1985 


\section{DOCTOR OF PHILOSOPHY DISSERTATION}

OF

SAMBASIVA RAO GHANTA

\section{Approved:}

Dissertation Committee

Major Professor
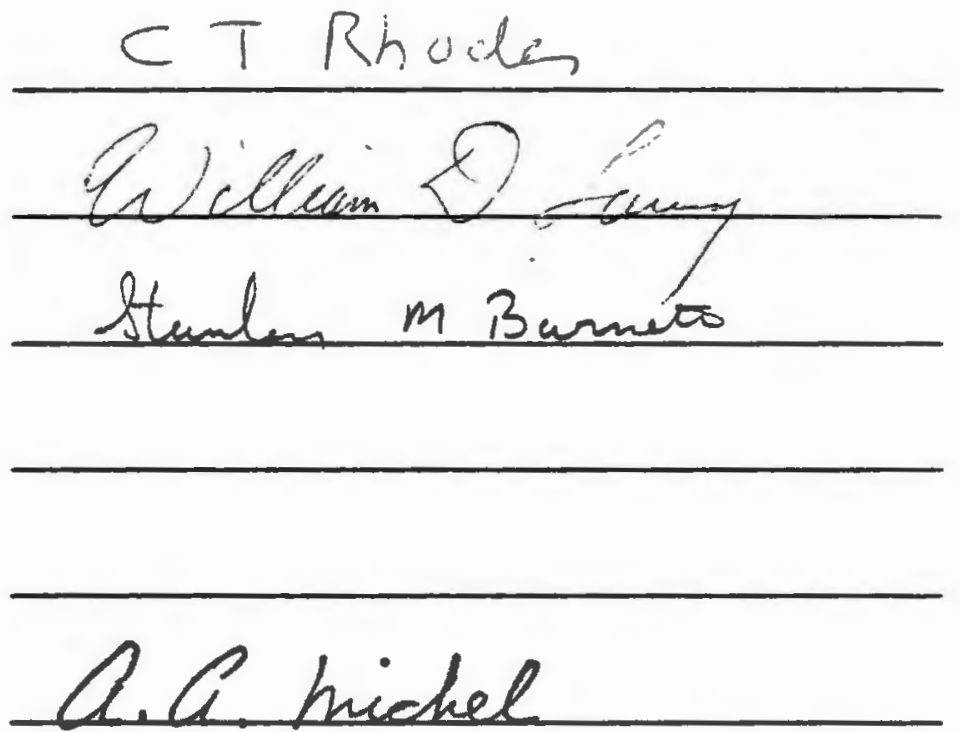

Dean of the Graduate School

UNIVERSITY OF RHODE ISLAND 


\section{ABSTRACT}

A Hobart mixer was instrumented with a slip ring torque sensor, signals were amplified and the output was recorded using a Bascom-Turner recorder. The relative dynamic torque on the paddle was measured in millivolts as a function of granulating fluid added and time. The data generated from a formulation containing lactose, corn starch and povidone were reproducibile. The maximum relative standard deviation was less than two percent at any time point on the torque curve. Formulations containing lactose, dicalcium phosphate and mannitol matrices (with four different drugs) showed five distinct phases in the torque profile. Phases I, II, and III of the wet granulation process were studied for formulations containing five drugs (phenylpropanolamine, theophylline, hydrochlorothiazide, phenytoin and acetaminophen). Granule properties were evaluated using scanning electron microscopy, particle size measurement and determination of bulk physical properties, including flow rate as well as compressibility. A computer-interfaced instrumented tablet press was used to generate compression profiles from which the compressibility of the granules was assessed. The instrumented tablet press data substantiated a simple theory for the relationship between granulation properties and ease of compaction.

The data suggest optimum flowable and compressible granulations can be obtained only from phase III of the process irrespective of the drug, drug concentration and matrix. The disintegration and hardness for some formulations (theophylline, phenylpropanolamine and hydrochlorothiazide) were sensitive to variations in the wet granulation 
process. However, dissolution and friability for these formulations were relatively insensitive to changes in the processing variables.

A $(3 \times 2 \times 3)$ factorial experimental design was used to investigate the effect of binder, binder level and granulating fluid on the wet granulation process. It was found that all these factors exerted statistically significant effects on granulations flow rate, tablet ejection force, hardness, disintegration and dissolution at fifteen and thirty minutes. A second factorial experimental design $(4 \times 5 \times 3)$ was used for the study of the effect of disintegrant, disintegrant concentration and percent intragranular disintegrant on the dissolution rate of tablets made by wet granulation process. The data indicate that these factors exerted statistically significant effects on disintegration and dissolution at fifteen and thirty minutes. This instrumentation can be used to determine the optimum amount of granulation fluid necessary for the wet granulation process. In addition, it can be a valuable tool for validation of the wet granulation process. 


\section{ACKNOWLEDGEMENTS}

I want to thank Dr. Christopher T. Rhodes for his interest, guidance and support throughout my graduate study. His unending patience and understanding will always be remembered.

I wish to thank the faculty members of the Department of Pharmaceutics, for their suggestions and assistance. Also, I want to acknowledge the interest, encouragement and sound advice of my committee members Dr. Stanley M. Barnett and Dr. William D. Lawing.

I extend my thanks and appreciation to Dr. Ragunath Srinivas, Mr. Melvin M. Noseworthy, Dr. David S. Dresback, Dr. Armando J. Aguiar and other friends at Pfizer Inc. for their support and encouragement throughout my graduate study.

In addition to acknowledging the help and advice of the several present and former Pfizer executives listed above, I also wish to record my thanks to Pfizer Inc., which, thanks to the support of these listed above, was most accomodating to me in my efforts to obtain the Ph.D degree. While I was a full time employee at the Groton facility, the company generously allowed me a modification in my work schedule, so that I could take courses at the University of Rhode Island. All my co-workers at Pfizer encouraged me to continue my studies.

I extend my thanks to Miss. Asa Tummala for the preparation of figures and Dr. George E. Osborne for proofreading this manuscript . 
To my wife,

\section{Bhavani}

\section{and to my children,}

Ravi and Ajay 
This manuscript is divided into seven sections, numbered in Roman numerals. The sections are: I. Introduction, II. Experimental, III. Results and Discussion, IV. Conclusions and suggestions for further work, V. References, VI. Appendices, and VII. Bibliography. The tables and figures are numbered in Roman and Arabic numerals respectively.

In this investigation, torque (mv) on the mixer paddle was recorded as a function of time and granulating fluid. In this thes is the term "phase of the wet granulation process", is often used. The meaning of the term is defined on the page 64 . In some instances, the abscissa in torque plots was marked from right to left, because of the type of chart recorder used. For the purpose of visual clarity, arrows were drawn to show the direction of increase in time and Arabic numerals were used to denote the phases on the figures rather than Roman numerals that were used in the text.

In some cases, the figures in this manuscript depict plots of relationship between two to six different batches. Therefore, for the purpose of visual clarity, both solid and dotted lines have been used. The dotted lines do not differ in any manner from the solid lines. In all cases, no mathematical or empirical relationships are implied; the lines are the result of the joining of the data points. All the error bars represent standard deviation unless otherwise marked differently in the key of the figure. 


\section{PUBLICATIONS AND PRESENTATIONS}

Based on the work presented in this manuscript, the following papers were published or presented at a national meeting. PUBLICATIONS

1. Use of Mixer-Torque measurements as an aid to optimizing the wet granulation process. Drug Development and Industrial Pharmacy, 10 (2), 302-311 (1984). S.R. Ghanta, R. Srinivas and C.T. Rhodes.

2. Some studies of the effect of processing variables on the properties of granules and tablets made by wet granulation. Pharmaceutics Acta Helvetiae, in press. S.R. Ghanta, R. Srinivas and C.T. Rhodes.

\section{PRESENTATIONS}

1. Use of Mixer-Torque measurements as an aid to optimizing the wet granulation process. Presented at 35 th national meeting of Academy of Pharmaceutical Sciences, Miami Beach, Florida. November, 1983. S.R. Ghanta, R. Srinivas and C.T. Rhodes.

2. Some studies of the effect of processing variables on the properties of granules and tablets made by wet granulation. Presented at 36 th national meeting of Academy of Pharmaceutical Sciences, Montreal, Canada. May, 1984. S.R. Ghanta, R. Srinivas and C.T. Rhodes. 
3. Some studies of the effect of formulation and processing variables on the properties of wet granulations. Presented at 132nd annual meeting of American Pharmaceutical Association, San Antonio, Texas. February, 1985. S.R. Ghanta, R. Srinivas and C.T. Rhodes.

4. Studies of wet granulation of relevence to validation and optimization of process. Presented at Society of Manufacturing Engineers meeting, Philadelphia, Pennsylvania. May, 1985. S.R. Ghanta and C.T. Rhodes 
Page

Abstract

Acknowledgements

Plan of the thesis

Publications and presentations

Table of contents

List of tables $x$

List of figures

I. Introduction

II. Experimental 20

III. Results and discussion 60

IV. Conclusions and suggestions for further work -- 210

V. References - 213

VI. Appendices - 219

VII. Bibliography - 235 
Table

I. Formulation 1 - 35

II. Phenylpropanolamine, theophylline and hydrochlorothiazide tablet formulations -

III. Phenytoin tablet formulations-_... 38

IV. Acetaminophen granule formulations -..-..- 40

V. Acetaminophen tablet formulations -

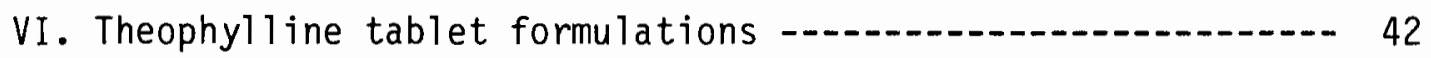

VII. Hydrochlorothiazide formulations with soluble and insoluble matrices. - - 44

VIIl. Experimental design I : Formulation variables (independent) - 45 IX. Factorial design - 45 $x$. Hydrochlorothiazide tablet formulations 47

XI. Experimental design II : Formulation variables (independent) 49

XII. Factorial design - $\quad 50$

XIII. Hydrochlorothiazide tablet formulations 54

XIV. Formulations with two different grades of lactose -...-. 56

$X V$. Lactose formulations with different levels of sucrose -...-- 57

XVI. Lactose formulations with different levels of Avicel PH 10158

XVII. Granulation of lactose with different rates of mixing -..--- 59

XVIII. Formulation 1 : Torque - Time Profile -......- 63

XIX. Particle size distribution of raw materials

$X X$. Particle size distribution of raw materials -............ 68 
LIST OF TABLES (continued)

Table

XXI. Bulk properties of raw materials -...- 69

XXII. Solubility and cohesiveness of drugs used in this study - 70

XXIII. Particle size distribution of hydrochlorothiazide granulations

XXIV. Granulation and tablet properties of hydrochlorothiazide formulations

XXV. Particle size distribution of phenytoin granulations --.- 87

XXVI. Granulation properties of phenytoin formulations -...-.- 88

XXVII. Tablet properties of phenytoin formulations - 89

XXVIII. Tablet properties of phenytoin formulation with

starch 1500

XXIX. Particle size distribution of acetaminophen granulations - 91

XXX. Granulation properties of acetaminophen formulations --.- 92

XXXI. Tablet properties of acetaminophen formulations -.-.-..- 93

XXXII. Theophylline granule and tablet properties (phase I) ---- 126

XXXIII. Theophylline granule and tablet properties (phase II) --- 127

XXXIV. Theophylline granule and tablet properties (phase III) -- 128

$x x x V$. Hydrochlorothiazide formulations with soluble or insoluble

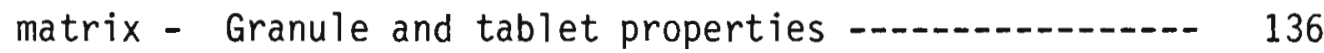

XXXVI. Exp. Design I : \% w/w granulating fluid/mixing time $(\mathrm{sec})-140$

XXXVII. Particle size distribution of

hydrochlorothiazide granulations (Granulating fluid:Water) 141 


\section{LIST OF TABLES (continued)}

Table

Page

XXXVIII. Exp. Design I: Granulating fluid : 3A denatured alcohol 142

XXXIX. Granulating fluid : Isopropanol _......... 143

XL. Granulations flow rate -.-.-.-.--.-- 164

XLI. Granule bulk density - $\quad 165$

XLII. Percentage compressibility of granulations 166

XLIII. Compression force - $\quad 167$

XLIV. $\quad$ Ejection force -

XLV. Tablet hardness - Tan- 169

XLVI. Tablet friability - $\quad 170$

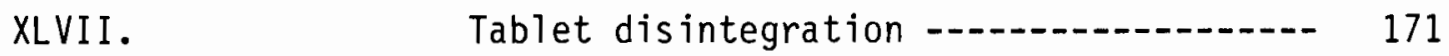

XLVIII. Tablet dissolution-percent drug dissolved

at 15 min.

XLIX. $\quad 30 \mathrm{~min}$.

L. $45 \mathrm{~min}$.

LI. Exp. design II : Granulations flow rate -...-...- 176

LII. Bulk density - $\quad 177$

LIII. $\quad$ \% Compressibility - 178

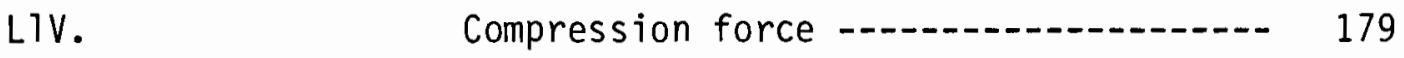

LV. $\quad$ Ejection force - $\quad 181$

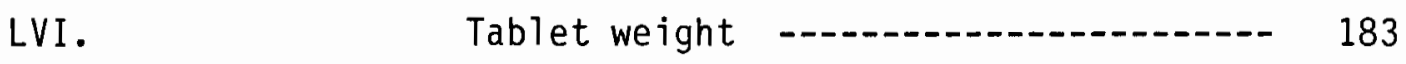

LVII. Tablet hardness - $\quad 185$




LIST OF TABLES (continued)

Table

page

LIX. Exp. Design II:

Tablet friability

188

$L X$.

Tablet disintegration time -.-.-.---- 189

LXI.

Tablet dissolution - percent drug

dissolved at 15 min. -

LXII.

$30 \mathrm{~min}$.

192 


\section{LIST OF FIGURES}

Figure page

1. Instrumented Hobart mixer 27

2. Recording Powder Flowmeter 30

3. Formulation 1 : Torque - time profile 61

4. A typical torque profile 65

5. Theophylline and phenylpropanolamine formulations:

Torque - time profiles 72

6. Scanning electron micrographs of theophylline formulations

Powder blend before wet granulation and phase 1 granulation -- 73

7.

Phase 2 and 3 granulations 74

8. Scanning electron micrographs of phenylpropanolamine formulations

Powder blend before wet granulation and phase 1 granulation --- 75

9.

phase 2 and 3 granulations 76

10. Particle size distribution of theophylline granulations ----- 77

11. Particle size distribution of phenylpropanolamine granulations- 78

12. Granulation flow profile: Formulation 3: 80

13.

Formulations 2 - 4 :

14.

Formulations 5 and $7:-\ldots 2$

15. Granule bulk profile : Formulation 2: 83

16. Formulation 3: $\quad 84$

17. Tablet hardness as a function of wet mixing time : Formulation 2: 95

18.

Formulation 3: 96

19. Disintegration time as a function of hardness

Formulations 2 and 3: 97

$x i v$ 


\section{LIST OF FIGURES (continued)}

Figure $\quad$ page

20. Dissolution profile : Formulation 2

21. Formulation 3:

22. Phenytoin tablet dissolution profile

23. Phenytoin tablet with and without Starch 1500:

Dissolution profile 101

24. Acetaminophen tablet dissolution profile 102

25. Phenylpropanolamine formulation: Effect of extended mixing on

particle size distribution of phase 1 granulations $\ldots \ldots$

26.

Phase 2 granulations --.-- 104

27.

Phase 3 granulations -....-. 105

28. Phenylpropanolamine formulation: Effect of extended mixing on

flow rate of phase 1 granulations 107

29. Phase 2 granulations 108

30. Phase 3 granulations 109

31. Phenylpropanolamine formulation: Effect of extended mixing on

bulk properties of phase 1,2 and 3 granulations -......... 110

32. Theophylline formulation 3: Effect of extended mixing on

particle size distribution of phase 1 granulations

33.

Phase 2 granulations -........- 112

34. 


\section{LIST OF FIGURES (continued)}

Figure

page

35. Theophylline formulation 3: Effect of extended mixing on

flow rate of phase 1 granulations

36.

Phase 2 granulations - 115

37.

Phase 3 granulations 116

38. Theophylline formulation 3: Effect of extended mixing on

bulk properties of phase 1 granulations 117

39.

Phase 2 granulations

40.

Phase 3 granulations

41. Theophylline formulations 9-11: Particle size distribution of

phase 1 granulations --.--- 121

42.

Phase 2 granulations -...-.- 122

43.

Phase 3 granulations -.--.-- 123

44. Theophylline formulations 9 - 11: Granulations flow profiles -- 124

45. Percent compressibility as a

function of phase of the wet granulation process 125

46. Hydrochlorothiazide formulation with mannitol matrix:

Torque - time profile

47.

Dicalcium phosphate matrix:

48. Hydrochlorothiazide formulations with mannitol or dicalcium phosphate matrix: Particle size distribution of phase 1 - 3

granulations -- 132

49.

Granulations flow profile 133 


\section{LIST OF FIGURES (continued)}

Figure

page

50. Percent compressibility as a function of phase of the wet granulation process : Formulations 12 and 13 -...-.-.-.-.-. 134

51. Experimental design I: Factorial design - 139

52.

53.

54.

55.

56.

57.

58.

59.

60.

61.

62.

63.

64.

65.

66.

67.

68.

69.

70.



Compression profile: 3\% Povidone -...--- 146

$6 \%$ Povidone -

$6 \%$ Methocel -

3\% Klucel -

$6 \%$ Klucel - 150

Water $w / 3 \%$ binders -................ 151

Water $w / 6 \%$ binders -.-.--- 152

3A ethanol $\mathrm{w} / 3 \%$ binders -............... 153

$3 \mathrm{~A}$ ethanol $\mathrm{w} / 6 \%$ binders -............ 154

Isopropanol w/ 3\% binders -...........- 155

Isopropanol w/ 6\% binders -............ 156

Ejection profile : Water / Povidone ---- 157

Water / Methocel ---- 158

Water / Klucel -....- 159

3A ethanol / Povidone -..--..--.- 160

3A ethanol / Methocel or Klucel 161

Isopropanol / Povidone -------- 162

Isopropanol / Klucel ---------- 163 


\section{LIST OF FIGURES (continued)}

Figure

page

71. Experimental design II: Dissolution profile of

$0.25 \%$ disintegrants -

72. $0.5 \%$ intragranular disintegrants $\ldots . .-194$

73. $1.0 \%$ intragranular disintegrants ---- 195

74. Dissolution profile of formulations w/ Explotab 196

75. W/ Crospovidone 197

76. W/ Starch 1500198

77. Formulations 14 and 15: Effect of different grades of lactose on the torque profile

78. Formulations 16 - 19: Effect of different levels of sucrose on the torque profile

79. Formulations 20 - 22: Effect of different levels of

Avicel PH101 on the torque profile -.-.-- 203

80. Formulation 23: Effect of different rates of mixing on the torque profile - 204

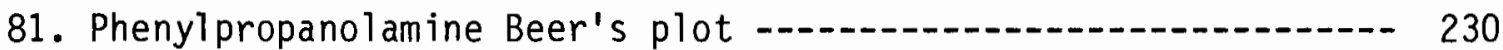

82. Theophyline Beer's plot - 231

83. Hydrochlorothiazide Beer's plot - 232

84. Phenytoin Beer's plot -...- 233

85. Acetaminophen Beer's plot - 234 


\section{INTRODUCTION}

In North America and Western Europe the most widely used dosage form in medicine today is the tablet. Tablets may be defined as solid pharmaceutical dosage forms containing drug substances with or without suitable diluents and prepared either by compression or molding methods (1). Tablets remain popular as a dosage form because of the advantages afforded to both the manufacturer (e.g., simplicity and economy of preparation, stability, and convenience in packaging, shipping, and dispensing) and the patient (e.g., accuracy of dosage, compactness, portability, blandness of taste, and ease of administration) (2).

The formulation has undergone rapid change and development over the last several decades. Efforts are continually being made to understand more clearly the physical characteristics of tablet compression and the factors affecting the availability of the drug substance from the dosage form after oral administration. With the emergence of induced die feeding, precompression, high speed (and most recently, ultra high speed) computer controlled presses, the manufacture of tablets has become one of the most sophisticated aspects of pharmaceutical production.

The design and formulation of the tablet dosage form as it exists today can be thought of as " the process whereby the formulator ensures that the correct amount of the drug, in the right form, is delivered at

or over the proper time at the proper rate and in the desired location, while having its chemical integrity protected to that point " (3).

Tablet presses continue to improve both as to production speed and the uniformity of tablets compressed. Recent advances in tablet 
technology have been reviewed $(4-7)$. In order to ensure that adequate weight uniformity is maintained, it is important, especially on high speed presses, that the materials to be compressed possess acceptable flow characteristics. For smooth operation of the tablet press, the feed mix must have good compressibility and lubricant properties. Many of the active ingredients and excipients do not meet these criteria, and it is therefore necessary to prepare a suitable granulation prior to the compression processes. Alternatively, a direct compression technique may be employed provided that the components meet the above mentioned criteria. A third method, dry granulation, is limited to situations where neither wet nor direct compression can be used.

A. Preparation of components for compression

1. Direct compression

As its name implies, direct compression consists of compressing tablets directly from powdered material without altering the physical nature of the material itself. A directly compressible vehicle is an inert substance which may be compacted with no difficulty and which can be compressed even when quantities of drugs are mixed with it. These direct compression materials possess cohesive and flow properties which make this compression process possible.

Since the pharmaceutical industry is constantly making efforts to increase the efficiency of tableting operations and to reduce costs by utilizing the smallest amount of floor space and labor as possible for a given operation, increasing attention is being given to this method of tablet preparation, which offers several advantages over wet granulation. First and foremost, the process is economical. Also, in 
tablets made from direct compression the particles do not exist in an agglomerate form. Hence upon contact with dissolution medium, a prime particle dissociation may be effected. This in turn may result in faster dissolution which may indeed be the single most important factor controlling product bioavailability (8). Since no moisture is involved in the preparation of the blends for direct compression, the tablets made from this process tend to be more stable than those produced by wet granulation (7).

However, direct compression has several disadvantages. Many active ingredients have poor flow and compression characteristics. Several advances have been made in modifying the particle shape and form of active ingredients and fillers to render them more suitable for direct compression processing. Such success has been achieved with aspirin, acetaminophen, and several vitamins. However, these modifications tend to increase the price of the raw material, thus negating, to some extent at least, the cost advantage of direct compression.

In most cases, the amount of active ingredient that can be incorporated into a matrix (dilution potential) is quite limited (usually less than $25 \%$ ) (9). On the other hand, adequate distribution is sometimes difficult when working with low dosage drugs. Static charges develop on the drugs during comminution and mixing which may prevent uniform mixing due to lack of or low levels of moisture. This segregation problem can also occur as a result of vast differences in particle size or density among the components of the blend. The blends are most susceptable to unblending particularly in the hopper or feed 
frame of the tablet press. Another limitation of this method is the difficulty of achieving deep and uniform color distribution in tablets.

2. Dry granulation method

Dry granulation is the process whereby granules of powder blends are obtained without the use of heat or solvent. This process has also been used for formulations which were found to resist compression when prepared by the wet granulation methods (eg. calcium lactate). This method is referred to as dry granulation, precompression, or the double compression method. The process entails the formation of slugs or compacted strips from the active ingredient and one or more excipient(s). These slugs are then broken down into a desired particle size distribution using a comminuting mill. The lubricant is added to the granulation, blended gently, and the material is compressed into tablets.

The type of equipment (slugging by heavy duty tablet press or compaction by roller compactor) is selected based on the batch size of the material to be processed. In a real sense, slugging / compacting is just a rather elaborate method of subjecting a material to increased compression time. This process is followed by screening and subsequent compression of the particles is roughly equivalent to an extended dwell time during the compression cycle. The two or more times that the material is subjected to compaction pressures causes a strengthening of the bonds which hold the tablet together. It also renders fluid those powder mixtures which will not flow well enough to fill the die satisfactorily. Excessive pressures which may be required to obtain 
cohesion of certain materials may result in a prolonged dissolution rate.

3. Wet granulation method

The most general and widely used method of tablet preparation is the wet granulation method. In spite of its costly nature requiring intensive labor, considerable material handling, and costly equipment, the wet granulation process is the only alternative for high dose and poorly compressible materials. Although many of the products currently being formulated by wet granulation could be made by direct compression, existing governmental regulations would define such changes as major modifications. These modifications would require changes in ingredients or at least, changes in physical form of previously used excipients. Hence, the newly formulated product would have to undergo stability, bioavailability, and possibly even safety studies, and a new submission to regulatory agencies.

Wet granulation offers several advantages over other methods. This method is used to improve: (a) flow, handling and resistance to segregration (10), (b) bioavailability (11), (c) homogeneity of low dose blends and (d) compression characteristics of tablet matrices. In addition, this method can help to overcome electrostatic problems of a powder blend (12) or can be used to make in-situ complexes to stabilize the dosage form.

The wet granulation method is not without its limitations. The process steps involved in the wet method are (a) weighing, (b) mixing, (c) granulation, (d) wet mass screening (some times), (e) drying, (f) sizing, (g) lubrication, and (h) compression. The selection of equipment 
for wet granulation is generally made based on the previous experience and economic conditions of the manufacturer. The type of equipment employed can affect granulation structure (13). Wet granulation is often referred to as one of the most difficult unit operations to reproduce and scale-up because of the lack of a precise means to measure process variables and detect the end point.

The granulations end point is still usually identified by intuitive, subjective judgement. The following subjective end point measurments were referred to in well recognized pharmaceutical text books: (a) "Once the granulation liquid has been added, mixing continues until uniform dispersion is attained and all of the mucilage has been activated. This kneading of the mass in large blenders requires from 15 minutes to an hour. The length of time depends on the wetting properties of the powder mixture and the granulating fluid. A rough way of determining the end point is to press a portion of the mass in the palm of the hand; if the ball crumbles under moderate pressure, the mixture is ready for the next stage of processing" (7) and (b) "The powder mass is wetted with the binding solution until the mass has the consistency of damp snow or brown sugar" (2). Much of this literature gives purely empirical production recipes arrived at by a process of trial and error. However, it is by no means certain how many of these empirical procedures might turn out to be of more general application and based upon sound principles if they were better correlated and more widely disseminated. It is important to understand the fundamentals of particle size growth in the granulation process before attempting to quantify the granulation process. 
a. Fundamentals of particle size enlargement by wet granulation

Particle size enlargement has been described in the granulation process by the following basic growth mechanisms. Growth occurs either by the collision and successful adherence of powder particles into discrete granules (coalescence) or by growth centered around a nucleus onto which particles collide and attach themselves to form a layer (layering or onion skinning). Again, this results in discrete granule formation $(14,15)$. In both cases, the particles are held together by cohesive forces at particle contact points. The overall strength of the granules is dependent on the magnitude and nature of the cohesive forces, particle size distribution and the number of bonding contact points per particle $(16,17)$.

Forces contributing to the formation of agglomerates from particulate solids are one of two kinds (18): natural and applied. The natural forces responsible for the formation of agglomerates can result from a number of sources: (a) the attraction between powder particles due to van der Waals' forces, or electrostatic charges, (b) the interlocking effects between particles, depending upon the shape of particles, (c) the adhesional and cohesional forces in bridging bonds, which are not freely movable, and very importantly, (d) the interfacial and capillary forces due to the presence of a liquid phase.

Rumpf (19) has developed a detailed expression for estimating the magnitude of these forces. His calculations indicate that the major contribution of the physical forces, in the presence of a liquid which completely wets the solid particle surface, is from the capillary forces 
and dependent on the relative distribution of the liquid and air phases in the porous agglomerate $(18-24)$. When the ratio of the liquid to void volume of the agglomerate is quite low, the liquid is held in discrete lens like rings at the point of contact between particles, and the air phase forms a continuous phase. The entrapped liquid is said to be in a pendular state. The strength of this pendular bond arises from the negative capillary pressure and the surface tension of the liquid rings tend to coalesce and form a continuous network, resulting in the air phase becoming trapped. The agglomerate is said to be in the funicular state. Finally, the agglomerate is said to be in a capillary state when the void volume of the agglomerate is completely filled by liquid.

Mechanical forces are required to bring the individual wetted particles, clusters or agglomerate species within the granulator into contact with one another so that the natural forces can bring about their growth (18). This mechanical action of moving the material is imparted by means of rolling, tumbling, agitating, kneading, extruding or compressing in suitable equipment.

In many instances the moisture content which promotes the cohesive force between point contacts in the granulate, and also to a degree the granulate growth mechanism is only an intermediate step in the determination of the physical properties of the final granulation. The phase changes from liquid to solid with increasing temperature can result in an increase in the final strength of the product. The major solid bridges form by crystallization of dissolved material and hardening of binders (25-27). 
b. Moisture content for granulation

The moisture content of a granulating mass is a very important parameter in deciding the successful outcome of the process, and in most continuous production processes it is the principal variable used to control granulation.

Newitt and Conway-Jones (23) first noted that the critical moisture content required for granulation to occur correlated with $90 \%$ of the moisture required to saturate the voidage in the powder. This void volume is measured by its packed bulk density. The remaining volume was assumed to be taken up by entrapped air. Capes and Danckwerts (27) found that granule growth occured over a range of moisture contents corresponding to $90-110 \%$ of that required to saturate the voidage in the packed sand. When they measured the actual voidage of formed granules, however, they found that the sand was only closely packed at low liquid content.

Using coarser sand to produce smaller granules, Sherrington (30) found that these granules were formed at liquid content much lower than that required to saturate the voidage in the sand. A simple geometric model was devised for a granule in which the internal pores are saturated with liquid but the surface is regarded as 'dry' with the liquid withdrawn into interstices between the outermost layer of sand grains.

Many other workers have observed that the rate of granule growth is strongly dependent upon the liquid content of the granulating mass $(23,27-29)$. This is variously attributed to the increased granule plasticity or surface moisture at higher liquid content leading to a 
greater probability that granules will stick together on collision. Kapur and Fuerstenau $(28,29)$ found a more complex growth behaviour for pulverised limestone and defined three growth regions- the nuclei growth region, a transition region and a ball growth region. For the nuclei growth region, they suggested a relationship of the form

$$
K=K_{1} \exp \left(K_{2} W\right)
$$

between their growth rate constant $K$ and the granulator water content $W$, where $k_{1}$ and $k_{2}$ are constants for a given powder of given surface area. Growth rate in the ball growth is slower and less sensitive to moisture content and its dependence on water (30) content has the opposite curvature to that of an exponential function (31).

When one or more of the components of the material being granulated is soluble in the granulation fluid it is the total volume fraction of liquid or solution phase rather than the moisture content per se which controls the granulation behaviour (32-34).

In the absence of any accepted predictive method, Capes et al. (35) have attempted to fit all of the available data on granulation moisture to a simple formula. The fit is very approximate and two constants are needed, for particles less than and greater than $30 \mu \mathrm{m}$ : For fine particles $(<30 \mu \mathrm{m})$

$$
W=1 / 1+1.85\left(P_{S} / P_{1}\right)
$$

For coarse particles ( $>30 \mathrm{~m}: \mathrm{m})$

$$
W=1 / 1+2.17\left(P_{S} / P_{1}\right)
$$

$W=$ weight fraction of binding liquid for agglomeration

$P_{S}=$ true density of particles

$P_{1}=$ density of binding liquid 
Leuenberger et al. (36-39) modified the Capes equation by adding a constant to take into account packing of the particles and provide a factor for equilibrium moisture uptake of the material.

$$
W=\left\{\gamma \varepsilon \rho_{\ell} / \varepsilon \rho_{\ell}+(1-\varepsilon) \rho_{S}\right\}+\delta_{H}
$$

In the equation (3), the authors took into account that cohesive forces arise even before the entire pore space is filled.

$\bar{\gamma}=0.213$ (mean value for cubic and rhombohedral particle packing)

$\varepsilon=$ porosity (obtained by tamped density measurements)

$\delta_{\mathrm{H}}=$ equilibrium moisture uptake of the solid materials when exposed to $100 \%$ relative humidity

These authors showed good correlation between the theoretical predictions and experimental data generated by the power consumption measurements.

c. Quantification of the wet granulation process

In the pharmaceutical industry, the wet granulation process is mainly performed as a manual, batch process. The result of the process depends on the skill of the operator, who estimates the process largely by visual inspection. To be able to quantify the process, it is necessary to possess objective measuring values of parameters which reflect real changes in the wet granulation process.

Recognizing this problem several researchers have attempted to quantifiably characterize the wet granulation process. For example, Toyoshima et al. (40) have used a strain gauge on a beam connected to the wall of a rotary wet granulator for measuring the pressure on the wa 11 . 
The power consumption of the mixer motor has been investigated by Hunter and Ganderton (41) for three different mixers ( $p l a n e t a r y, ~ Z-b l a d e$ and Lodige mixers). The method is rather imprecise since the actual fraction of the energy supplied as useful work to the mixer shaft is unknown. These authors did not attempt to correlate the power consumption to any independent or dependent variables.

Lindberg et al. (42) instrumented a change can mixer, (Artofex $\mathrm{PH}-15)$ with strain gauges in half bridge. Strain gauges were glued vertically on to the left mixer arm and protected from moisture by a curing silicone rubber coating. These authors concluded, that neither strain gauges nor Hall effect multiplier (power measurement equipment) in combination with an oscilloscope or a chart recorder are suitable instruments during routine granulation. In addition, they stated, bending moment and power consumption are suitable parameters in studying the granulation process.

Travers et al. (43) constructed a 'torque arm' mixer of about two kilogram capacity, where the mixer arm was driven by a motor mounted on a platform to move in a horizontal plane on a ball-bearing race. A pin, fixed on the circumference of that platform, bears on the arm of a correx tension gauge and resists the torque developed as the mixer arm rotates in the mass. The angular displacement of the platform, which for small displacement is proportional to the developed torque, operates a displacement transducer. This eqipment has serious engineering constraints which preclude scale-up.

Lindberg et al. (44) attached a horizontal bar with full strain gauge bridge to a planetary mixer (Tripas planet PL-25) paddle. The 
signals were processed using telemetric equipment and were registered on an oscilloscope or a chart recorder. These authors concluded that the telemetric equipment was useful for the instrumentation of a mixer, but it was not suitable for routine measurements in its present construction.

Leuenberger et al. (36-39) fitted a planetary mixer with instruments that allowed measurement of power consumption during the addition of granulating liquid. These authors did not publish the details of the instrumentation, because of their affiliation with private industry. Power consumption (watts) of the mixing motor as a function of continuous addition of granulating liquid was studied. In addition, these authors developed an equation (by modifying Capes et al. (35) equation) to predict the granulating fluid necessary for optimum granulation process. These authors showed that the calculated amount of granulation fluid necessary for optimum granulation within the phase III of the granulation process. In addition, these authors concluded that the absolute power requirement may differ with different mixers (planetary, z-mixer) using the identical granulating material but mixing phases one, two and three, and which are relevent to identify the end point, are clearly recognizable in both cases.

Lindberg et al. (45) equipped a small planetary mixer (Kenwood Major $707 \mathrm{~A}$ ) with a reconstructed dog clutch. The load on the beater was transmitted to a coil spring. The stretch of the spring was recorded by an optic-electronic device. Although the instrumentation was very simple and cheap, it had the drawbacks of hysteresis and friction of the spring (46). The above authors reconstructed the same mixer and equipped with a 
torque transducer consisting of a steel beam, with strain gauges in a full bridge circuit (46). The instrumentation required considerable reconstruction of certain parts of the machine.

Spring (47) modified a planetary mixer, so that the conductivity of the damp mass could be studied during the process of wet massing.

The traditional methods of timing and operator assessment are of limited use as primary strategies in high speed mixer-granulation (closed system) due to the inherent difficulties in standardising the end point condition. However, there is no doubt that they still provide an important additional check on the granulation end points determined by other control methods.

On the basis of observation of the current required during granulation experiments with a Lodige high-speed mixer, it was decided that the granulation cycle was apparently capable of being instrumented (48). Diosna P600, equipped with ammeters, indicated both the consumption of the impeller and that of the chopper (49). Systems based on current and power devices, or measurement of torque and mass temperature, were considered inconvenient. Therefore, a system (Boots-probe) was constructed which made it possible to detect changes in momentum of granules moving in a constant velocity region of the mixer bowl (50-52). Power measurements were also adapted with intensive mixers (39). Measurements of the power input to the impeller and the chopper motor of Diosna P25 was used in controlling the granulation process (53). Another technique which has been investigated includes the sound generated at the mixer shaft (54). 


\section{B. Validation of pharmaceutical processes}

In recent years, pharmaceutical companies have grown in size and complexity, the relative role of their individual scientists has decreased proportionately through a phenomenon known as compartmentalization. It is rare, except possibly at higher managerial levels, to have total technical responsibility for an entirely new drug process from the developmental phase through final manufacturing and quality control operations. Even when technical managers have such sweeping authority, they are usually not well versed in the details and complexity of the product manufacturing processes they operate.

At the scientific end of the organization, formulating scientists may be responsible for preparing only the first preclinical and clinical supplies of the drug, while others are only responsible for pilot work. Engineers may be assigned responsibility for equipment and facilities while others work on process - optimization assignments. There may be one person with a total view of the "big picture".

The traditional approach to this particular managerial dilemma is to form a special projects team with crossing or overlapping lines of authority to each important new product. This approach sometimes proves successful but often does not. Currently the official approach to solve this problem is to validate pharmaceutical production processes.

FDA in its recently proposed guidelines has offered the following definition for process validation:

"Process validation is a documented program which provides a high degree of assurance that a specific process will consistently produce a product meeting its predetermined specification and quality attributes". 
Process validation studies of new drug products often are carried out during the phase III of process development and product batch scale-up, and often with the participation of representatives from product development, engineering, manufacturing and quality control units. Such a natural interplay of technical as well as organizational talents forms a more desirable alternative to artificially created special project teams.

Arumbolo (55) advocated the following priority list for product validation:

Large volume parenterals

Small volume parenterals

Opthalmic and biologicals

Sterile solids

Low dose / high potency oral solids

Other tablets and capsules

Oral liquids and topicals

Products that can cause the most problems, if they are not manufactured by a completely controlled process, are given at the top of the list, however, it should be stressed that validation and quality of all of the products are important.

Although validation of existing tablet dosage form is not on top of the priority list, validation work for the new tablet dosage form as early as the preformulation stage is a logical step. Eventually the FDA will require all pharmaceutical processes to be fully validated.

All pharmaceutical scientists, whether in Development, Quality Assurance, Production, or Regulatory Affairs, are familiar with the 
concept that quality is not tested into a product but rather built into a product. This is an important concept, since it serves to support the underlying definition of validation, which is a systematic approach aimed at identifying, measuring, evaluating, documenting and reevaluating a series of critical steps in the manufacturing process that require control to a reproducible final product.

There are several important reasons for validating a product and / or process. First, manufacturers are required by law to comform to Current Good Manufacturing Practice (CGMP) regulations (56). Second, good business practice dictates that a manufacturer avoid the possibility of rejected or recalled batches. Third, validation helps to ensure product uniformity, reproducibility, and quality (57-59).

Most discussions (60-62) of product and process validation that have been recently published concentrate on validation associated with the full-scale manufacture of pharmaceutical processes and how equipment processing variables affect the overall quality of the finished product. Although this is certainly an important aspect of product validation, validation of numerous earlier aspects of development are critical to the subsequent phases of the process.

Without proper characterization, specification and control of these earlier developmental steps, the foundation will be weak and will not support the evolving product when it is challenged during the formal validation of pilot and production batches.

The validation process of a solid dosage form begins with a validation of the raw materials: both active ingredient and excipients (63). Variation in raw materials constitutes one of the major causes of 
the product variation from specification. Characteristics such as drug morphology, particle size, surface area, color, and other physical, chemical or biological properties are important in assessing drug availability and reproducibility of subsequent manufacturing processes (64). Particle size is directly interrelated to several key processing variables. Several of the most significant are flow, blend uniformity, granulation solution uptake, compressibility and lubricant efficiency (65). A comprehensive program for establishing validation and control procedures for raw materials is critical if one hopes to achieve product criteria batch after batch. Guidelines for process validation of solid dosage forms have been discussed by Rudolf (66).

C. Objectives of the present study

The wet granulation process has been used in the pharmaceutical industry for many years and yet the detection of the desired wet granulation end point is still usually made by intuitive, subjective judgement. From a state of absolute empiricism, some progress has been made in our understanding of the fundamentals of the subject to permit some qualitative rationalization of the results obtained. For the pharmaceutical scientist faced with developing a process for a new granulated product, however, these developments do no more than point the way, and a high degree of intuition and the willingness to undertake what may well turn out to be a long frustrating program of trial and error may still be needed. Progress in optimization and validation is seriously inhibited due to a lack of an objective, quantifiable, reproducible measuring technique. 
The objectives of this study were:

1. To instrument a laboratory size planetary mixer using commercially available electronic equipment in order to measure relative torque on the mixing paddle. It was hoped that the instrumentation could be used to quantify the end point of the wet granulation process. In addition, it was planned to investigate the reproducibility of the data generated by the instrumented mixer.

2. To examine the granulation process of different drugs and to evaluate the physical properties of granules and tablets made by the wet granulation process.

3. To determine the effect of some formulation and processing variables on the properties of granules and tablets produced by wet granulation and also, to investigate the properties of tablets so produced in order to distinguish which properties are more sensitive to granulation process variables and which are "robust".

It was hoped that this study has value of both theoretical and practical importance to the pharmaceutical industry. The instrumentation of a Hobart mixer was planned in January 1982 and the parts were ordered. Due to the manufacturing delay of a torque sensor, the instrumentation was completed in August 1982. Since 1982, some progress has been reported by other authors in the field of granulation studies. The results of those authors (post 1982) will be discussed in the results and discussion section in comparison with the data obtained in the present study. 


\section{EXPERIMENTAL}

A. Materials

1. Formulation components

Theophylline anhydrous (Lot \# R39717-2716) ${ }^{1}$

Phenylpropanolamine hydrochloride $(100 \mathrm{~F}-0393)^{1}$

Acetaminophen $(53 \mathrm{~F}-0305)^{1}$

5,5,- Diphenyl Hydantoin (phenyto in) $(124 \mathrm{~F}-0177)^{1}$

Hydrochlorothiazide $(\mathrm{NXO18})^{2}$

Povidone C-30 (R45642-0444) ${ }^{3}$

Crospovidone $(1433-3)^{3}$

Methyl cellulose 15LV (Methocel) (R30123-0375) ${ }^{4}$

Hydroxypropyl cellulose (Klucel) (R17682-0214) ${ }^{5}$

Corn starch (R52408-1131)

Starch 1500 (pregelatinized starch) $(404028)^{7}$

${ }^{1}$ Sigma Chemical Company, St. Louis, M0

${ }^{2}$ E.R. Squibb \& Sons Inc., Princeton, $\mathrm{NJ}$

${ }^{3}$ G.A.F. Corporation, New York, NY

${ }^{4}$ Dow Chemical Company, Saddle Brook, NJ

$5_{\text {Hercules Inc., Wilmington, } \mathrm{DL}}$

${ }^{6}$ Ruger Chemical Co., Irvington, $\mathrm{NJ}$

${ }^{7}$ Colorcon Corporation, Philadelphia, PA 
Explotab (sodium starch glycolate) $(2166)^{8}$

Emcompress (dicalcium phosphate dihydrate unmilled) $(9187)^{8}$

Ac-Di-Sol (croscarmellose sodium) (T309) ${ }^{9}$

Avicel PH101 (microcrystalline cellulose) $(14361)^{9}$

Lactose hydrous (1actose) (R52903-1212) ${ }^{10}$

Lactose anhydrous (4NL13) 10

Dicalcium phosphate anhydrous (R41864-0711) 11

Mannitol (R30222-1222) ${ }^{12}$

Magnesium stearate $(R 49610-0370)^{13}$

3A Denatured alcohol (3A ethanol) (R45246-1419) ${ }^{14}$

Isopropyl alcohol (isopropanol) (R55534-1416) 15

Hydrochloric acid (026490) 16

Monobasic Potassium phosphate $(722964)^{17}$

Sodium hydroxide $(720859)^{17}$

${ }^{8}$ Edward Mendel1 Co., Caramel, NY

9 FMC Corporation, Philadelphia, PA

${ }^{10}$ Sheffield Company, Memphis, TN

$11_{\text {Monsanto Pharmaceuticals, St. Louis, M0 }}$

${ }^{12}$ Pfizer Inc., New York, NY

13 Mallinckrodt Inc, St. Louis, M0

${ }^{14}$ U.S.I. Chemical Company, Newark, NJ

${ }^{15}$ J.T. Baker Chemical Co., Phillipsburg, NJ

${ }^{16}$ E. I. Dupont De Nemours \& Co. (Inc), Wilmington, DE

17 Fisher Scientific Company, Fair Lawn, $N J$ 


\section{Equipment}

Hobart mixer (model\# $\mathrm{C} 100)^{18}$

Slip ring torque sensor (model\# 1102-200) ${ }^{19}$

Rubber block couplings 19

Explosion proof motor $(1 / 4 \mathrm{HP})^{20}$

Strain gauge conditioner indicator 21

Bascom-Turner recorder 22

Aluminum plates 23

Burette $^{24}$

Mettler balances (models\# PC4400,PR1200). ${ }^{25}$

Mettler digital/analog converter (model\# GC47) 25

Stokes hot air oven 26

Stokes model $F$ tablet press hopper 26

Stokes model B2 rotary tablet press ${ }^{26}$

Stokes oscillating granulator 26

${ }^{18}$ Hobart Manufacturing Co., Troy, $\mathrm{OH}$

${ }^{19}$ Lebow Products, Eaton Corporation, Troy, MI

${ }^{20}$ General Electric, Fort Wayne, IN

${ }^{21}$ Ana $\log$ Devices, Norwood, MA

${ }^{22}$ Bascom-Turner Instruments, Newton, MA

${ }^{23}$ Pfizer Inc., New York, NY

${ }^{24}$ Thomas Scientific, Philadelphia, PA

${ }^{25}$ Mettler Instrument Corporation, Princeton, NJ

${ }^{26}$ Stokes - Penwalt Co., East Stroudsberg, PA 
Twin - She 11 blender 27

Turbula rapid blender 28

Manesty Beta press 29

Manesty model F3 tablet machine hopper

Fitzpatrick comminuting machine (model $\mathrm{M})^{30}$

Heberlein hardness tester 31

Erweka hardness tester, type TBT (NR 19306) 32

Friabilator (Roche) ${ }^{33}$

Thickness gauge 34

USP disintegration apparatus 34

USP dissolution apparatus 34

Tap density tester 34

Apple computer (model I Ie) 35

Printer 36

27 Paterson - Kelly Co., East Stroudsberg, PA

28 Wiley A. Bachoven Co., Troy, $\mathrm{OH}$

${ }^{29}$ Thomas Engineering Inc., Hoffman Estates, IL

30 W.J. Fitzpatrick Co., Chicago, IL

${ }^{31}$ Cherry - Burrel Corporation, Cedar Rapids, IA

32 Erweka Apparatabau, W. Germany

${ }^{33}$ Mitertoya, Japan

${ }^{34}$ Vanderkamp, Vankel Industries, Chatham, CA

${ }^{35}$ Apple computer company, Cuperton, CA

${ }^{36}$ Integaral Data Systems, Milford, $\mathrm{NH}$ 
Perkin - Elmer Hitachi 200 spectrophotometer 37

Cenco - Meinger sieve shaker ${ }^{38}$

Ohaus moisture balance ${ }^{39}$

37 Hitachi, LTD., Tokyo, Japan

${ }^{38}$ Central Scientific Company, Chicago, IL

${ }^{39}$ Ohaus scale corporation, Florham Park, NJ 


\section{B. Methods}

1. Instrumentation of Hobart mixer

A Hobart mixer consists of (a) bowl support, bowl and lift unit, (b) base and pedestal unit and (c) transmission case unit. The back cover from the base and pedestal unit was opened. The transmission unit was taken off from the pedestal unit and its cover was removed and wiring disconnected. The motor was pulled from the transmission case unit and the windings removed from the shaft. A $0.375 \times 22.0 \times 6.5$ in. aluminum support plate was installed on the pedestal unit. The transmission case unit cover was bored to make it possible to connect its driving shaft to the driving shaft of the slip ring transducer and the transmission case unit was then installed on top of the aluminum plate. The slip ring transducer was aligned accurately between the transmission unit and the 1/4 HP explosion proof motor using aluminum support blocks. The driving shafts were connected with rubber block couplings, which could accomodate an angular misalignment of $1^{0}$, parallel misalignment of $1 / 16$ to $1 / 4$ inch and axial play of $1 / 16$ to $1 / 2$ inch. The entire unit was installed on second aluminum plate $(0.375 \mathrm{X}$ $28.75 \times 6.5$ inches) and the end of the top aluminum plate was supported with one inch diameter aluminum post for stability. The back plate of the bowl support was shortened by about 0.375 inch to accomodate the aluminum plate which supports the slip ring unit and motor. The position of the bowl support was adjusted by turning the bowl lift stud. The transducer unit was connected to the amplifier (strain gauge conditioner indicator), while the amplifier in turn, was connected to the Bascom-Turner (Model\# 4120) recorder. 
Torque sensors consist of specially designed structures which perform in a predictable and repeatable manner when a force is applied. This force is translated into a signal voltage by the resistance change of strain gauges which are applied to the torque sensor structure. The change in resistance indicates the degree of deformation, and in turn, the load on the structure. The strain gauges are connected in a four arm (Wheatstone bridge) configuration, which acts as an adding and subtracting electrical net work and allows compensation for temperature effects as well as cancellation of signals caused by extraneous loading. The strain gauge bridge is connected to four silver slip rings mounted on the rotating shaft. Silver graphite brushes rub on these slip rings and provide on electrical path for the incoming bridge excitation and the outgoing signal.

A voltage of $5 \vee(D . C)$ was used to excite the strain gauge bridge. A force applied to the structure unbalances the Wheatstone bridge, causing an output voltage to appear. The gain was set at 179.6 such that 1 volt output equalled 100 in.oz. of applied load (Figure 1).

2. Wet granulation using instrumented Hobart mixer A previously mixed powder blend $(0.5$ or $1.0 \mathrm{~kg})$ was placed in a 2.8 liter bowl and was blended for five minutes at slow speed (145 RPM) using the instrumented Hobart mixer. Granulating fluid was added at a constant rate, using a burette, while mixing at low speed. Output in millivolts as a function of time was recorded using a strip chart recorder. The strip chart recorder was set on 0.5 volt and ten $\mathrm{cm} /$ minute settings. Different phases of the torque profile were identified. The experiments for phase I, II and III were repeated in order to quantify 


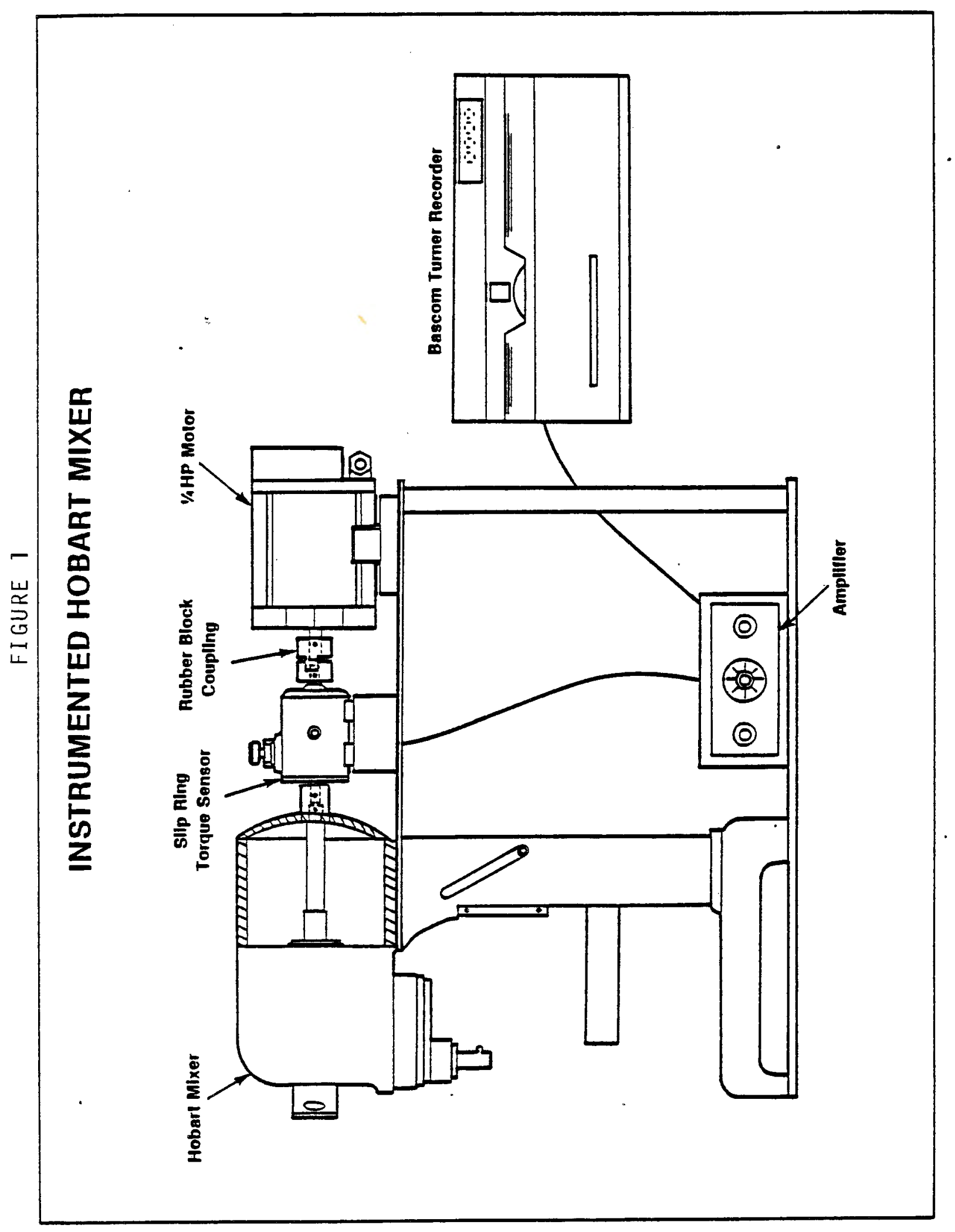


reproducibility. Wet mass from phases IV and $V$ were beyond the normal granulating process and were discontinued in this study. Wet granulations were dried at $50^{\circ} \mathrm{c}$ to less than one percent moisture level. Dried granulations were sized and studied for physical characteristics, such as particle size distribution, flow properties, bulk properties and tabletability using an instrumented tablet press.

3. Granulation characterization

a. Particle size analysis

A nest of sieves, sizes (U.S. standard) $20,40,60,80,100,140,200$

and 325 , was used to measure the particle size distribution. A 100 gram sample was placed on the top screen and the sieve stack was shaken for 20 minutes on a Cenco Meizer sieve shaker. The shaker was set on \# 6 setting. The cumulative weight percentage of powder at each sieve level was calculated.

\section{b. Bulk density}

The bulk density determination procedure developed by Butler and Ramsey (67) was adapted, with a modification that a graduated measuring cylinder was tapped 2000 times instead of a few times by a tap density tester. A sample of $50 \mathrm{~cm}^{3}$ of powder was carefully introduced using a glass funnel into a tared $100 \mathrm{~cm}^{3}$ graduated cylinder, weighed and tapped using the above tap density tester. If $V$ is the tapped volume in $\mathrm{cm}^{3}$ of $W$ grams of material in the cylinder, then the tapped bulk density in $\mathrm{g} / \mathrm{cm}^{3}$ is given by:

$$
P_{b}=W / V
$$

and loose bulk density $P_{1}$

$$
p_{1}=w / 50
$$


compressibility of material was calculated by:

$$
\% c=\left(P_{b}-P_{1}\right) / P_{b} \times 100
$$

In theory, as compressibility of the powder increases, the flowability decreases (68).

$$
\text { c. Flow measurements }
$$

Granule flow was measured using a recording powder flowmeter. The flowmeter consists of a digital balance, digital/analog converter, Bascom-Turner recorder, and a stainless steel tablet machine hopper. The hopper was fixed so that the orifice of the hopper was $12 \mathrm{cms}$. above the balance (Figure 2). Sample size was varied depending on the batch size. Flow index (Linearity) was determined using the procedure developed by Jordan and Rhodes (69). The recorder was calibrated such that the sample weight, when placed on the balance (tared with holding pan) would cause the recording pen to deflect the entire scale. A sample of the material to be evaluated was placed in the hopper. When the orifice of the hopper was opened, the powder fell on the pan, causing the pen to respond in a manner characteristic of the powder system. The recorder was set on a trigger before the opening of the hopper orifice. The falling weight of the powder was recorded as a function of time. The pen tracings (flow gram) were then analyzed for linearity and mass flow (grams / second). The linearity term was calculated from the formula:

$$
\text { Linearity }=\left(r^{2}-0.8\right) \times 100
$$

where $r^{2}$ is the coefficient of determination. Three replicate flow grams were determined for each granulation system. The values for mass flow and linearity were averaged. 
FIGURE 2

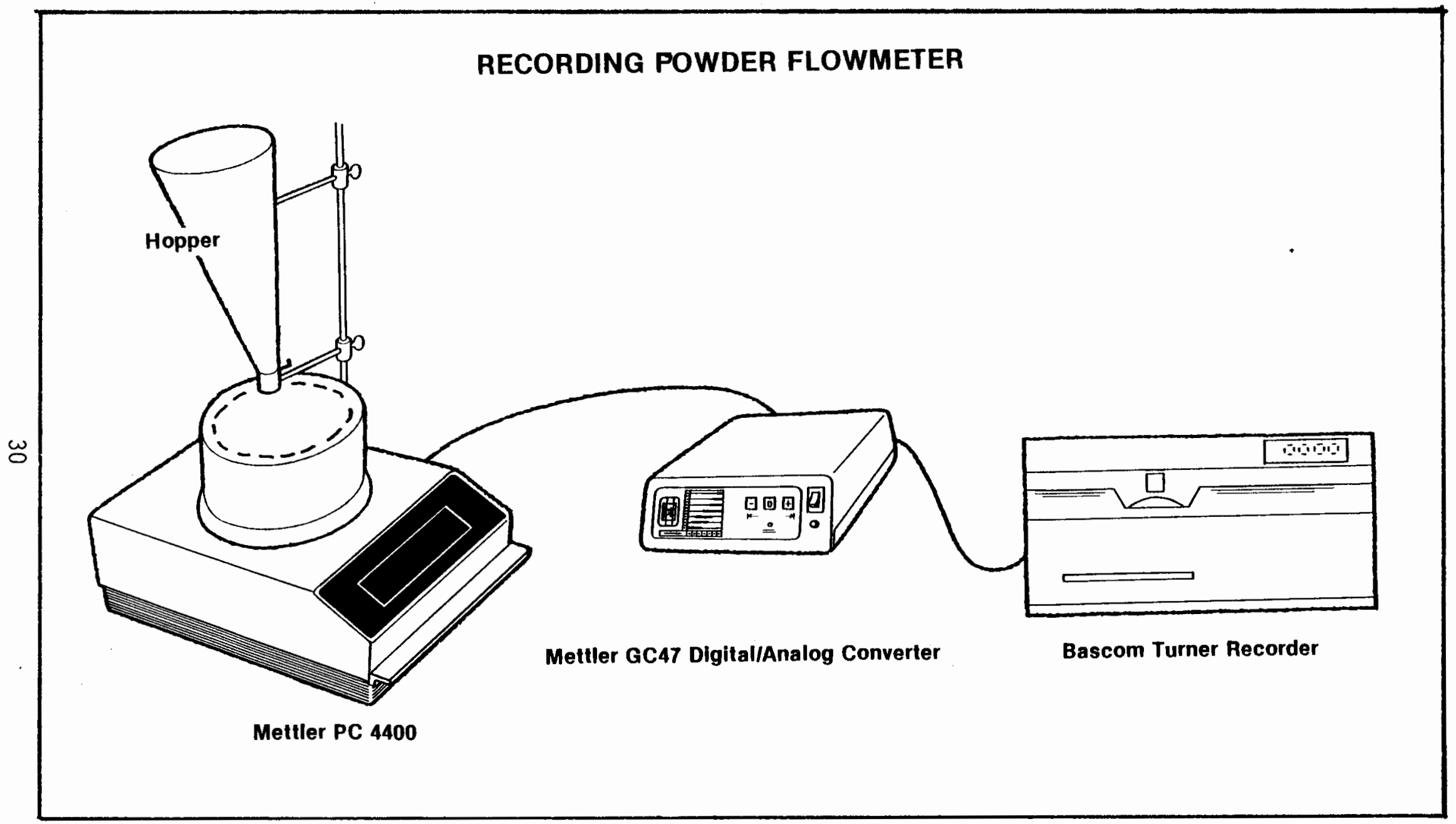




\section{d. Electron microscopy}

The granulations were placed on an adhesive coated steel stub and were then coated with a gold palladium mixture $(50 / 50)$. The coated stubs were then placed in a scanning electron microscope and photographed with a Polaroid camera which captures the image of the sample as the electron beam illuminates it. The various micrographs used in this study were taken with the assistance of Mr. Kevin Ramey of the Howmedica division of Pfizer Inc., located at the Groton, Connecticut facility.

$$
\text { e. Moisture determination }
$$

The moisture content of each granulation after drying was determined using an Ohaus moisture balance operating at a temperature of $80^{\circ} \mathrm{C}$ for lactose based granulations and $105^{\circ} \mathrm{C}$ for dicalcium phosphate based granulations, for 30 minutes.

f. Compression

Part of the study was done using an instrumented Manesty Beta press, located at Pfizer Central Research, Groton. The tablet press was instrumented with strain gauges. Compression force was measured by the strain gauges which were bonded to the tie rod and the ejection force by the strain gauges glued to a cantilever beam. One end of the cantilever beam was pressed against the ejection cam and the other end was attached to the body of the press. Strain gauges were calibrated with weights. These bridges were energized by 24 volts (D.C) and the gain was set, so that one volt of output equals to 10,000 pounds for compression and 1,000 pounds for ejection respectively. The output was acquired and recorded using a two channel Bascom-Turner recorder which converts 
analog signals to digital signals and stores the data on a floppy disc. The output was also monitored by using an oscilloscope.

A major part of compression work was done by an instrumented Stokes $\mathrm{B} 2$ rotary tablet press located in the Department of Pharmaceutics of the University of Rhode Island. This tablet press was instrumented with four piezo-electric transducers and interfaced with an Apple IIe computer. One transducer was installed by horizontally sectioning the eye bolt to measure compression force and the remaining three transducers were installed underneath the ejection cam in a series to measure ejection force. The software ${ }^{\star}$ for the Apple IIe computer enabled the calculation of peak height (compression and ejection curves) by picking signals off the press at the rate of 100 data points per millisecond. A mean peak height from data on ten tablets was calculated. In addition, it also calculates mean area under the compression, ejection curves, mean area to height ratio for compression and standard deviation for all the above parameters.

4. Tablet characterization

a. Weight

The weight of each individual tablet was determined after dedusting, and placing it on an electronic balance. This procedure was repeated for ten tablets in most cases, and sometimes for twenty tablets if the variation was significantly large (over $2 \%$ ). The data from the tablets were analyzed for sample mean and standard deviation.

\footnotetext{
*The author gratefully acknowledges the use of software developed by $\mathrm{Mr}$. John R. Hoblitzell.
} 


\section{b. Thickness}

The thickness of ten tablets was determined by first dedusting, and then placing it in the jaws of micrometer. The measurements were recorded and analyzed for mean value and standard deviation.

C. Hardness

The hardness of ten tablets was determined for each system by placing each individual tablet in a hardness tester (Heberlein or Erweka) which recorded the breaking strength of the tablet in kilograms. This procedure was repeated and the data were analyzed for sample mean and standard deviation.

\section{d. Friability}

This test is a measure of the abrasion resistance and was determined by first weighing twenty tablets after dedusting, then placing them in a tumbling chamber for four minutes at twenty five RPM. The tablets were dedusted and weighed after tumbling, and the percent friability was determined as follows:

$\%$ Friability $=(($ Intial weight - final weight $) /$ Intial weight $) \times 100$

e. Appearance of finished products

Tablets were examined using a 10X magnifying glass for chipping, cracking, picking or mottling of the surface as an in-process check.

f. Ease of manufacturing

The noise and vibration from the tablet press was carefully monitored subjectively to identify any problems in manufacturing tablets. 


\section{g. Disintegration}

Tablet disintegration was tested by using the USP apparatus, aS described in the U.S.Pharmacopoeia and the National Formulary (1) without discs. The time needed for all the palpable fragments to pass through the screen at the bottom of the cage was detected visually, and was recorded. Six tablets were used in each test and mean and standard deviation were calculated.

\section{h. Dissolution}

When a drug was to be measured for rate and extent of dissolution, a sample of the lot of drug to be used was placed in various concentrations in a spectrophotometer to measure the $\lambda \max$ for that particular drug. Once this value was determined, the spectrophotometer was set at that wavelength, and each sample was analyzed for absorbance. The result was recorded on a Beer's plot and correlation between absorbance and concentration was recorded. The monograph, as it appeared in the USP (1) was used as a reference for determining the dissolution medium for the test. A sample of six tablets was used for each system. The samples at specified time intervals were withdrawn and diluted with dissolution medium to read the absorbance between 0.1 to 0.7 . The data were analyzed using a computer program (appendix I). 
5. List of formulations used in this study

TABLE I

Formulation 1

\begin{tabular}{ll} 
Ingredients & \% weight per batch \\
Lactose & 85.0 \\
Corn starch & 10.0 \\
Povidone C-30 & 5.0 \\
& 100.0 \\
\hline
\end{tabular}

Three batches each of one kilogram weight, were prepared. All the excipients in a batch were blended together in a "V" shell blender for ten minutes. The powder mix was passed through a 40 mesh screen and reblended fifteen minutes. The powder blend was placed in a 2.8 liter Hobart bowl and dry mixed for five minutes. The powder mix was wet granulated using the slow speed of the instrumented Hobart mixer by adding water $(200 \mathrm{~g})$ at a constant rate $(34.3 \mathrm{ml} / \mathrm{minute})$ while recording the torque (mv). This procedure was repeated two more times. The output voltage for a11 three experiments was recorded one on top of the other by changing the base line and using the same starting point on the chart. The torque values were digitalized for every twenty second interval. Mean and relative standard deviation were calculated to determine the reproducibility of the output. 
TABLE II

Phenylpropanolamine, Theophylline, and Hydrochlorothiazide Tablet Formulations.

\begin{tabular}{|c|c|c|c|}
\hline & \multicolumn{3}{|c|}{ Formulation } \\
\hline & 2 & 3 & 4 \\
\hline Ingredients & \multicolumn{3}{|c|}{$\%$ weight per tablet } \\
\hline Phenylpropanolamine hydrochloride & 10.0 & - & - \\
\hline Theophylline anhydrous & - & 10.0 & - \\
\hline Hydrochlorothiazide & - & - & 10.0 \\
\hline Lactose & 83.5 & 83.5 & 83.5 \\
\hline Povidone $\mathrm{C}-30$ & 5.0 & 5.0 & 5.0 \\
\hline AC-Di-Sol & 1.0 & 1.0 & 1.0 \\
\hline Magnesium stearate & 0.5 & 0.5 & 0.5 \\
\hline
\end{tabular}

Drug, lactose and povidone were blended together in a "V" shell blender for ten minutes. The powder blend was passed through a 40 mesh screen and reblended for fifteen minutes. The powder mix $(985.0 \mathrm{~g})$ was dry mixed and wet granulated in a 2.8 liter bowl fitted to an instrumented mixer. The mixer was operated at a slow speed and the granulation fluid, 3A denatured alcohol (295.5 g) was added at a constant rate ( $31.5 \mathrm{ml} /$ minute) while recording the output. Different phases of the torque profile were identified for each formulation. 
Triplicate batches for phases I, II, and III were repeated for each formulation. "The experiments repeated for phases I, II, and III refer to the terminal point on the curve for phase I, II, and III on the torque profile". The wet granulations were dried (four hours) at $50^{\circ} \mathrm{C}$ in a forced hot air oven for a moisture content less than $1 \%$. A sample of the dried granulations was screened through \#10 mesh screen and photographed by scanning electron microscopy. The remaining granulations were sized through \#18 mesh fitted to an oscillating granulator. These granulations were tested for particle size distribution, bulk properties, and flow properties.

AC-Di-Sol was added to the granulation and blended fifteen minutes. The lubricant (magnesium stearate) was added and blended for five minutes. The tablet blend was compressed on an instrumented rotary tablet machine fitted with four sets of $1 / 4$ inch standard round concave tooling. The tablet weight was maintained at $135 \mathrm{mg}$. and the compressional force was set at $10 \mathrm{kN}$. These tablets were tested for weight variation, thickness, hardness, friability, physical appearance, disintegration and dissolution.

Phenylpropanolamine and theophylline formulations were also studied for extended wet mixing after discontinuing the addition of granulating fluid. Wet mixing was continued until ten and twenty minutes for each phase of the formulation. The wet granulations were dried, sized, and studied for all the parameters listed above. 
TABLE III

Phenytoin tablet formulations

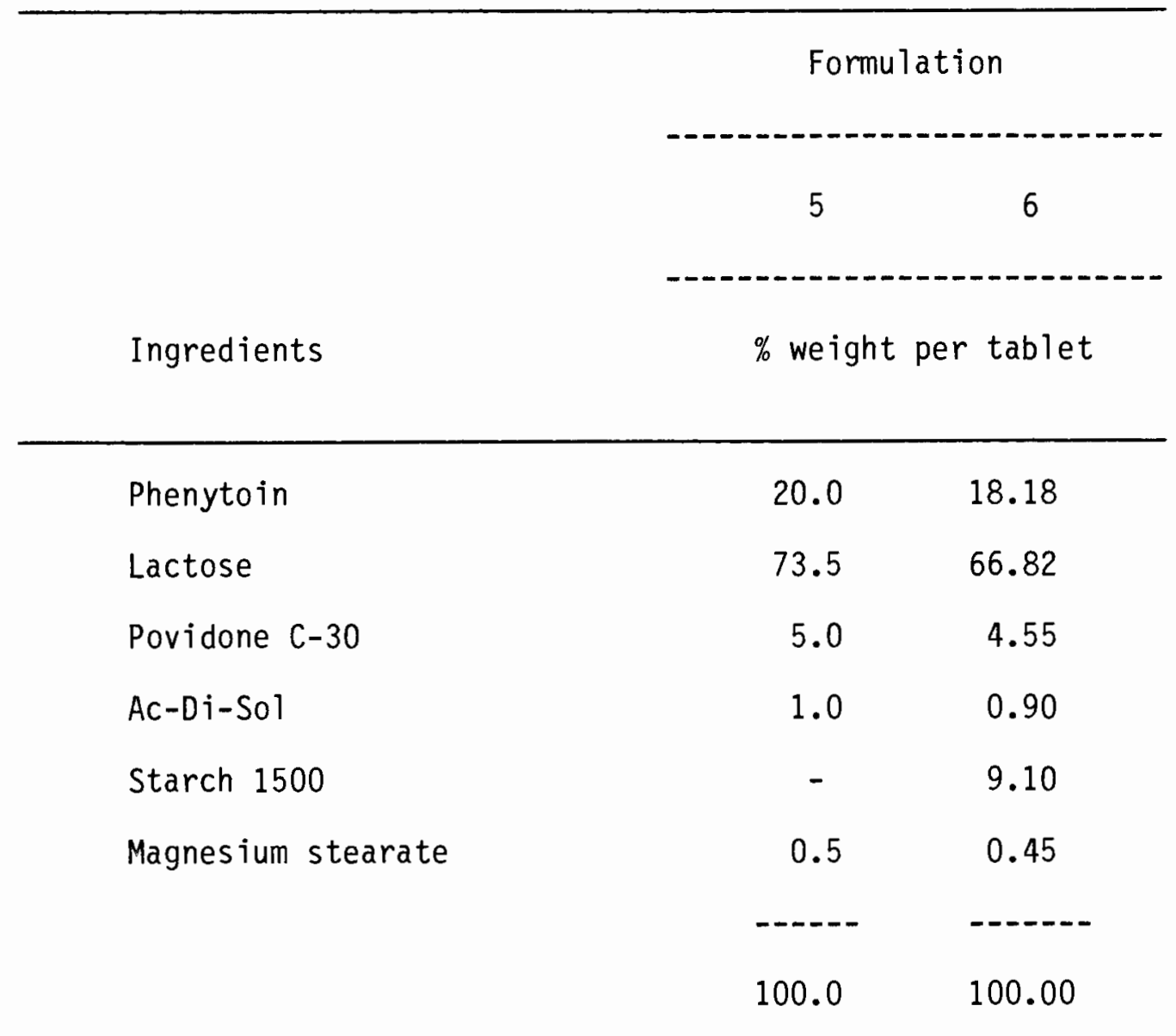

Phenytoin, lactose and povidone were blended together, passed through a 40 mesh screen, and reblended. The mixture was wet granulated with $3 A$ denatured alcohol, using the same procedure as in previous formulations. All five phases were identified and the experiments were repeated for phases I, II, and III. The wet granulations were dried at $50^{\circ} \mathrm{C}$ for four hours in a forced hot air oven. Dry granulations were sized through \#2A (0.093 inches opening) plate fitted to a Fitazpatrick model M comminutor, Knives forward and slow speed. Granulations were 
evaluated for physical properties and then AC-Di-Sol was added and blended fifteen minutes. Each batch was subdivided into two portions. For one of the two portions 9.1 percent Starch 1500 by weight to the total formulation was added and blended fifteen minutes. Magnesium stearate was added to both blends and blended for five minutes. Tablets were compressed using an instrumented Stokes B2 tablet press fitted with four sets of $3 / 8$ inch standard round concave tooling. Tablet weight was set at 250 and $275 \mathrm{mg}$ for formulations 5 and 6 respectively.

These tablets were tested for 211 physical parameters. In addition, these tablets were also tested for dissolution, compared against commercially available Parke Davis $50 \mathrm{mg}$ active tablets and also tablets made with drug - $\beta$-cyclodextrin complex* ${ }^{*}$.

*Tablets containing $50 \mathrm{mg}$ drug were supplied by Mr. R.P. Hegde (70). The author gratefully acknowledges help from Mr. Hegde. 
TABLE IV

Acetaminophen granule formulations

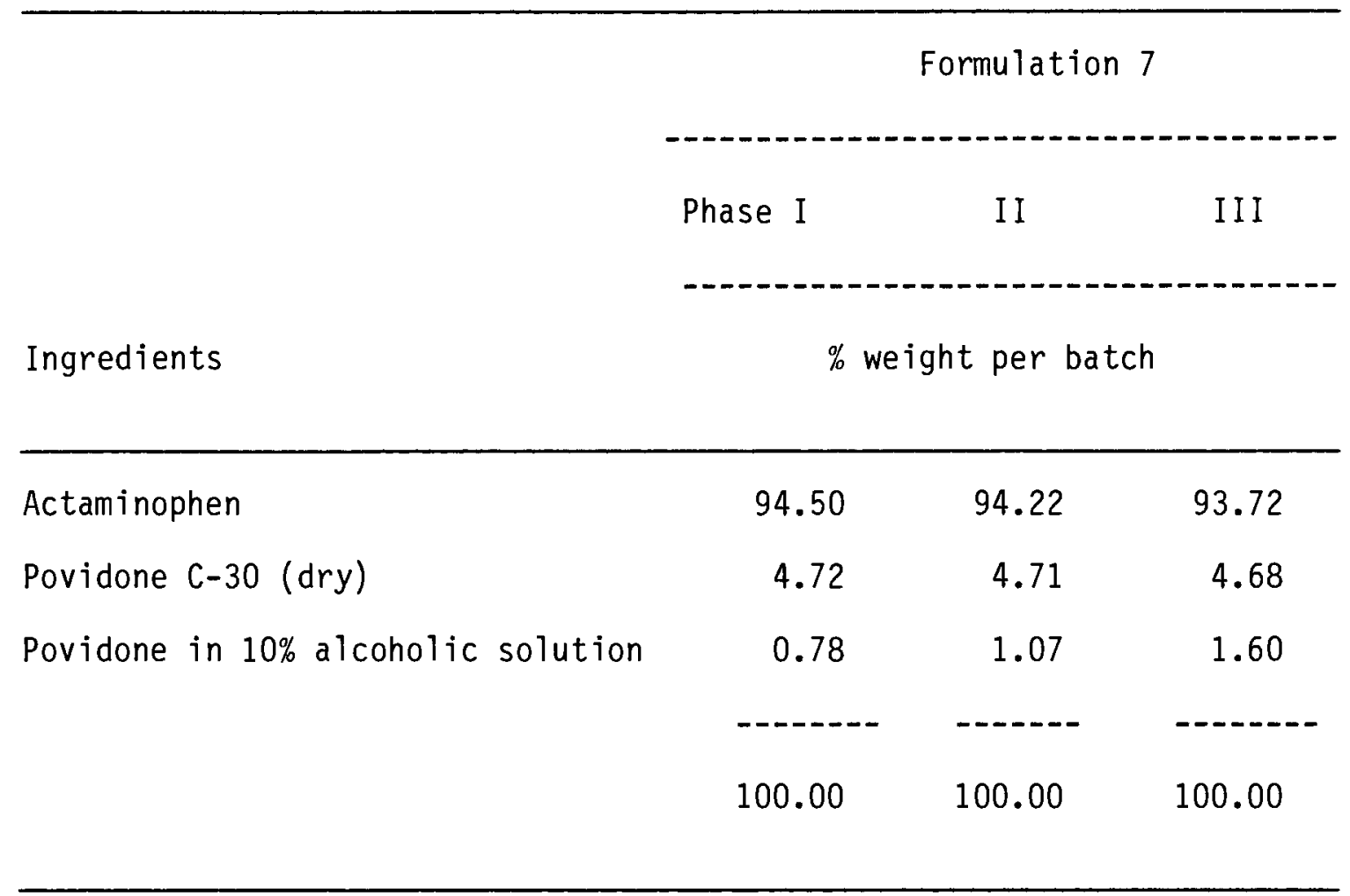

Acetaminophen was blended with povidone, the blend was passed through a 40 mesh screen, and reblended for ten minutes using the Turbula blender. This powder $\operatorname{mix}(500 \mathrm{~g})$ was mixed another five minutes in a Hobart bowl and wet granulated with $10 \%$ solution of povidone in alcohol, by adding the solution at a constant rate. Five phases of the wet granulation process were identified and the experiments were repeated for phase I, II, and III. These wet granulations were dried at $50^{\circ} \mathrm{C}$ for four hours in a forced hot air oven for moisture content less than $1 \%$. Dried granulations were sized through \# $2 A$ plate fitted to a Fitzpatrick model M comminuting machine. These granulations were tested for all granule physical properties and then used in tablet formulation. 
TABLE V

Acetaminophen tablet formulations

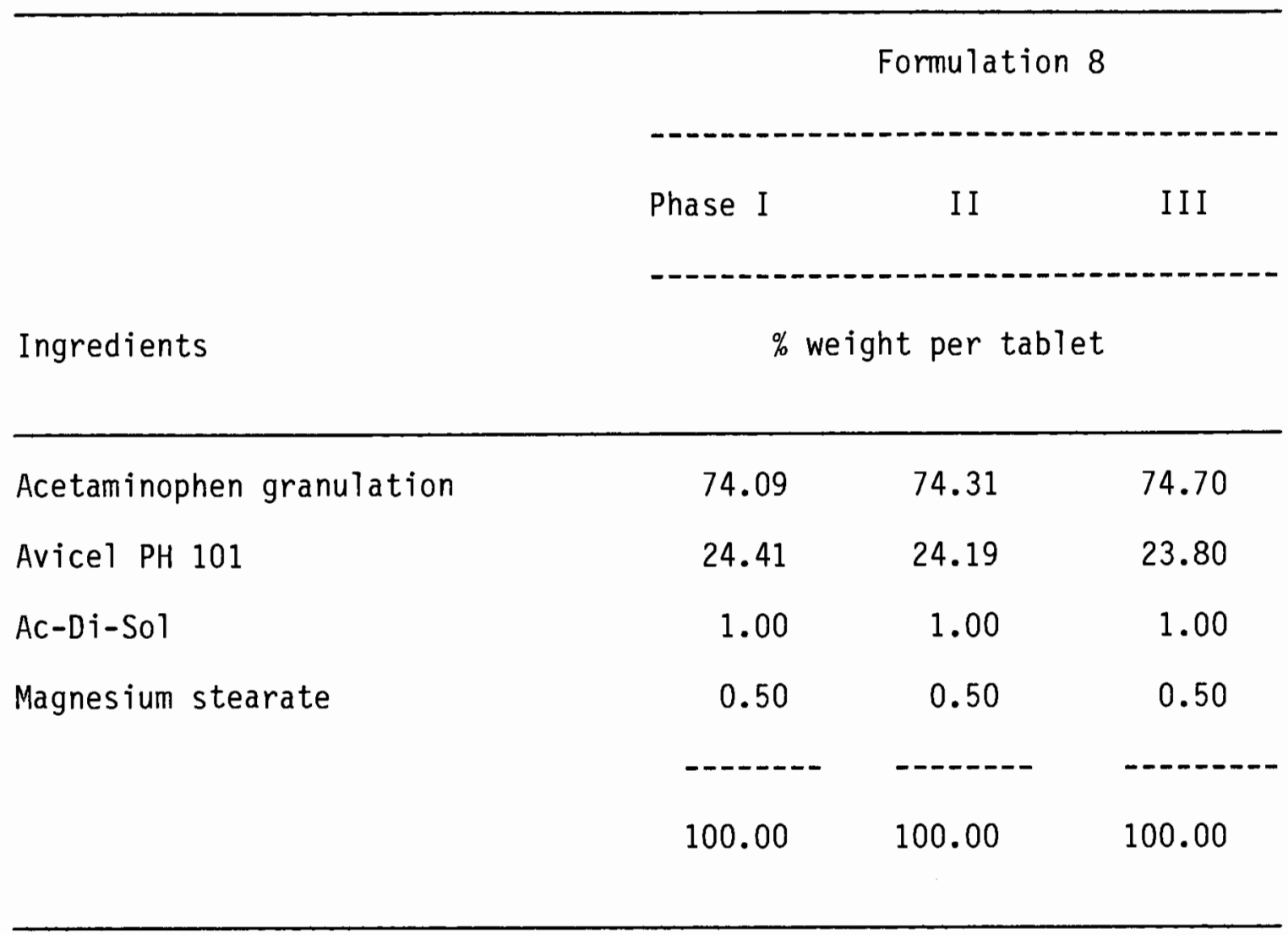

Three tablet blends were made using granulations from phase I, II, and III of formulation 8, utilizing the following procedure. Acetaminophen granulation, Avicel PH 101, and AC-Di-Sol were blended together for ten minutes, using the Turbula blender. Magnesium stearate was added to the above powder blend and blended five minutes. Tablets were compressed using an instrumented Stokes B2 tablet press. Tablet weight was set at $464.3 \mathrm{mg}$ (i.e $325 \mathrm{mg}$ of drug). The compression force was set at $16.0 \mathrm{kN}$; (This value was selected after examination of the compression profile). Tablets were tested for all the properties listed in the tablet characterization section. 
TABLE VI

Theophylline tablet formulations

\begin{tabular}{|c|c|c|c|}
\hline \multirow[b]{3}{*}{ Ingredients } & \multicolumn{3}{|c|}{ Formulation } \\
\hline & 9 & 10 & 11 \\
\hline & \multicolumn{3}{|c|}{$\%$ weight per tablet } \\
\hline Theophylline anhydrous & 10.0 & 40.0 & 75.5 \\
\hline Lactose & 83.5 & 53.5 & 18.5 \\
\hline Povidone $\mathrm{C}-30$ & 5.0 & 5.0 & 5.0 \\
\hline Ac-Di-Sol & 1.0 & 1.0 & 1.0 \\
\hline \multirow[t]{3}{*}{ Magnesium stearate } & 0.5 & 0.5 & 0.5 \\
\hline & ---- & $-\cdots-$ & ---- \\
\hline & 100.0 & 100.0 & 100.0 \\
\hline
\end{tabular}

Theophyline, lactose and povidone were blended together, passed through a 40 mesh screen and reblended for fifteen minutes using a "V" shell blender. The powder mix was placed in a 2.8 liter bowl and mixed five minutes using an instrumented Hobart mixer set at slow speed. The powder blend was wet granulated with $3 \mathrm{~A}$ denatured alcohol by adding at a constant rate $(35.3 \mathrm{ml} /$ minute) while recording the relative torque on the paddle. Five phases of the torque profile were identified. Phase I, II, and III for each formulation were repeated and the wet granulations were dried at $50^{\circ} \mathrm{C}$ for four hours in a forced hot air oven. Dried 
granulations were sized through \#18 mesh screen fitted to an oscillating granulator. These granulations were studied for all the physical parameters.

AC-Di-Sol was added to the granulations, blended ten minutes using the Turbula blender, added lubricant and blended five minutes. Tablets were compressed on an instrumented Stokes B2 rotary tablet press. Tablet weight and compression force were set at $135 \mathrm{mg}$ and $4 \mathrm{KN}$ respectively. These tablets were tested for all the parameters listed in the tablet characterization section. 
TABLE VII

Hydrochlorothiazide formulations with soluble and insoluble matrices

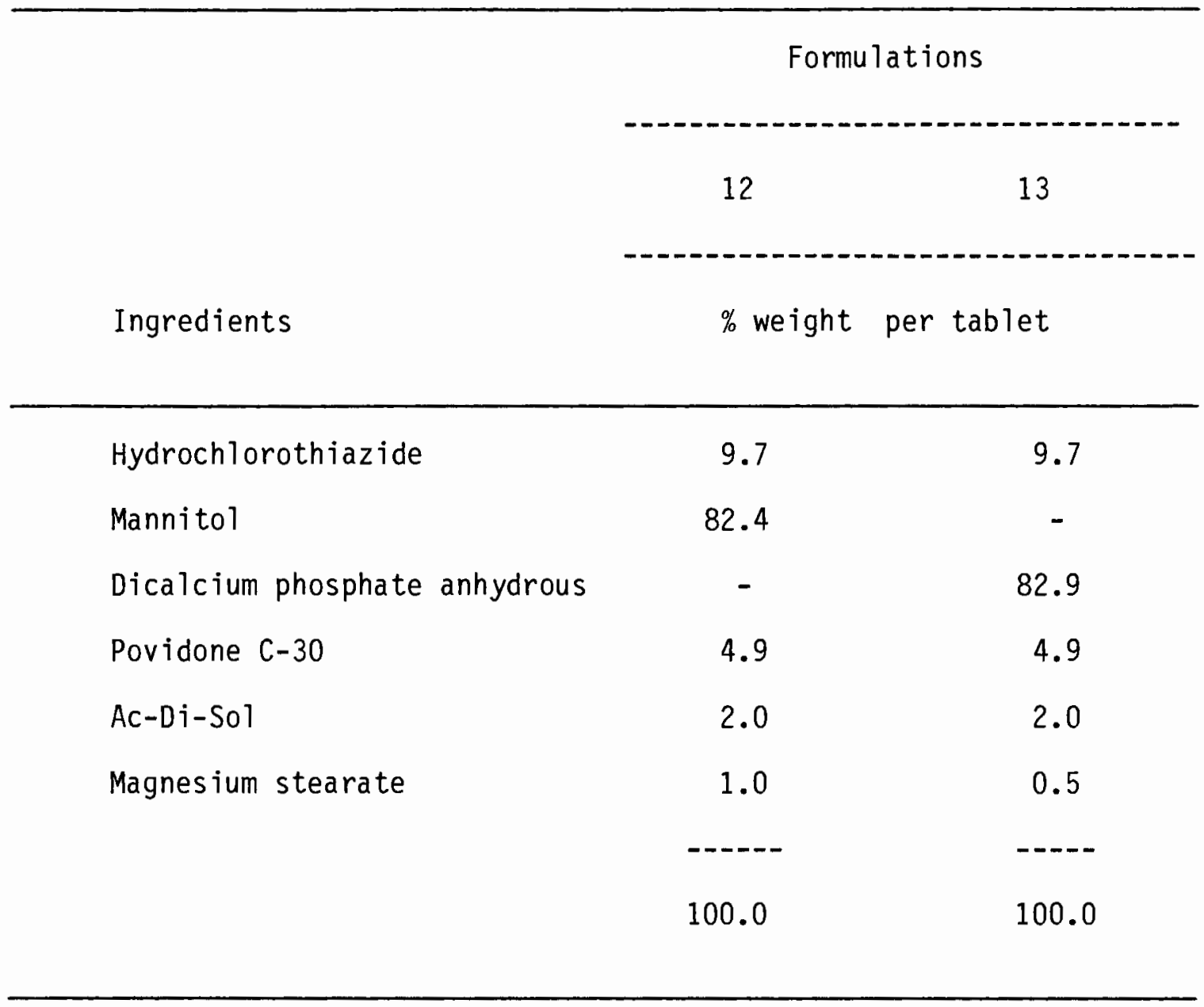

The same manufacturing procedure was used as for the theophylline formulations, except water was used as granulating fluid and added at a rate of $40 \mathrm{ml} /$ minute. Granulations were studied for their physical properties. Mannitol tablets were compressed at $2.2 \mathrm{KN}$ and dicalcium phosphate tablets at $6.4 \mathrm{KN}$. These tablets were studied for their physical parameters listed in tablet characterization section. 
TABLE VIII

Experimental design I - Formulation variables (independent)

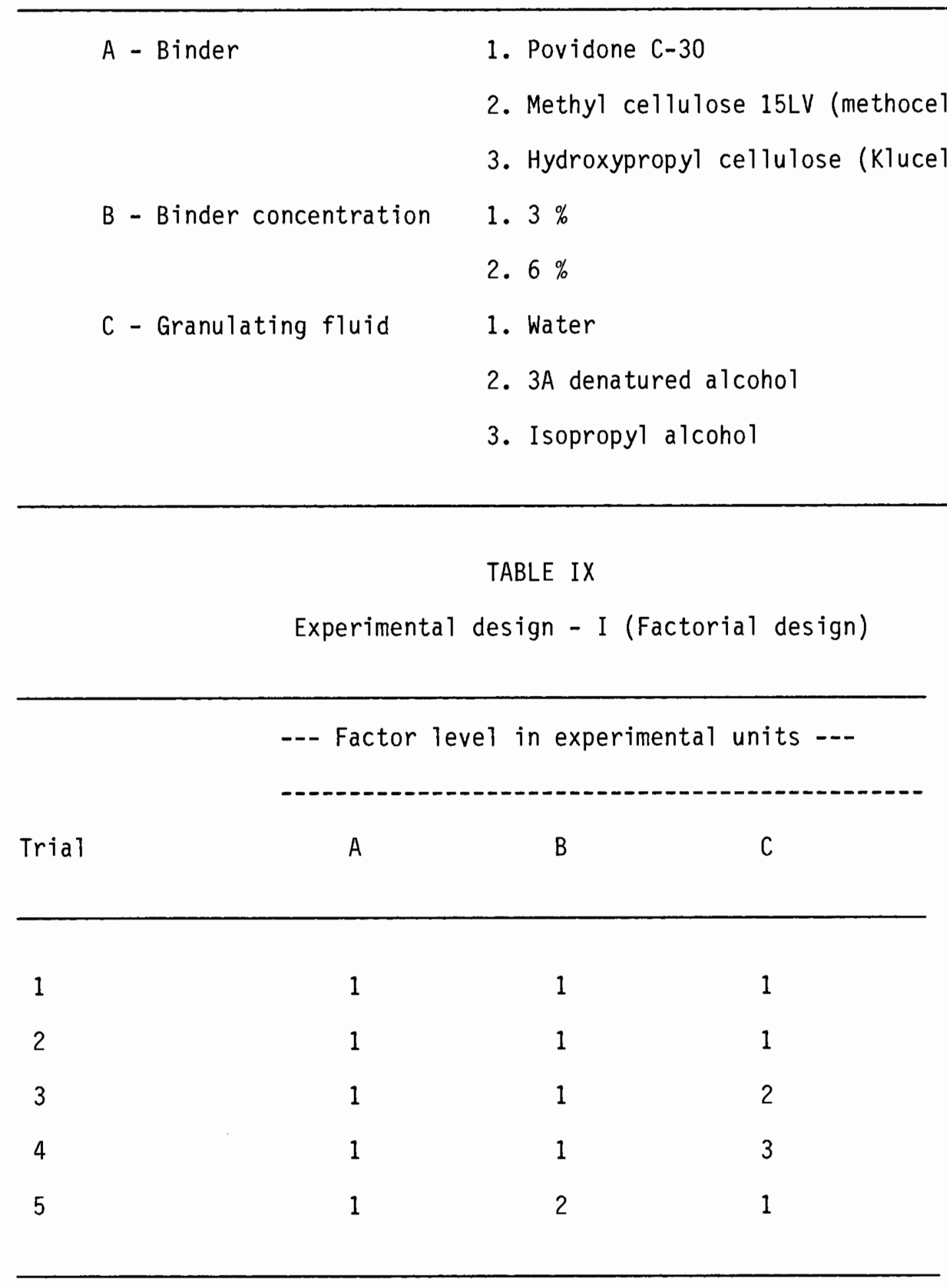


Table IX Continued

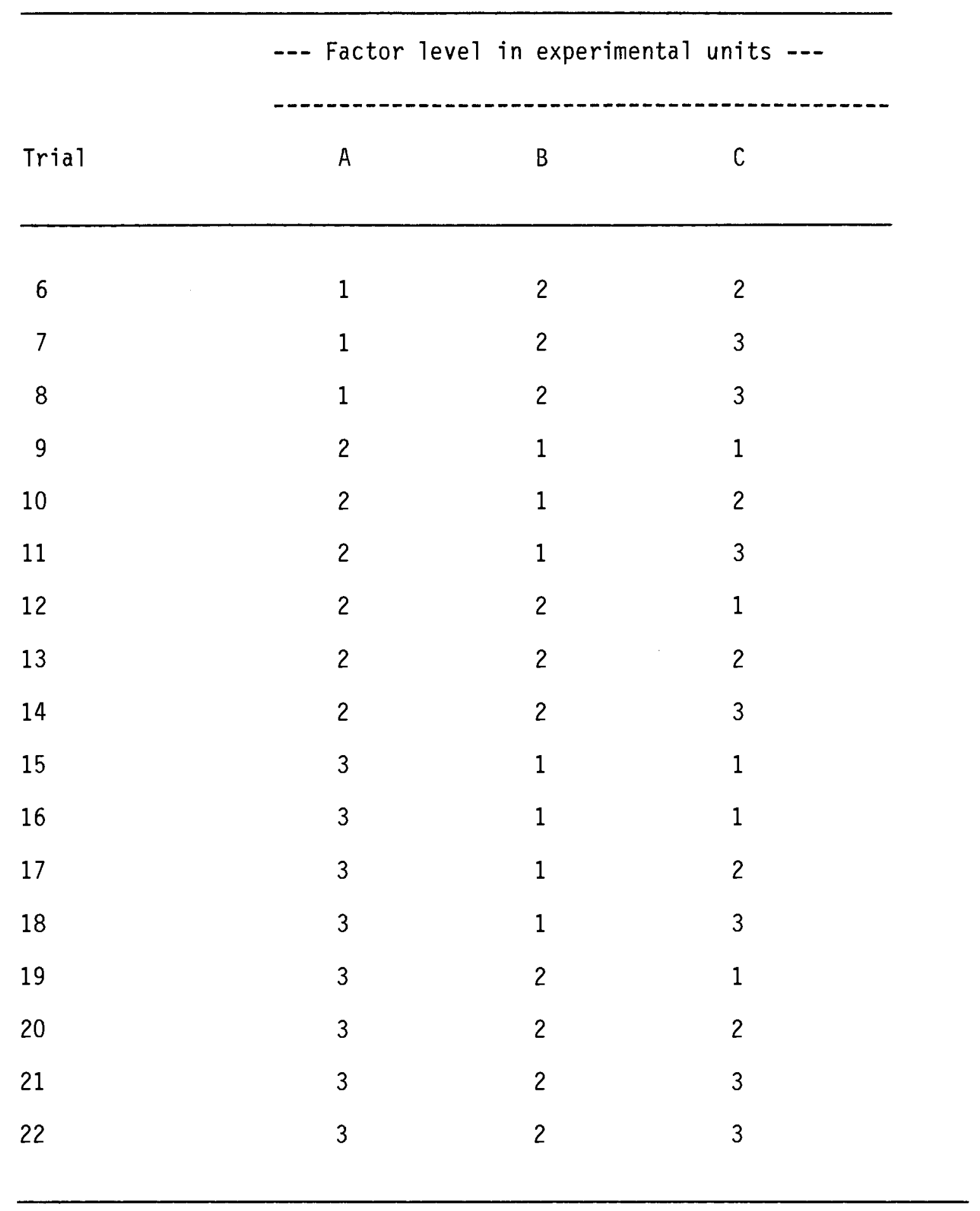


TABLE $X$

Experimental design - I: Hydrochlorothiazide tablet formulations

\begin{tabular}{lc}
\hline Ingredients & \% weight per tablet \\
\hline Hydrochlorothiazide & 10.0 \\
Binder & $\mathrm{A}$ \\
Binder concentration & $\mathrm{B}$ \\
Granulating fluid & $\mathrm{C}$ \\
Dicalcium phosphate anhydrous & $(87.5-\mathrm{B})$ \\
Ac-Di-Sol & 2.0 \\
Magnesium stearate & 0.5 \\
& $-\ldots . .-\ldots$ \\
\hline
\end{tabular}

In all the experiments in this design, the following factors were kept constant: drug level, disintegrant concentration, lubricant level, batch size, dry mixing time, rate of addition of granulating fluid, rate of mixing, drying temperature, moisture level after drying, screen used for sizing granulation after drying, tablet weight, compression force for final tableting and all the equipment used.

Hydrochlorothiazide, binder and anhydrous dicalcium phosphate were mixed together for ten minutes. The powder mix was passed through a 40 mesh screen and reblended fifteen minutes using a "V" shell blender. This powder mix $(1 \mathrm{~kg})$ was mixed in a 2.8 liter Hobart bow for five minutes at 145 RPM and then wet granulated using a specified granulating 
fluid by adding at a constant rate $(25.6 \mathrm{ml} /$ minute) while recording the relative torque on the paddle. Five phases of the torque profile were identified and 211 experiments were repeated to the end of phase III. All twenty-two batches of wet granulations were dried at the same time in the same forced hot air tray dryer at $50^{\circ} \mathrm{C}$. Granulations were dried to less than $1 \%$ moisture level.

To reach a $1 \%$ moisture level, drying times for wet granulations made with alcohol ( $3 \mathrm{~A}$ ethanol or isopropanol) and with water required six and ten hours respectively. These dried granules were sized through \#18 mesh screen fitted to an oscillating granulator. These granulations were tested for all the physical parameters. Ac-Di-Sol was added, blended fifteen minute, added lubricant and blended five minutes using the Turbula blender. Compression and ejection profiles were generated for each batch by keeping the tablet weight $(200 \mathrm{mg}$ ) constant using the Stokes B2 instrumented rotary press. Four sets of $1 / 4$ inch standard round concave tooling were used. Final tablets were compressed at $6 \mathrm{kN}$. The tablets were studied for all the parameters listed in the tablet characterization section. 
TABLE XI

Experimental design II - Formulation variables (independent)

A. Disintegrant

B. Disintegrant concentration

C. \% Intragranular disintegrant
0. Control (no disintegrant)

1. Ac-Di-Sol

2. Explotab

3. Crospovidone

4. Starch 1500

0.0

1. 0.25

2. 0.50

3. 1.00

4. 2.00

5. 4.00

1. 0

2. 50

3. 100 


\section{TABLE XII}

Experimental design - II Factorial design

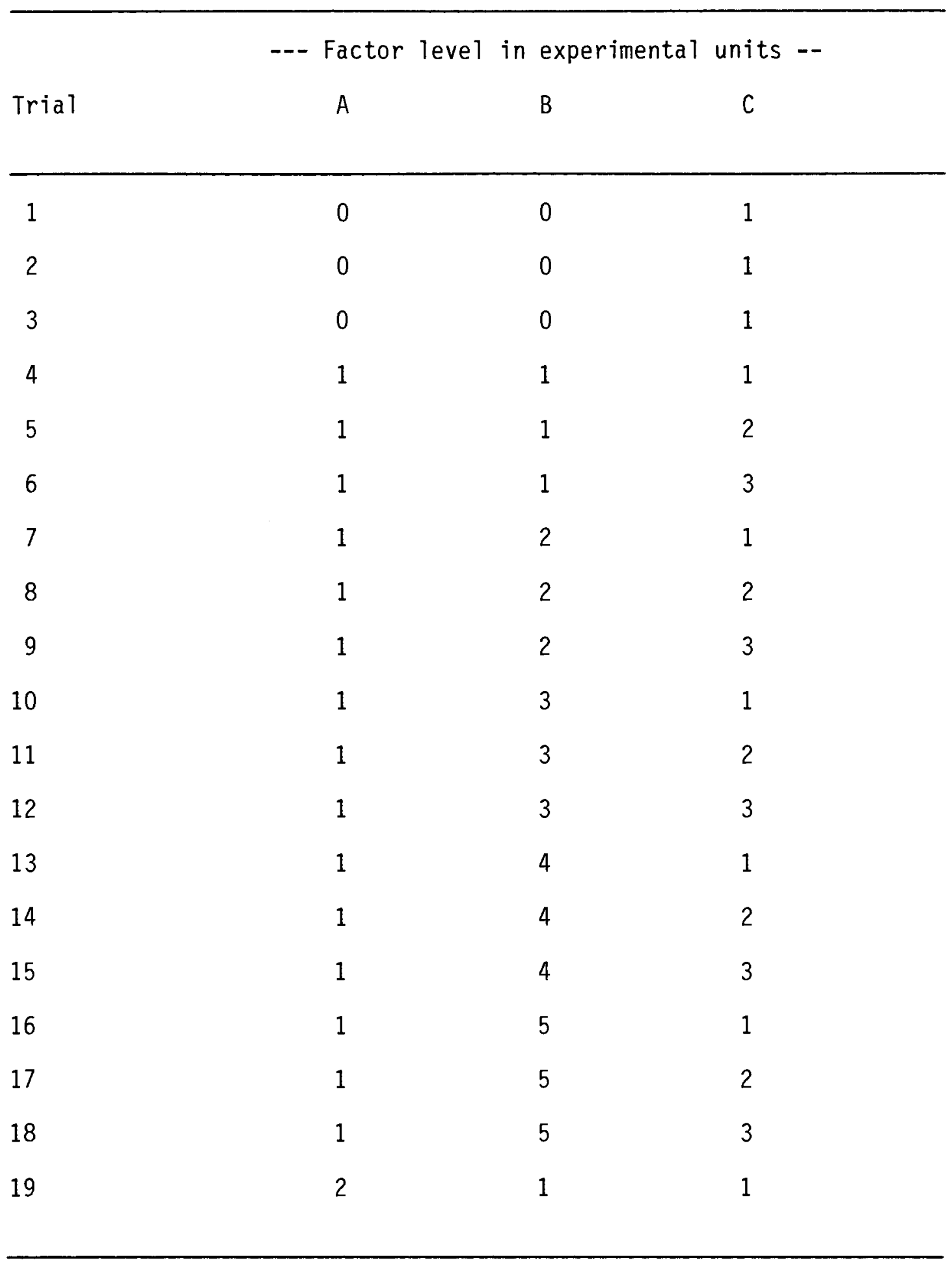


Table XII Continued--.---.----

$$
\text { Experimental design - II Factorial design }
$$

\begin{tabular}{|c|c|c|c|}
\hline & -.- Factor level in & & units -- \\
\hline Trial & $A$ & B & $c$ \\
\hline 20 & 2 & 1 & 2 \\
\hline 21 & 2 & 1 & 3 \\
\hline 22 & 2 & 2 & 1 \\
\hline 23 & 2 & 2 & 2 \\
\hline 24 & 2 & 2 & 3 \\
\hline 25 & 2 & 3 & 1 \\
\hline 26 & 2 & 3 & 2 \\
\hline 27 & 2 & 3 & 3 \\
\hline 28 & 2 & 4 & 1 \\
\hline 29 & 2 & 4 & 2 \\
\hline 30 & 2 & 4 & 3 \\
\hline 31 & 2 & 5 & 1 \\
\hline 32 & 2 & 5 & 2 \\
\hline 33 & 2 & 5 & 3 \\
\hline 34 & 3 & 1 & 1 \\
\hline 35 & 3 & 1 & 2 \\
\hline 36 & 3 & 1 & 3 \\
\hline 37 & 3 & 2 & 1 \\
\hline
\end{tabular}


Table XII Continued-_.....-

Experimental design - II Factorial design

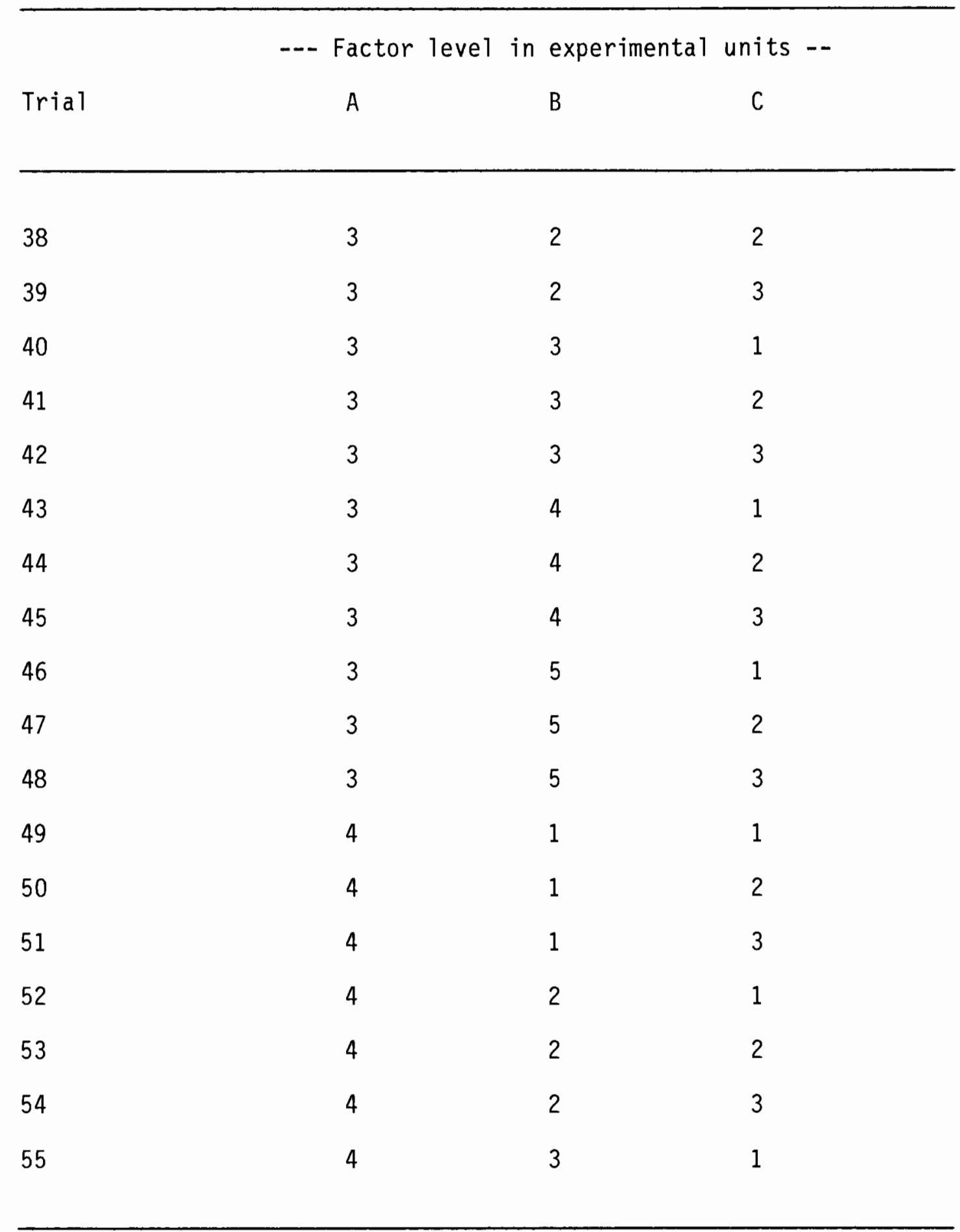


Table XII Continued-----------

$$
\text { Experimental design - II Factorial design }
$$

\begin{tabular}{lccc}
\hline & --- Factor lever in experimental units -- \\
Trial & A & B & C \\
& & & \\
56 & 4 & 3 & 2 \\
57 & 4 & 3 & 3 \\
58 & 4 & 4 & 1 \\
59 & 4 & 4 & 2 \\
60 & 4 & 4 & 3 \\
61 & 4 & 5 & 1 \\
62 & 4 & 5 & 2 \\
63 & 4 & 5 & 3 \\
\hline
\end{tabular}


TABLE XIII

Experimental design - II Hydrochlorothiazide tablet formulations

\begin{tabular}{ll}
\hline Ingredients & \% weight per tablet \\
\hline Hydrochlorothiazide & 10.0 \\
Disintegrant & A \\
Disintegrant concentration & B \\
\% Intragranular disintegrant & $\mathrm{C}$ \\
Dicalcium phosphate anhydrous & $(84.5-\mathrm{B})$ \\
Povidone C-30 & 5.0 \\
Magnesium stearate & 0.5 \\
& ------- \\
\hline
\end{tabular}

In all the experiments in this design, the following factors were kept constant: drug level, binder level, lubricant level, batch size, dry mixing time, wet mixing time, drying temperature and time, moisture level after drying, screen used for sizing granulation after drying, tablet weight, compression force and all the equipment used.

Drug, povidone, dicalcium phosphate anhydrous, and disintegrant (with or without) were mixed together for ten minutes, passed through a 40 mesh screen, and reblended fifteen minutes. This powder mix (1 kg) was mixed five more minutes in a 2.8 liter Hobart bowl and wet granulated with water by adding at a constant rate $(38.3 \mathrm{ml} /$ minute) while recording the relative torque on the paddle. Five phases of torque 
profile were identified for all the experiments and the experiments were repeated to phase III. Mixing time (four minutes) was kept constant but the rate of addition of water was varied (38 to $48 \mathrm{ml} / \mathrm{minute}$ ). Wet granulations were dried at $50^{\circ} \mathrm{C}$ in a forced hot air oven at the same time for ten hours. Dried granulations were sized through \#18 mesh screen fitted to an oscillating granulator. These granulations were tested for all the physical parameters.

Disintegrant was added, blended ten minutes using the Turbula blender, magnesium stearate was added and blended five minutes. Tablets were compressed using an instrumented Stokes B2 rotary press fitted with four sets of $1 / 4$ inch standard round concave tooling. Tablet weight was set at $200 \mathrm{mg}$ and compression force at $3.4 \mathrm{KN}$. Tablets were tested for all the parameters listed in the tablet characterization section. 


\section{TABLE XIV}

Formulations with two different grades of lactose

Formulation

Ingredients

14

15

\section{$\%$ weight per batch}

\begin{tabular}{lcc} 
Lactose & 95.0 & - \\
Lactose anhydrous & - & 95.0 \\
Povidone C-30 & 5.0 & 5.0 \\
\hline
\end{tabular}

Lactose and povidone were mixed for ten minutes, passed through a 40 mesh screen, and reblended for fifteen minutes. This powder mix was charged to a 2.81 iter Hobart bowl and mixed for five minutes. The powder blend $(1 \mathrm{~kg})$ was wet granulated with water $(300 \mathrm{~g})$ by adding at a constant rate and recorded the torque as a function of time. The same procedure was used for the second formulation and the torque was recorded on the same chart paper, to compare one against the other. 
TABLE XV

Lactose formulations with different levels of sucrose

\begin{tabular}{|c|c|c|c|c|}
\hline Formulation & 16 & 17 & 18 & 19 \\
\hline Ingredient & & weic & able & \\
\hline Lactose & 100 & 95 & 90 & 80 \\
\hline Sucrose & 0 & 5 & 10 & 20 \\
\hline
\end{tabular}

Granular sucrose was milled through \#000 plate $(0.020$ inch opening) fitted to a Fitzpatrick model M comminuting mill, hammers forward and high speed. Lactose and sucrose were blended together, passed through a 40 mesh screen and reblended for fifteen minutes. The powder mix $(500 \mathrm{~g})$ was wet granulated using the slow speed of the Hobart mixer by adding water $(150 \mathrm{~g})$ at a constant rate while recording the torque (mv). The same procedure was used for all the formulations and the torque profiles were recorded. These torque profiles were cut and pasted one on top of the other, to show the effect of soluble material on the wet granulation process. 
TABLE XVI

Lactose formulations with different levels of Avicel PH 101

\begin{tabular}{lrcc} 
Formulation & 20 & 21 & 22 \\
Ingredients & \% weight per batch \\
& 95 & 90 & 80 \\
Lactose & 5 & 10 & 20 \\
Avicel PH 101 & & & \\
\hline
\end{tabular}

The same blending procedure was used as in previous formulations. The powder blends (500 g each) were wet granulated with ten percent $\mathrm{W} / \mathrm{W}$ solution of povidone in denatured alcohol $(150 \mathrm{~g})$ and the torque on the paddle was recorded for each formulation. These torque profiles were cut and pasted one on top of the other, to show the effect of Avicel on lactose formulations in the wet granulation process. 
Granulation of lactose with different rates of mixing

Formulation

23

Ingredients

$\%$ weight per batch

$\begin{array}{lll}\text { Lactose } & 100 & 100 \\ \text { solution } & (30) & (30) \\ \text { Mixing rate (rpm) } & 145 \text { (slow speed) } & \\ \end{array}$

Lactose was wet granulated with ten percent $W / W$ solution of povidone in denatured alcohol using the slow speed of the instrumented Hobart mixer, and the torque on the paddle was recorded. The same procedure was repeated using the medium speed of the instrumented mixer and the torque on the paddle was recorded on the same chart paper, to show the effect of mixing rate on the wet granulation process. 


\section{RESULTS AND DISCUSSION}

In the past relatively little attention has been given to the method of liquid addition in the wet granulation process. Normally, the binder solution is either poured into the bowl within a short time or aliquots of solution are added at fixed intervals (71-91). The factor having perhaps the largest effect on mean granule size is the mesh size of the screen used to wet granulate. In these methods, subjective judgement is involved in every stage of the process, such as, selecting the amount of granulating fluid, duration of kneading, and screen size to wet granulate. The literature is often conflicting as to the effects of processing and formulation variables on the properties of granules and the present state of useful knowledge is approximately zero.

In this study, granulating fluid was added at a slow constant rate while recording the torque on the paddle of the instrumented Hobart mixer. This procedure allows uniform wetting of powder particles. The amount of granulating fluid added at any time point can be quantified. In addition, it also allows to study the changes of the torque values on the paddle as a function of granulating fluid and mixing time. The instrumentation of the mixer reported in this study is cheap and covenient. All the parts used in this instrumentation are commercially available.

Formulation 1 (Table I) was used to test the reproducibility of the data generated by the instrumented Hobart mixer. Figure 3 shows, that the output from the triplicate experiments using formulation 1 were plotted on the same chart paper, one above the other. The base line of 


\section{FIGURE 3}

Formulation 1: Torque - time profile

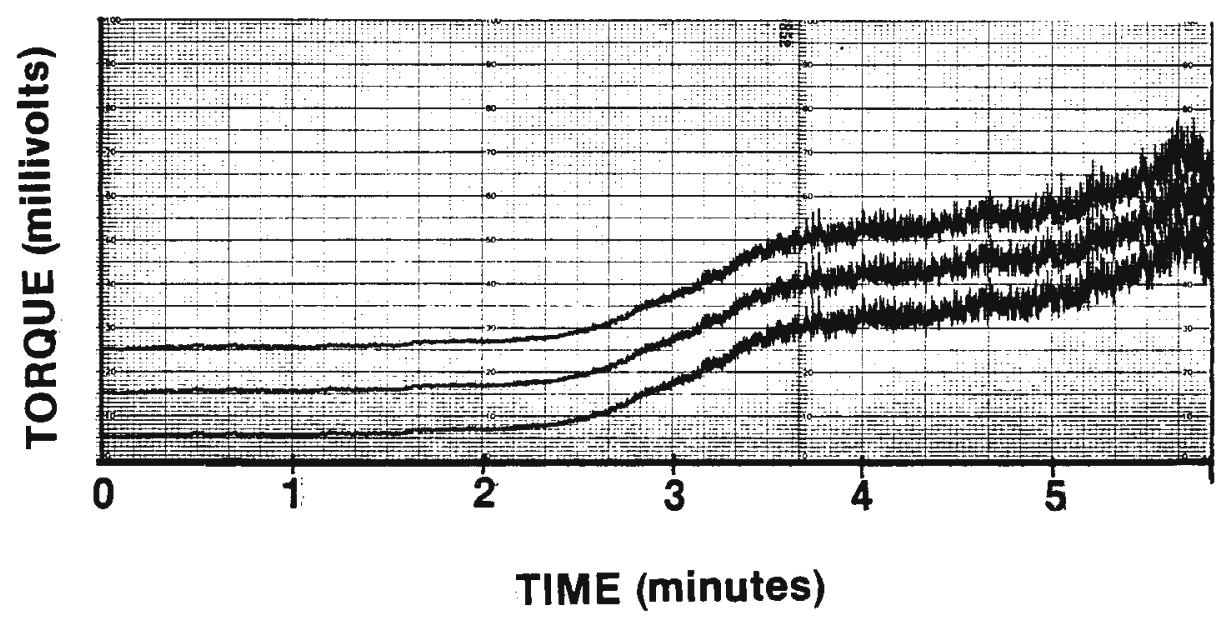


plots one and two were adjusted by subtracting 200 and $100 \mathrm{mv}$ respectively. Mean and relative standard deviation (Table XVIII) of the torque values indicate that the data were reproducible. The maximum relative standard deviation was less than two percent.

After switching on the instrumented mixer, a certain time (less than two minutes) is needed to reach steady state torque values without any load on the paddle. This phenomenon is due to the viscosity changes of the lubricant (grease) in the transmission case unit. To avoid this problem, all the dry powder blends were mixed for five minutes before starting the addition of granulation fluid.

Ideally, in designing the equipment one would prefer to have the torque-measuring sensor as close as possible to the place where the granulation process is occurring. If the absolute work done during the process of agglomeration were of concern, this equipment would not be suitable. The torque (mv) output generated by this equipment is relative to the actual torque applied on the paddle rather than absolute due to the location of measuring equipment. However, in this investigation we were interested only in the relative changes in torque occurring during the addition of granulating fluid. In the mixing process, changes in torque occur as a result of the change in the cohesive force or of the tensile strength of the agglomerates in the moistened powder bed.

The shape of the torque profile seems to be similar to the power consumption profile reported by Leuenberger (39) using the same type of formulation. A power - torque relationship is as follows (92): This relationship is derived from the fact that power is simply as the rate of doing work. Power $P$ is the derivative of work with respect to time or 
TABLE XVIII

Formulation I : Torque - Time Profile

\begin{tabular}{|c|c|c|c|c|c|}
\hline \multicolumn{6}{|c|}{ Torque (mv) } \\
\hline Time (sec) & Trial 1 & 2 & 3 & $\bar{X}(m v)$ & R.S.D \\
\hline 0 & 240 & 238 & 240 & 239.33 & 0.48 \\
\hline 20 & 250 & 252 & 248 & 250.00 & 0.80 \\
\hline 40 & 260 & 258 & 258 & 258.67 & 0.45 \\
\hline 60 & 255 & 255 & 260 & 256.67 & 1.12 \\
\hline 80 & 260 & 258 & 260 & 259.33 & 0.45 \\
\hline 100 & 260 & 260 & 260 & 260.00 & 0.00 \\
\hline 120 & 270 & 272 & 270 & 270.67 & 0.43 \\
\hline 140 & 280 & 281 & 280 & 280.33 & 0.21 \\
\hline 160 & 310 & 312 & 310 & 310.67 & 0.37 \\
\hline 180 & 370 & 375 & 370 & 371.67 & 0.78 \\
\hline 200 & 450 & 455 & 450 & 451.67 & 0.64 \\
\hline 220 & 500 & 495 & 495 & 496.67 & 0.58 \\
\hline 240 & 530 & 540 & 550 & 540.00 & 1.85 \\
\hline 260 & 520 & 525 & 530 & 525.00 & 0.95 \\
\hline 280 & 575 & 570 & 570 & 571.67 & 0.50 \\
\hline 300 & 580 & 582 & 590 & 584.00 & 0.91 \\
\hline 320 & 620 & 625 & 620 & 621.67 & 0.46 \\
\hline 340 & 720 & 725 & 720 & 721.67 & 0.40 \\
\hline
\end{tabular}




$$
P=d W / d t=2 \pi T \cdot R P M
$$

and

$$
T=P / 2 \pi \cdot R P M
$$

Horse Power HP or the rate of doing work is defined by:

$$
1 H P=550 \text { 1b. ft. } / \mathrm{sec} .=33000 \text { 1b. ft. } / \mathrm{min} \text {. }
$$

We, therfore have the following convenient relations

$$
\begin{aligned}
& T=(33000 \cdot \mathrm{HP} / 2 \pi \cdot \mathrm{RPM}) \text { 1b.ft. } \\
& T=(5252 \cdot \mathrm{HP} / \mathrm{RPM}) \text { 1b. ft. }
\end{aligned}
$$

also 1 Watt $=44.167 \mathrm{lb} . \mathrm{ft} . / \mathrm{min}$.

Therefore, we also have the relations that

$$
T=(7.03 \text {. Watt / RPM) 1b. ft. }
$$

Power consumption (watt) $=(T$. RPM / 7.03) 1b. ft. / min.

For a syncronous motor, power consumption is directly proportional to torque.

Figure 4 shows a typical torque profile. The curve can be divided into five distinct phases, in relation to the quantity of the granulating fluid added. In the first phase, the powder mix is moistened without any observable increase in the torque value, which remains the same as in the dry powder mixing phase. In this phase, the drops of granulating fluid contact the dry powder mix and the powder forms agglomerates. The surface of these agglomerates and the remaining powder mix was dry. In phase two of the process, the surface of the charge was still dry but the powder balls were broken by shearing and compacting forces. Torque on the paddle increases sharply, to an extent dependent on the granulate composition, and the solid particles begin to 
FIGURE 4

A TYPICAL TORQUE PROFILE

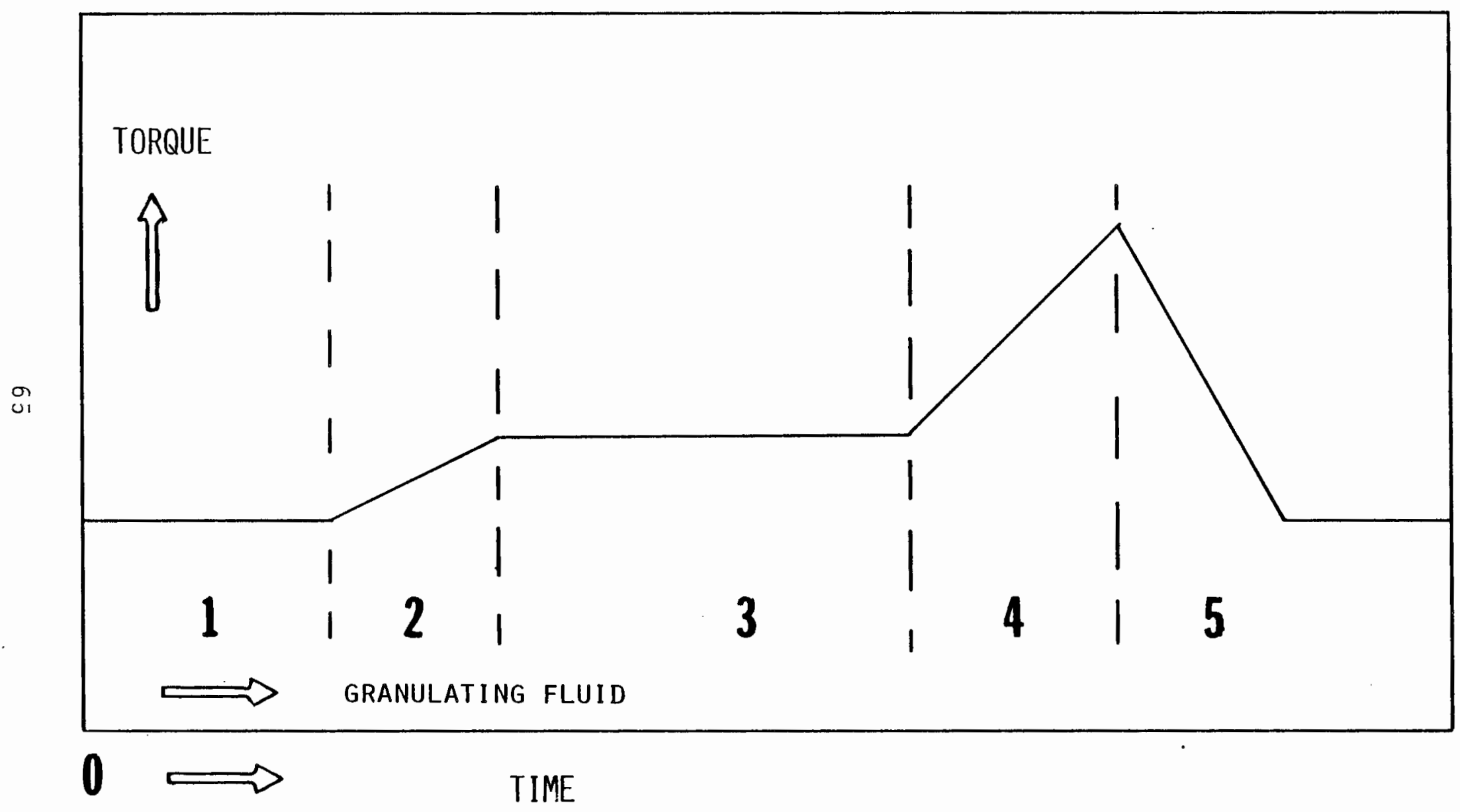


agglomerate. During the third phase torque levels off. The surface of the solid particles was wet and further agglomeration was observed. At the end of the phase three all the granules were wet and shiny. In phase four torque increases and reaches a maximum. In this phase the wet granules stick together, grow uncontrolably and finally become a pasty mass. During the fifth phase, torque falls steeply, and the pasty mass, which is still firm in the fourth phase, breaks down and slowly passes into a suspension. These five phases were obtained with practically all types of powder blends investigated except microcrystalline cellulose. For this system it is possible that the granulation fluid diffuses into the inner pores and leaves the surface dry in the microcrystalline cellulose powder blends. In general, volume of liquid phase present at the surface of the solid particles during the processing is one of the most important factors governing the degree of agglomeration (33).

The physical properties of the raw materials used in this study are recorded in the tables XIX - XXII. Experimental results of theophylline, phenytoin and acetaminophen solubility in water at twenty five degrees centigrade are in agreement with the results reported in the literature (93-95).

The lactose matrix formulations were investigated with theophylline, phenylpropanolamine or hydrochlorothiazide as drugs at ten percent level. Physical properties of each drug system were different. In these experiments, all the formulation and processing variables were kept constant except the type of the drug in the formulation (Table II). The torque profiles of these formulations contained all five phases reported earlier. Torque profiles of theophylline and phenypropanolamine 
TABLE XX

Percent Particle Size Distribution of Raw Materials

\begin{tabular}{rrrrrr}
\hline Size $(\mu \mathrm{m})$ & Theophyl1ine & Phenytoin & PPA & HTZ & APAP \\
$0-44$ & 3.0 & 0.0 & 4.5 & 10.0 & 0.4 \\
$44-74$ & 15.7 & 1.2 & 16.9 & 19.7 & 4.7 \\
$74-105$ & 31.3 & 14.7 & 30.0 & 33.3 & 12.8 \\
$105-149$ & 31.5 & 39.4 & 24.8 & 36.2 & 27.7 \\
$149-177$ & 14.9 & 37.8 & 13.0 & 0.4 & 23.0 \\
$177-250$ & 3.5 & 3.7 & 9.1 & 0.0 & 20.1 \\
$250-420$ & 0.0 & 3.1 & 1.7 & 0.4 & 11.3 \\
\hline
\end{tabular}

PPA = Phenylpropanolamine Hydrochloride

HTZ = Hydrochlorothiazide

APAP = Acetaminophen 


\section{TABLE XIX}

Percent Particle Size Distribution of Raw Materials

\begin{tabular}{rrrrr}
\hline Size $(\mu \mathrm{m})$ & $\begin{array}{c}\text { Lactose } \\
\text { hydrous }\end{array}$ & $\begin{array}{l}\text { Lactose } \\
\text { anhydrous }\end{array}$ & $\begin{array}{c}\text { Dicalcium } \\
\text { Phosphate }\end{array}$ & Mann \\
$0-44$ & 2.8 & 0.4 & 32.6 & 6.7 \\
$44-74$ & 25.6 & 23.0 & 24.4 & 16.6 \\
$74-105$ & 59.4 & 11.2 & 24.5 & 28.9 \\
$105-149$ & 11.7 & 16.6 & 12.7 & 18.9 \\
$149-177$ & 0.4 & 9.8 & 4.2 & 16.9 \\
$177-250$ & 0.0 & 23.6 & 1.2 & 6.1 \\
$250-420$ & 0.0 & 15.4 & 0.3 & 6.0 \\
\hline
\end{tabular}


TABLE XXI

Bulk Properties of Raw Materials

\begin{tabular}{llll}
\hline & \multicolumn{2}{c}{ Density } & \\
& $\left(\mathrm{g} / \mathrm{cm}^{3}\right)$ & $\begin{array}{c}\text { Tapped } \\
\left(\mathrm{g} / \mathrm{cm}^{3}\right)\end{array}$ & \% Compressibility \\
& 0.474 & 0.752 & 37.0 \\
Theophylline anh. & 0.390 & 0.765 & 49.0 \\
Phenytoin & 0.355 & 0.703 & 49.5 \\
Phenylpropanolamine & $\mathrm{HCl}$ & 0.973 & 45.2 \\
Hydrochlorothiazide & 0.533 & 0.822 & 56.6 \\
Acetaminophen & 0.357 & 0.847 & 40.0 \\
Lactose hydrous & 0.508 & 0.787 & 28.2 \\
Lactose anhydrous & 0.565 & 1.720 & 42.8 \\
Dicalcium Phosphate anh. & 0.983 & 0.690 & 45.1 \\
Mannitol & 0.379 & & \\
\hline
\end{tabular}

$\%$ Compressibility $=($ Tapped bulk density - loose bulk density $) /$ Tapped bulk density $\times 100$ 


\section{TABLE XXII}

Solubility and Cohesiveness of Drugs used in this Study

\begin{tabular}{lccc}
\hline & Solubility in Water at $25{ }^{\circ} \mathrm{C}$ & Cohesiveness $^{*}$ \\
Drug & $\mathrm{mg} / \mathrm{ml}$ & $\%$ \\
Theophyl ine anhydrous & 8.0 & (Ref. 93) & 54.0 \\
Phenytoin & 0.0143 (Ref. 94) & 31.0 \\
Phenylpropanolamine hydrochloride & 390.0 & 10.0 \\
Hydrochlorothiazide & 1.29 & 62.0 \\
Acetaminophen & 15.0 & (Ref. 95) & 21.0 \\
\end{tabular}

* Reference 68 
formulations (Fig. 5) show that condensation of phase II and III was seen for the phenylpropanolamine formulation compared with the theophylline formulation. This can be explained by the good wettability and solubility of the phenylpropanolamine. Hardesty reported $(33,34)$, that the moisture requirement for agglomeration decreases linearly with increasing proportion of salt in the granulation liquid. This suggests a possible relationship between the solubility of the solid phase in the granulation fluid and its tendency to decrease the moisture requirement for optimum agglomeration.

Scanning electron micrographs (Fig's. 6-9) of the theophylline and phenypropanolamine system show the nuclei for agglomeration were formed in phase I of the process. These photographs indicate that the powder was agglomerated and increased in size with the increase in addition of granulation fluid and mixing time. These photographs also indicate that the small powder particles decreased while the coarser fractions increased. The shape and structure of the agglomerates indicate that the granule growth is due to a coalescence mechanism for these formulations which were granulated using a planetary mixer.

Particle size distributions of granulation (after sizing) of the formulations 2 thru 4 show, an increase in median particle size from phase I to II and also from phase II to III (Fig's. 10,11 and Table XXIII). Although, scanning electron microscopy showed an increase in particle size from phase II to III for phenylpropanolamine formulation, there was no difference after sizing the granulation (Fig's. 9 and 11). Particle size distributions of phenytoin and acetaminophen granulations (Tables XXV and XXIX) show data which follow the same pattern as in 
FIGURE 5

TOROQUE - TIME PROFILES

THEOPHYLLINE FORMULATION

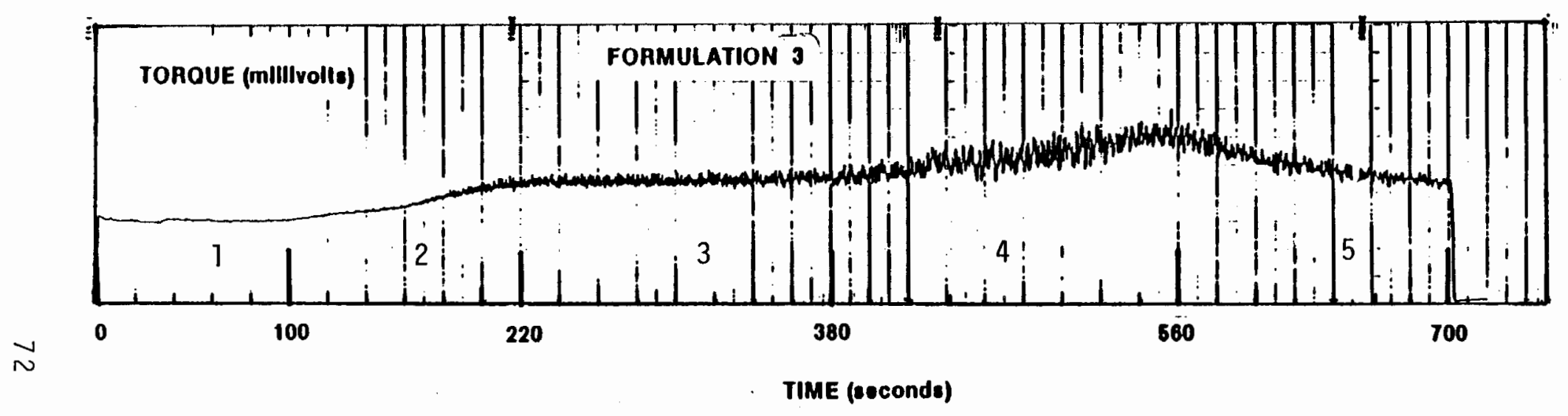

PHENYLPROPANOLAMINE HYDROCHLORIDE FORMULATION






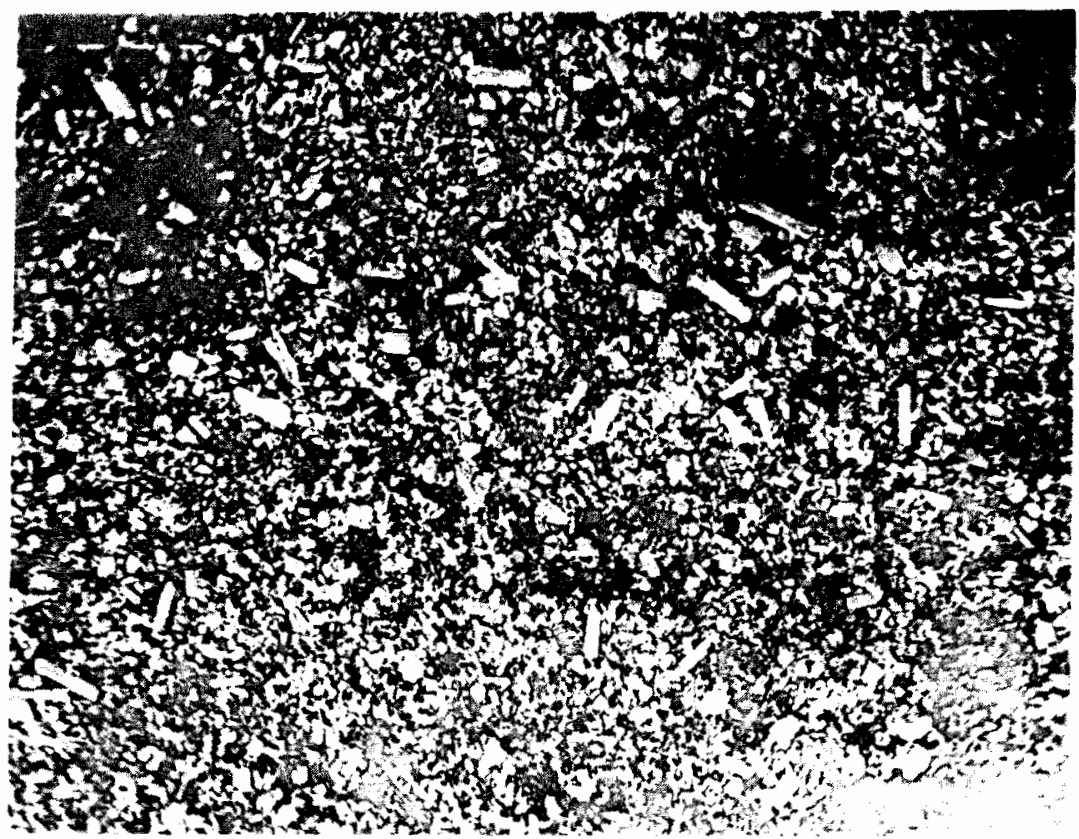

\section{Powder Blend}

before Granulation

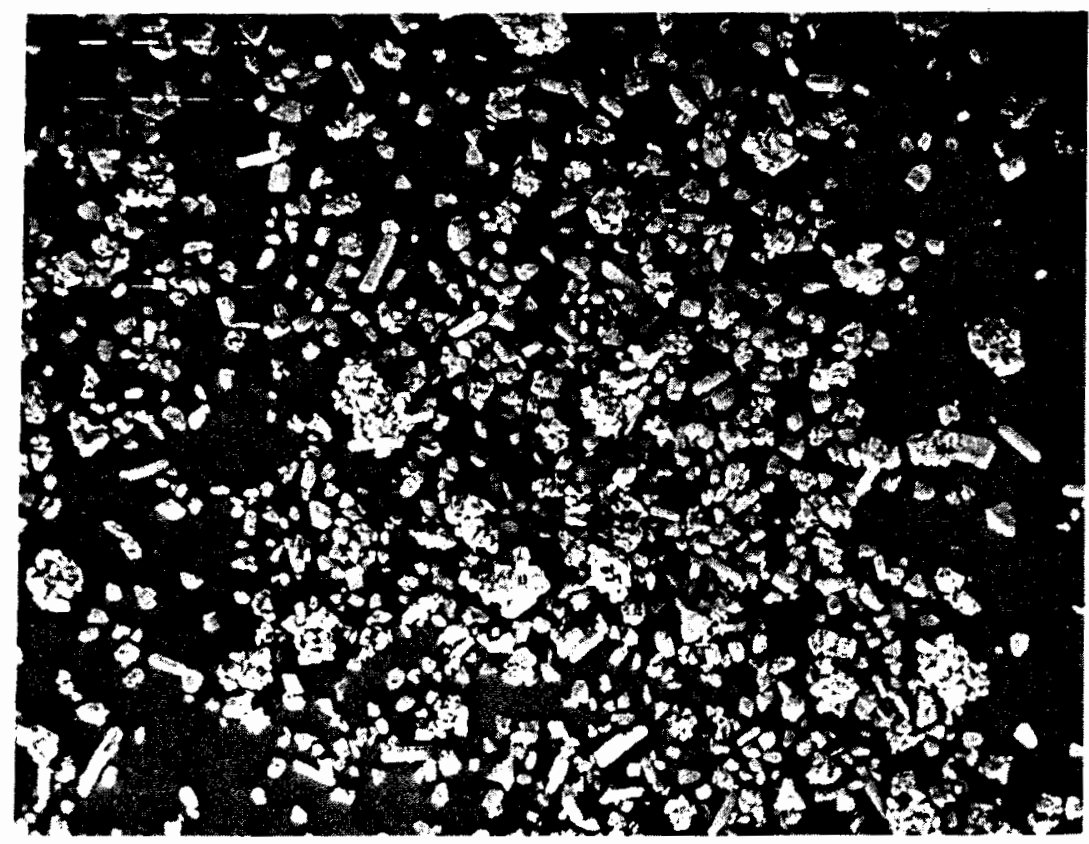

Phase 1 Granulation 
Scanning electron micrographs of theophylitine formulations

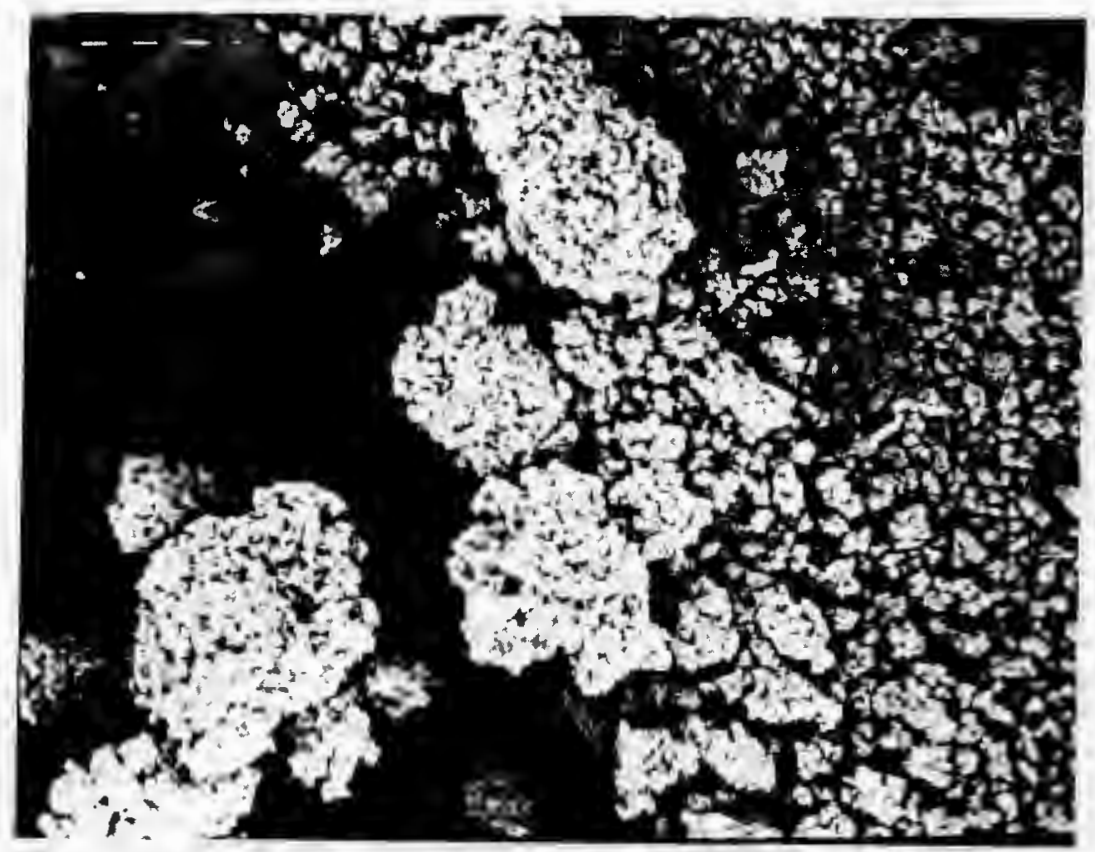

Phase 2 Granulation

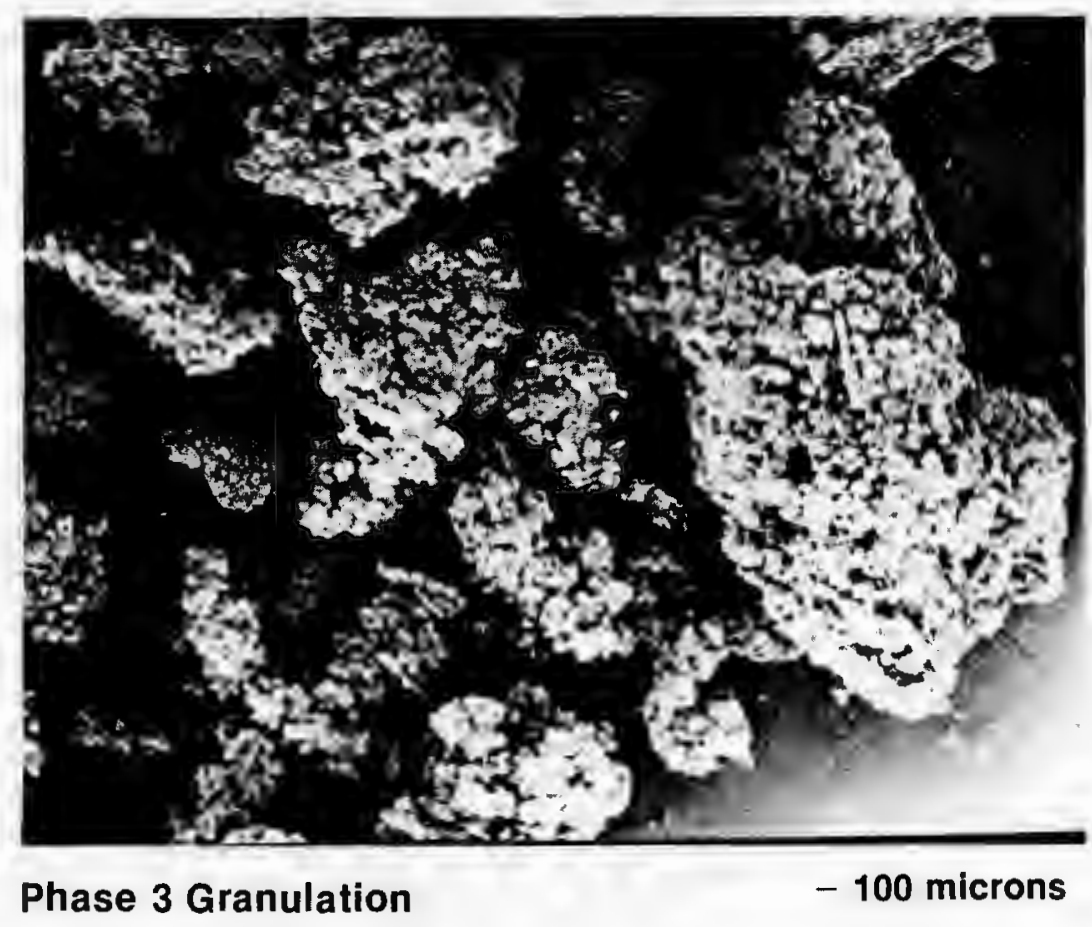


Scanning electron micrographs of phenylpropanolamine formulations

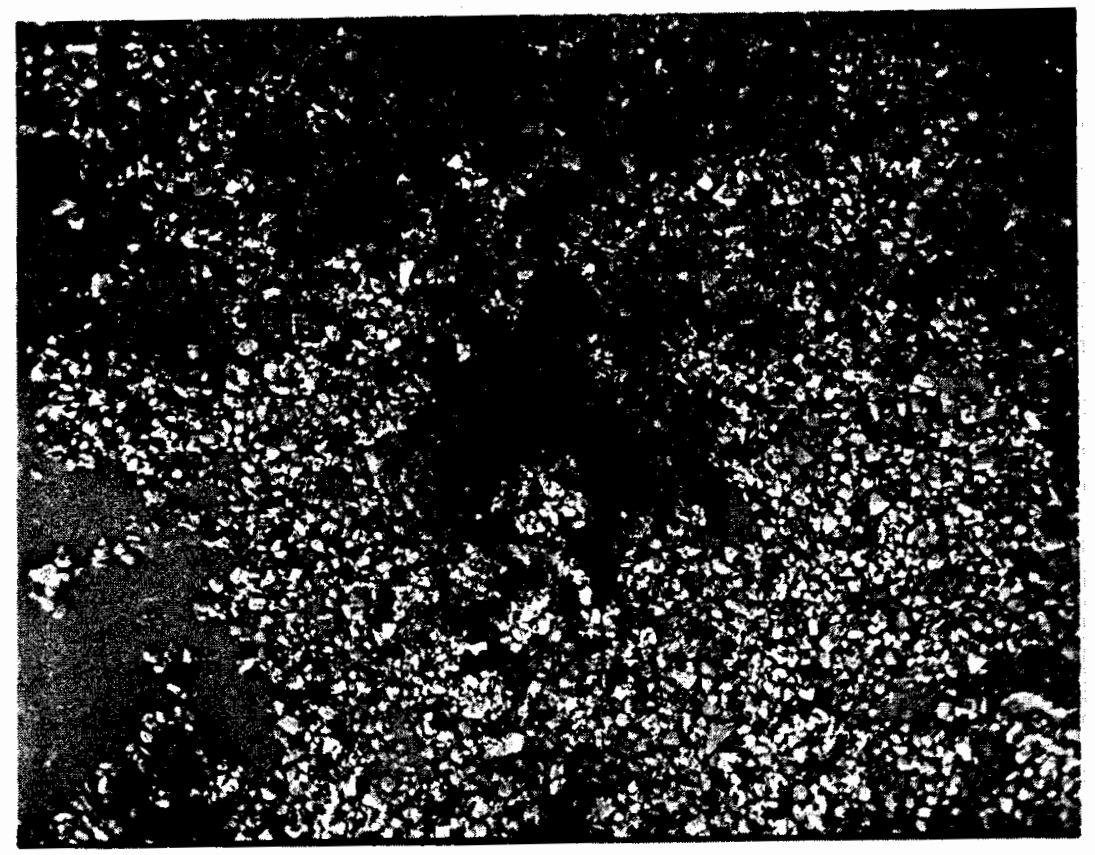

Powder Blend before Granulation



Phase 1 Granulation 
FIGURE 9

Scanning electron micrographs of phenylpropanolamine formulations

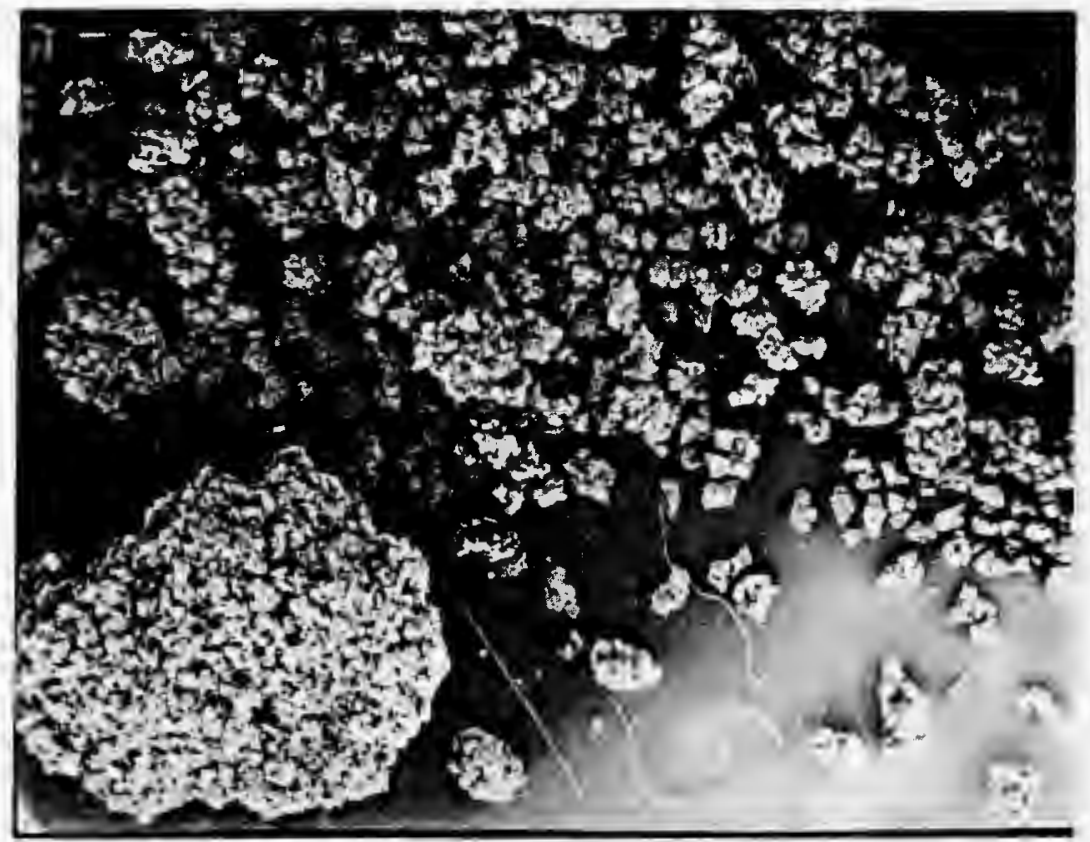

Phase 2 Granulation

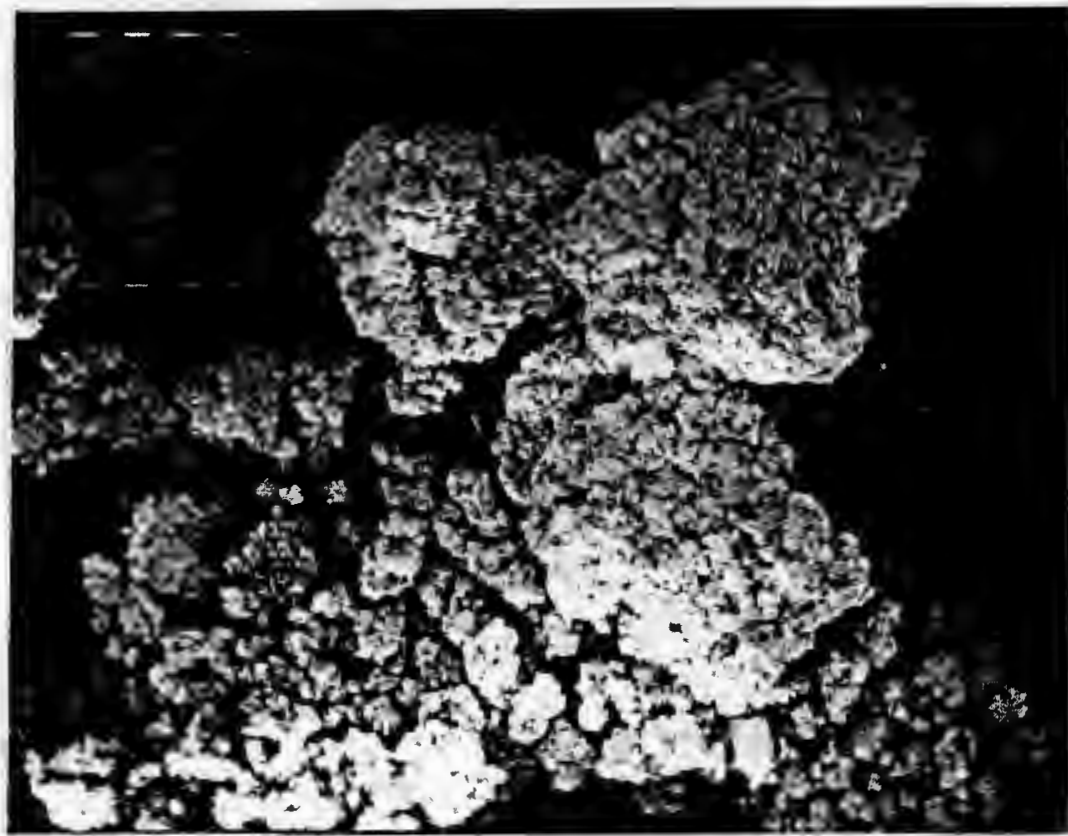

Phase 3 Granulation

- 100 microns 
FIGURE 10

Particle size distribution of theophylline granulations

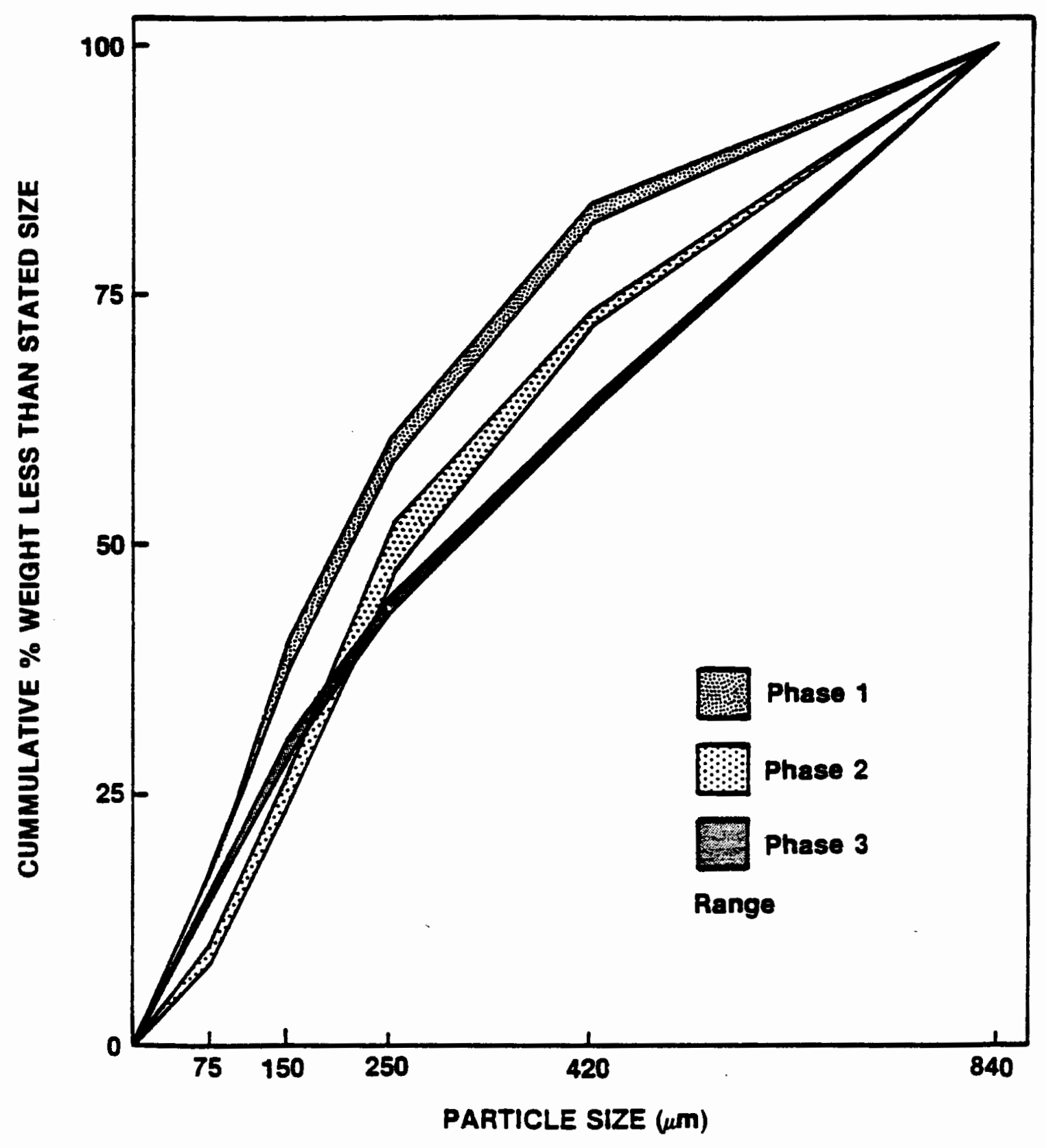




\section{FIGURE 11}

Particle size distribution of phenylpropanolamine granulations

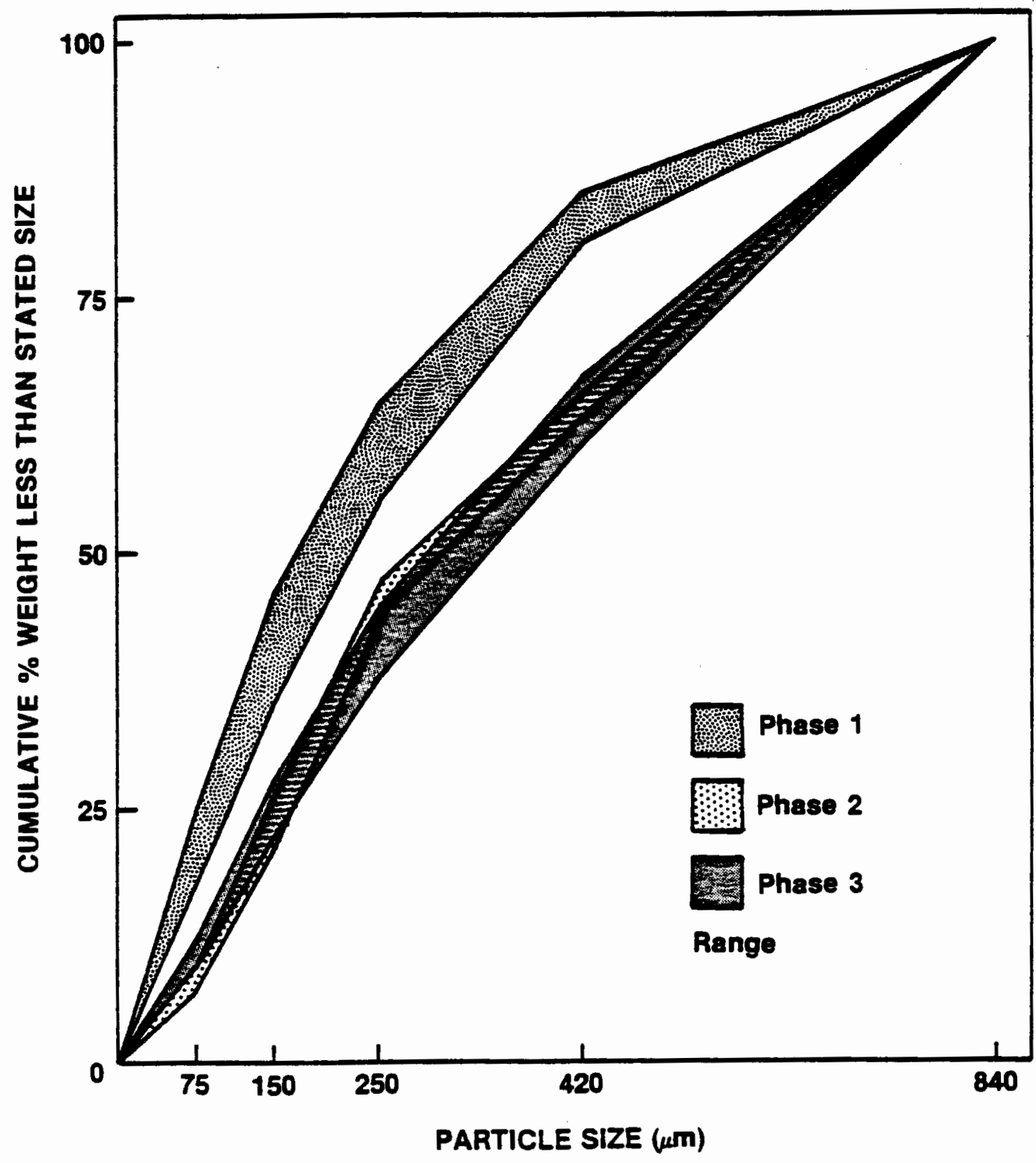


theophylline and hydrochlorothiazide formulations. In general, it can be concluded that mean granule size increases as the volume of the granulating fluid is increased and mixing time is increased.

Granulation flow property is one of the most important factors which affects the final properties of tablets. Flow properties of the formulation 2 thru 5 and 7 is shown in Figures 13 and 14. A significant increase in flow rate from the powder blend before granulation to phase I granulation and also from phase I to II granulations is apparent. There is no significant difference between phase II and III granulations, except for the phenytoin granulation (Fig's. 13 and 14). Figure 12 shows the effect of sizing the theophylline granulation with two types of equipment. The flow rate of granulation sized through \# 18 mesh screen (fitted to an oscillating granulator) was slightly better than the granulation sized through \# 2 plate, (fitted to a Fitz mill), but it is not statistically significant.

Bulk properties of granulations from formulations 2 thru 4 and 7 showed (Fig's. 15,16 and Tables XXIV,XXX) that the granulation goes through a stage of decreased bulk density due to a loosely held agglomerates. Phase II granules of these formulations showed a minimum loose and tapped bulk density compared to other granules. In the case of phenytoin granulations, bulk density increased with increased addition of granulating fluid and mixing time. In general, the powder particles randomly collide with each other in the presence of binding liquid and mixing, forms loose aggregates, these loose aggregates densify with further addition of liquid and mixing. Percent compressibility values 
FIGURE 12

Formulation 3: Granulation flow profile

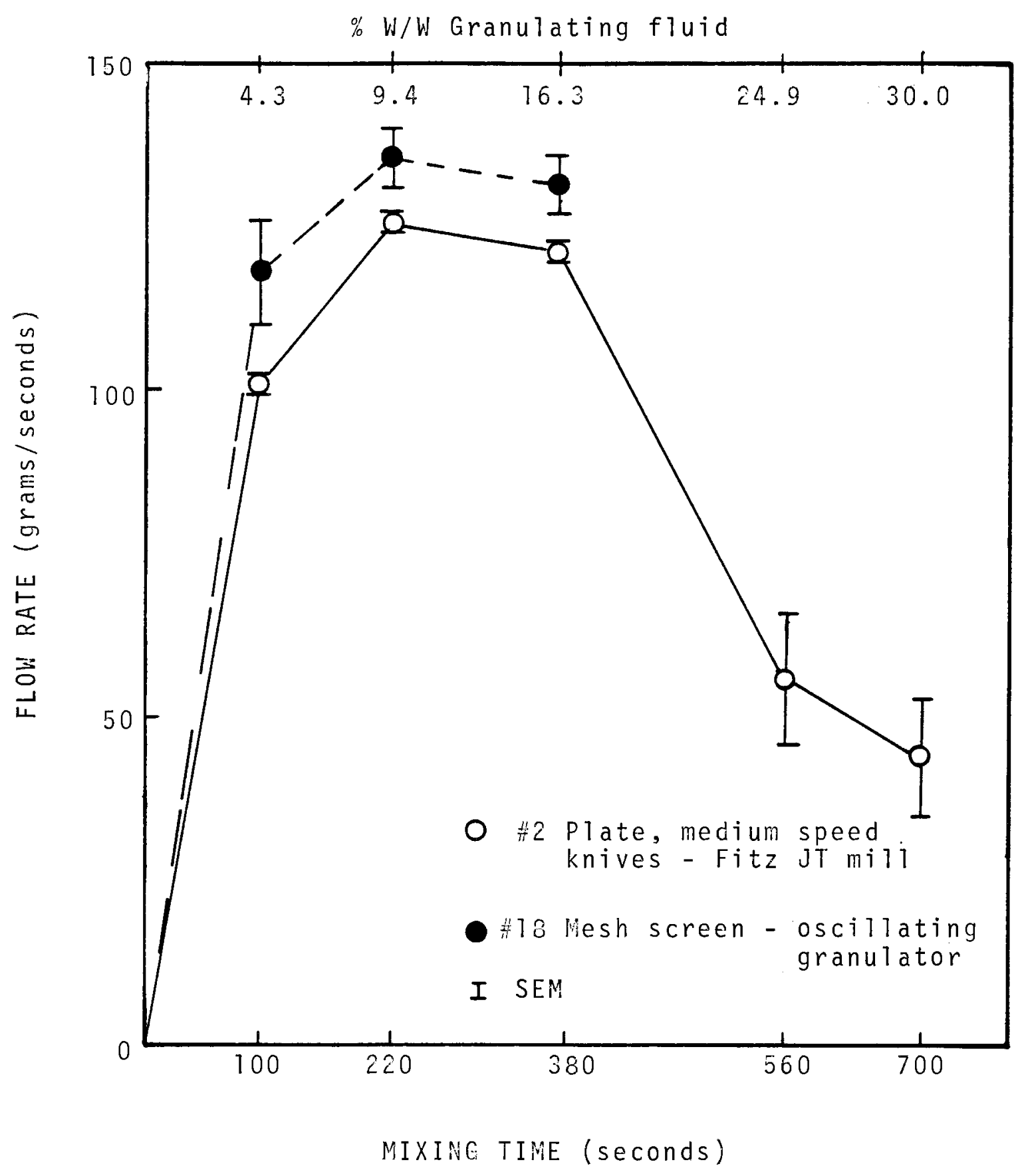




\section{FIGURE 13}

Formulations 2 - 4: Granulations flow profile






\section{FIGURE 14}

Formulations 5 and 7 : Granulations flow profile

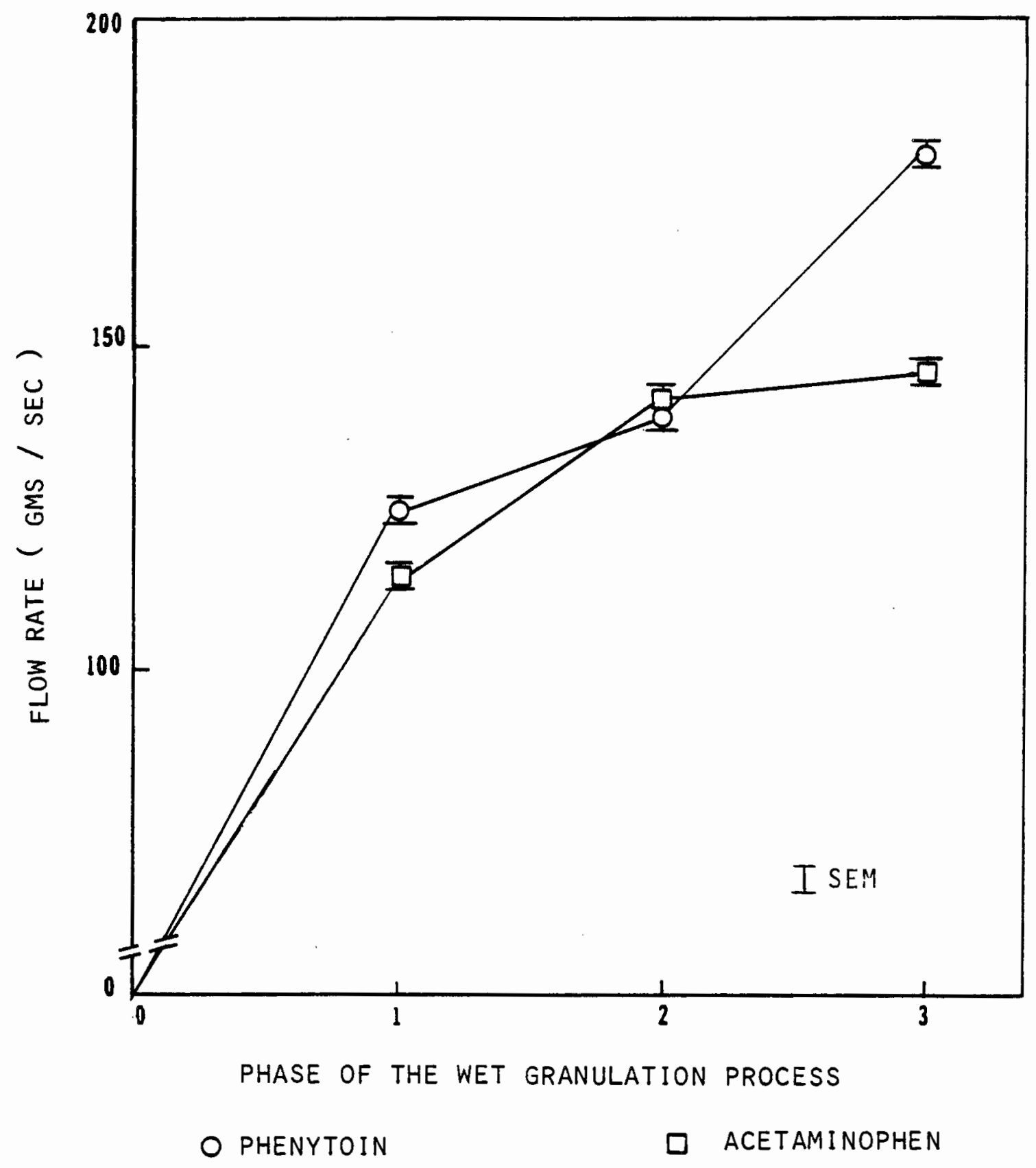


FIGURE 15

Formulation 2: Granule bulk profile

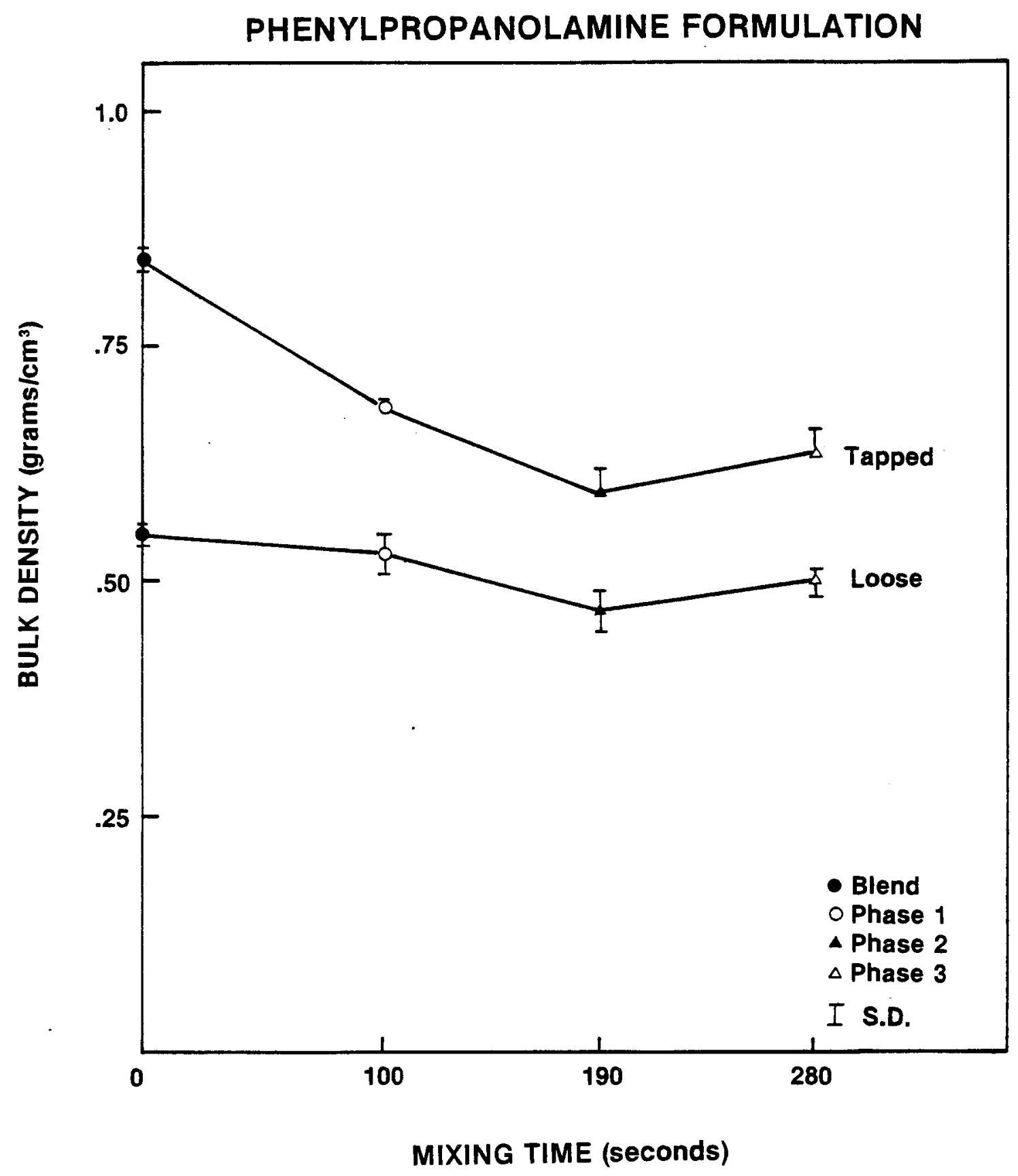


FIGLRE 76

Formulation 3: Granule bulk profile

THEOPHYLLINE FORMULATION

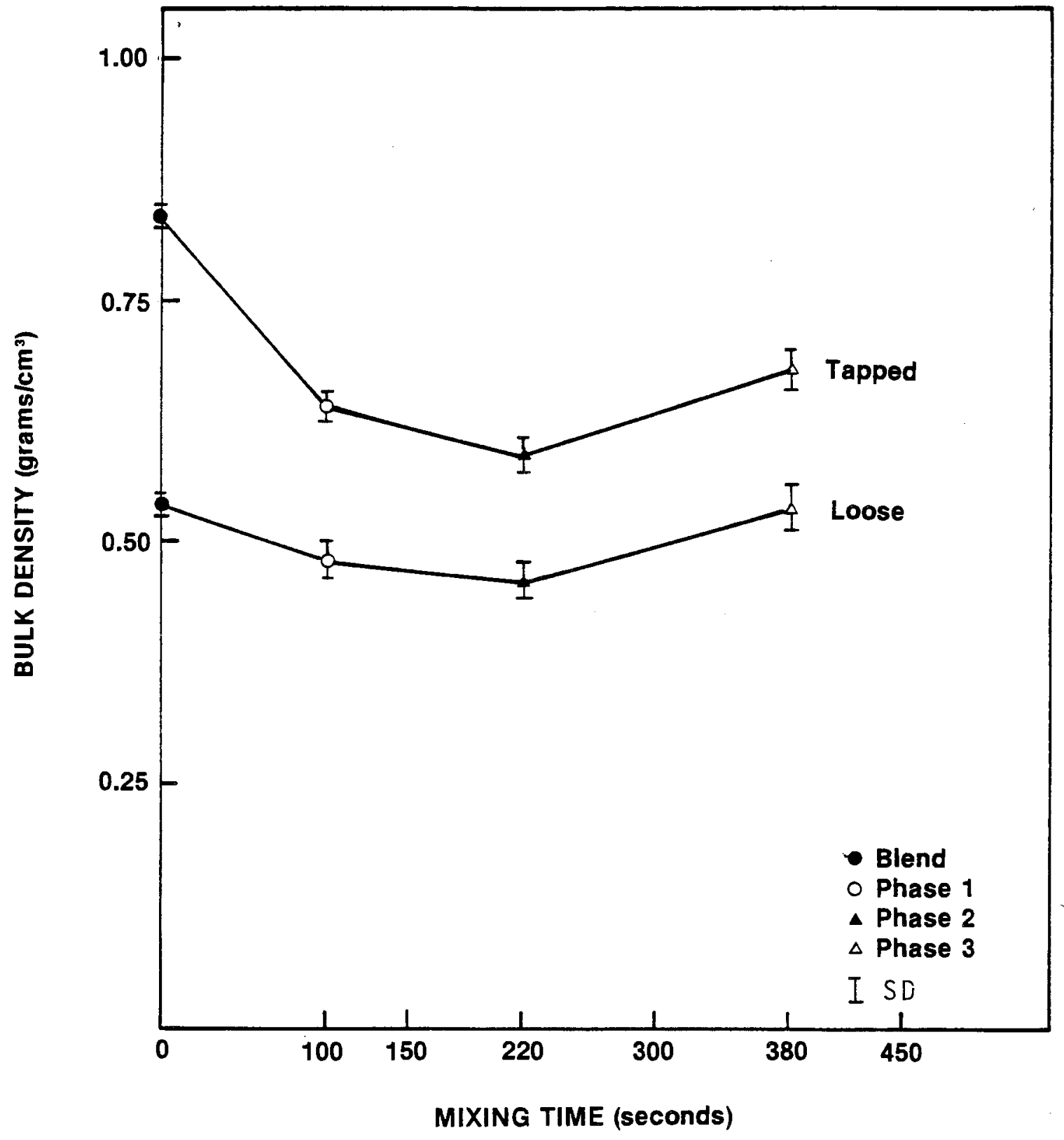


TABLE XXIII

Percent Particle Size Distribution of Hydrochlorothiazide Granulations

\begin{tabular}{rrrrr}
\hline & \multicolumn{5}{c}{ Phase of the Wet Granulation Process } \\
Size $(\mu \mathrm{m})$ & I & I I & I I I & V \\
\hline $0-74$ & 5.7 & 3.0 & 6.1 & 13.0 \\
$74-149$ & 31.1 & 32.6 & 31.2 & 22.9 \\
$149-177$ & 14.1 & 12.8 & 11.4 & 4.3 \\
$177-250$ & 13.0 & 12.4 & 11.1 & 7.0 \\
$250-420$ & 25.3 & 27.7 & 25.2 & 23.0 \\
$420-840$ & 10.8 & 11.4 & 15.1 & 29.7 \\
$840-1000$ & 0.0 & 0.0 & 0.0 & 0.1 \\
\hline
\end{tabular}


TABLE XXIV

Granulation and Tablet Properties of Hydrochlorothiazide Formulation

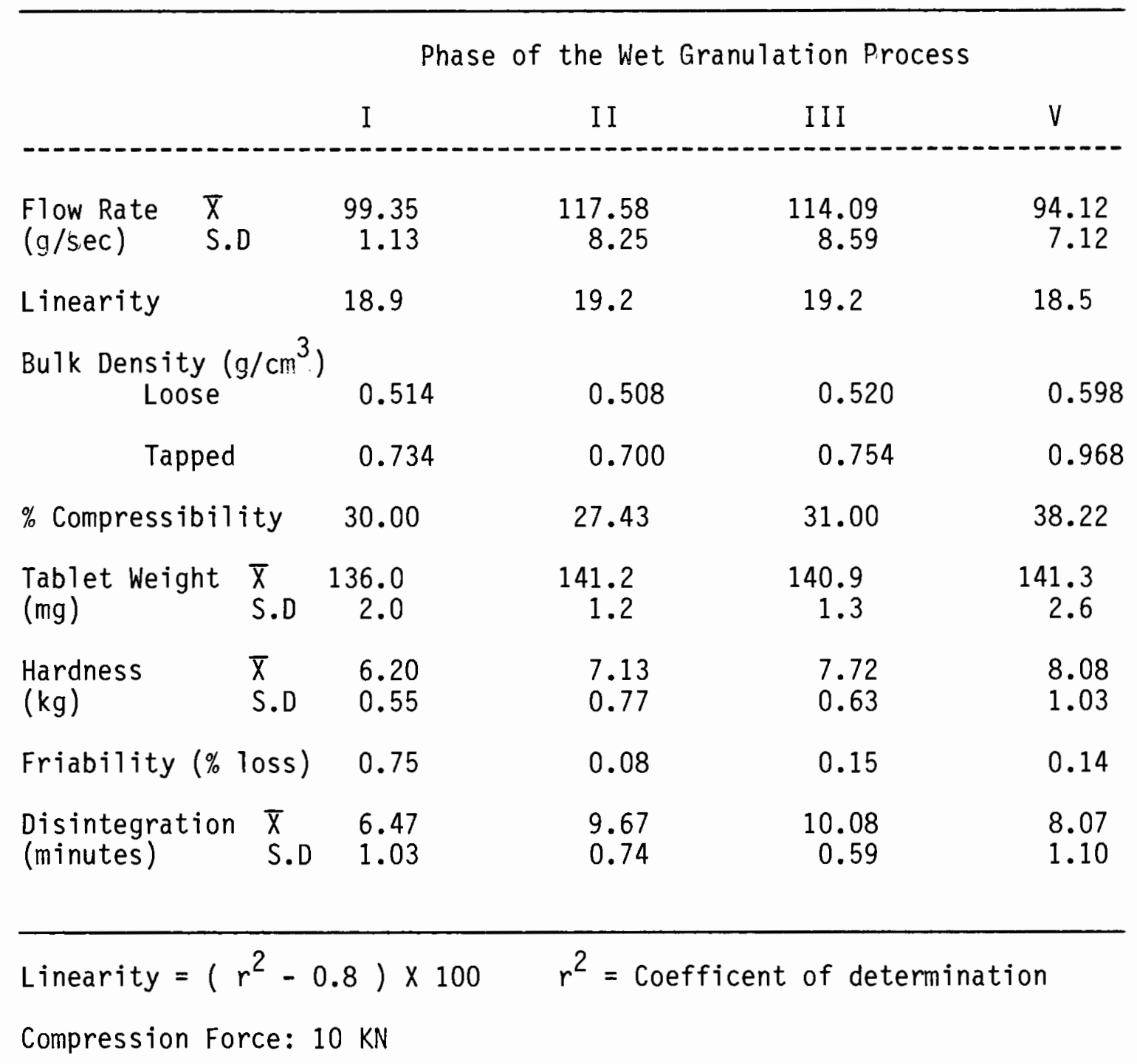


TABLE XXV

Percent Particle Size Distribution of Phenytoin Granulations

\begin{tabular}{rrrrrr}
\hline & \multicolumn{5}{c}{ Phase of the Wet Granulation Process } \\
Size $(\mu \mathrm{m})$ & I & I I & I I I & IV & V \\
\hline $0-74$ & 0.8 & 1.2 & 1.4 & 8.4 & 11.4 \\
$74-105$ & 8.5 & 6.0 & 4.2 & 16.3 & 15.1 \\
$105-149$ & 14.3 & 11.5 & 6.2 & 15.1 & 23.7 \\
$149-250$ & 24.9 & 23.1 & 8.2 & 8.0 & 11.2 \\
$250-420$ & 22.7 & 21.5 & 12.0 & 5.4 & 6.4 \\
$420-840$ & 17.3 & 20.1 & 25.2 & 10.2 & 10.6 \\
$840-1000$ & 11.5 & 16.5 & 42.8 & 36.5 & 21.5 \\
\hline
\end{tabular}


TABLE XXVI

Granulation Properties of Phenytoin Formulations

Phase of the wet Granulation Process

\begin{tabular}{|c|c|c|c|c|c|}
\hline & $I$ & I I & I I I & IV & V \\
\hline $\begin{array}{l}\text { \% Granulating fluid/ } \\
\text { Mixing time (sec) }\end{array}$ & $8.72 / 150$ & $11.16 / 192$ & $19.19 / 330$ & $26.83 / 462$ & $30.00 / 516$ \\
\hline $\begin{array}{ll}\text { Flow Rate } & \bar{X} \\
\text { (g/sec) } & \text { S.D }\end{array}$ & $\begin{array}{r}124.50 \\
0.87\end{array}$ & $\begin{array}{r}139.00 \\
3.90\end{array}$ & $\begin{array}{r}179.80 \\
6.63\end{array}$ & $B^{*}$ & $B^{*}$ \\
\hline Linearity & 19.20 & 19.60 & 19.60 & 0 & 0 \\
\hline \multicolumn{6}{|l|}{$\begin{array}{l}\text { Bulk Deुnsity } \\
\left(\mathrm{g} / \mathrm{cm}^{3}\right)\end{array}$} \\
\hline Loose & 0.463 & 0.481 & 0.555 & 0.625 & 0.595 \\
\hline Tapped & 0.625 & 0.641 & 0.676 & 0.862 & 0.862 \\
\hline$\%$ Compressibility & 25.90 & 25.00 & 17.90 & 27.50 & 31.00 \\
\hline
\end{tabular}

Linearity $=\left(r^{2}-0.8\right) \times 100$

$r^{2}=$ Coefficent of determination

$B^{*}=$ Blocked 
TABLE XXVII

Tablet Properties of Phenytoin Formulations

\begin{tabular}{|c|c|c|c|c|}
\hline & & \multicolumn{3}{|c|}{ Phase of the wet Granulation Process } \\
\hline & & $\mathrm{I}$ & I I & I I I \\
\hline $\begin{array}{l}\text { Compression Force } \\
\text { (Newtons) }\end{array}$ & $\begin{array}{l}\bar{X} \\
\text { S.D }\end{array}$ & $\begin{array}{r}7202 \\
532\end{array}$ & $\begin{array}{r}7276 \\
414\end{array}$ & $\begin{array}{r}7322 \\
493\end{array}$ \\
\hline $\begin{array}{l}\text { Ejection Force } \\
\text { (Newtons) }\end{array}$ & $\begin{array}{l}\bar{X} \\
\text { S.D }\end{array}$ & $\begin{array}{r}449 \\
41\end{array}$ & $\begin{array}{r}458 \\
33\end{array}$ & $\begin{array}{r}432 \\
26\end{array}$ \\
\hline Weight (mg) & $\begin{array}{l}\bar{X} \\
\text { S.D }\end{array}$ & $\begin{array}{r}249.30 \\
3.32\end{array}$ & $\begin{array}{r}251.00 \\
3.74\end{array}$ & $\begin{array}{r}248.50 \\
3.20\end{array}$ \\
\hline Thickness (inches) & $\begin{array}{l}\bar{X} \\
\text { S.D }\end{array}$ & $\begin{array}{l}0.140 \\
0.001\end{array}$ & $\begin{array}{l}0.141 \\
0.001\end{array}$ & $\begin{array}{l}0.139 \\
0.001\end{array}$ \\
\hline Hardness $(\mathrm{kg})$. & $\begin{array}{l}\bar{X} \\
\text { S.D }\end{array}$ & $\begin{array}{l}4.70 \\
0.19\end{array}$ & $\begin{array}{l}4.90 \\
0.47\end{array}$ & $\begin{array}{l}4.70 \\
0.42\end{array}$ \\
\hline Friability (\% loss) & & 0.30 & 0.22 & 0.34 \\
\hline $\begin{array}{l}\text { Disintegration } \\
\text { (minutes) }\end{array}$ & $\begin{array}{l}\bar{X} \\
\text { S.D }\end{array}$ & $\begin{array}{l}8.17 \\
0.52\end{array}$ & $\begin{array}{l}7.84 \\
0.85\end{array}$ & $\begin{array}{l}9.29 \\
0.99\end{array}$ \\
\hline
\end{tabular}


TABLE XXVIII

Tablet Properties of Phenytoin Formulations (with Starch 1500)

\begin{tabular}{llccc}
\hline & \multicolumn{4}{c}{ Phase of the Wet Granulation Process } \\
& & I & I I & III \\
\hline & & & & \\
& & & & \\
Compression Force & $\bar{X}$ & 7049 & 611 & 7137 \\
(Newtons) & S.D & 329 & 620 & 610 \\
Ejection Force & $\bar{X}$ & 373 & 404 & 376 \\
(Newtons) & S.D & 43 & 44 & 25 \\
Weight (mg) & $\bar{X}$ & 275.50 & 279.5 & 273.8 \\
& S.D & 3.72 & 2.88 & 3.43 \\
Thickness (inches) & $\bar{X}$ & 0.153 & 0.155 & 0.152 \\
& S.D & 0.001 & 0.001 & 0.001 \\
Hardness (kg) & $\bar{X}$ & 3.20 & 3.00 & 3.10 \\
& S.D & 0.18 & 0.05 & 0.08 \\
Friability (\% 10sS) & & 0.31 & 0.25 & 0.20 \\
Disintegration & $\bar{X}$ & 6.82 & 8.46 & 8.89 \\
(minutes) & S.D & 0.34 & 0.66 & 0.73 \\
& & & & \\
\hline
\end{tabular}


TABLE XXIX

Percent Particle Size Distribution of Acetaminophen Granulations

\begin{tabular}{|c|c|c|c|c|}
\hline \multicolumn{5}{|c|}{ Phase of the Wet Granulation Process } \\
\hline Size $(\mu \mathrm{m})$ & I & I I & I I I & v \\
\hline $0-74$ & 0.1 & 0.0 & 0.2 & 0.2 \\
\hline $74-105$ & 0.4 & 0.2 & 0.5 & 0.4 \\
\hline $105-149$ & 1.1 & 1.1 & 0.9 & 5.9 \\
\hline $149-250$ & 7.3 & 6.4 & 2.3 & 10.4 \\
\hline $250-420$ & 41.7 & 27.7 & 8.5 & 15.9 \\
\hline $420-840$ & 29.6 & 41.2 & 44.0 & 12.0 \\
\hline $840-1000$ & 19.9 & 23.5 & 43.6 & 55.3 \\
\hline
\end{tabular}




\section{TABLE $X X X$}

Granulation Properties of Acetaminophen Formulations

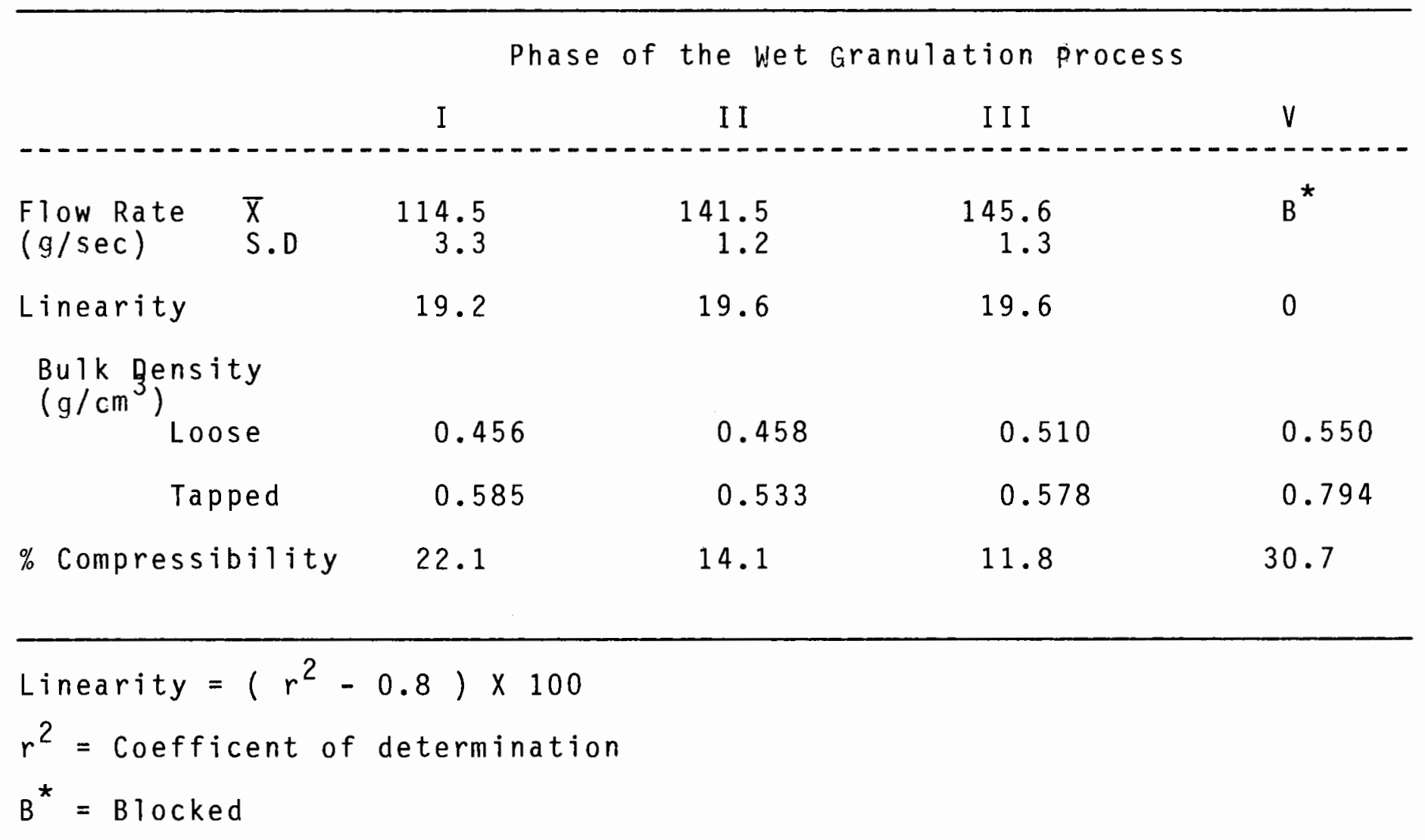


TABLE XXXI

Tablet Properties of Acetaminophen Formulations

\begin{tabular}{|c|c|c|c|c|}
\hline & & Pha: & wet Granul. & ess \\
\hline & & I & II & I I I \\
\hline $\begin{array}{l}\text { Compression Force } \\
\text { (Newtons) }\end{array}$ & $\begin{array}{l}\bar{X} \\
\text { S.D }\end{array}$ & $\begin{array}{r}16294 \\
395\end{array}$ & $\begin{array}{r}16452 \\
795\end{array}$ & $\begin{array}{r}16098 \\
649\end{array}$ \\
\hline $\begin{array}{l}\text { Ejection Force } \\
\text { (Newtons) }\end{array}$ & $\begin{array}{l}\bar{X} \\
\text { S.D }\end{array}$ & $\begin{array}{r}160 \\
23\end{array}$ & $\begin{array}{r}189 \\
9\end{array}$ & $\begin{array}{r}183 \\
19\end{array}$ \\
\hline Weight $(\mathrm{mg})$ & $\begin{array}{l}\bar{X} \\
\text { S.D }\end{array}$ & $\begin{array}{r}466.0 \\
3.2\end{array}$ & $\begin{array}{r}464.0 \\
2.4\end{array}$ & $\begin{array}{r}472.0 \\
3.8\end{array}$ \\
\hline Thickness (inches) & $\begin{array}{l}\bar{X} \\
\text { S.D }\end{array}$ & $\begin{array}{l}0.196 \\
0.001\end{array}$ & $\begin{array}{l}0.196 \\
0.001\end{array}$ & $\begin{array}{l}0.197 \\
0.001\end{array}$ \\
\hline Hardness ( $\mathrm{kg})$ & $\begin{array}{l}\bar{X} \\
\text { S.D }\end{array}$ & $\begin{array}{l}4.00 \\
0.52\end{array}$ & $\begin{array}{l}4.53 \\
0.32\end{array}$ & $\begin{array}{l}4.98 \\
0.23\end{array}$ \\
\hline Friability (\% loss) & & 0.83 & 0.64 & 0.69 \\
\hline $\begin{array}{l}\text { Disintegration } \\
\text { (minutes) }\end{array}$ & $\begin{array}{l}\bar{X} \\
\text { S.D }\end{array}$ & $\begin{array}{l}0.93 \\
0.08\end{array}$ & $\begin{array}{l}2.47 \\
0.43\end{array}$ & $\begin{array}{l}4.76 \\
0.23\end{array}$ \\
\hline
\end{tabular}


calculated from bulk density values showed a good correlation with flowability of the granulation measured by Recording Powder Flowmeter. Granulations from formulations 2 thru 4 were tableted at $10 \mathrm{KN}$ compression force using 1/4 inch standard round concave tooling. The tablet hardness is shown in figures 17 and 18 as a function of wet mixing time and phase of the wet granulation process. Tablet hardness was increased with increased addition of granulating fluid and wet mixing time (Fig's. 17, 18 and Table XXIV). Disintegration time of these tablets was directly proportional to the hardness (Fig. 19 and Table XXIV). Dissolution profiles of these formulations (Fig's. 20 and 21) indicate no difference between the tablets made from granulations from different phases. Tablet data for phenytoin and acetaminophen are shown in Tables XXVII, XXVIII and XXXI. Phenytoin tablets from phase I to III were compared with Parke-Davis tablet and the $\beta$-cyclodextrin-drug complex tablet for the rate of dissolution (Fig. 22). There was no difference in dissolution rate between phase I to III tablets. The dissolution rate of phase I to II tablets were significantly better than the commercially available Parke-Davis tablet and significantly slower than the $\beta$-cyclodextrin-drug complex tablet. The dissolution rate of phase III tablets with and without starch 1500 is shown in Figure 23. Acetaminophen tablet dissolution data are shown in Figure 24.

Phenylpropanolamine and theophylline formulations (Table II) were used to test the effect of extended mixing on the wet granulations after discontinuing the addition of granulating fluid. Figures 25 thru 27 show the particle size distribution of phenylpropanolamine phase I to III 
FIGURE 17

Formulation 2: Tablet hardness as a function of wet mixing time

PHENYLPROPANOLAMINE HYDROCHLORIDE FORMULATION

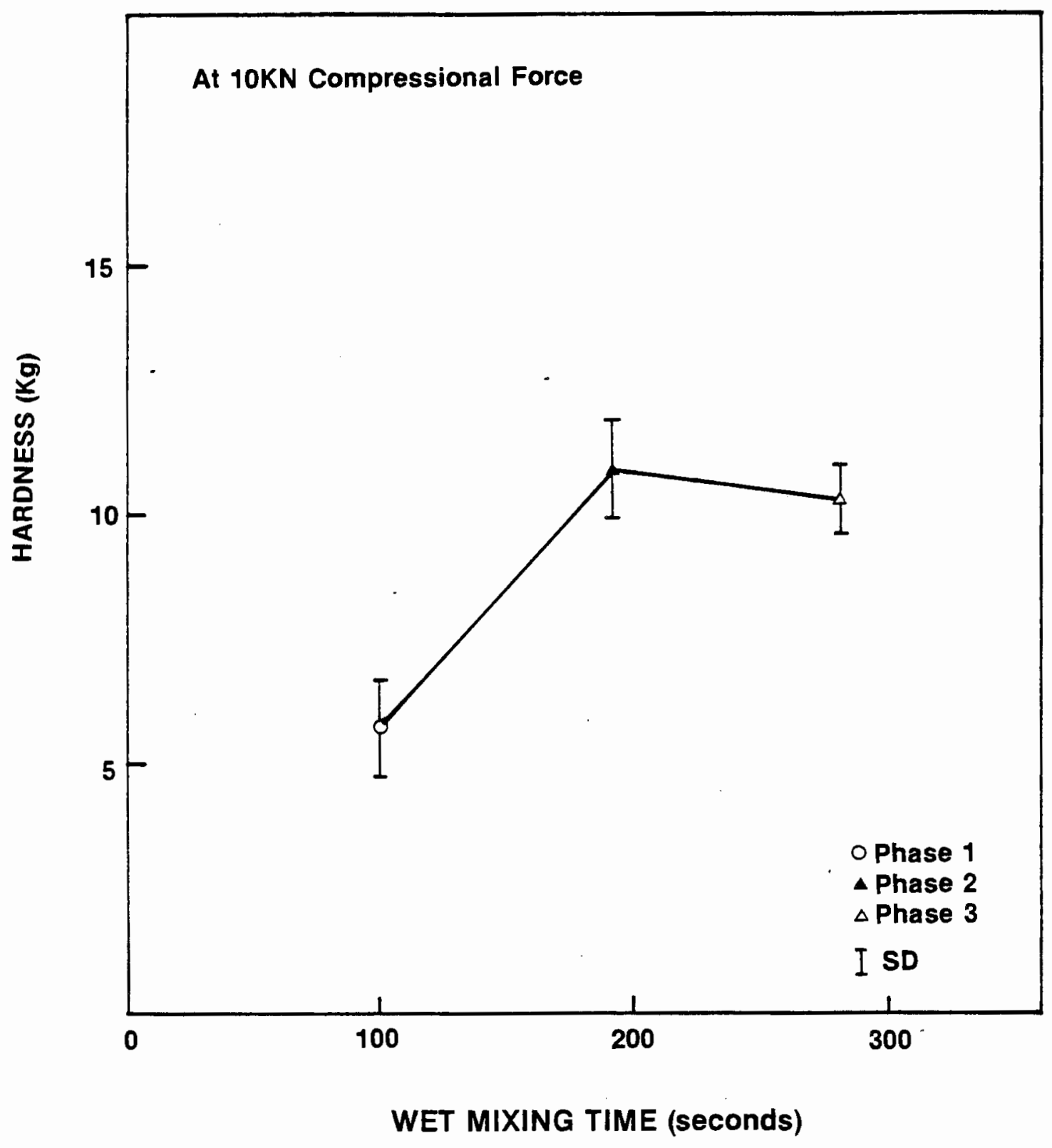


FIGURE 18

Formulation 3: Tablet hardness as a function of wet mixing time

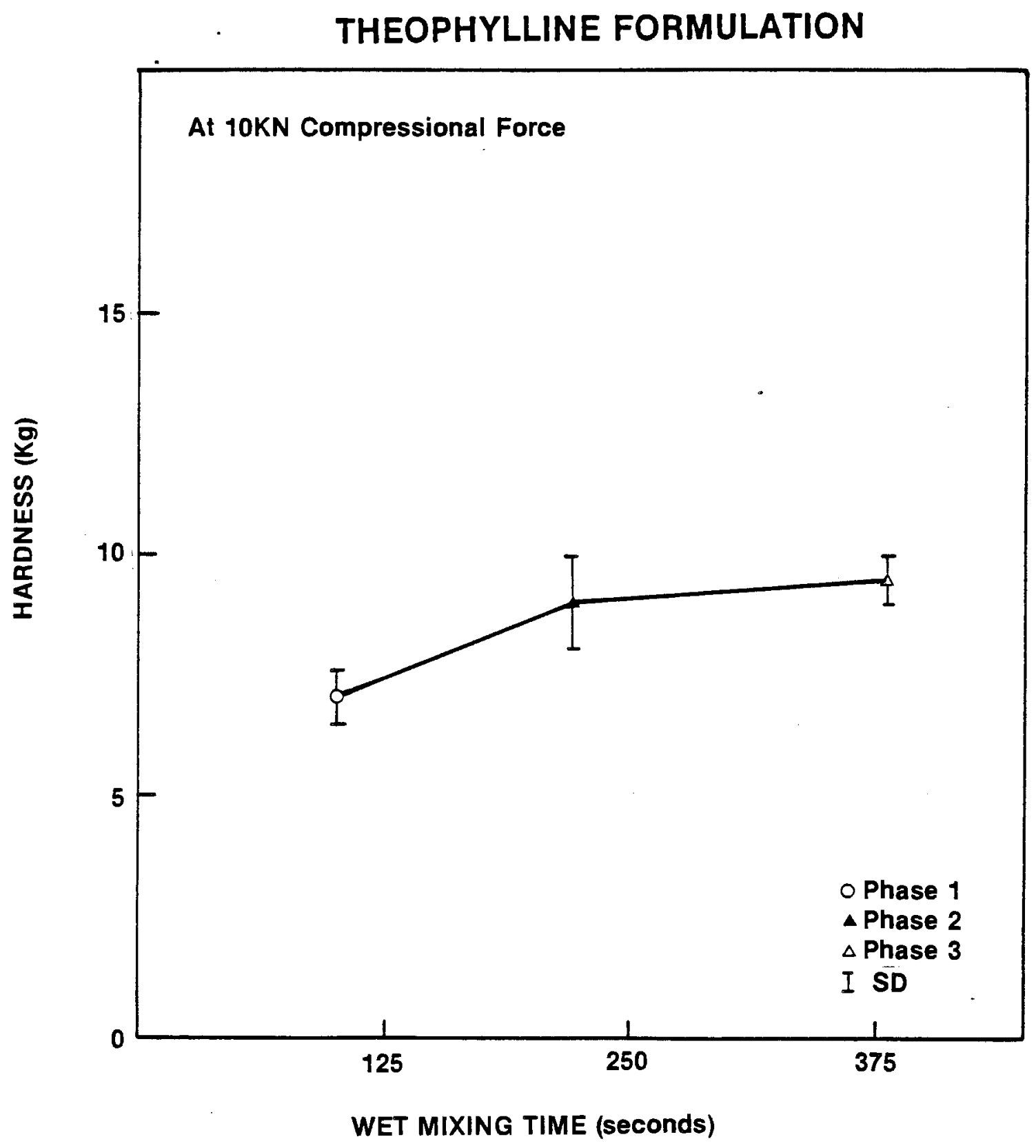




\section{FIGURE 19}

\section{Formulations 2 and 3 :}

Disintegration time as a function hardness

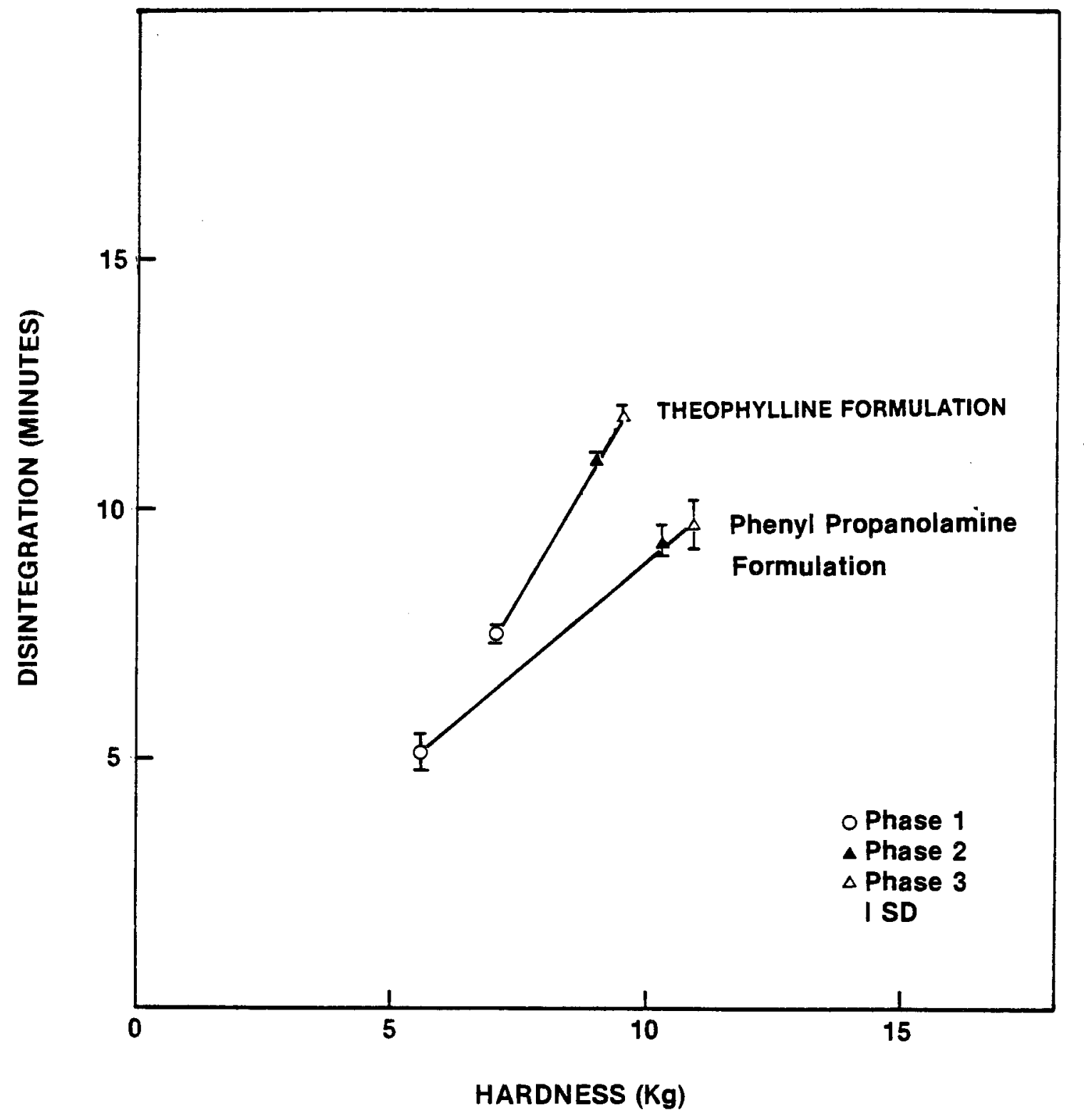


FIGURE 20

Formulation 2: Dissolution profile

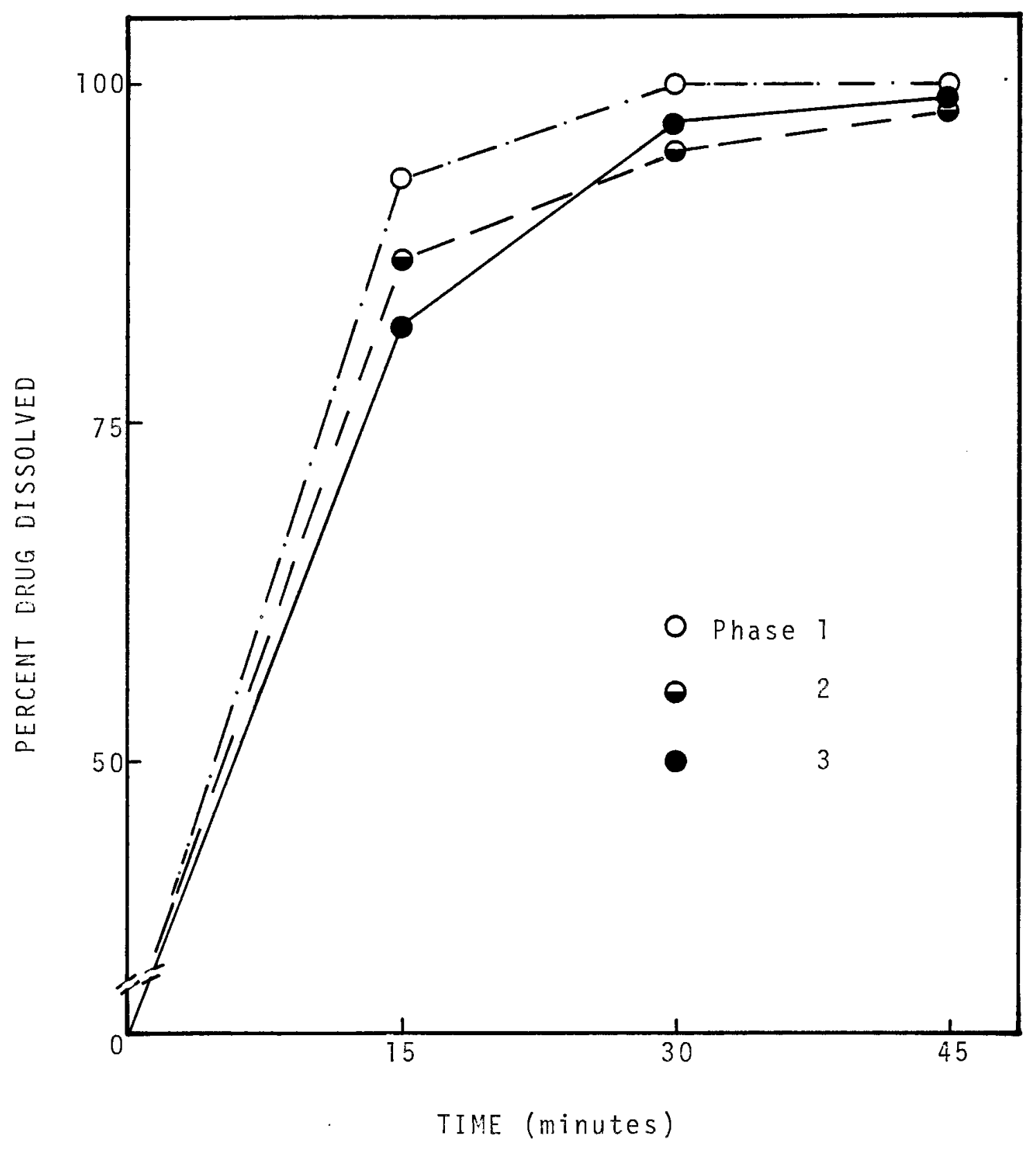




\section{FIGURE 2]}

Formulation 3: Dissolution profile

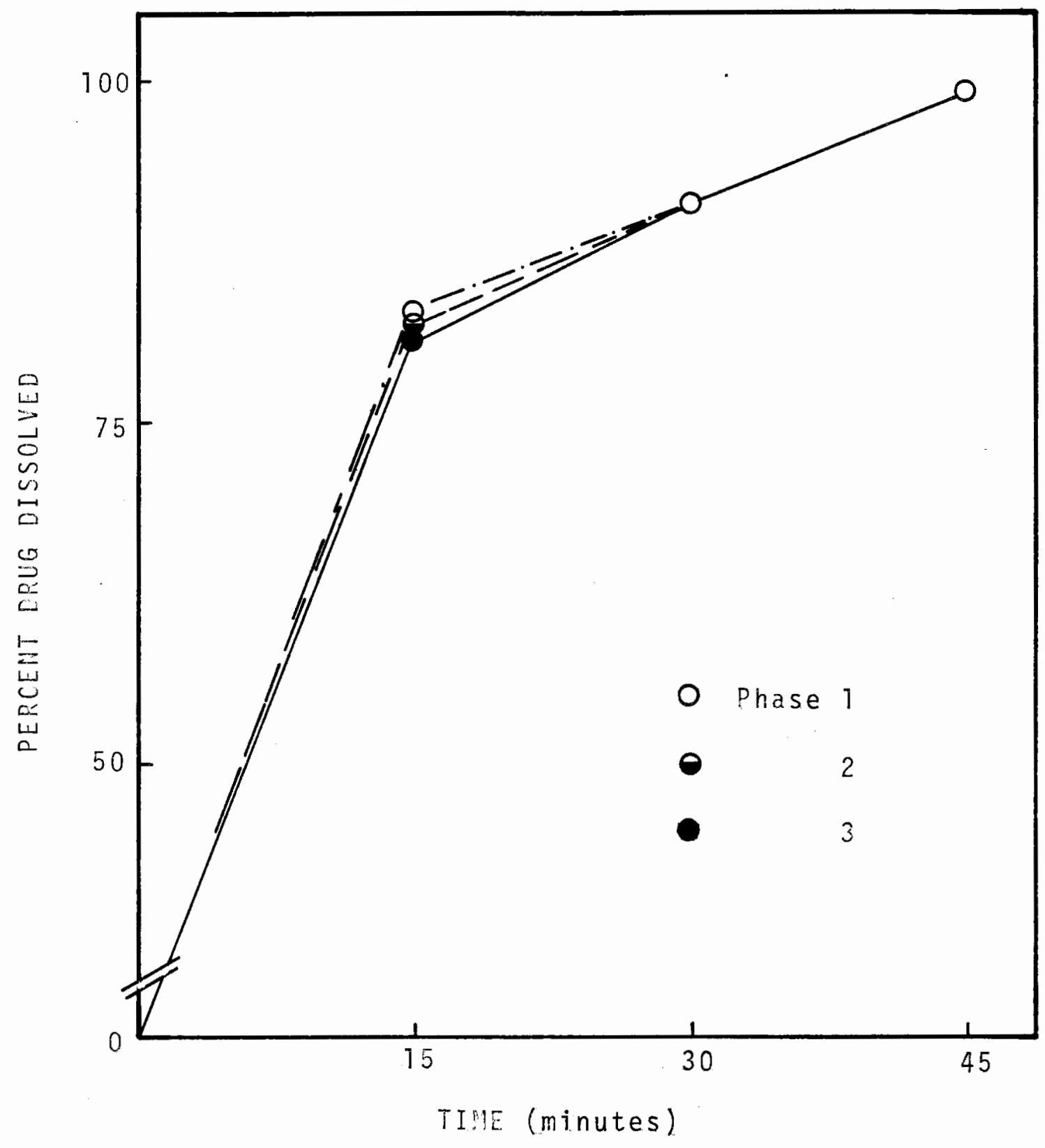




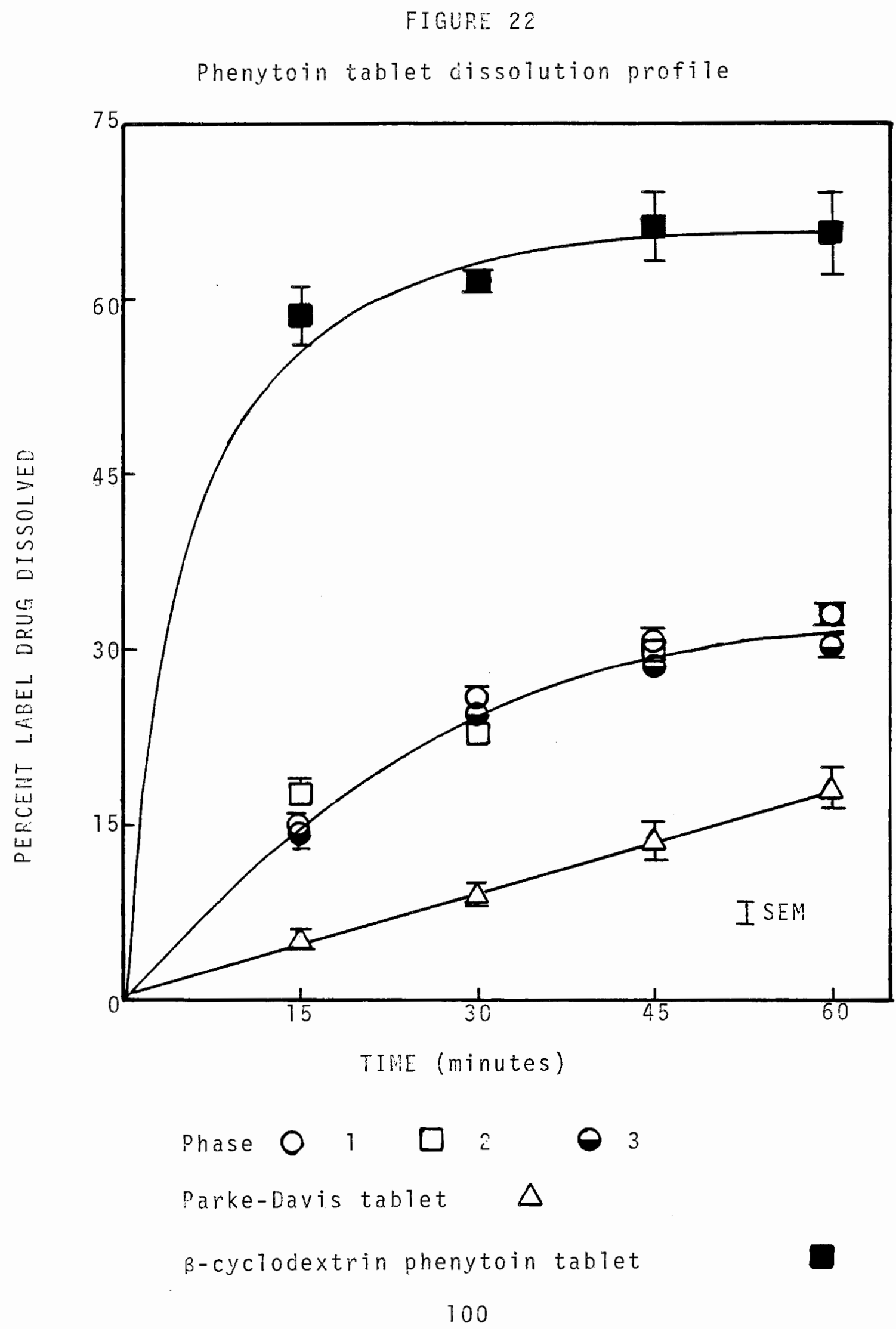




\section{FIGURE 23}

Phenytoin tablet with and without Starch 1500:

Dissolution profile

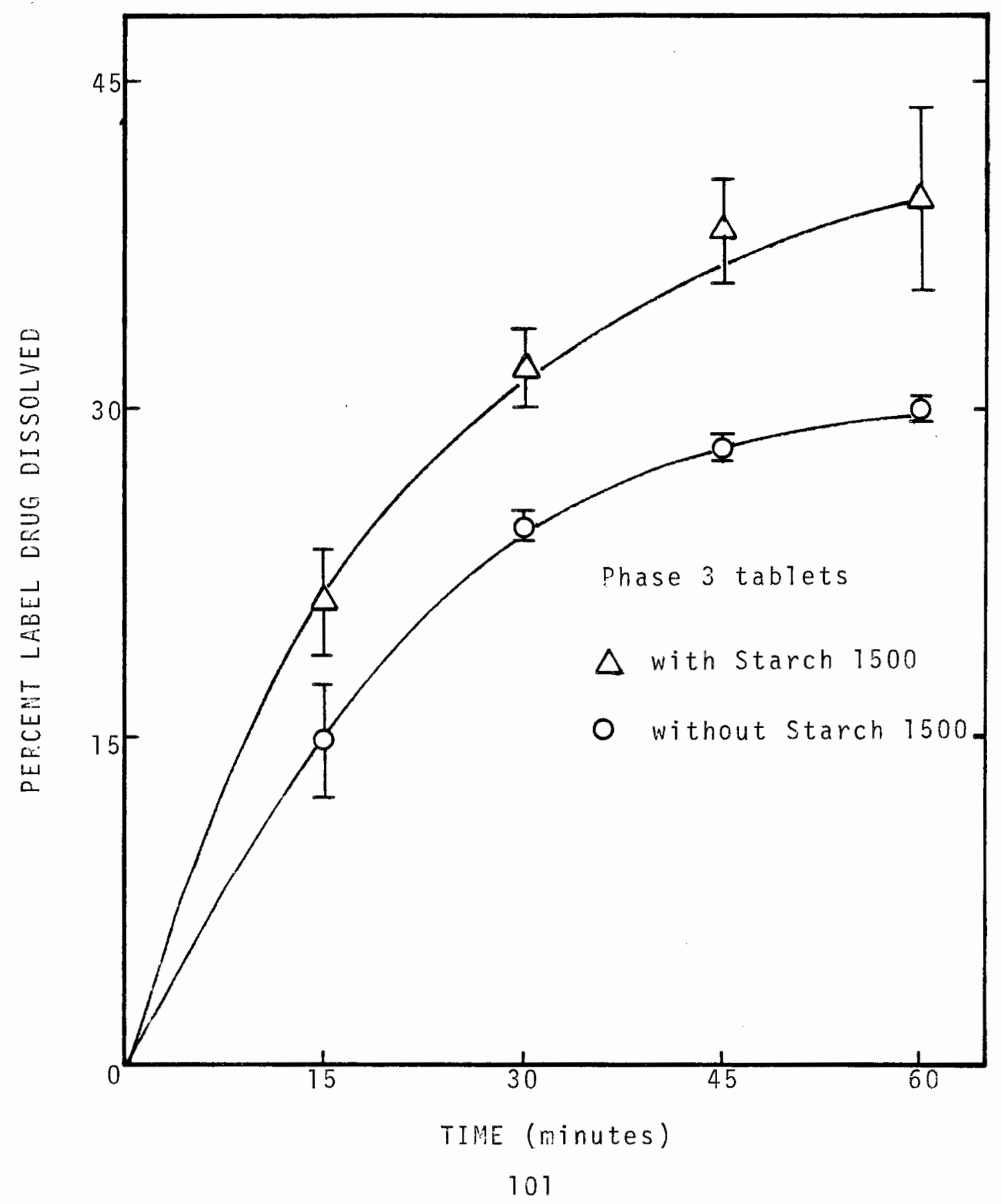




\section{FIGURE 24}

Acetaminophen tablet dissolution profile

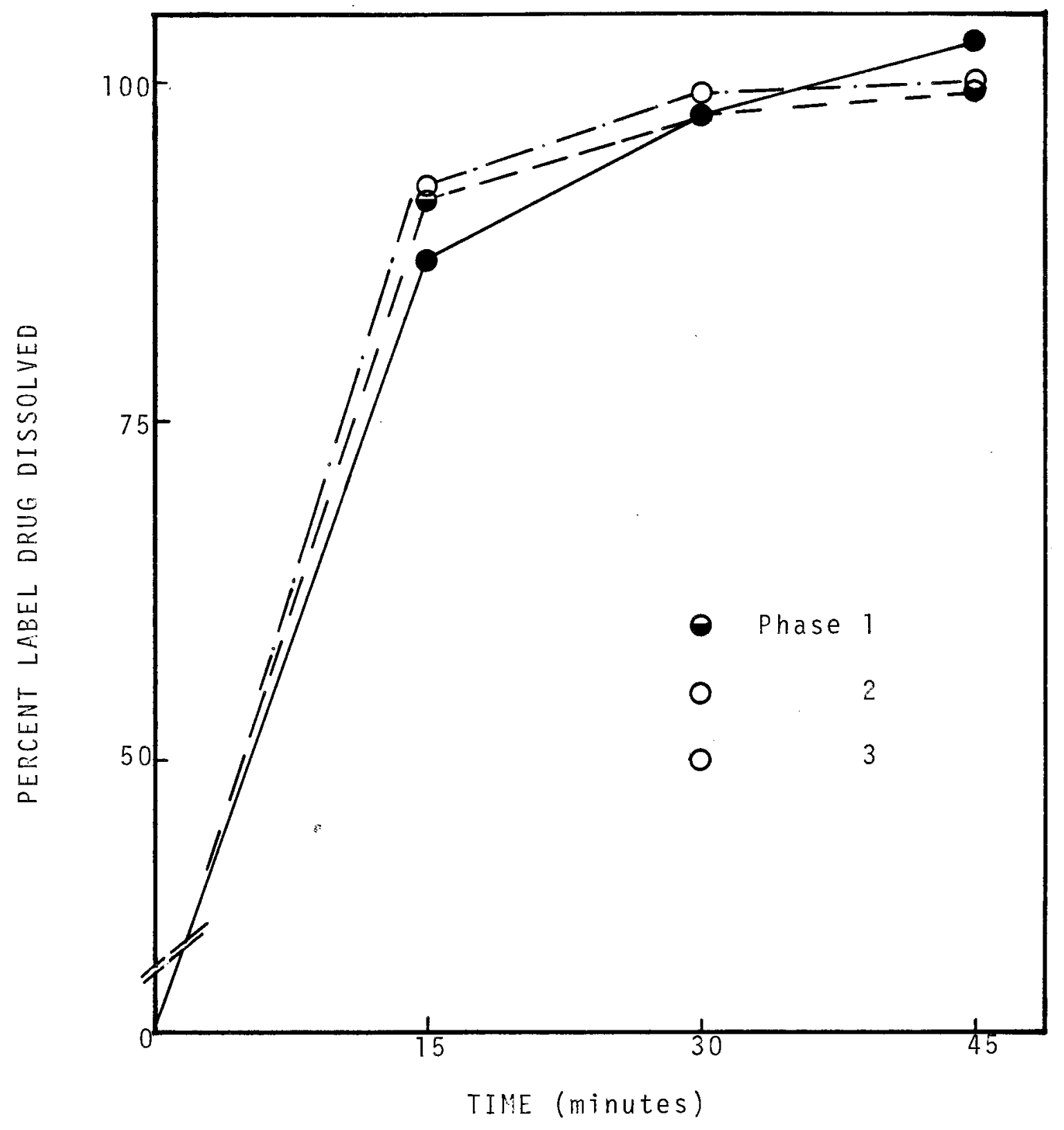




\section{FI GURE 25}

\section{Effect of extended mixina on}

particle size distribution of phase 1 granulations

\section{PHENYLPROPANOLAMINE HYDROCHLORIDE FORMULATION}

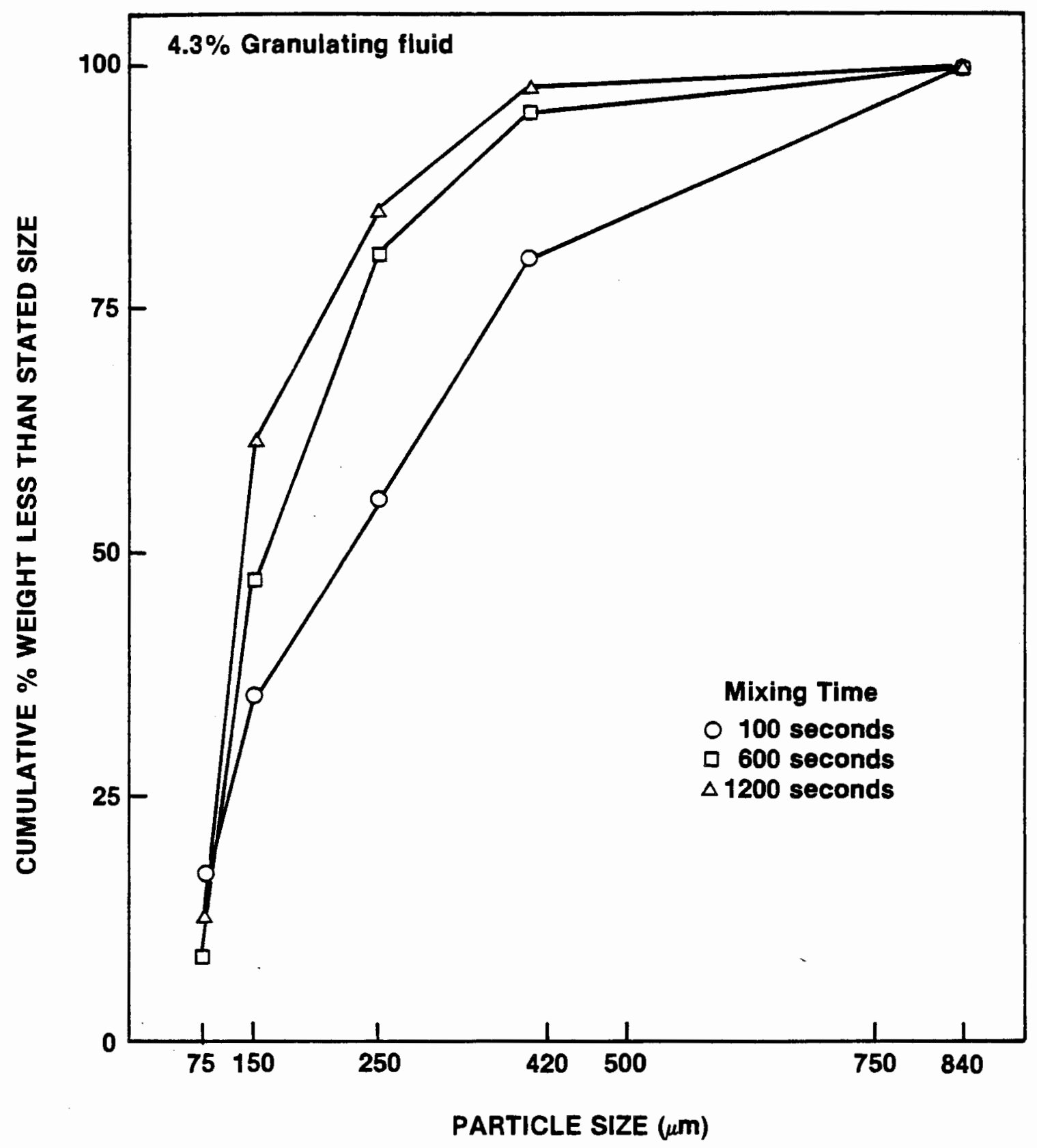




\section{FIGUPE 26}

\section{Effect of extended mixing on}

particle size distribution of phase 2 granulations

\section{PHENYLPROPANOLAMINE HYDROCHLORIDE FORMULATION}

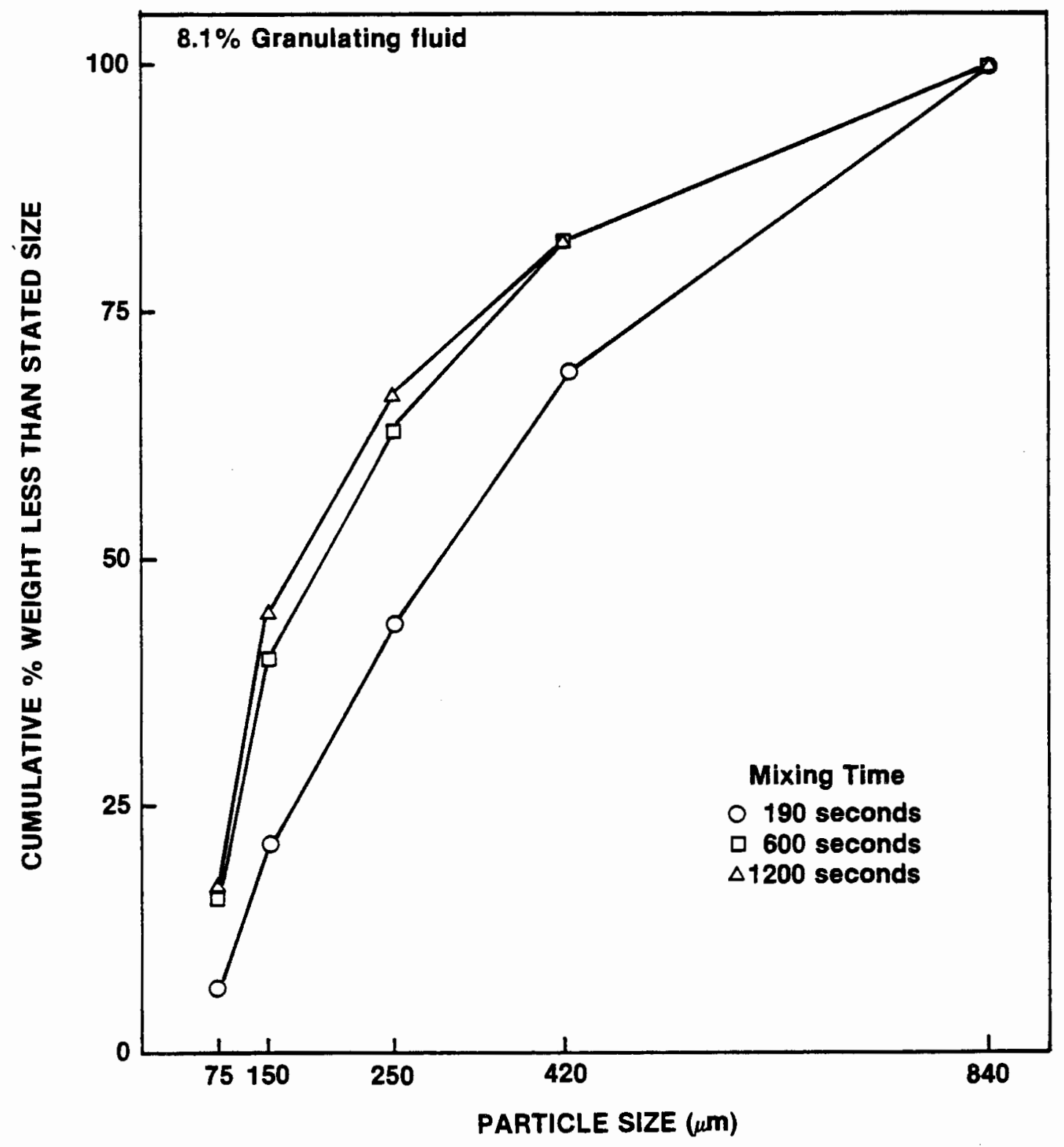




\section{FIGURE 27}

Effect of extended mixing on

particle size distribution of phase 3 granulations

\section{PHENYLPROPANOLAMINE HYDROCHLORIDE FORMULATION}

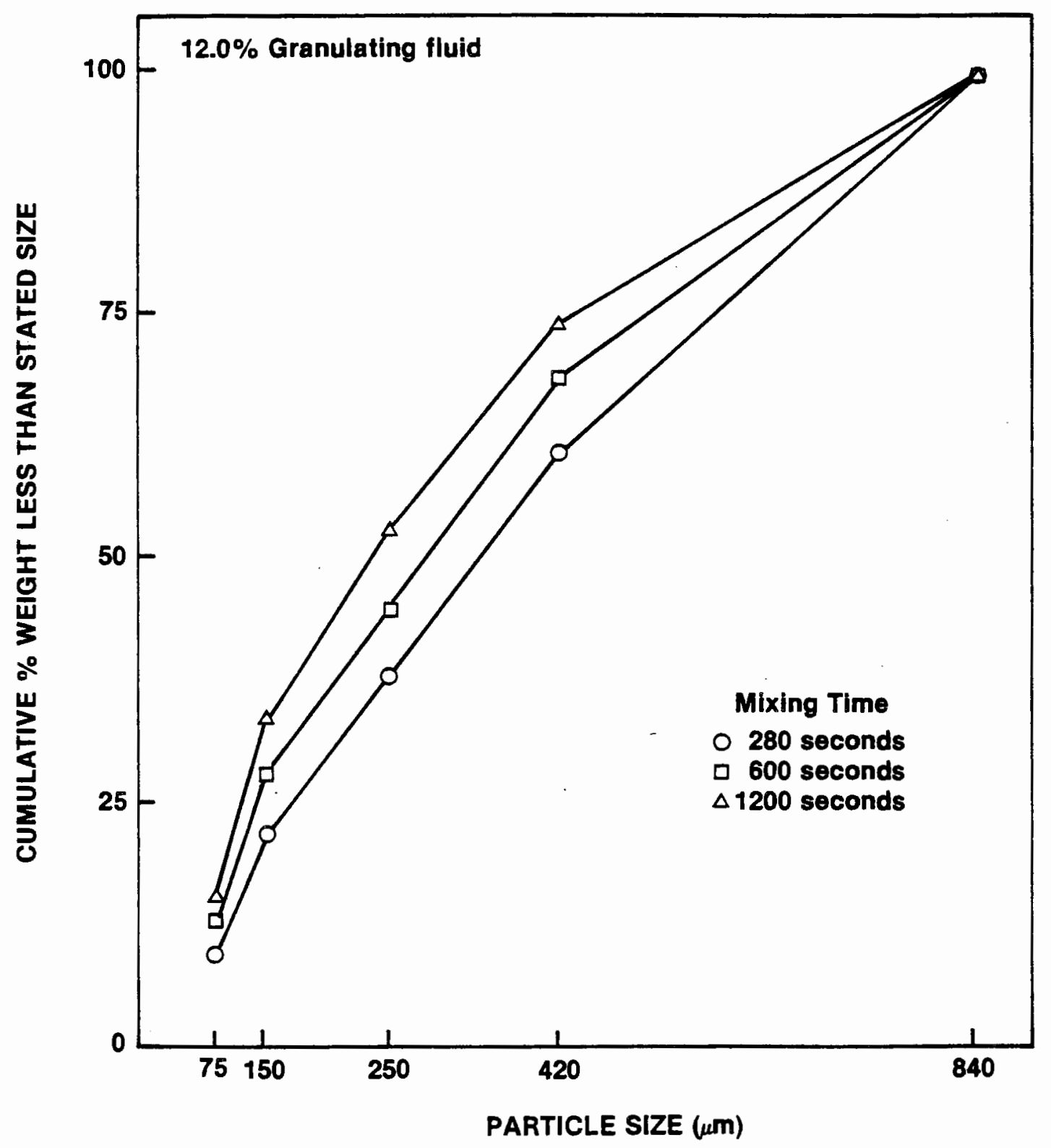


granulations. Mean particle size was decreased in all cases with increased mixing time. Phase I and II granulations were more sensitive to mixing in the first ten minutes compared to the later ten minutes. Phase III granulations were also decreased in mean particle size, but these systems were not as sensitive as phase I and II granulations. Flow properties (Fig's. 28-30) of these granulations reflected the mean particle size of granulations. The flow rate seems to decrease with increased wet mixing, but it is not statistically significant. Bulk density (Fig. 31) of the granulations was increased with extended wet mixing irrespective of the amount of granulating fluid used.

Figures 32 thru 34 show the particle size distributions of Phase I to III of theophylline formulation. Mean particle size was decreased in the case of phase I and II granulations and particle size was increased in phase III with extended wet mixing. Phase II granulations were decreased in mean particle size but they were not as sensitive as phase I granulations. These data indicate that the amount of granulation fluid has a direct effect on the particle size distribution in the case of extended wet mixing also. Extended mixing of granulations from phase I and II has no significant effect on the flow rate (Fig's. 35 and 36 ) of these granulations. Phase III granulations of theophylline formulations increased mean particle size and flow properties (Fig. 37) with extended wet mixing to twenty minutes. Bulk density (Fig's. 38-40) of the phase I and II granulations was increased and phase III granulations was decreased with extended wet mixing. In general, we can conclude that the formulations containing more soluble material are more sensitive to the amount of granulating fluid and also extended wet mixing. 
FIGURE 28

Effect of extended mixing on

flow rate of phase 1 granulations

\section{PHENYLPROPANOLAMINE HYDROCHLORIDE FORMULATION}

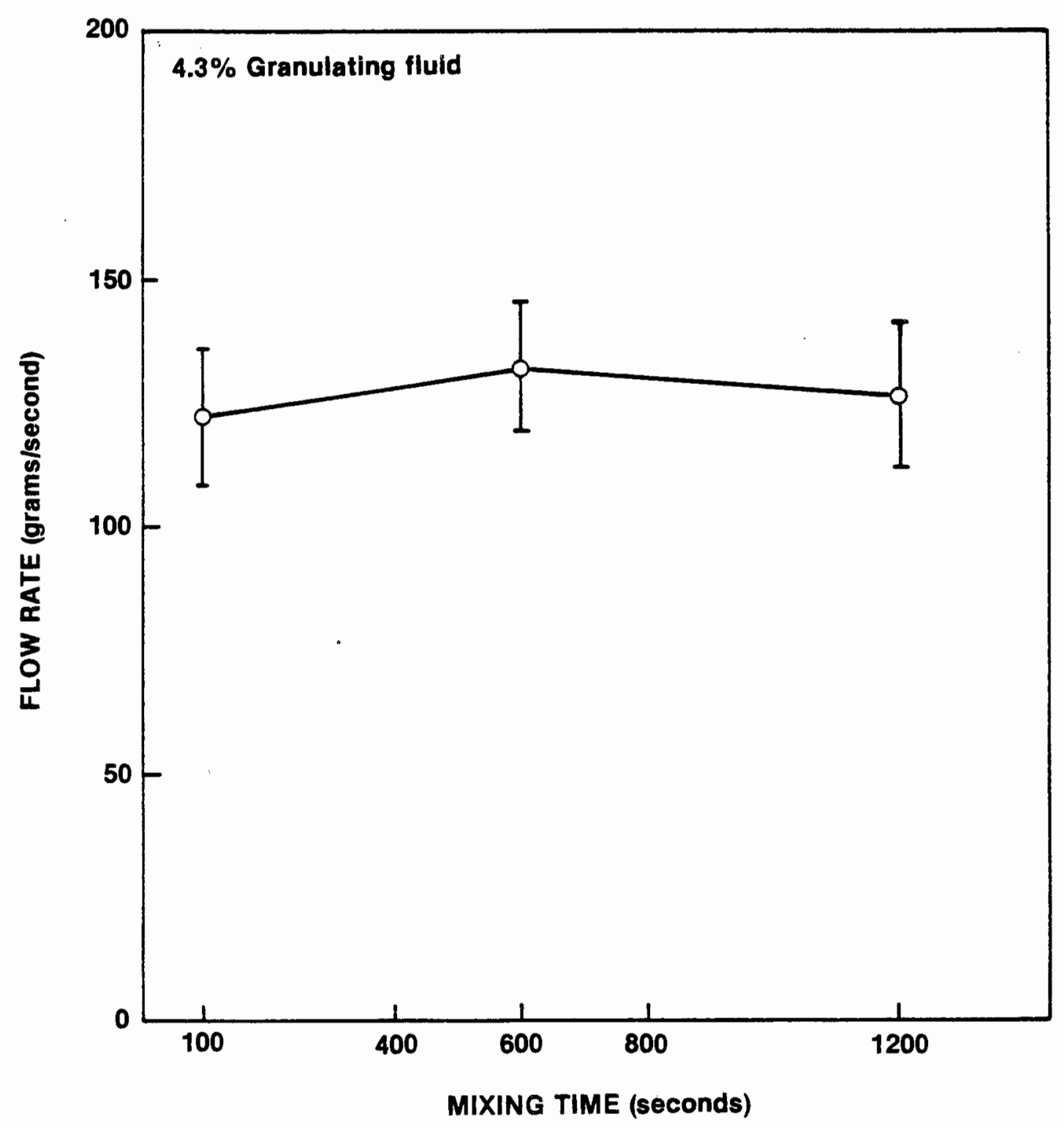




$$
\begin{gathered}
\text { FIGURE } 29 \\
\text { Effect of extended mixing on } \\
\text { flow rate of phase } 2 \text { granulations }
\end{gathered}
$$

\section{PHENYLPROPANOLAMINE HYDROCHLORIDE FORMULATION}

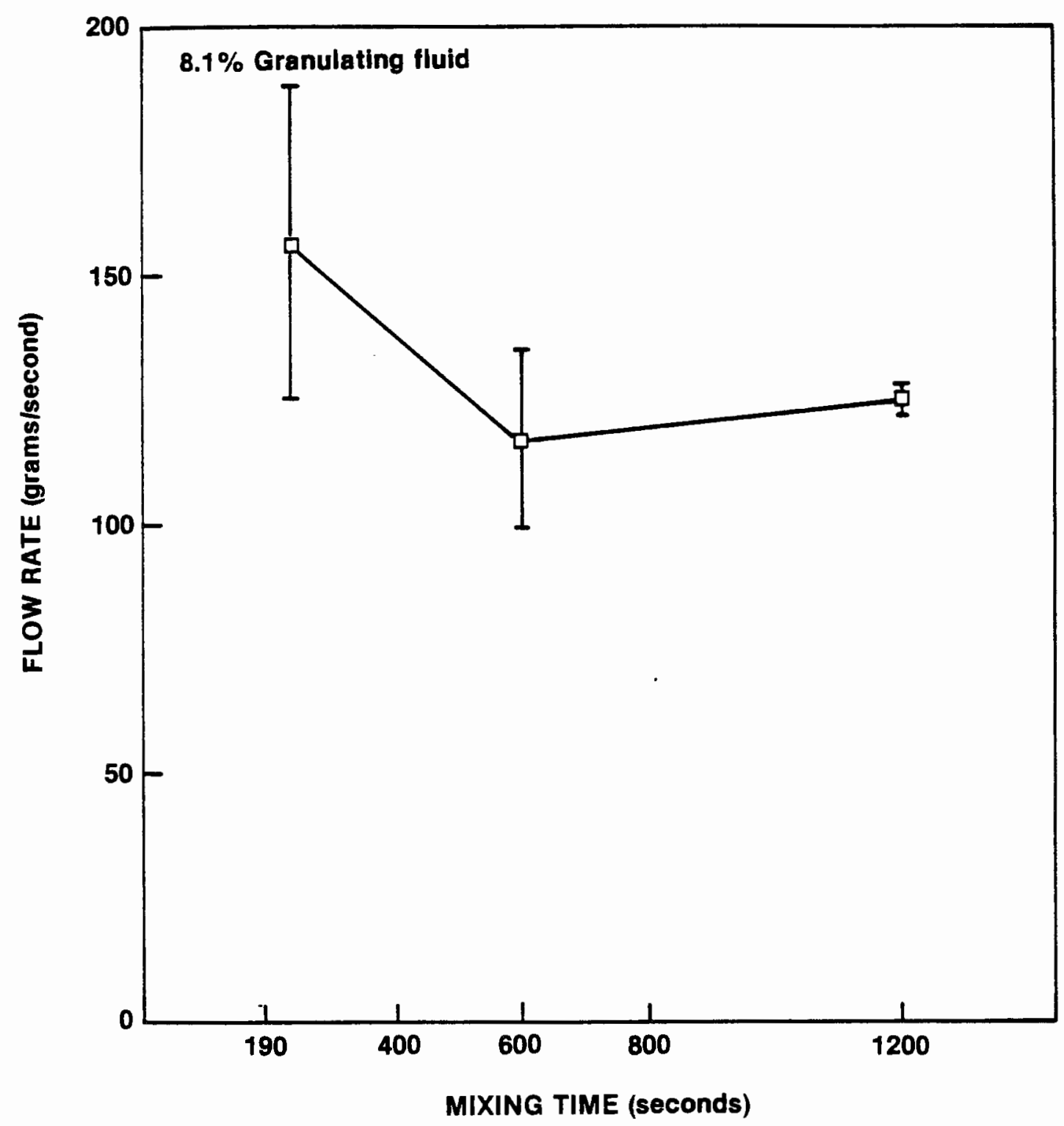


FIGURE 30

Effect of extended mixing on

flow rate of phase 3 granulations

\section{PHENYLPROPANOLAMINE HYDROCHLORIDE FORMULATIION}

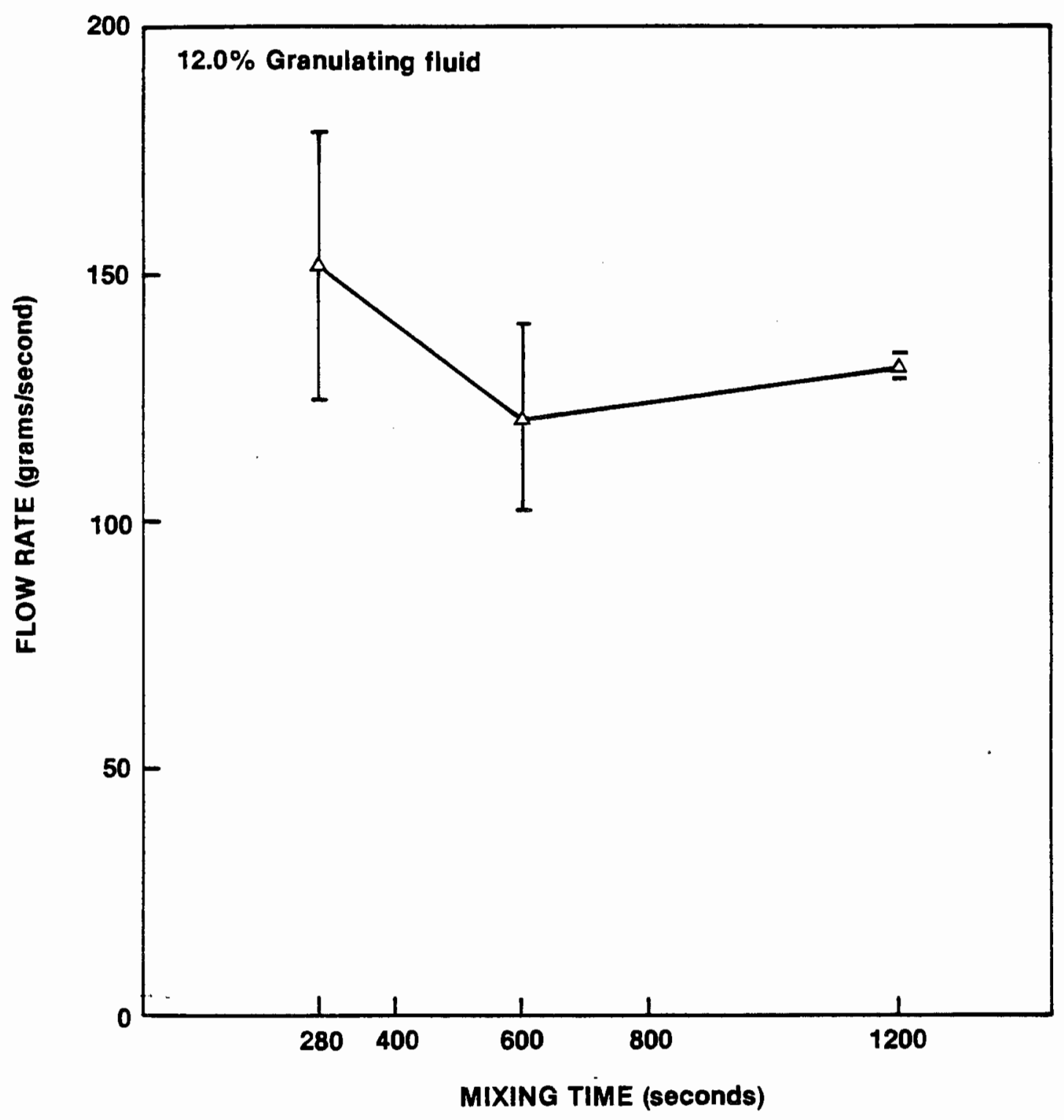




\section{FIGURE 31}

\section{Effect of extended mixing on}

bulk properties of phase 1,2 and 3 granulations

\section{PHENYLPROPANOLAMINE HYDROCHLORIDE FORMULATION}

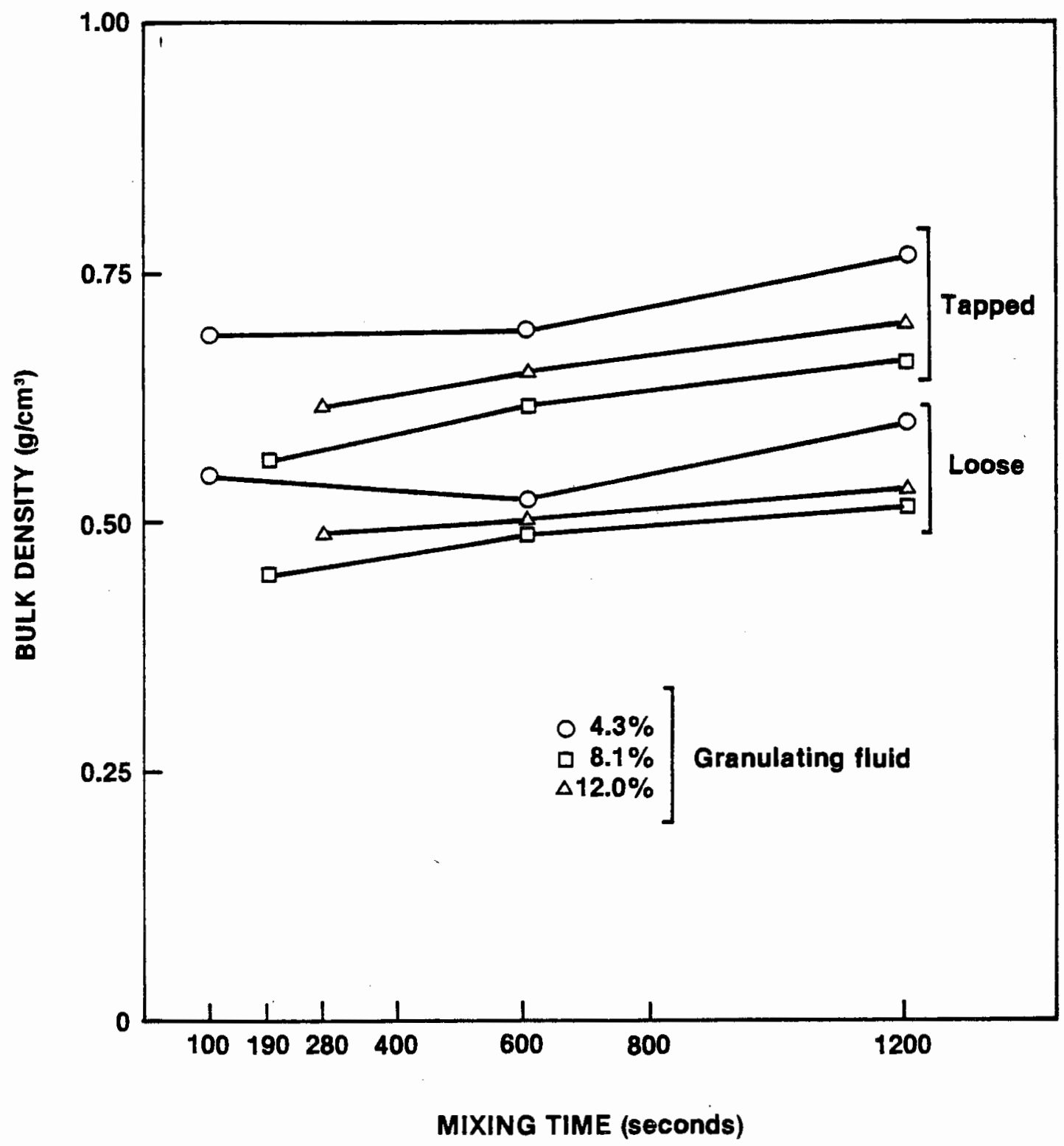




\section{FIGURE 32}

Effect of extended mixing on

particle size distribution of phase 1 granulations

THEOPHYLLINE FORMULATION

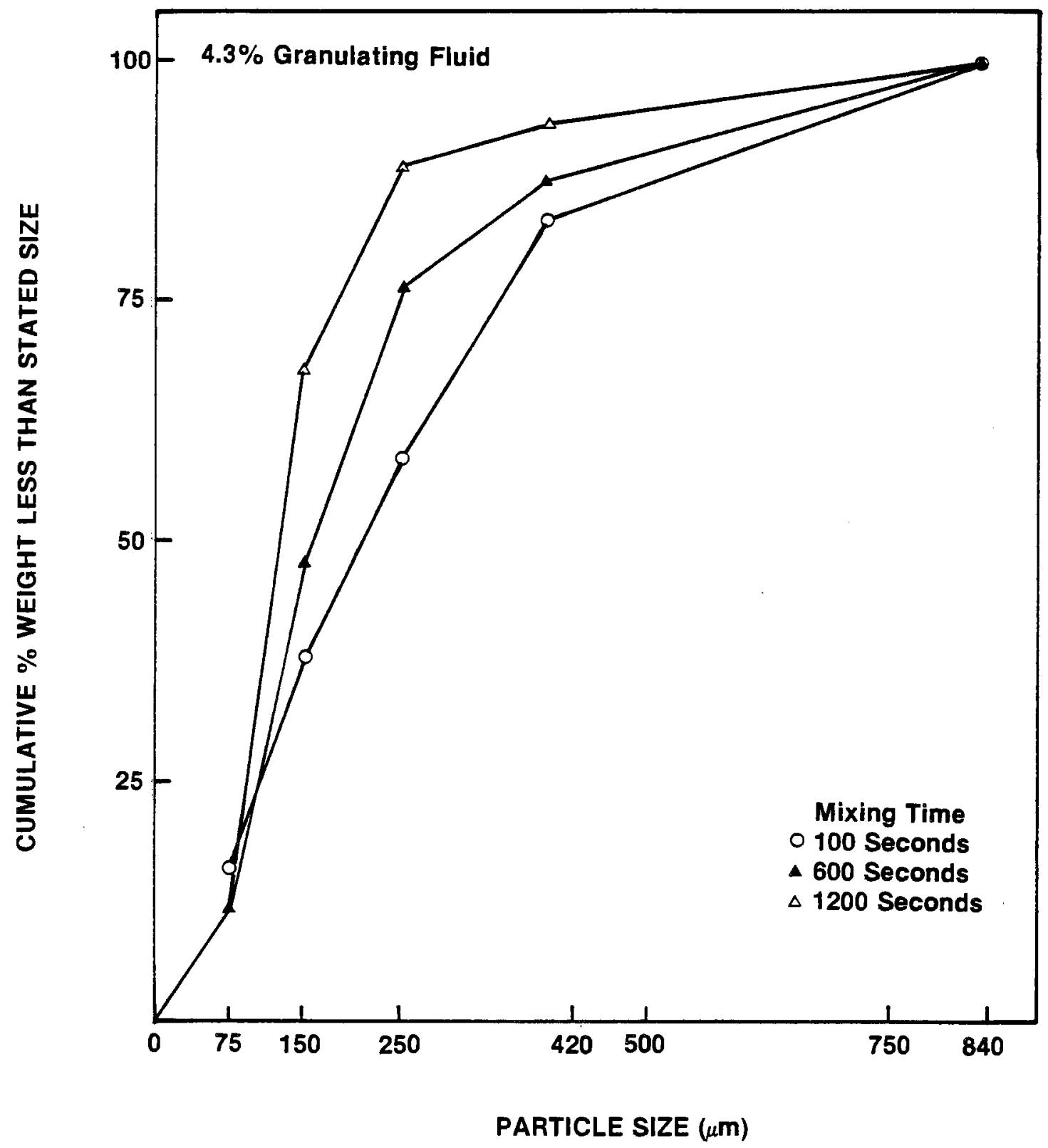

111 


\section{FIGLRE 33}

Effect of extended mixing on

particle size distribution of phase 2 granulations

\section{THEOPHYLLINE FORMULATION}

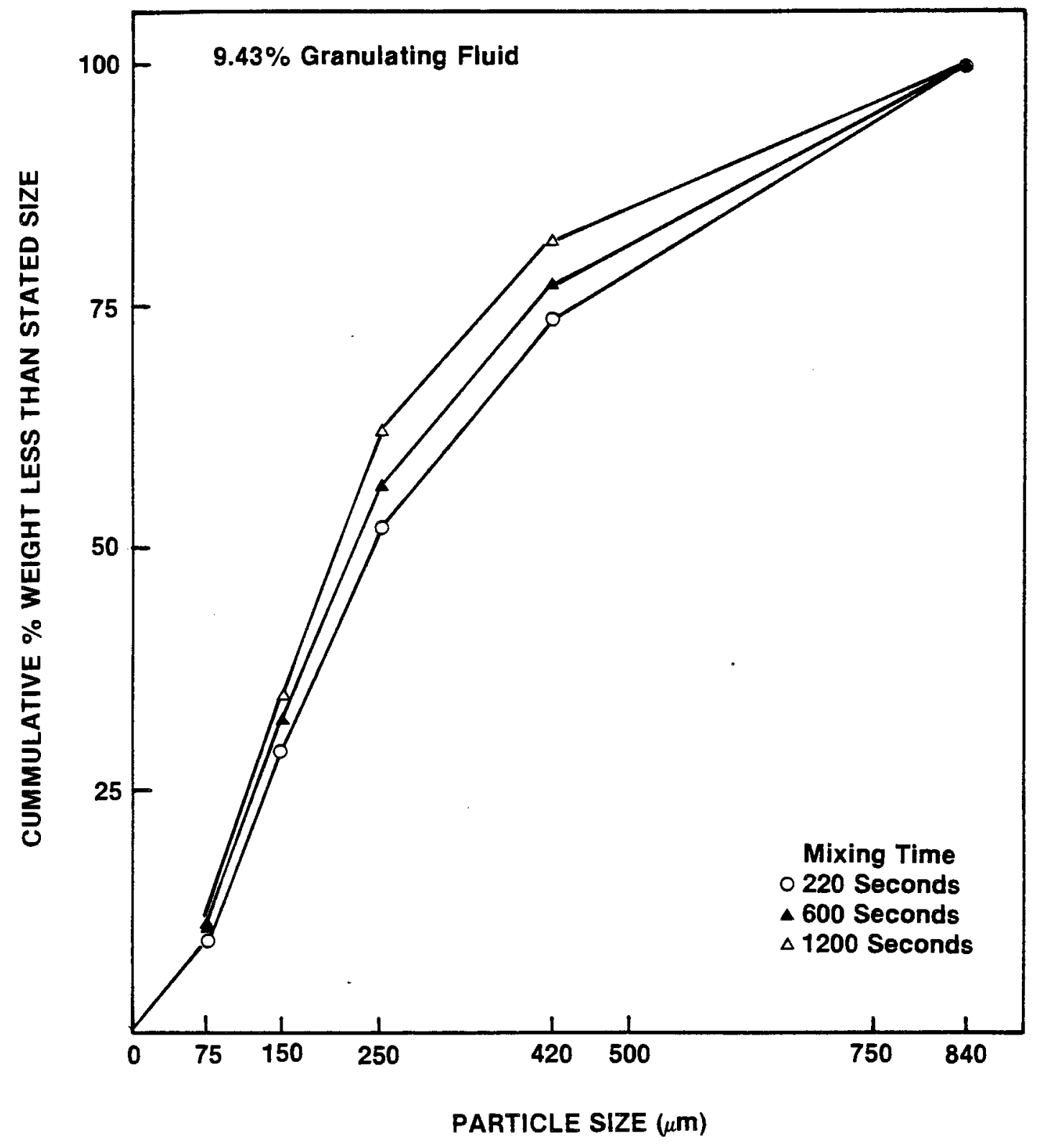

112 
FIGURE 34

Effect of extended mixing on

particle size distribution of phase 3 granulations

THEOPHYLLINE FORMULATION

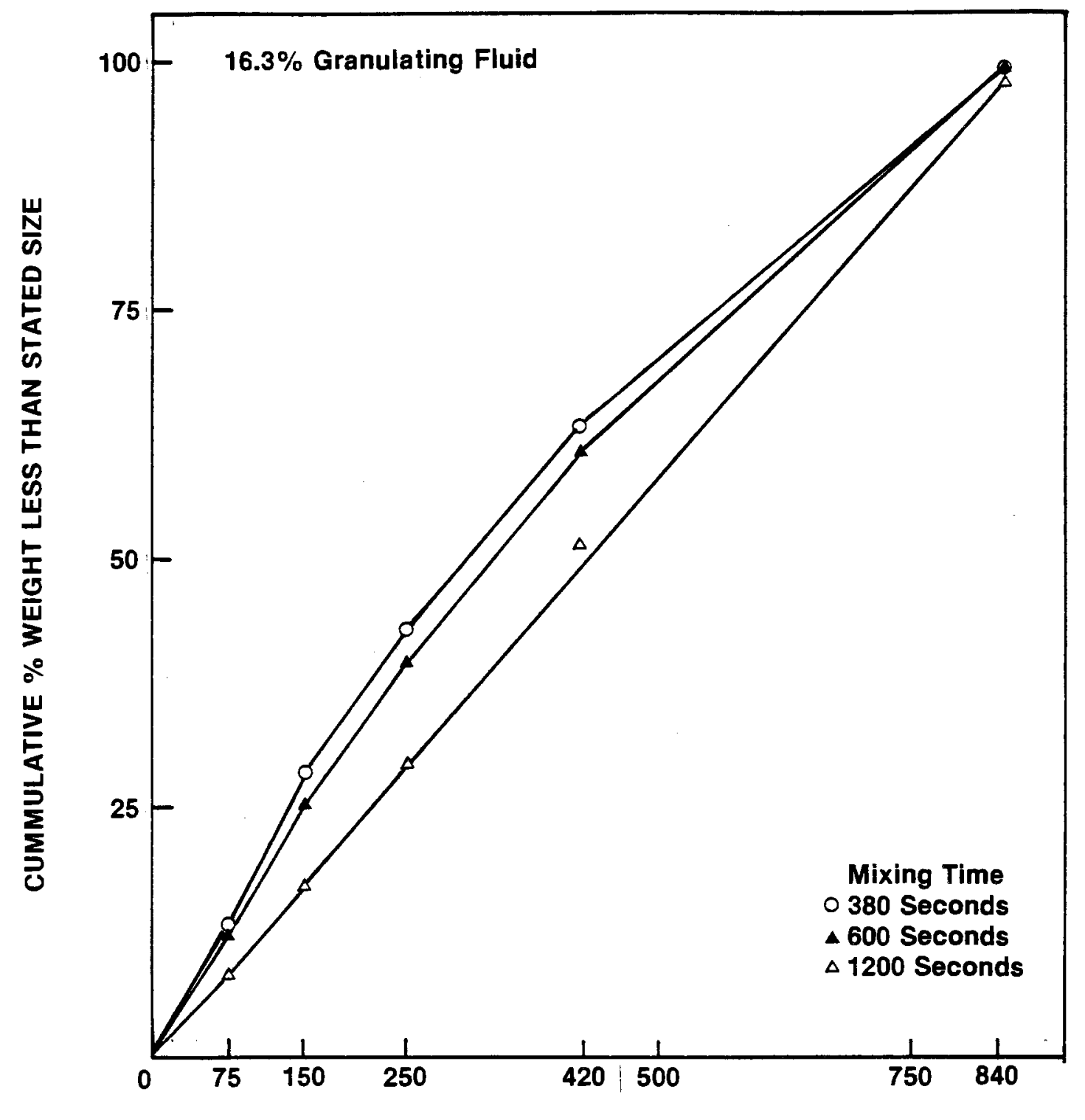

PARTICLE SIZE $(\mu \mathrm{m})$ 
FIGURE 35

Effect of extended mixing on

flow rate of phase 1 granulations

\section{THEOPHYLLINE FORMULATION}

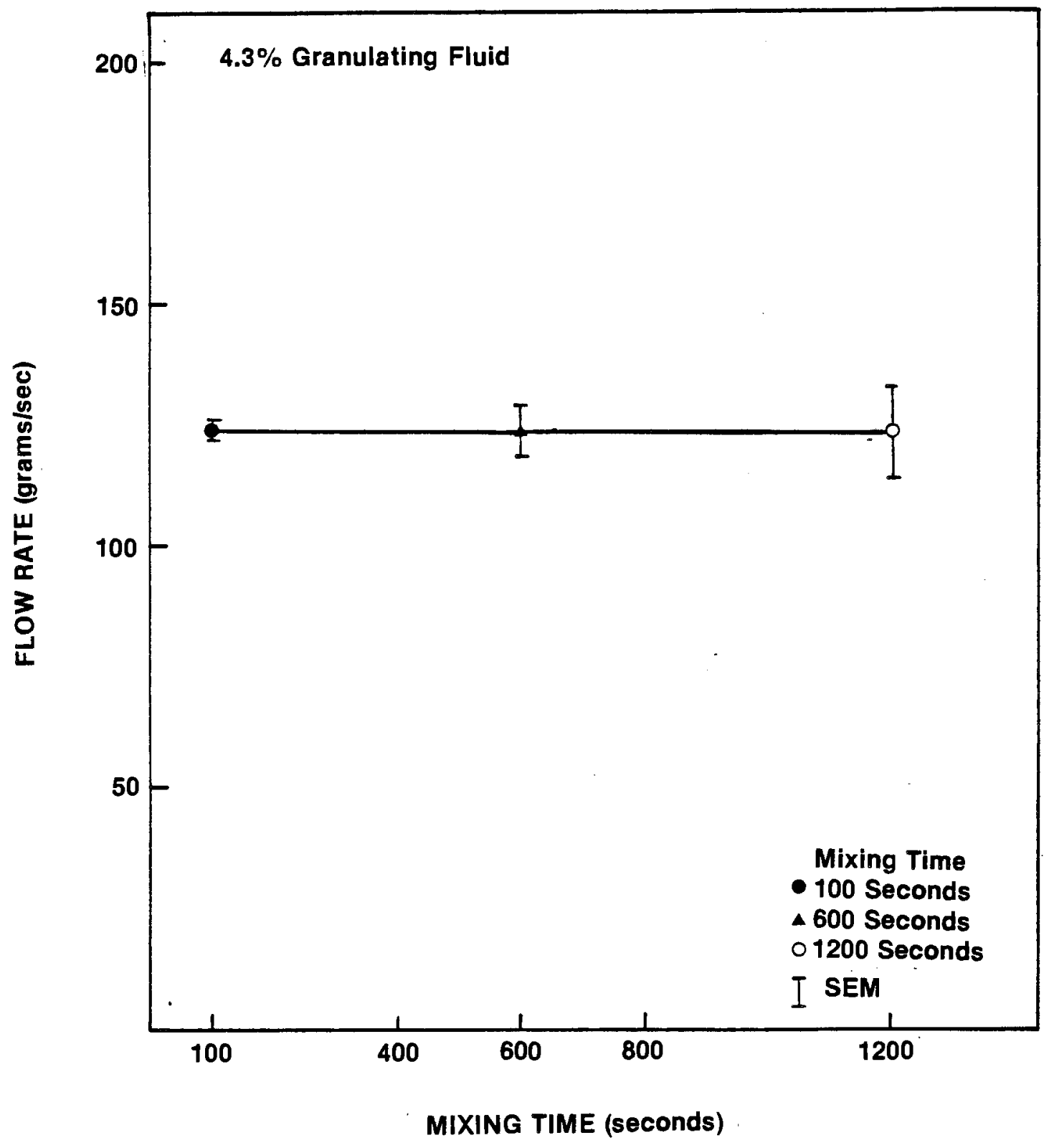


FIGURE 36

Effect of extended mixing on

flow rate of phase 2 granulations

THEOPHYLLINE FORMULATION

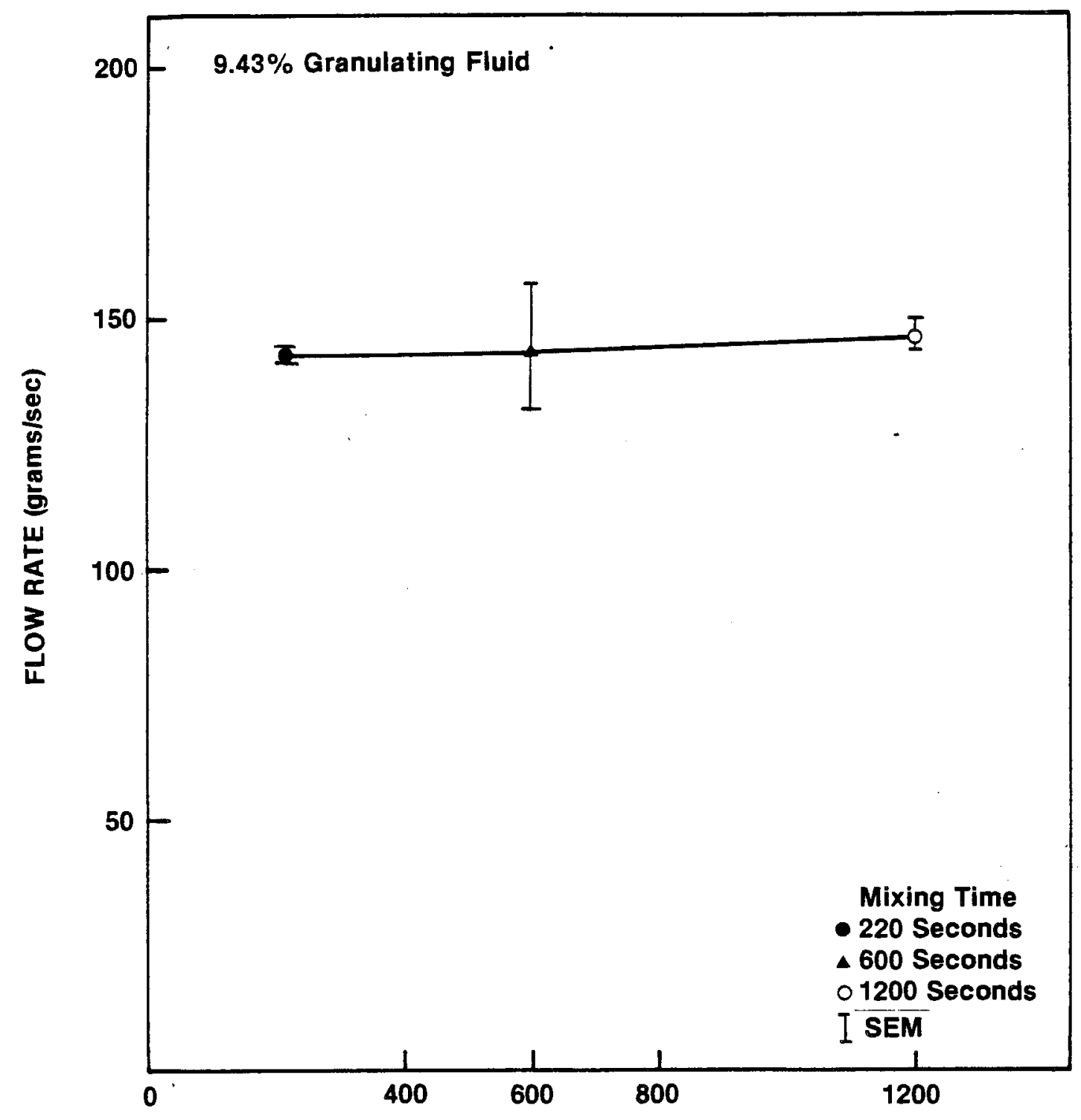

MIXING TIME (seconds) 


\section{FIGURE 37 \\ Effect of extended mixing on \\ flow rate of phase 3 granulations \\ THEOPHYLLINE FORMULATION}

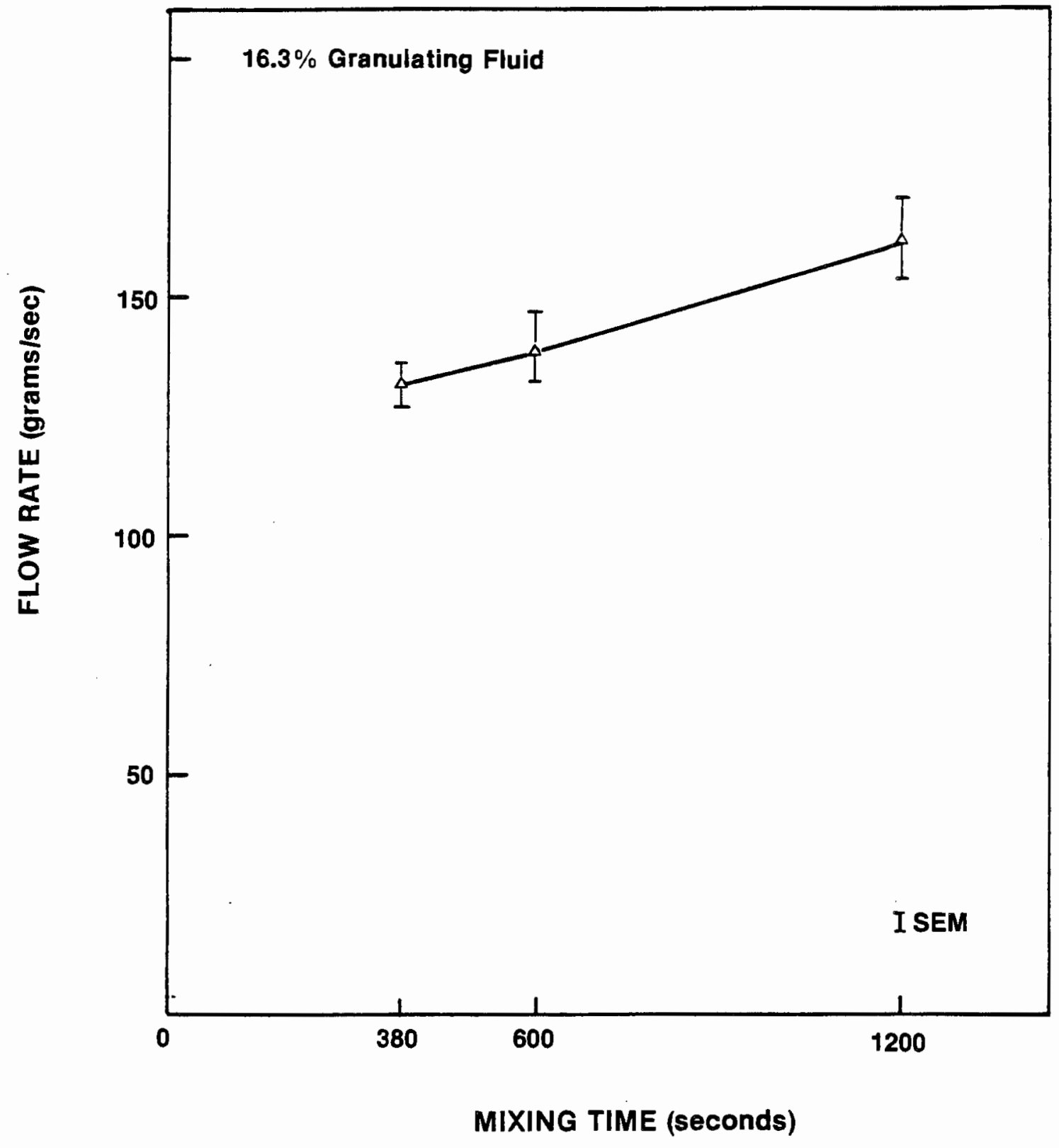




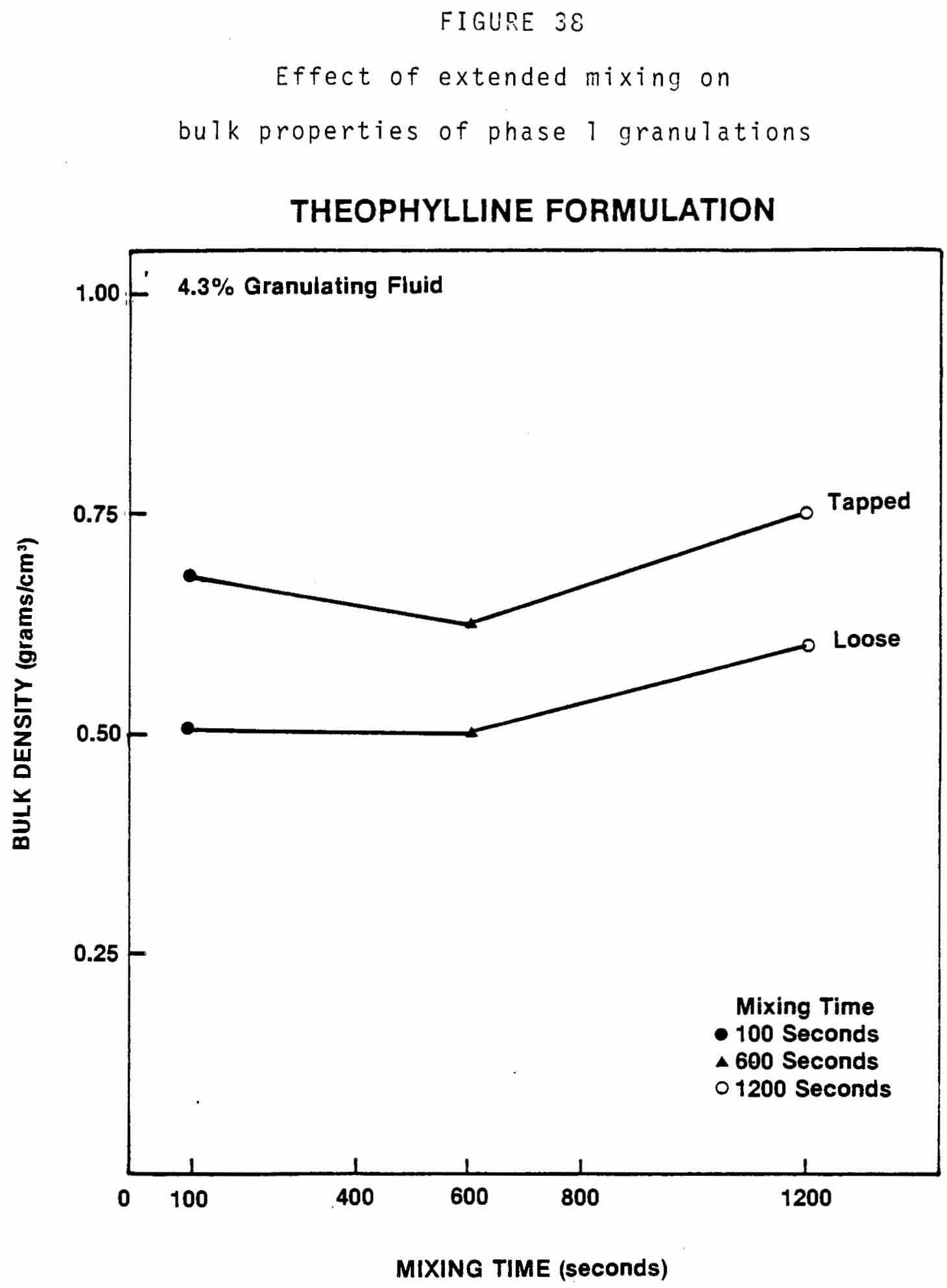




\title{
FIGURE 39
}

\author{
Effect of extended mixing on
}

bulk properties of phase 2 granulations

\section{THEOPHYLLINE FORMULATION}

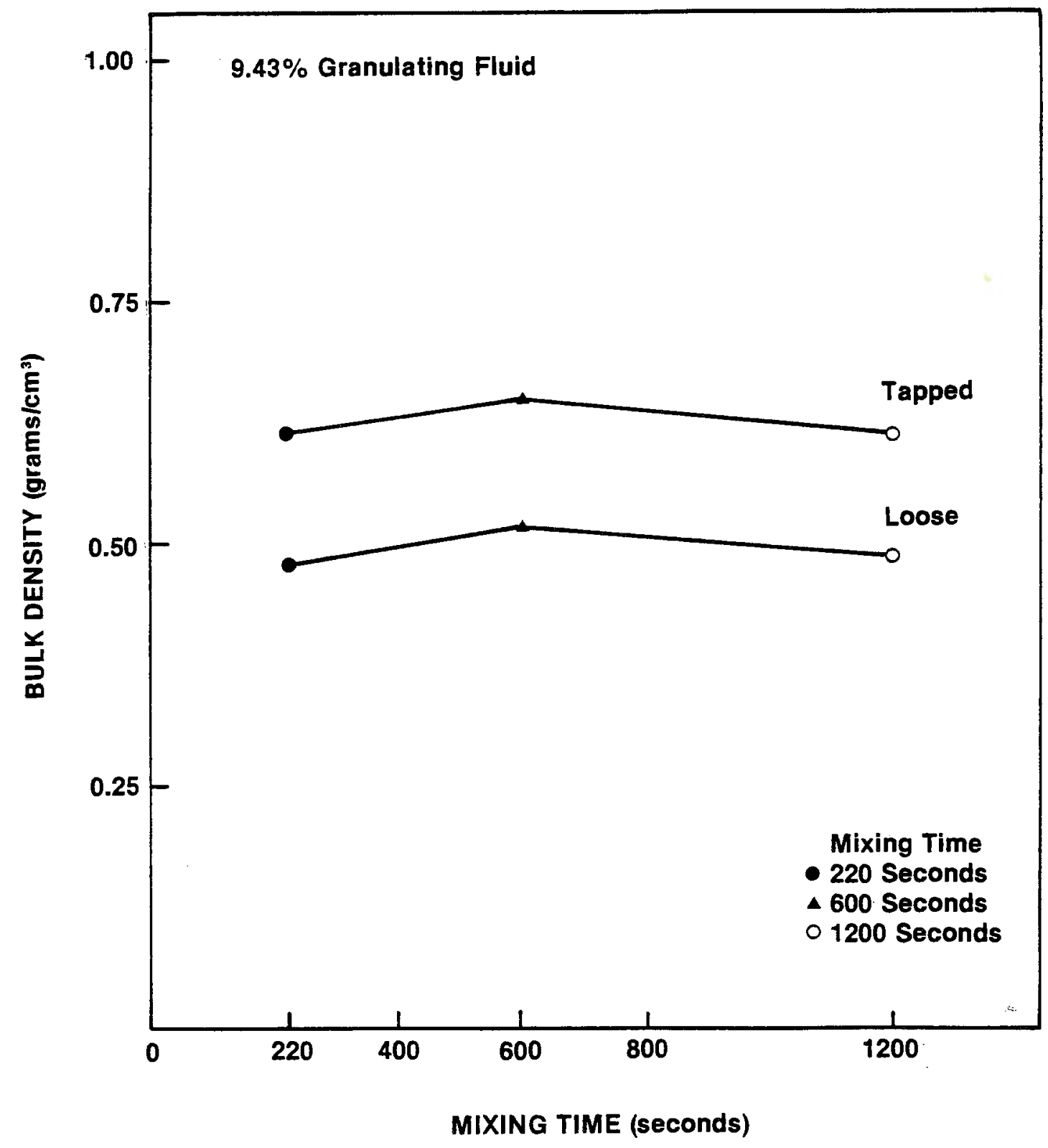




$$
\begin{gathered}
\text { FIGURE } 40 \\
\text { Effect of extended mixing on }
\end{gathered}
$$

bulk properties of phase 3 granulations

\section{THEOPHYLLINE FORMULATION}

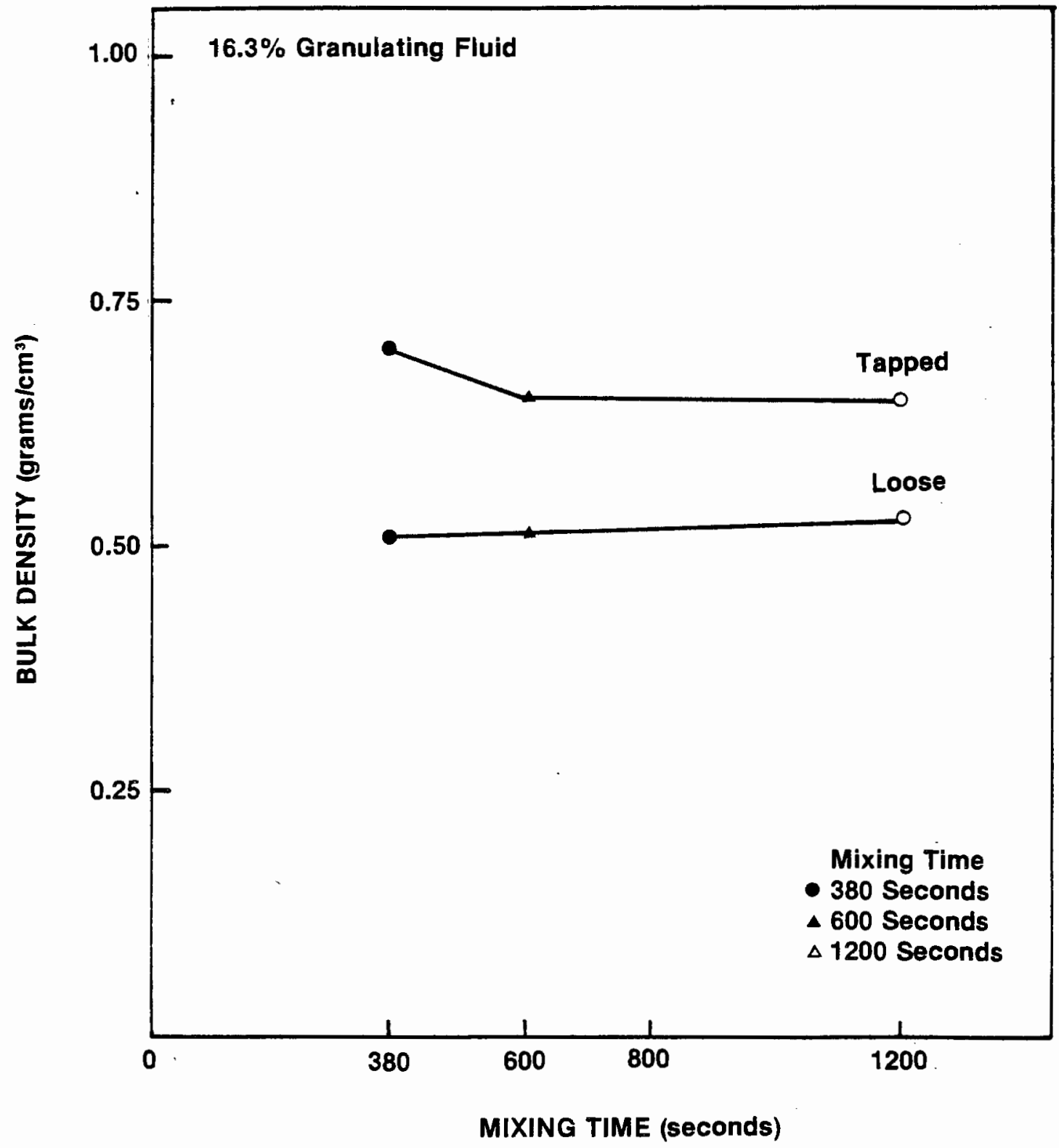

119 
Formulations (Table VI) containing different levels of theophylline were used to find the effect of concentration of drug on the wet granulation process. The torque profiles of these formulations contained all five distinct phases. The particle size distribution of phase I to III of these formulations is shown in Figures 41 thru 43. These figures indicate that the higher the concentration of drug in the formulation the smaller the mean particle size in phase I to III of the granulation process. Although, the higher drug concentration in the formulation produced smaller mean particle size in phase III, but the difference in granule size is very small between $40 \%$ and $75 \%$ drug formulations. Flow properties of the granulations from phase I to III of formulations 9 thru 11 are shown in Figure 44. These flow data indicate that phase III of the granulation process is the optimum with respect to the amount of granulating fluid and mixing time needed for the wet granulation process, irrespective of the concentration of drug in the formulation. Percent compressibility data calculated from bulk densities are shown in Figure 45. Tablet properties of formulations 9 thru 11 are recorded in Tables XXXII thru XXXIV. Tablet weight variation data and compression force data directly correlate with the granulations flow properties. Tablets compressed from granulations with poor flow properties showed higher standard deviation from mean of tablet weight and compressional force. These data support the well-recognized fact that the quality of the tablets is dependent upon the quality of the granulations used in the manufacture of final product. Tablet disintegration data indicate that when the concentration of theophylline was raised, an increase in disintegration time was observed. 


\section{FIGURE 4.1}

Theophylline formulations $9-11$ :

Particle size distribution of phase 1 granulations

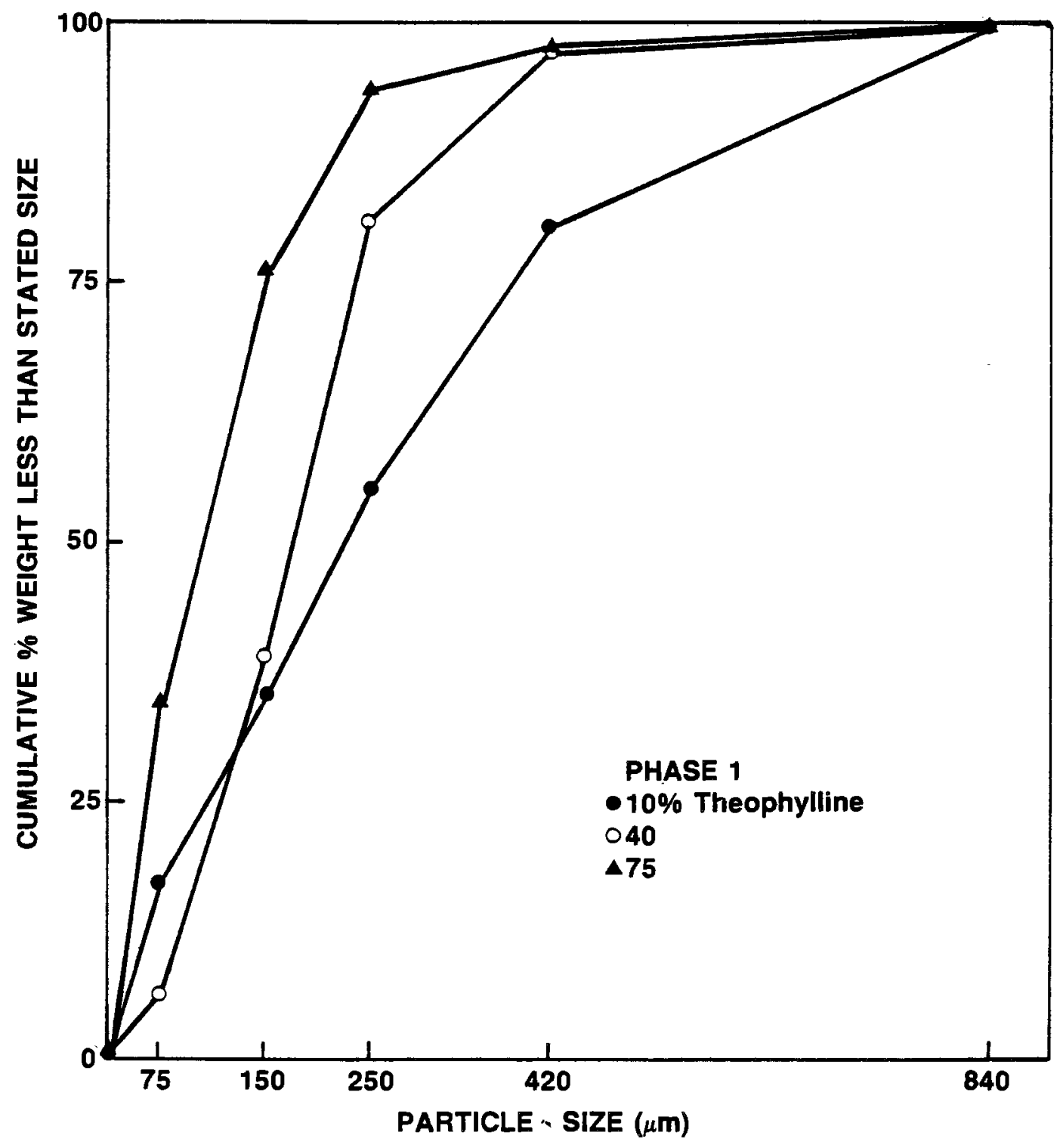




\section{FIGLRE 42}

Theophylline formulations $9-.17$ :

Particle size distribution of phase 2 granulations

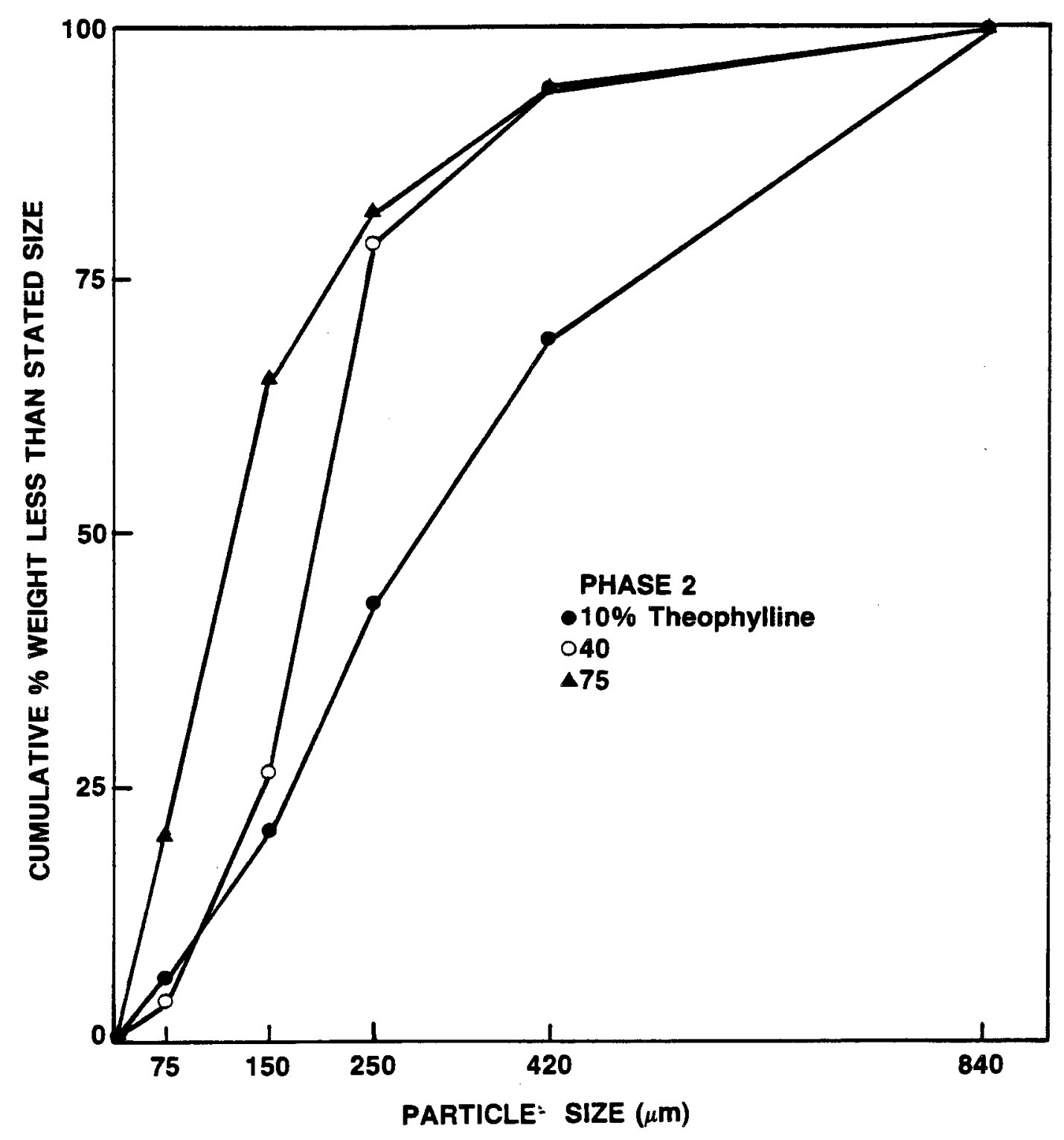




\section{FIGURE 43}

Theophylline formulations $9-11$ :

Particle size distribution of phase 3 granulations

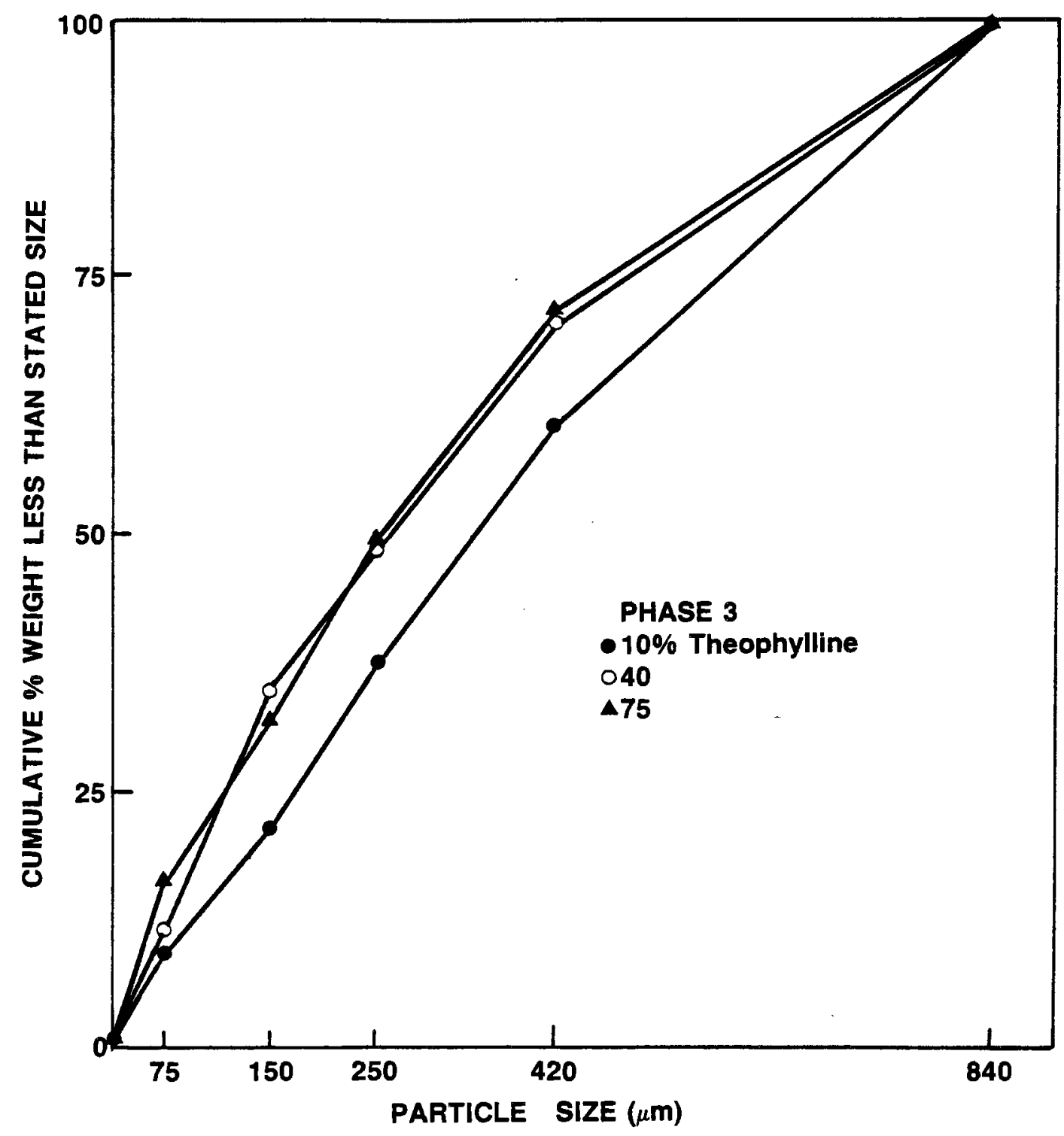




\section{FIGURE 44}

Theophylline formulations 9 - 11: Granulations flow profiles

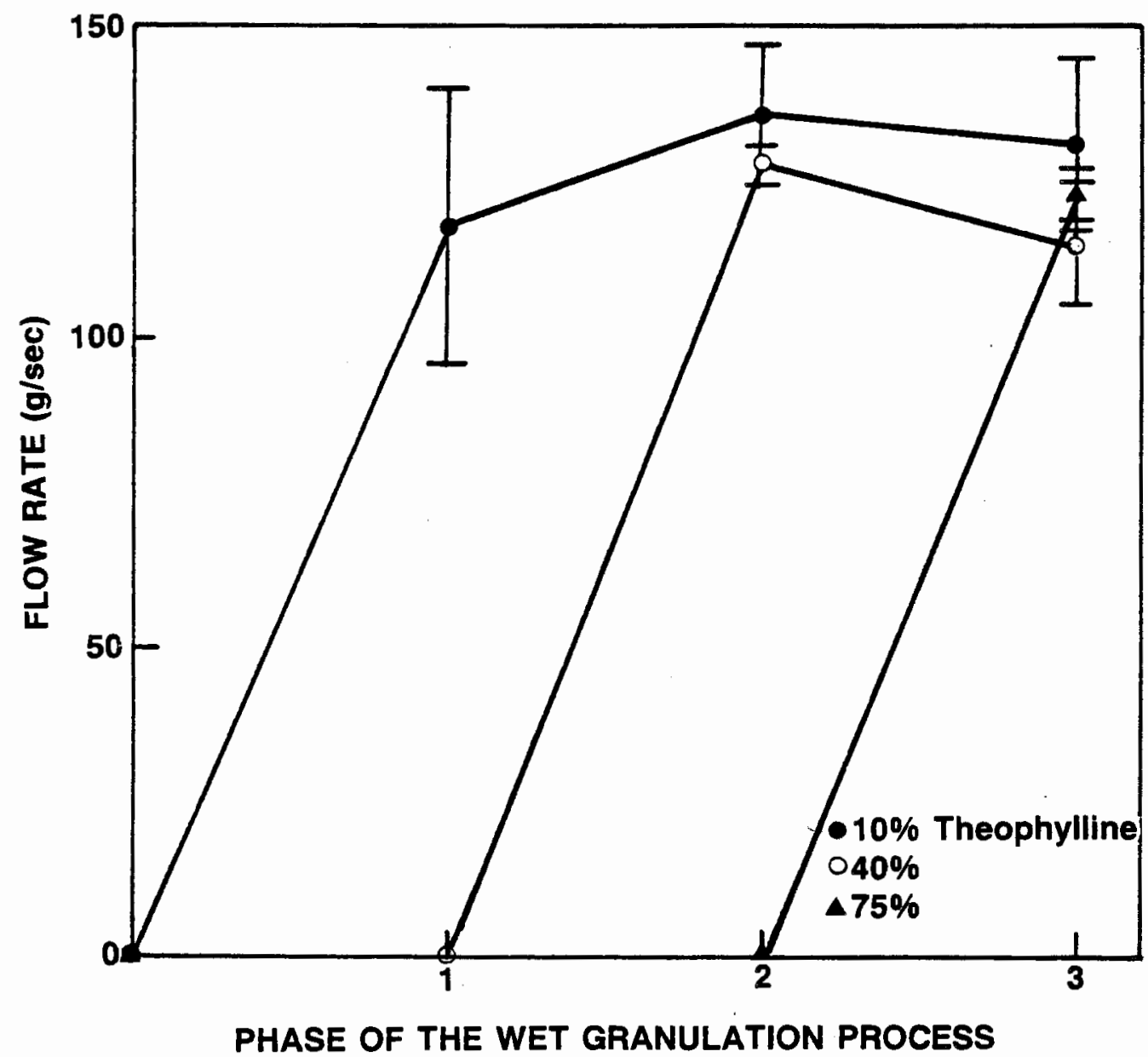




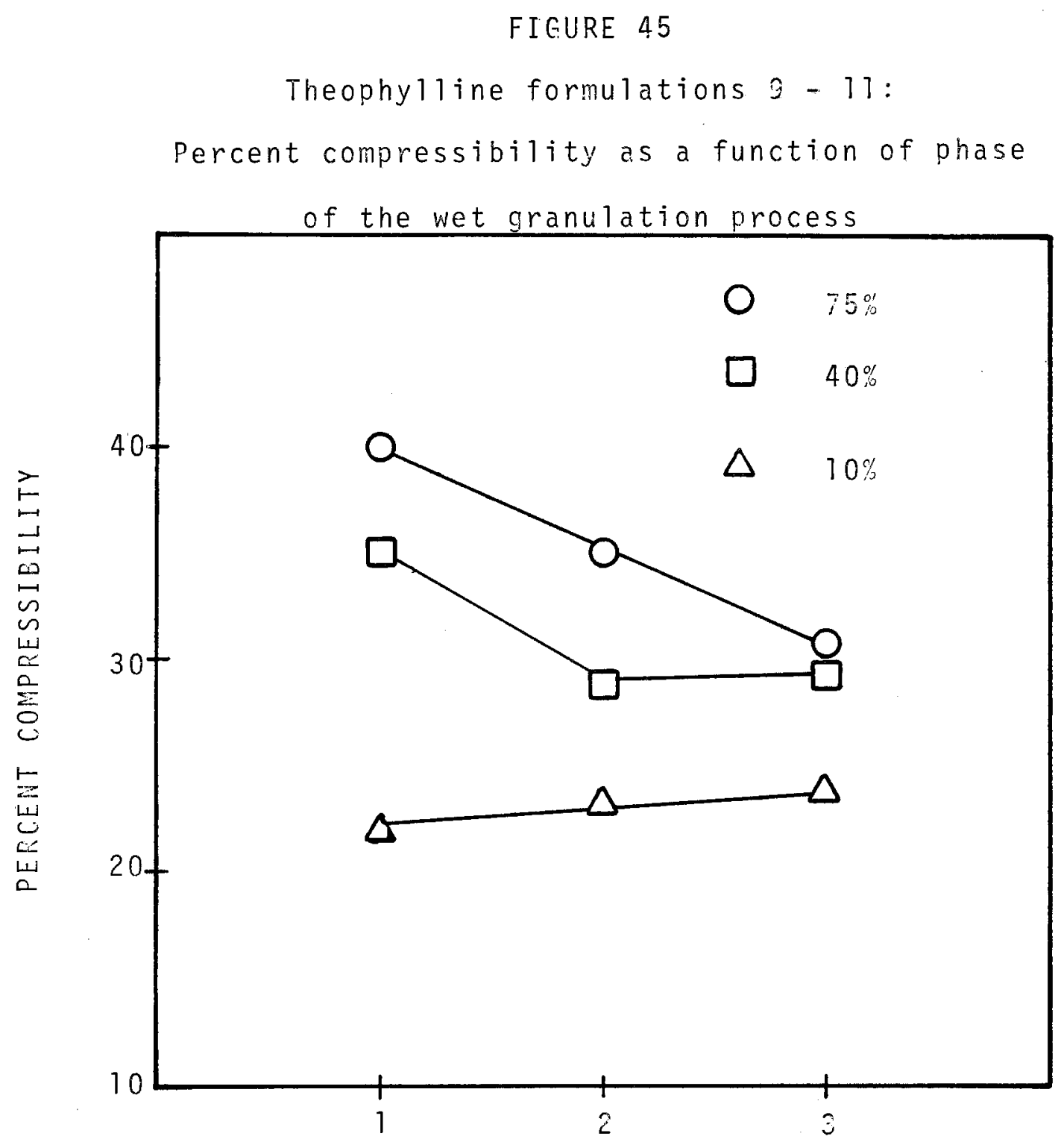

PHASE OF THE WET GRANULATION PROCESS 
TABLE XXXII

Theophylline Formulations (Granule and Tablet Properties)

\begin{tabular}{|c|c|c|c|c|}
\hline \multirow{2}{*}{\multicolumn{2}{|c|}{ Formulation }} & \multicolumn{3}{|c|}{ Phase I } \\
\hline & & 9 & 10 & 11 \\
\hline \multicolumn{2}{|c|}{$\begin{array}{l}\text { W/W Granulating fluid/ } \\
\text { Mixing time (sec) }\end{array}$} & $4.3 / 90$ & $4.3 / 90$ & $2.8 / 59$ \\
\hline \multicolumn{2}{|l|}{ Linearity } & 18.9 & - & - \\
\hline \multicolumn{5}{|c|}{ Bulk Density $\left(\mathrm{g} / \mathrm{cm}^{3}\right)$} \\
\hline \multicolumn{2}{|c|}{ Loose } & 0.514 & 0.486 & 0.452 \\
\hline \multicolumn{2}{|c|}{ Tapped } & 0.657 & 0.748 & 0.753 \\
\hline \multicolumn{2}{|l|}{$\%$ Compressibility } & 21.8 & 35.0 & 40.0 \\
\hline $\begin{array}{l}\text { Compression Force } \\
\text { (Newtons) }\end{array}$ & $\begin{array}{l}\bar{X} \\
\text { S.D }\end{array}$ & $\begin{array}{r}3948 \\
136\end{array}$ & $\begin{array}{r}4013 \\
467\end{array}$ & $\begin{array}{r}3937 \\
528\end{array}$ \\
\hline $\begin{array}{l}\text { Ejection Force } \\
\text { (Newtons) }\end{array}$ & $\begin{array}{l}\bar{X} \\
\text { S.D }\end{array}$ & $\begin{array}{r}202 \\
59\end{array}$ & $\begin{array}{r}212 \\
70\end{array}$ & $\begin{array}{r}157 \\
43\end{array}$ \\
\hline $\begin{array}{l}\text { Weight } \\
\text { (mg) }\end{array}$ & $\begin{array}{l}\bar{X} \\
S . D\end{array}$ & $\begin{array}{r}132.6 \\
1.6\end{array}$ & $\begin{array}{r}137.0 \\
7.4\end{array}$ & $\begin{array}{r}135.6 \\
14.8\end{array}$ \\
\hline $\begin{array}{l}\text { Hardness } \\
(\mathrm{kg})\end{array}$ & $\begin{array}{l}\bar{X} \\
\text { S.D }\end{array}$ & $\begin{array}{l}4.4 \\
0.3\end{array}$ & $\begin{array}{l}4.4 \\
0.4\end{array}$ & $\begin{array}{l}5.9 \\
0.8\end{array}$ \\
\hline \multicolumn{2}{|l|}{ Friability (\% loss) } & 0.08 & 0.13 & 0.04 \\
\hline $\begin{array}{l}\text { Disintegration } \\
\text { (minutes) }\end{array}$ & $\begin{array}{l}\bar{X} \\
\text { S.D }\end{array}$ & $\begin{array}{l}4.44 \\
0.26\end{array}$ & $\begin{array}{l}9.50 \\
0.45\end{array}$ & $\begin{array}{l}9.40 \\
3.80\end{array}$ \\
\hline
\end{tabular}


TABLE XXXIII

Theophylline Formulations (Granule and Tablet Properties)

\begin{tabular}{|c|c|c|c|c|}
\hline \multirow{2}{*}{\multicolumn{2}{|c|}{ Formulation }} & \multicolumn{3}{|c|}{ Phase II } \\
\hline & & 9 & 10 & 11 \\
\hline \multicolumn{2}{|c|}{$\begin{array}{l}\text { W/W Granulating fluid/ } \\
\text { Mixing time (sec) }\end{array}$} & $9.4 / 197$ & $10.4 / 218$ & $8.1 / 170$ \\
\hline \multirow{2}{*}{\multicolumn{2}{|c|}{$\begin{array}{l}\text { Linearity } \\
\text { Bulk Density }\left(\mathrm{g} / \mathrm{cm}^{3}\right)\end{array}$}} & 19.5 & 19.3 & - \\
\hline & & & & \\
\hline \multicolumn{2}{|c|}{ Loose } & 0.484 & 0.463 & 0.358 \\
\hline \multicolumn{2}{|c|}{ Tapped } & 0.630 & 0.649 & 0.551 \\
\hline \multicolumn{2}{|l|}{ \% Compressibility } & 23.2 & 28.7 & 35.0 \\
\hline $\begin{array}{l}\text { Compression Force } \\
\text { (Newtons) }\end{array}$ & $\begin{array}{l}\bar{X} \\
\text { S.D }\end{array}$ & $\begin{array}{r}3999 \\
116\end{array}$ & $\begin{array}{r}4050 \\
124\end{array}$ & $\begin{array}{r}4097 \\
479\end{array}$ \\
\hline $\begin{array}{l}\text { Ejection Force } \\
\text { (Newtons) }\end{array}$ & $\begin{array}{l}\bar{X} \\
\text { S.D }\end{array}$ & $\begin{array}{r}188 \\
33\end{array}$ & $\begin{array}{r}162 \\
4\end{array}$ & $\begin{array}{r}104 \\
3\end{array}$ \\
\hline $\begin{array}{l}\text { Weight } \\
\text { (mg) }\end{array}$ & $\begin{array}{l}\bar{X} \\
\text { S.D }\end{array}$ & $\begin{array}{r}132.6 \\
1.4\end{array}$ & $\begin{array}{r}131.4 \\
1.3\end{array}$ & $\begin{array}{r}136.3 \\
7.8\end{array}$ \\
\hline $\begin{array}{l}\text { Hardness } \\
(\mathrm{kg})\end{array}$ & $\begin{array}{l}\bar{X} \\
\text { S.D }\end{array}$ & $\begin{array}{l}6.1 \\
0.7\end{array}$ & $\begin{array}{l}6.5 \\
0.4\end{array}$ & $\begin{array}{l}8.0 \\
0.5\end{array}$ \\
\hline \multicolumn{2}{|l|}{ Friability (\% loss) } & 0.08 & 0.00 & 0.00 \\
\hline $\begin{array}{l}\text { Disintegration } \\
\text { (minutes) }\end{array}$ & $\begin{array}{l}\bar{X} \\
\text { S.D }\end{array}$ & $\begin{array}{l}7.10 \\
0.49\end{array}$ & $\begin{array}{r}16.80 \\
0.68\end{array}$ & $\begin{array}{l}26.25 \\
1.33\end{array}$ \\
\hline
\end{tabular}


TABLE XXXIV

Theophylline Formulations (Granule and Tablet Properties)

\begin{tabular}{|c|c|c|c|c|}
\hline \multirow{2}{*}{\multicolumn{2}{|c|}{ Formulation }} & \multicolumn{3}{|c|}{ Phase I I I } \\
\hline & & 9 & 10 & 11 \\
\hline \multicolumn{2}{|c|}{$\begin{array}{l}\text { W/W Granulating fluid/ } \\
\text { Mixing time (sec) }\end{array}$} & $16.3 / 273$ & $21.7 / 363$ & $20.7 / 347$ \\
\hline \multirow{2}{*}{\multicolumn{2}{|c|}{$\begin{array}{l}\text { Linearity } \\
\text { Bulk Density }\left(\mathrm{g} / \mathrm{cm}^{3}\right)\end{array}$}} & 19.4 & 19.3 & 19.3 \\
\hline & & & & \\
\hline \multicolumn{2}{|c|}{ Loose } & 0.480 & 0.548 & 0.433 \\
\hline \multicolumn{2}{|c|}{ Tapped } & 0.629 & 0.774 & 0.623 \\
\hline \multicolumn{2}{|l|}{ \% Compressibility } & 23.7 & 29.2 & 30.5 \\
\hline $\begin{array}{l}\text { Compression Force } \\
\text { (Newtons) }\end{array}$ & $\begin{array}{l}\bar{X} \\
\text { S.D }\end{array}$ & $\begin{array}{r}3974 \\
167\end{array}$ & $\begin{array}{r}3909 \\
126\end{array}$ & $\begin{array}{r}4064 \\
211\end{array}$ \\
\hline $\begin{array}{l}\text { Ejection Force } \\
\text { (Newtons) }\end{array}$ & $\begin{array}{l}\bar{X} \\
\text { S.D }\end{array}$ & $\begin{array}{r}176 \\
15\end{array}$ & $\begin{array}{r}198 \\
40\end{array}$ & $\begin{array}{r}140 \\
32\end{array}$ \\
\hline $\begin{array}{l}\text { Weight } \\
\text { (mg) }\end{array}$ & $\begin{array}{l}\bar{X} \\
\text { S.D }\end{array}$ & $\begin{array}{r}135.9 \\
1.4\end{array}$ & $\begin{array}{r}136.0 \\
1.0\end{array}$ & $\begin{array}{r}135.0 \\
0.7\end{array}$ \\
\hline $\begin{array}{l}\text { Hardness } \\
(\mathrm{kg})\end{array}$ & $\begin{array}{l}\bar{X} \\
\text { S.D }\end{array}$ & $\begin{array}{l}7.3 \\
0.8\end{array}$ & $\begin{array}{l}5.8 \\
0.6\end{array}$ & $\begin{array}{l}7.1 \\
0.4\end{array}$ \\
\hline \multicolumn{2}{|c|}{ Friability (\% loss) } & 0.00 & 0.04 & 0.01 \\
\hline $\begin{array}{l}\text { Disintegration } \\
\text { (minutes) }\end{array}$ & $\begin{array}{l}\bar{X} \\
\text { S.D }\end{array}$ & $\begin{array}{r}11.63 \\
0.26\end{array}$ & $\begin{array}{r}18.60 \\
0.38\end{array}$ & $\begin{array}{r}34.50 \\
1.05\end{array}$ \\
\hline
\end{tabular}


Formulations 12 and 13 (Table VII) were used to study the effect of matrices (soluble or insoluble) on the wet granulation process. Figure 46 shows the torque-time profile of formulation containing soluble mannitol matrix. It contains all five distinct phases reported earlier with lactose matrix, but the torque in phase III did not level off. The torque in phase III was increased with the addition of granulation fluid. For highly soluble systems it is possible that the porosity of the solid material collapses and leaves the surface of the material wet. This phenemenon may be causing rapid agglomeration and also increased cohesiveness between the granules. Figure 47 shows the torque time profile of formulation containing insoluble dicalcium phosphate matrix. This torque profile contained all five phases reported earlier. The particle size distribution of phase I to III of formulation 12 and 13 are shown in Figure 48. In both formulations the mean particle size increases with increased addition of granulating fluid and mixing time. The mannitol formulations produced finer granules compared to the dicalcium phosphate formulations in every phase of the wet granulation process. Figure 49 shows the effect of mannitol and dicalcium phosphate on the flow properties of granulations produced at phase I to III. The dicalcium phosphate matrix produced significantly $(P<0.05)$ better granulations at every phase of the granulation. Flow rate of dicalcium phosphate granulations from phase I to III showed no significant $(P<$ 0.05) difference. The mannitol matrix granulation showed a significant difference $(P<0.05)$ in flow rate between each phase. Percent compressibility data support the granulation flow data (Figure 50). The results of granule and tablet properties of hydrochlorothiazide 
FIGURE 46

Torque - time profile

Hydrochlorothiazide formulation with mannitol matrix

$\vec{\omega}$

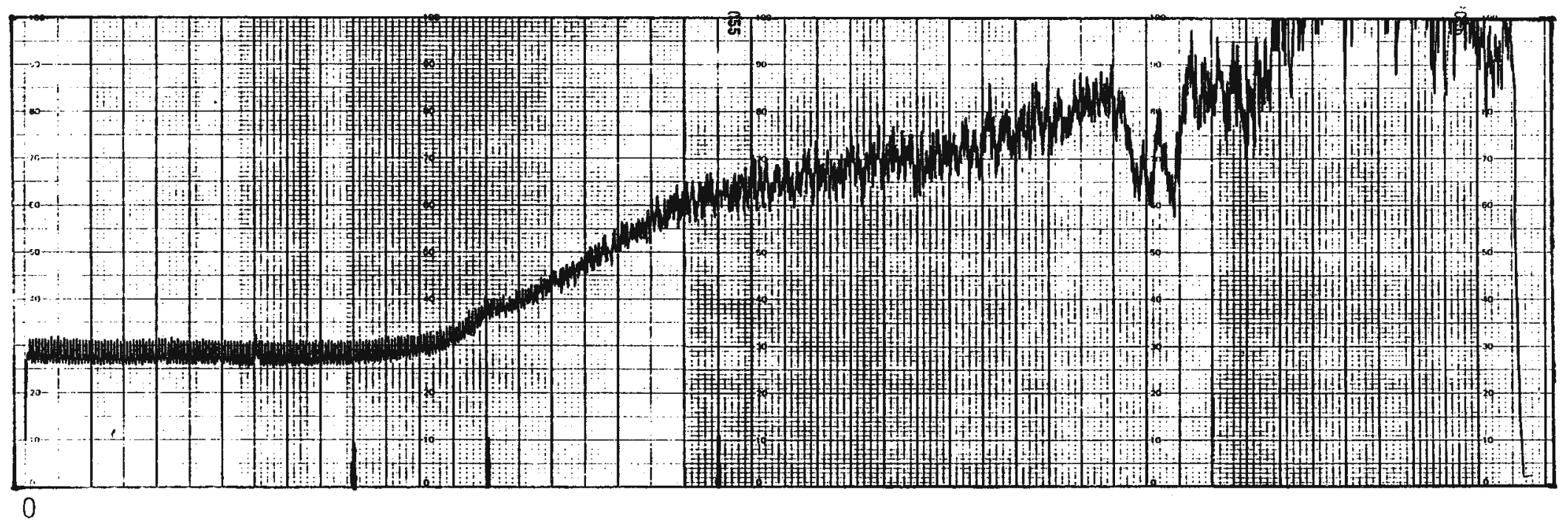

TIME (seconds) 
FIGUPE 47

Torque - time profile

Hydrochlorothiazide formulation with dicalcium phosphate matrix

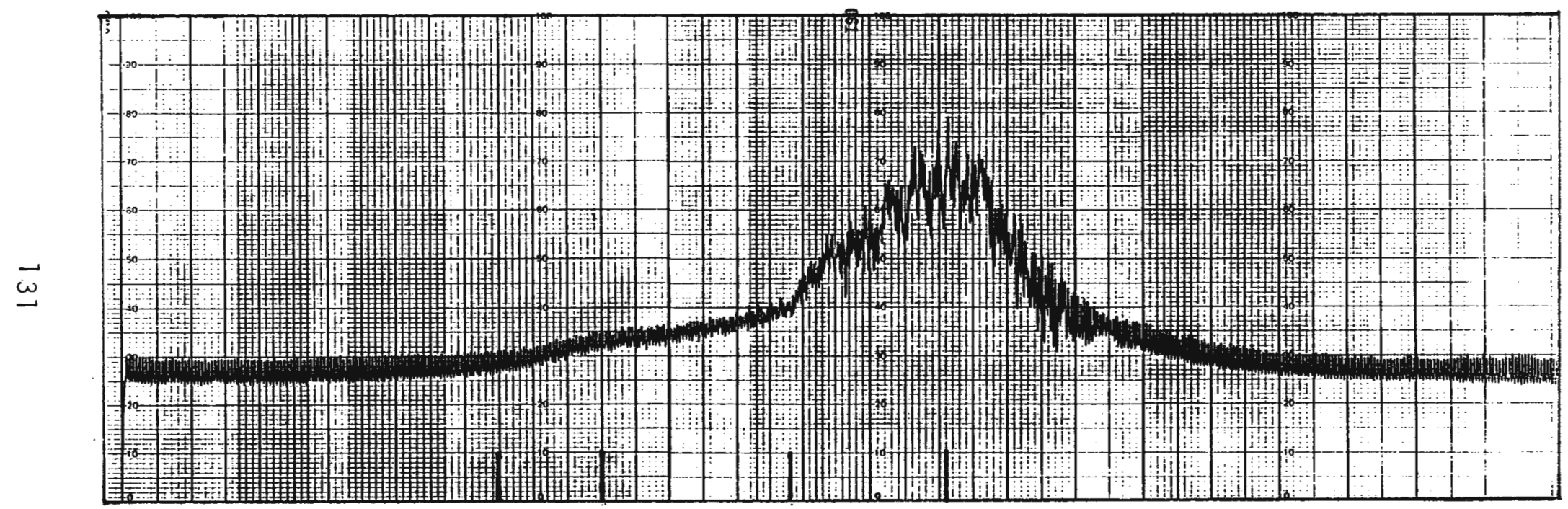
0

TIME (seconds) 


\section{FIGURE 48}

Hydrochlorothiazide formulations with mannitol or dicalcium phosphate matrix: Particle size distribution of phase 1 - 3 granulations

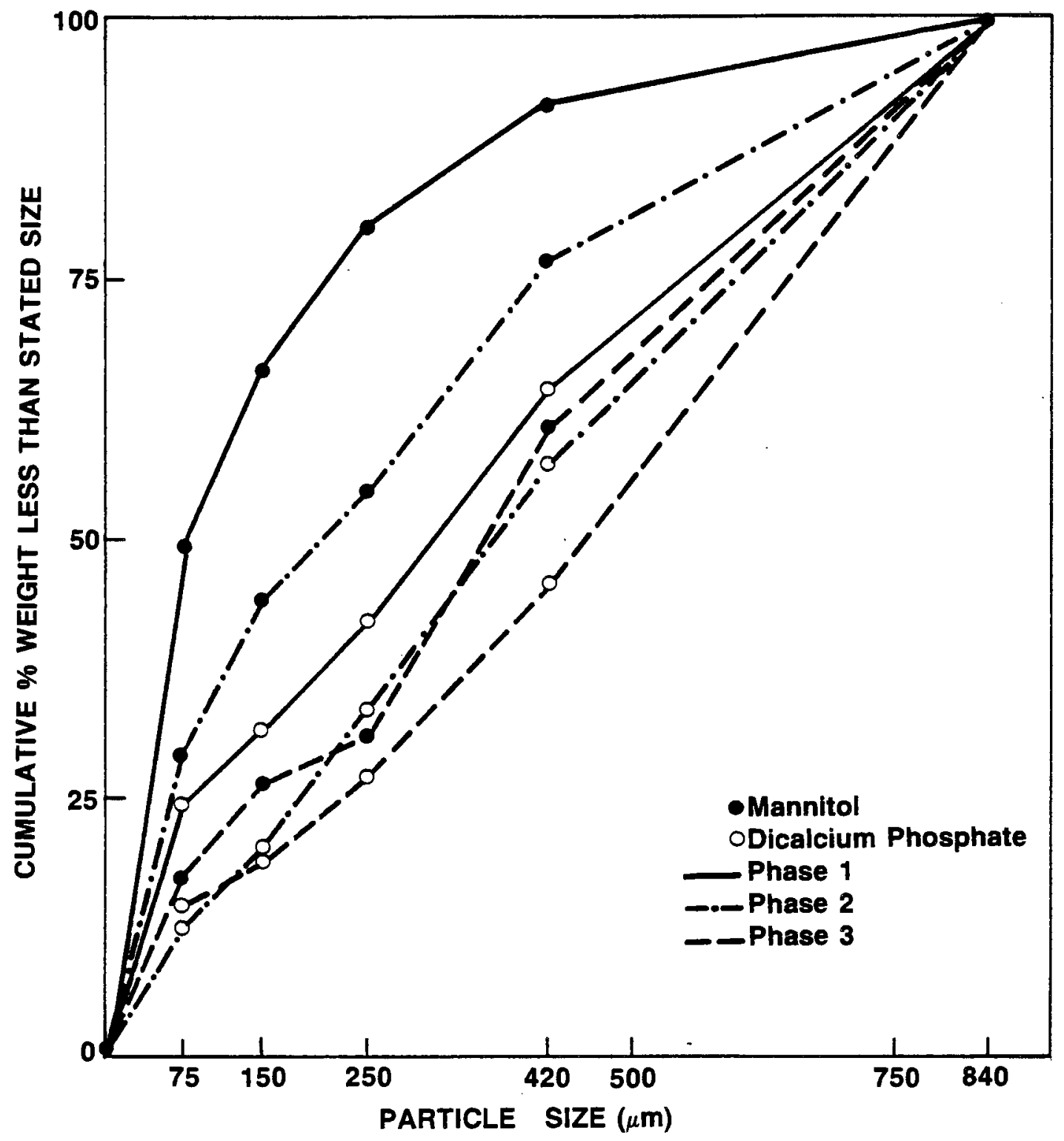




\section{FIGURE 49}

Hydrochlorothiazide formulations with mannitol or dicalcium phosphate matrix: Granulations flow profile

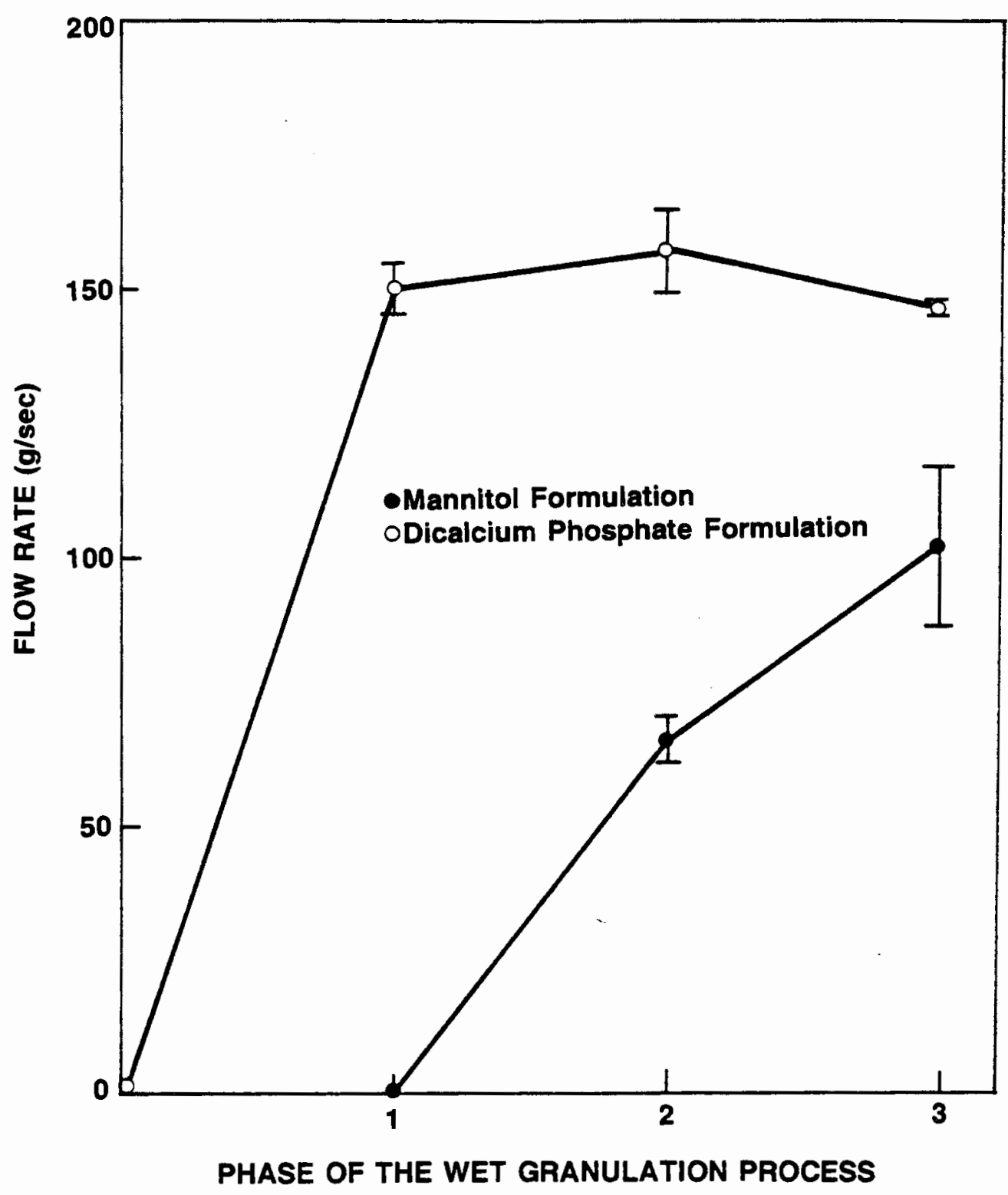




\section{FIGURE 50}

Hydrochlorothiazide formulations with mannitol or dicalcium phosphate matrix: Percent compressibility as a function of the wet granulation process

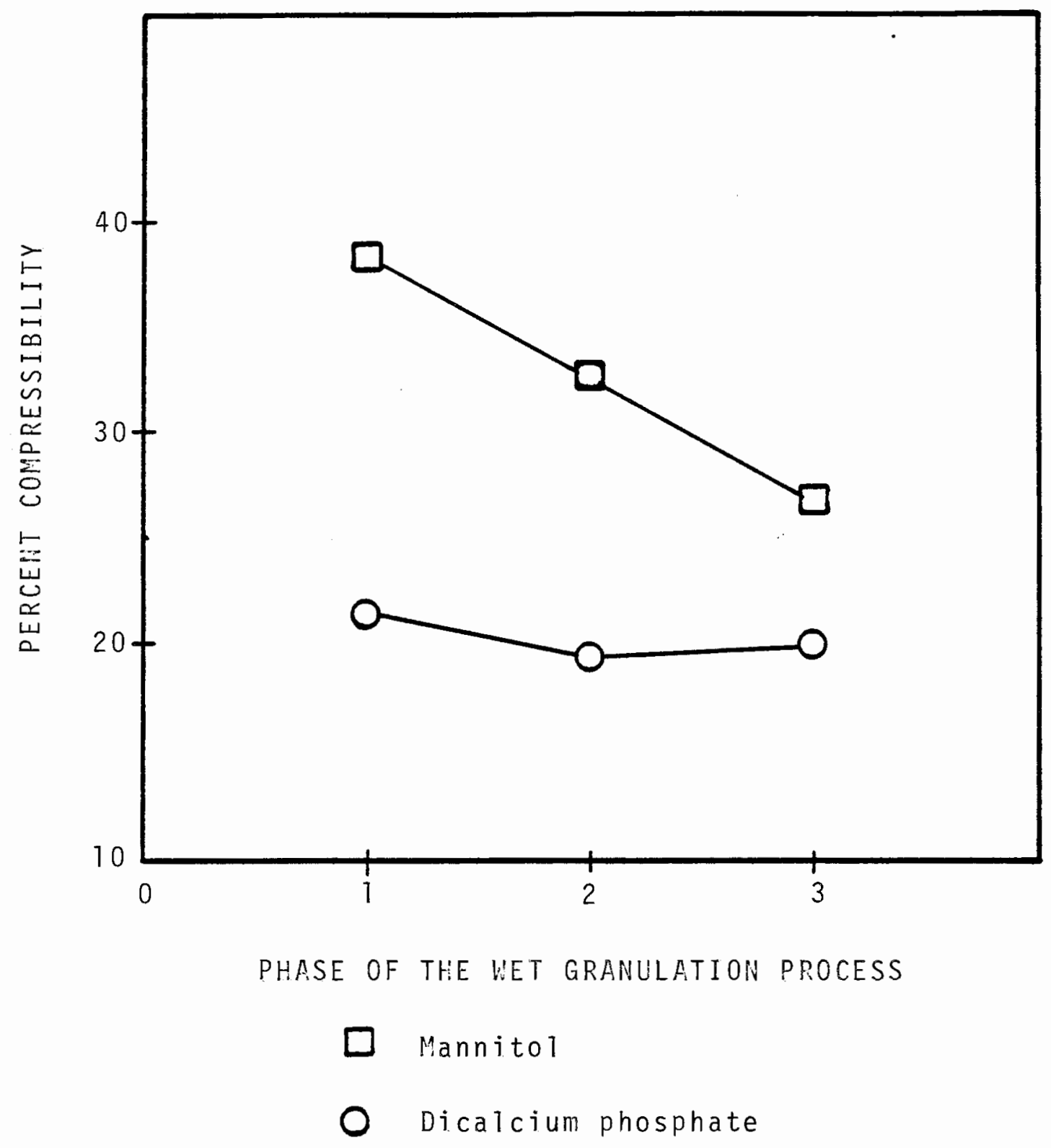


formulations with soluble or insoluble drug are recorded in the Table $X X X V$. The mannitol formulations needed a higher level (1.0\%) of magnesium stearate as lubricant to compress tablets. Due to the elastic nature of the mannitol matrix, satisfactory tablets were formed at a very narrow compressional force range. The tablets were capped at higher compressional force and softer tablets were produced below 2KN force. Because of the granulation density difference between mannitol and dicalcium phosphate matrices, tablets with different weights were manufactured using the same size tooling. Although, it is not possible to compare directly one tablet against the other, these tablet physical properties gave sufficient information to generalise the effects of the matrices on the granulation process. The dicalcium phosphate matrix produced significantly better flowable and compressible granulation than the mannitol matrix at every phase of the wet granulation process. The results of tablet dissolution (Table XXXV) show no significant difference between the formulations at every phase of the process.

Based on the data so far, (four different drugs with lactose matrix, hydrochlorothiazide with dicalcium phosphate and mannitol matrices) it can be seen granulations from phase II showed optimum flow and compression characteristics, irrespective of the concentration and solubility of drug, type of matrix and other physical properties of the starting materials. Some tablet properties such as hardness and disintegration are more sensitive than others (dissolution and friability) to changes in the processing variables. 
TABLE XXXV

Hydrochlorothiazide Formulations with Soluble or Insoluble Matrix

(Granule and Tablet Properties)

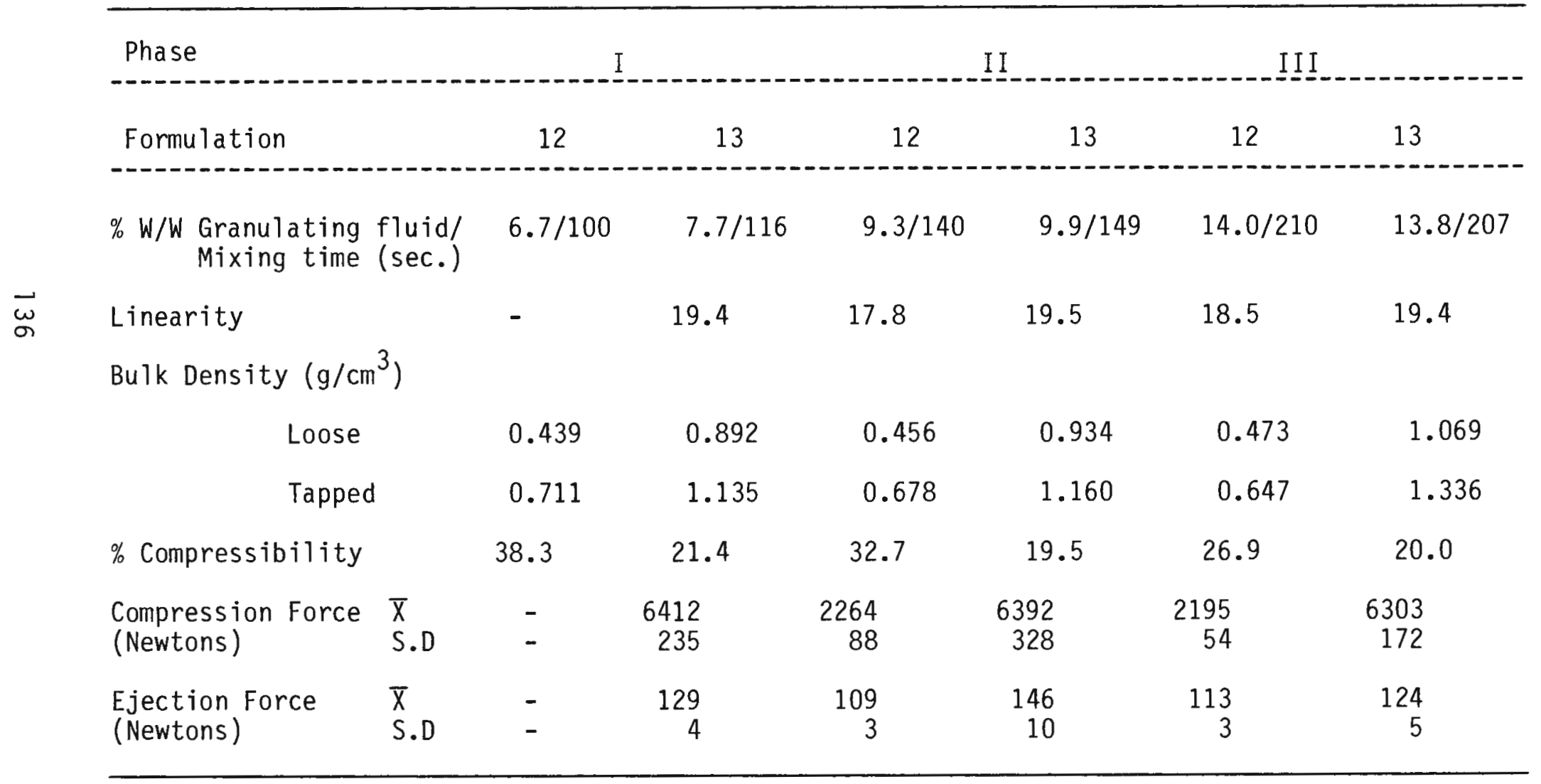


TABLE XXXV ----Continued

\begin{tabular}{|c|c|c|c|c|c|c|c|c|}
\hline \multicolumn{3}{|l|}{ Phase } & \multicolumn{2}{|c|}{ I } & \multicolumn{2}{|r|}{ II } & \multicolumn{2}{|c|}{ I I I } \\
\hline \multicolumn{3}{|c|}{ Formulation } & 12 & 13 & 12 & 13 & 12 & 13 \\
\hline \multicolumn{2}{|c|}{ Weight (mg) } & $\begin{array}{l}\bar{X} \\
\text { S.D }\end{array}$ & - & $\begin{array}{r}165.0 \\
2.9\end{array}$ & $\begin{array}{r}141.4 \\
2.4\end{array}$ & $\begin{array}{r}167.0 \\
3.5\end{array}$ & $\begin{array}{r}141.2 \\
2.0\end{array}$ & $\begin{array}{r}165.4 \\
3.8\end{array}$ \\
\hline \multicolumn{2}{|c|}{ Hardness (kg) } & $\begin{array}{l}\bar{X} \\
\text { S.D }\end{array}$ & - & $\begin{array}{l}5.3 \\
0.6\end{array}$ & $\begin{array}{l}3.6 \\
0.6\end{array}$ & $\begin{array}{l}6.2 \\
0.6\end{array}$ & $\begin{array}{l}3.2 \\
0.4\end{array}$ & $\begin{array}{l}6.3 \\
0.5\end{array}$ \\
\hline \multicolumn{3}{|c|}{ Friability (\% loss) } & - & 0.06 & 0.18 & 0.09 & 0.18 & 0.48 \\
\hline \multicolumn{2}{|c|}{$\begin{array}{l}\text { Disintegration } \\
\text { (minutes) }\end{array}$} & $\begin{array}{l}\bar{X} \\
\text { S.D }\end{array}$ & - & $\begin{array}{r}10.92 \\
0.59\end{array}$ & $\begin{array}{l}6.92 \\
0.50\end{array}$ & $\begin{array}{r}13.67 \\
0.52\end{array}$ & $\begin{array}{l}8.42 \\
0.41\end{array}$ & $\begin{array}{r}16.92 \\
0.26\end{array}$ \\
\hline \multicolumn{4}{|c|}{ Dissolution } & \multicolumn{4}{|c|}{ Percent drug dissolved } & \\
\hline \multirow[t]{3}{*}{ minutes } & 15 & $\begin{array}{l}\bar{X} \\
\text { S.D }\end{array}$ & - & $\begin{array}{r}92.75 \\
1.42\end{array}$ & $\begin{array}{r}92.72 \\
2.29\end{array}$ & $\begin{array}{r}90.84 \\
2.31\end{array}$ & $\begin{array}{r}91.90 \\
2.13\end{array}$ & $\begin{array}{r}95.39 \\
1.45\end{array}$ \\
\hline & 30 & & - & $\begin{array}{r}97.53 \\
0.46\end{array}$ & $\begin{array}{r}100.81 \\
2.15\end{array}$ & $\begin{array}{r}97.98 \\
1.31\end{array}$ & $\begin{array}{r}101.01 \\
1.16\end{array}$ & $\begin{array}{r}99.09 \\
0.70\end{array}$ \\
\hline & 45 & & & $\begin{array}{r}98.10 \\
0.68\end{array}$ & $\begin{array}{r}101.40 \\
1.61\end{array}$ & $\begin{array}{r}99.44 \\
0.79\end{array}$ & $\begin{array}{r}102.00 \\
0.82\end{array}$ & $\begin{array}{r}99.28 \\
0.65\end{array}$ \\
\hline
\end{tabular}


Based on this information, phase III was selected as an end point. The author then designed two factorial experiments, details of which are given below.

A factorial design is shown in Figure $51^{*}$. This experimental design was used to study the effect of type of binder, binder concentration and the type of granulation fluid $(3 \times 2 \times 3)$ on the wet granulation process. Tables VIII and IX show the independent variables and the factor level in experimental units. Granulating fluid / mixing time needed to reach the terminal portion of phase III of the experiments is seen in Table $X X X V 1$. These data show that the higher level of povidone in the formulation required the lower amount of granulation fluid, for phase III wet granulation process. In the case of Methocel and Klucel, there is no general conclusion can be drawn, based on these data.

Particle size distributions of granulations from these experiments showed (Table XXXVII-XXXIX) that an increase in mean particle size was seen with the increase of binder level in the formulation. A General Linear Model was used to analyze the data using the SAS package. Binder, binder level and granulating fluid exerted statistically significant ( $P$ $0.05)$ effects on the flow properties of granulations, ejection force, hardness, disintegration time and dissolution at fifteen minutes and thirty minutes. In addition, that can be drawn all two-way and the single three-way interactions were significant.

\footnotetext{
* The author gratefully acknowledges help from Dr. W.D. Lawing in design of the study and interpretation of results.
} 


\section{FIGURE 51}

Experimental design I: Factorial design

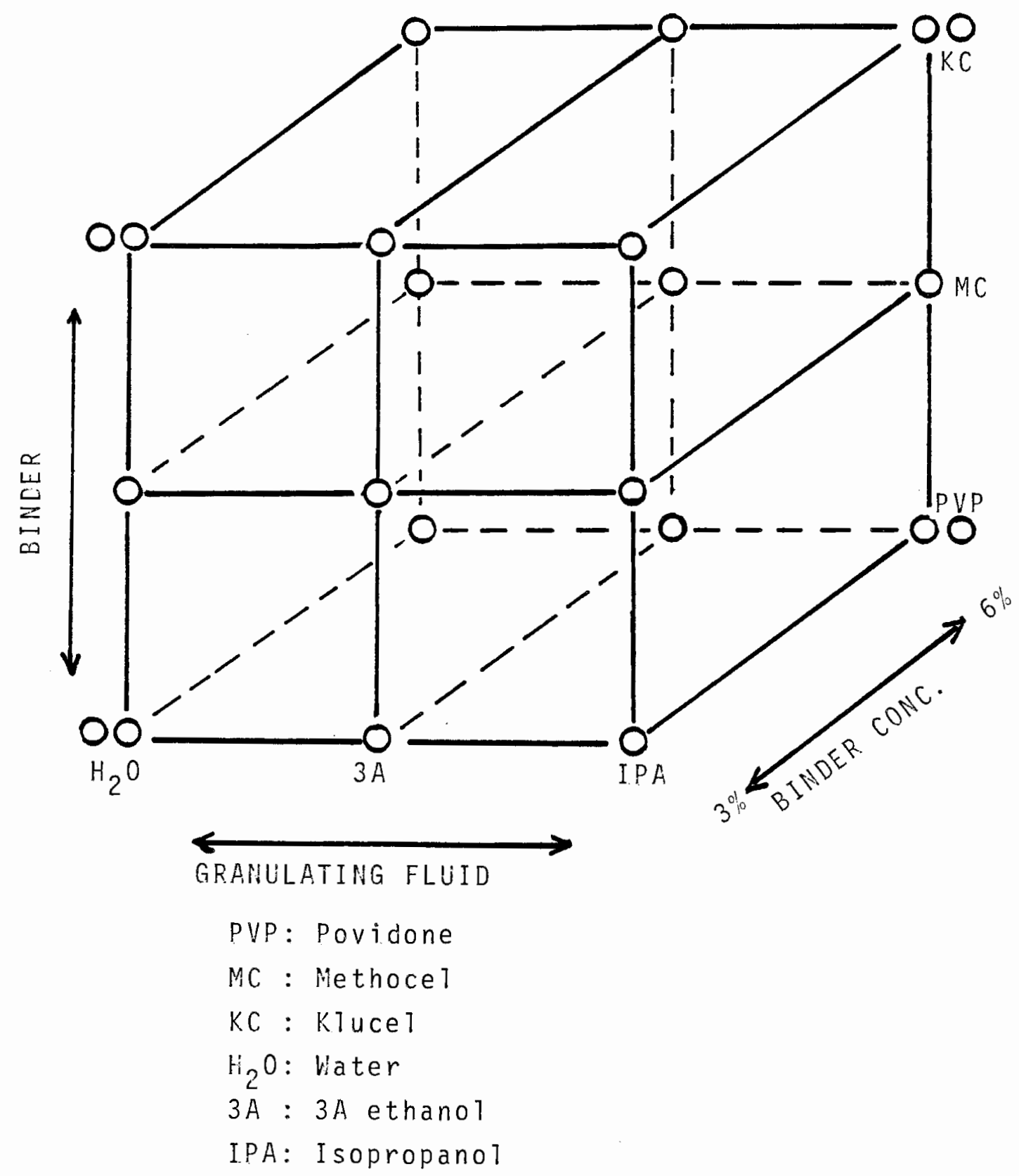


TABLE XXXVI

Experimental Design I : \% W/W Granulating Fluid / Mixing Time (Seconds)

\begin{tabular}{|c|c|c|c|c|c|c|}
\hline & \multicolumn{2}{|c|}{ Povidone } & \multicolumn{2}{|c|}{ Methoce 1} & \multicolumn{2}{|c|}{ K1uce 1} \\
\hline & $3 \%$ & $6 \%$ & $3 \%$ & $6 \%$ & $3 \%$ & $6 \%$ \\
\hline Water & $\begin{array}{l}14.1 / 358 \\
14.1 / 358\end{array}$ & $12.5 / 320$ & $18.5 / 464$ & $19.7 / 493$ & $\begin{array}{l}16.7 / 421 \\
16.7 / 421\end{array}$ & $12.5 / 320$ \\
\hline $3 A$ ethanol & $14.5 / 368$ & $12.2 / 313$ & $27.1 / 672$ & $20.1 / 502$ & $16.0 / 404$ & $16.4 / 414$ \\
\hline I sopropanol & $14.5 / 368$ & $\begin{array}{l}12.5 / 320 \\
12.5 / 320\end{array}$ & $18.0 / 452$ & $23.2 / 577$ & $17.8 / 447$ & $\begin{array}{l}20.4 / 510 \\
20.4 / 510\end{array}$ \\
\hline
\end{tabular}




\section{TABLE XXXVII}

Experimental Design I

Percent Particle Size Distribution of Hydrochlorothiazide Granulations

Granulating Fluid: Water

\begin{tabular}{rrrrrrr}
\hline & \multicolumn{2}{c}{ Povidone } & \multicolumn{2}{c}{ Methocel } & \multicolumn{2}{c}{ K1uce l } \\
Size $(\mu \mathrm{m})$ & $3 \%$ & $6 \%$ & $3 \%$ & $6 \%$ & $3 \%$ & $6 \%$ \\
\hline $0-74$ & 17.9 & 7.9 & 17.8 & 9.2 & 15.8 & 8.2 \\
$74-105$ & 3.5 & 1.7 & 3.1 & 1.8 & 2.6 & 3.1 \\
$105-149$ & 6.0 & 2.6 & 3.7 & 2.5 & 3.9 & 4.9 \\
$149-250$ & 14.6 & 8.3 & 8.1 & 7.4 & 10.5 & 12.8 \\
$250-420$ & 22.1 & 25.1 & 18.0 & 21.7 & 23.4 & 25.7 \\
$420-840$ & 35.4 & 53.7 & 48.4 & 57.1 & 43.5 & 44.9 \\
$840-1000$ & 0.5 & 0.8 & 0.9 & 0.2 & 0.3 & 0.4 \\
\hline
\end{tabular}


TABLE XXXVIII

Experimental Design I

Percent Particle Size Distribution of Hydrochlorothiazide Granulations Granulation Fluid: $3 A$ Denatured alcohol

\begin{tabular}{rrrrrrr}
\hline & \multicolumn{2}{c}{ Povidone } & \multicolumn{2}{c}{ Methocel } & \multicolumn{2}{c}{ K1ucel } \\
Size $(\mu \mathrm{m})$ & $3 \%$ & $6 \%$ & $3 \%$ & $6 \%$ & $3 \%$ & $6 \%$ \\
\hline $0-74$ & 16.9 & 13.2 & 58.9 & 56.1 & 14.2 & 10.6 \\
$74-105$ & 2.2 & 2.7 & 6.0 & 15.0 & 2.8 & 2.7 \\
$105-149$ & 3.3 & 3.3 & 4.6 & 10.4 & 3.4 & 3.3 \\
$149-250$ & 9.3 & 7.2 & 7.8 & 8.3 & 9.2 & 8.1 \\
$250-420$ & 25.1 & 19.9 & 13.1 & 7.0 & 22.2 & 20.9 \\
$420-840$ & 42.7 & 51.7 & 9.4 & 3.3 & 47.9 & 53.7 \\
$840-1000$ & 0.4 & 2.0 & 0.1 & 0.0 & 0.3 & 0.8 \\
\hline
\end{tabular}


TABLE XXXIX

Experimental Design I

Percent Particle Size Distribution of Hydrochlorothiazide Granulations Granulation fluid: Isopropanol

\begin{tabular}{rrrrrrr}
\hline & \multicolumn{2}{c}{ Povidone } & \multicolumn{2}{c}{ Methocel } & \multicolumn{2}{c}{ Kluce 1 } \\
Size $(\mu \mathrm{m})$ & $3 \%$ & $6 \%$ & $3 \%$ & $6 \%$ & $3 \%$ & $6 \%$ \\
\hline $0-74$ & 12.7 & 9.5 & 66.5 & 66.5 & 20.1 & 18.8 \\
$74-105$ & 2.9 & 1.9 & 15.1 & 12.9 & 2.8 & 4.1 \\
$105-149$ & 4.8 & 2.4 & 7.3 & 9.4 & 3.2 & 4.5 \\
$149-250$ & 15.6 & 7.6 & 8.8 & 8.1 & 7.3 & 9.5 \\
$250-420$ & 30.2 & 23.5 & 1.9 & 2.6 & 18.2 & 20.8 \\
$420-840$ & 33.6 & 54.4 & 0.4 & 0.5 & 47.9 & 40.3 \\
$840-1000$ & 0.2 & 0.7 & 0.0 & 0.0 & 0.4 & 1.9 \\
\hline
\end{tabular}


The results are shown in tables XL thru L. Formulations containing methocel produced unsatisfactory granules when granulated with $3 \mathrm{~A}$ ethanol and isopropanol. Binders at six percent level in the formulations produced significantly better flowable and compressible granulations compared to three percent level (Fig. 52). Percentage compressibility data calculated from bulk density data supported powder flow measurements obtained using Recording Powder Flowmeter. Tablets were compressed by setting tablet weight at $135 \mathrm{mg}$ and compression force at $6 \mathrm{KN}$. The higher level of binder in formulations was reflected in lower ejection force in the tablet operation. Compression and ejection profiles are seen in Figures 53 thru 70. Granulations prepared with povidone or Klucel as binder, $3 \mathrm{~A}$ ethanol or isopropanol as granulating fluid produced harder tablets compared to the granulations made with water as granulating fluid. Ejection profiles showed that the higher the binder level in formulation at higher compressional forces, the lower ejection force was needed to eject the tablets out of the die. At lower compressional forces no significant difference in ejection force was seen. This property can be attributed to the lower elastic recovery of tablets compressed with higher compressional forces. Although, these formulations contained two percent disintegrant (AC-Di-Sol), tablet disintegration (Table XLVII) seem to be slower with the tablets containing higher level binders. Tablet dissolution data are recorded in tables XLV111 thru L. A11 the factors exerted statistically significant effects on dissolution at fifteen and thirty minutes, but these effects are probably not practically important in production. The dissolution 


\section{FIGURE 52}

Experimental design I: Granulation flow profile

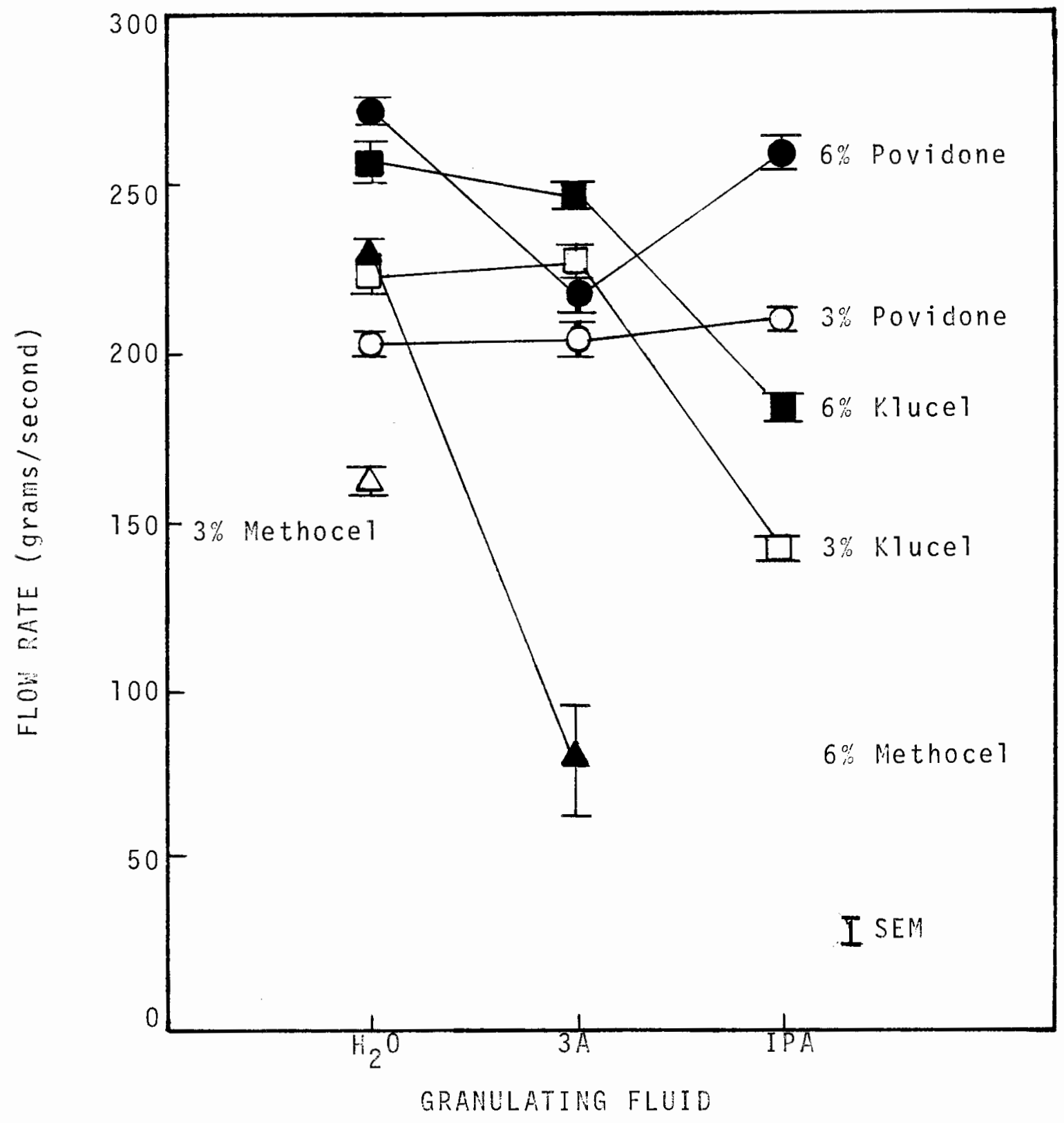




\section{FIGURE 53}

Experimental design I: Compression profile: $3 \%$ Povidone

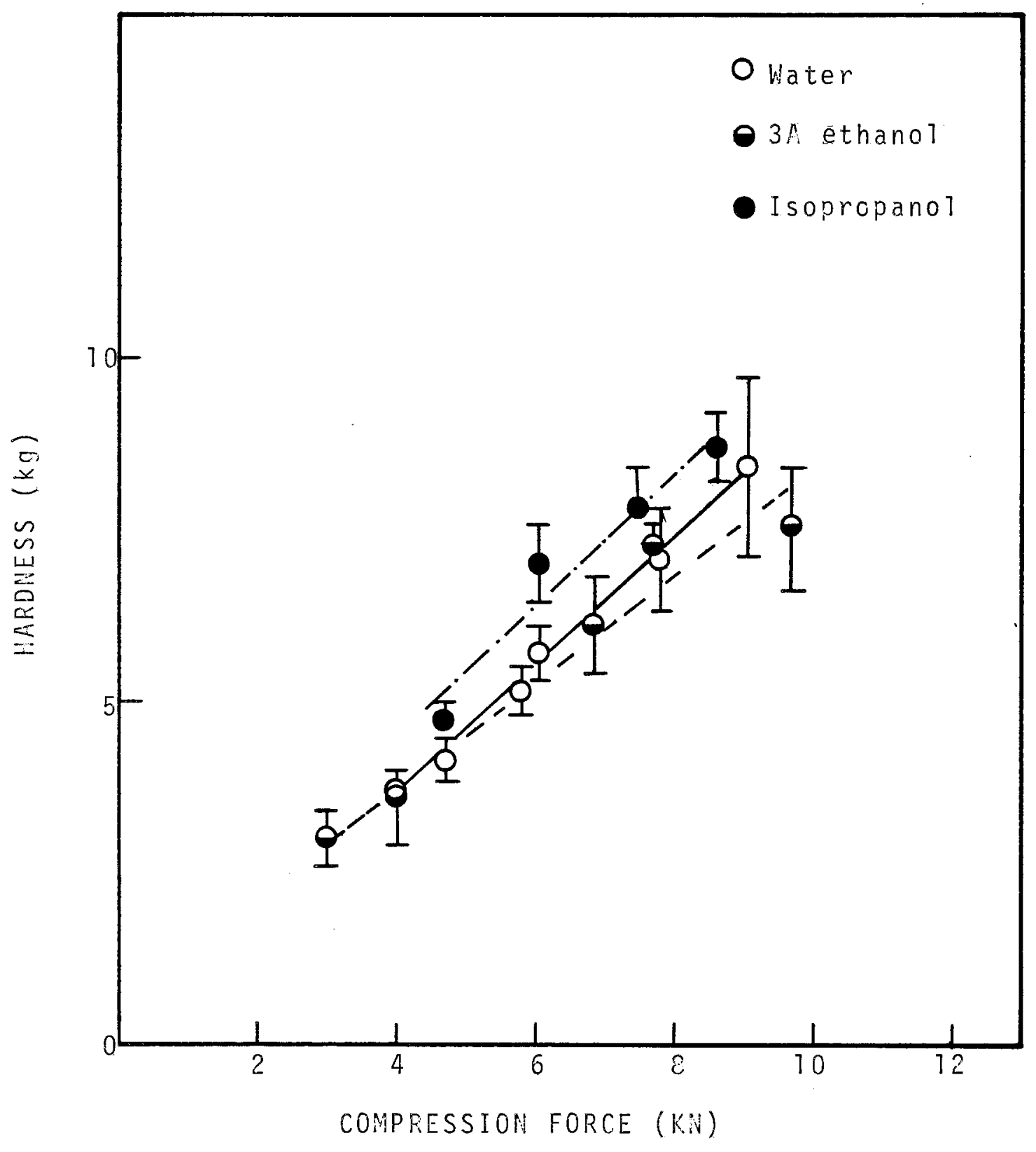




\section{FIGURE 54}

Experimental design I: Compression profile: $6 \%$ Povidone

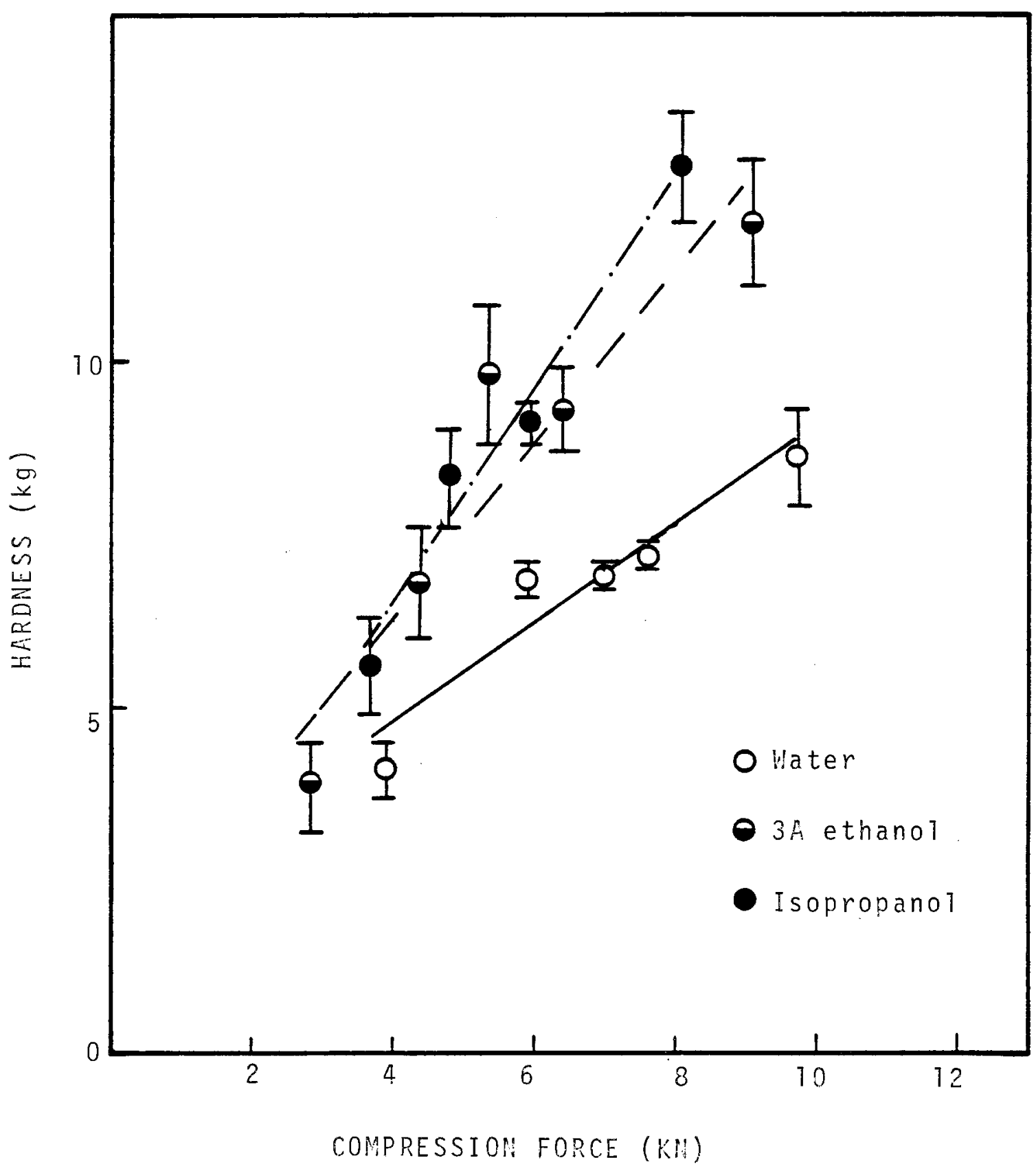




\section{FIGURE 55}

Experimental design I : Compression profile: $6 \%$ Methocel






\section{FIGURE 56}

Experimental ciesign İ: Compression profile: $3 \%$ Klucel

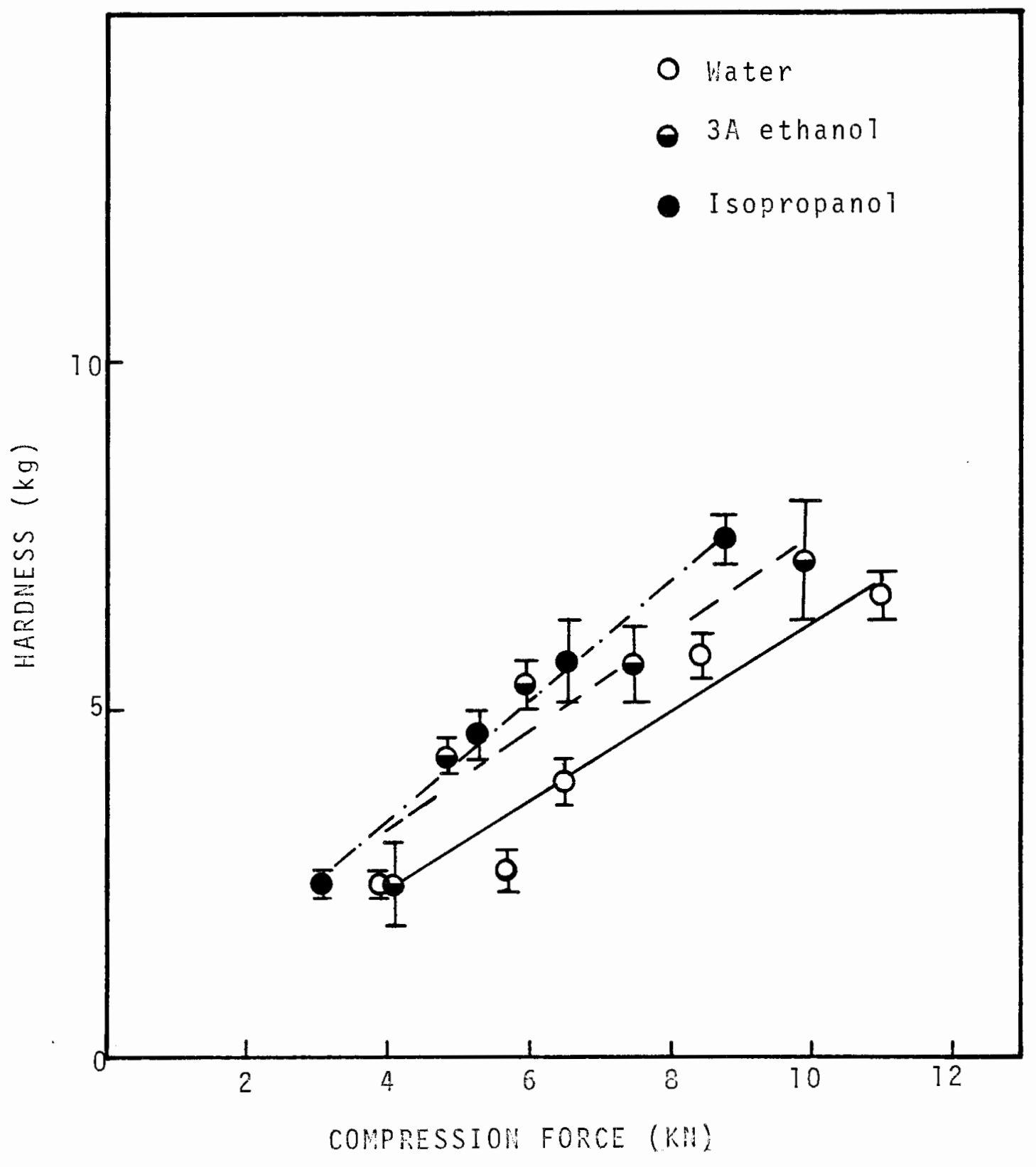


FIGURE 57

Experimental design I: Compression profile: $6 \%$ KTuce 1

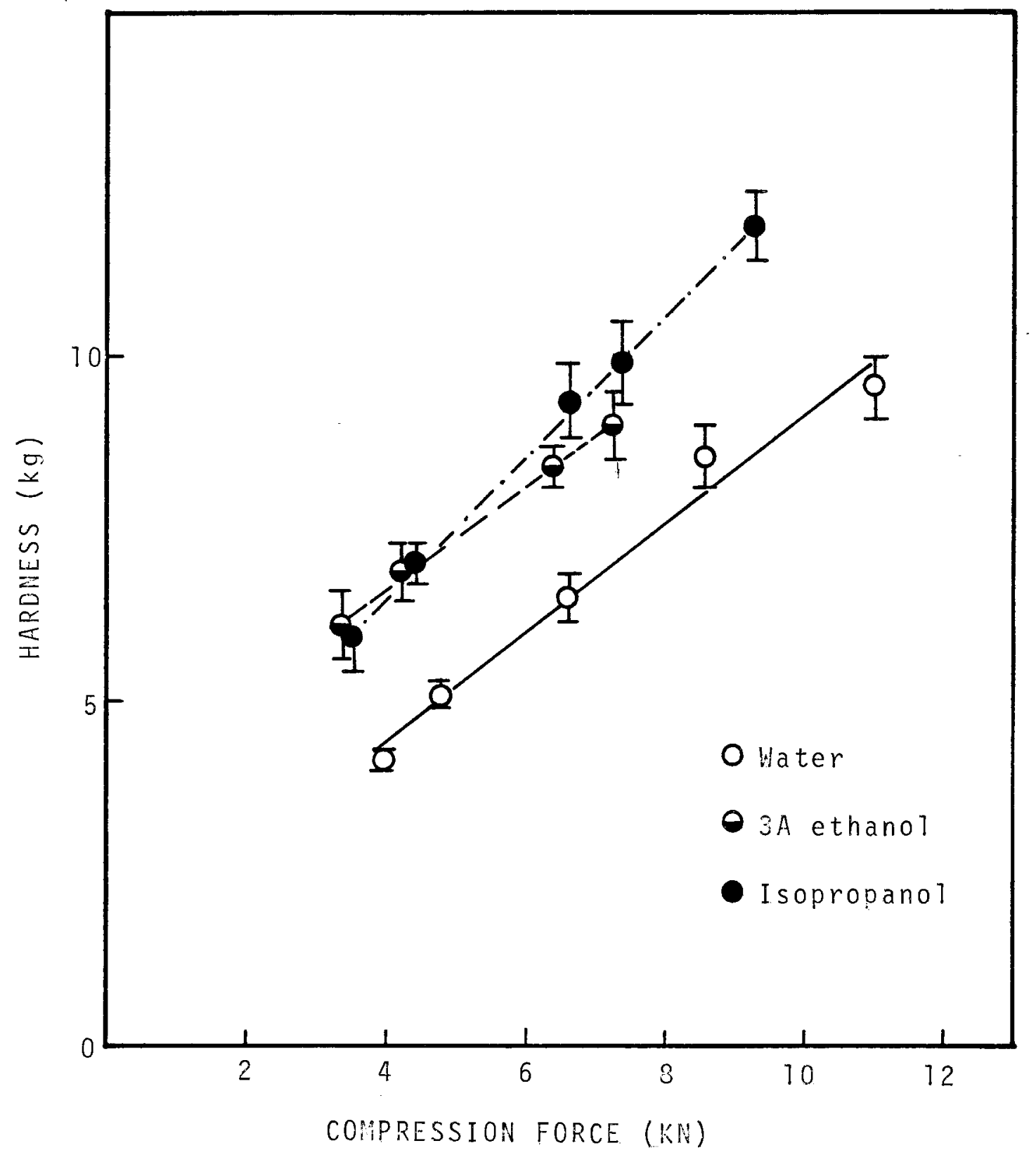


FIGURE 58

Experimental design I: Compression profile:

Water $w / 3 \%$ binders

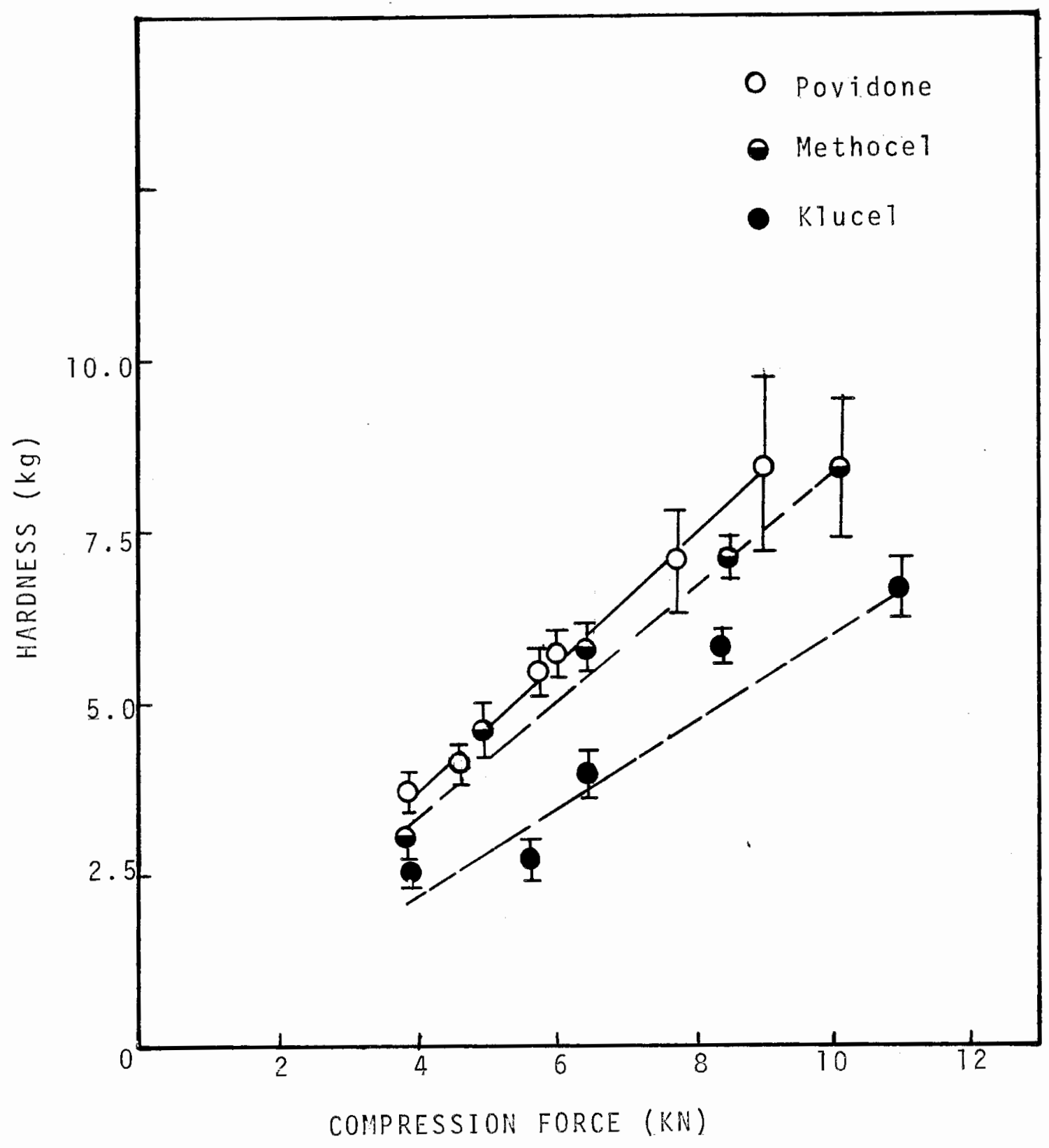


FIGURE 59

Experimental design I : Compression profile:

Water $w / 6 \%$ binders

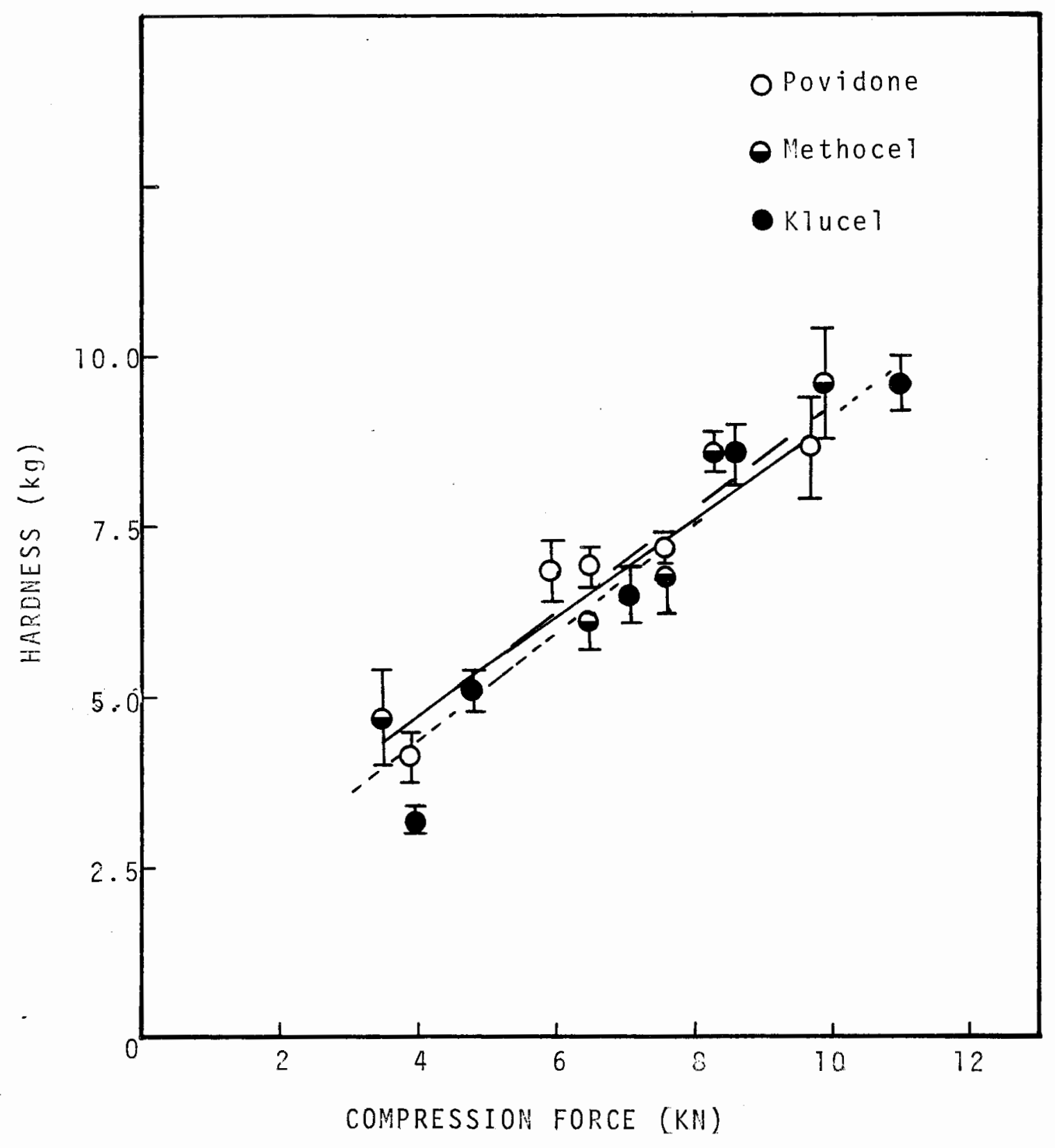




\section{FIGURE 60}

Experimental design I: Compression profile:

$3 \mathrm{~A}$ ethanol $\mathrm{W} / 3 \%$ binders

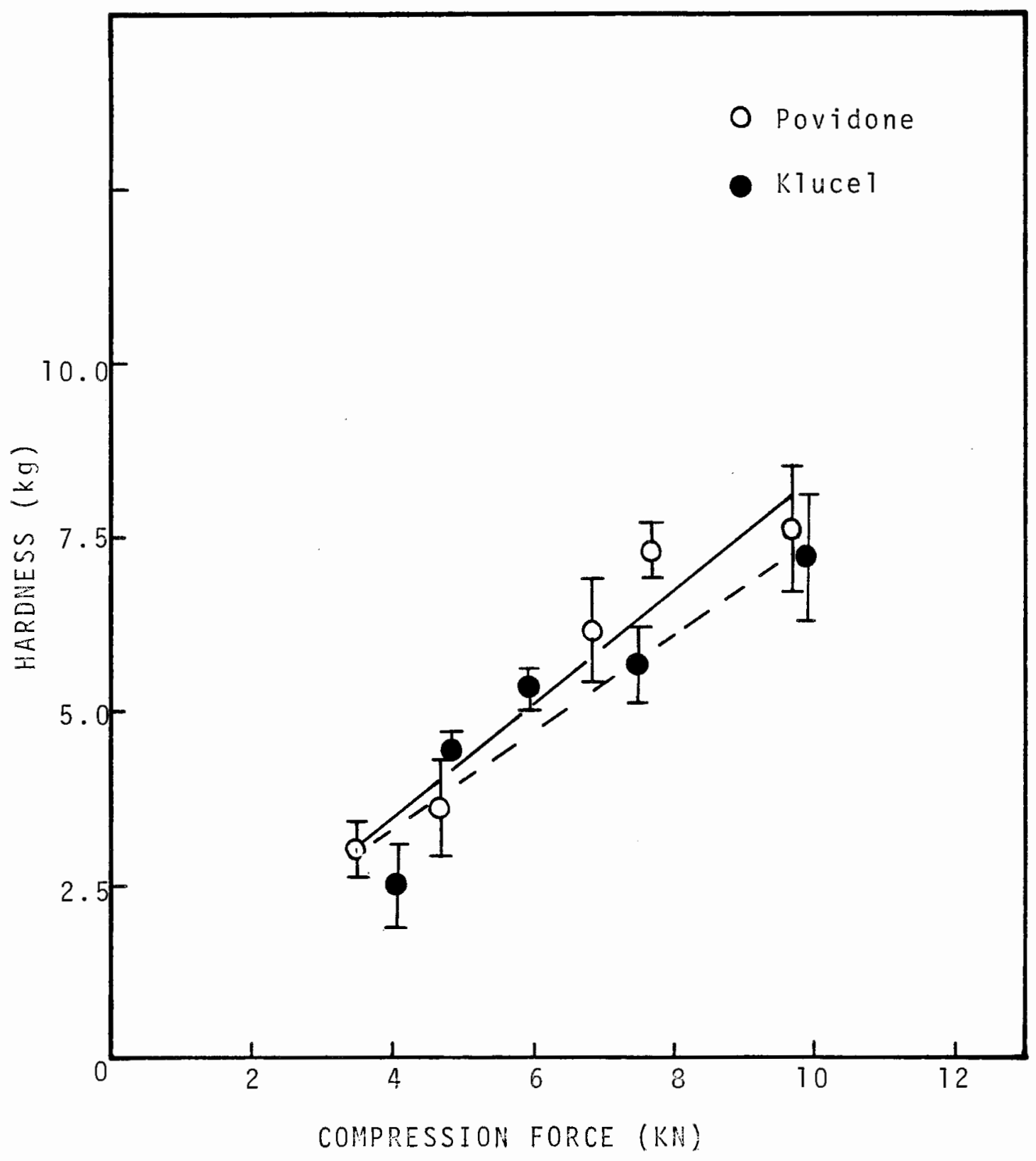




\section{FIGURE 61}

Experimental design I: Compression profile:

$3 \mathrm{~A}$ ethanol $\mathrm{W} / 6 \%$ binders

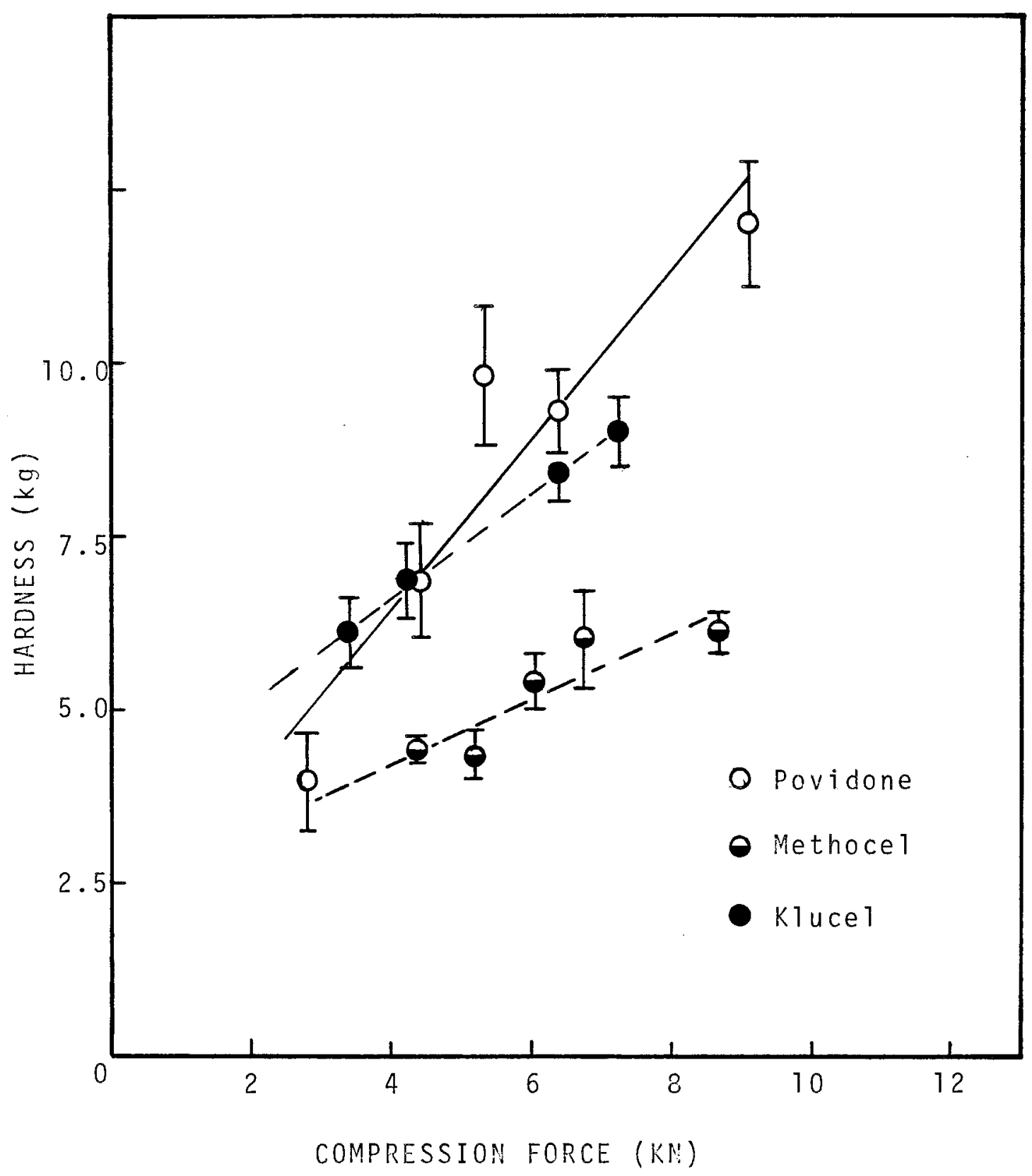


FIGURE 62

Experimental design I: Compression profile:

Isopropanol w/ 3\% binders

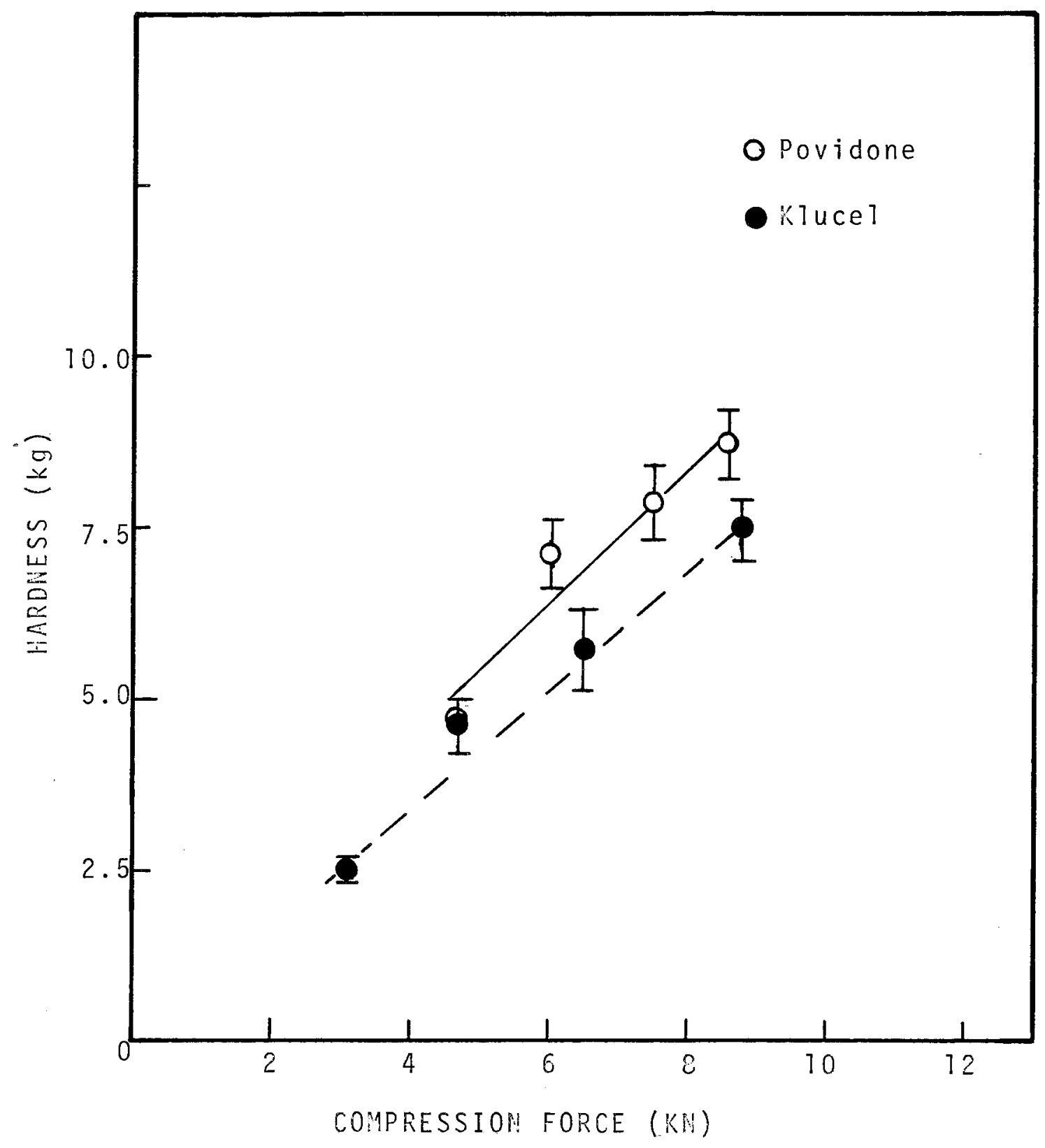


FIGURE 63

Experimental design I: Compression profile:

Isopropanol w/ 6\% binders

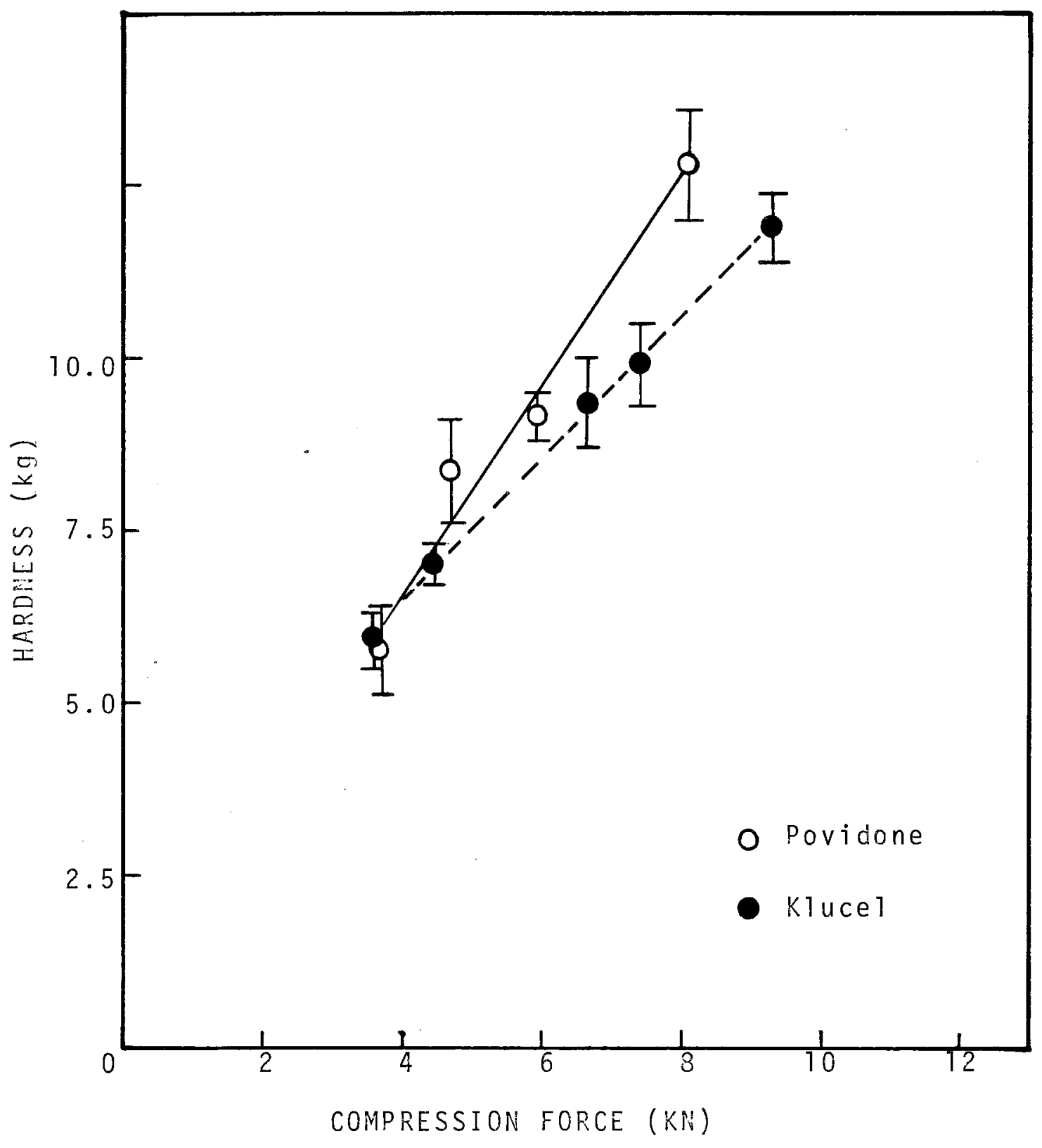


FIGURE 64

Experimental design I: Ejection profile:

Water / Povidone

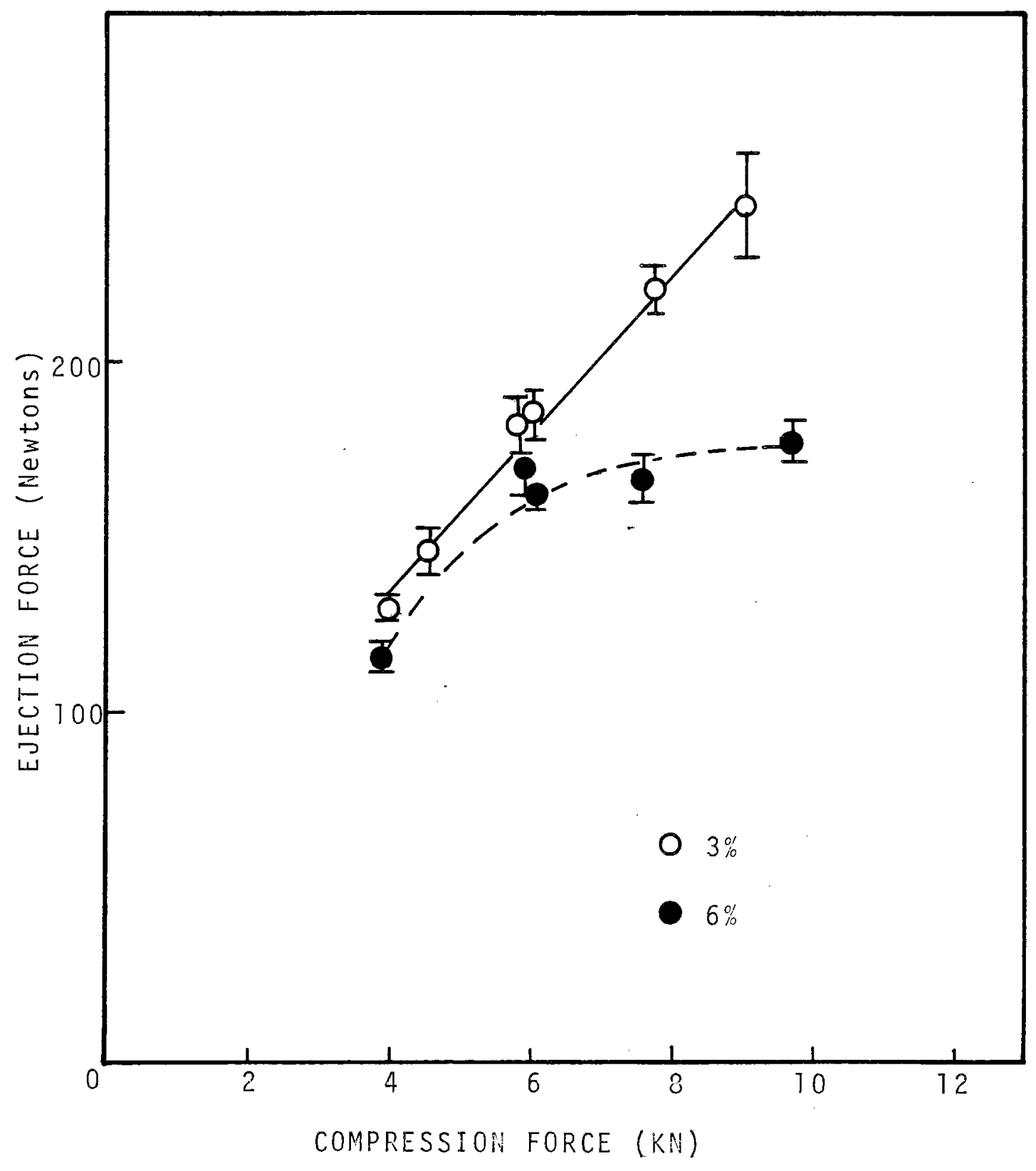




\section{FIGURE 65}

Experimental design I: Ejection profile:

Water / Methocel

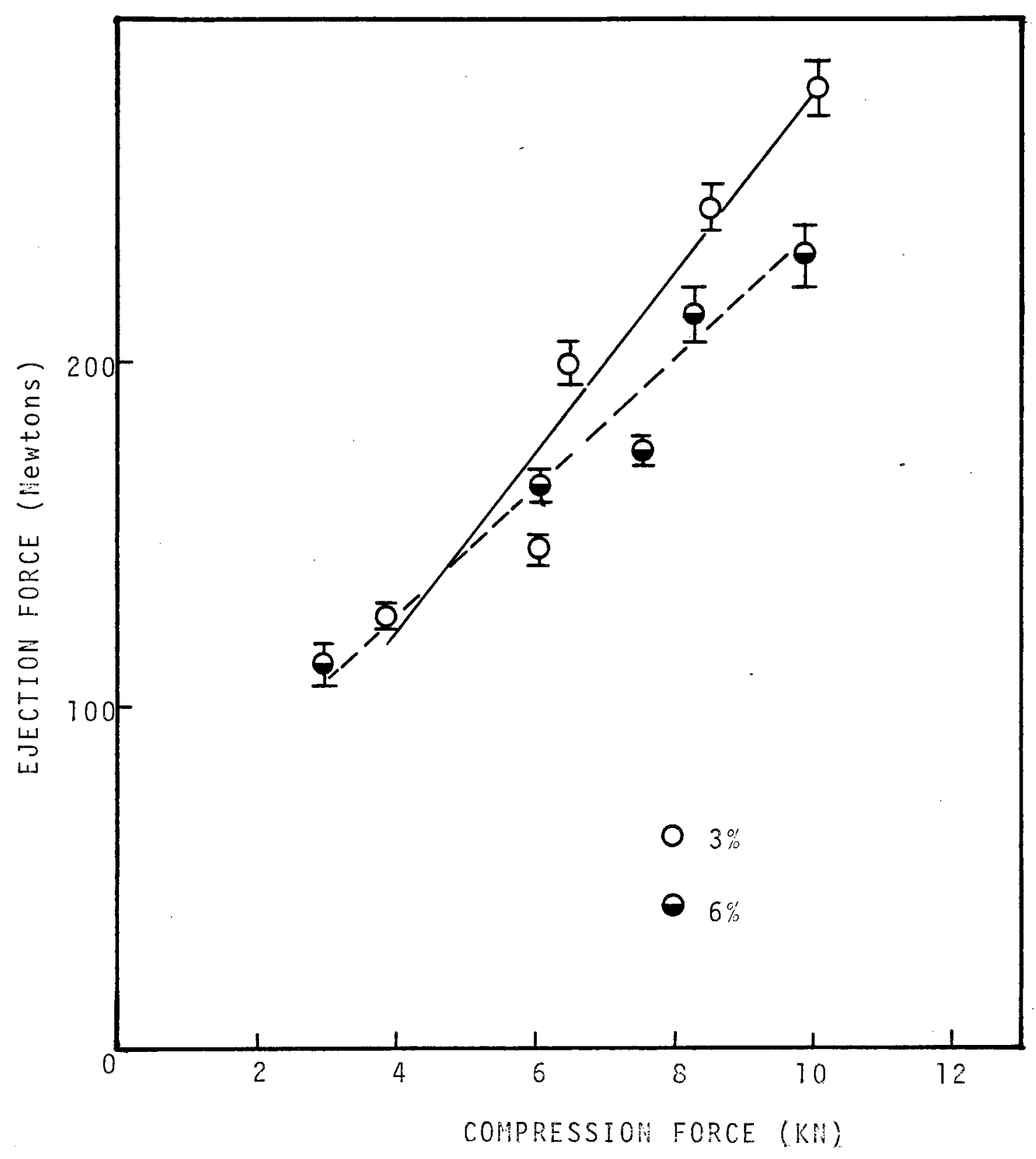




\section{FIGURE 66}

Experimental design I: Ejection profile:

Hater / K1ucel






\section{FIGURE 67}

Experimental design I: Ejection profile:

3 A ethanol / Povidone






\section{FIGURE 68}

Experimental design I: Ejection profile:

$3 \mathrm{~A}$ ethanol / Methocel or Klucel

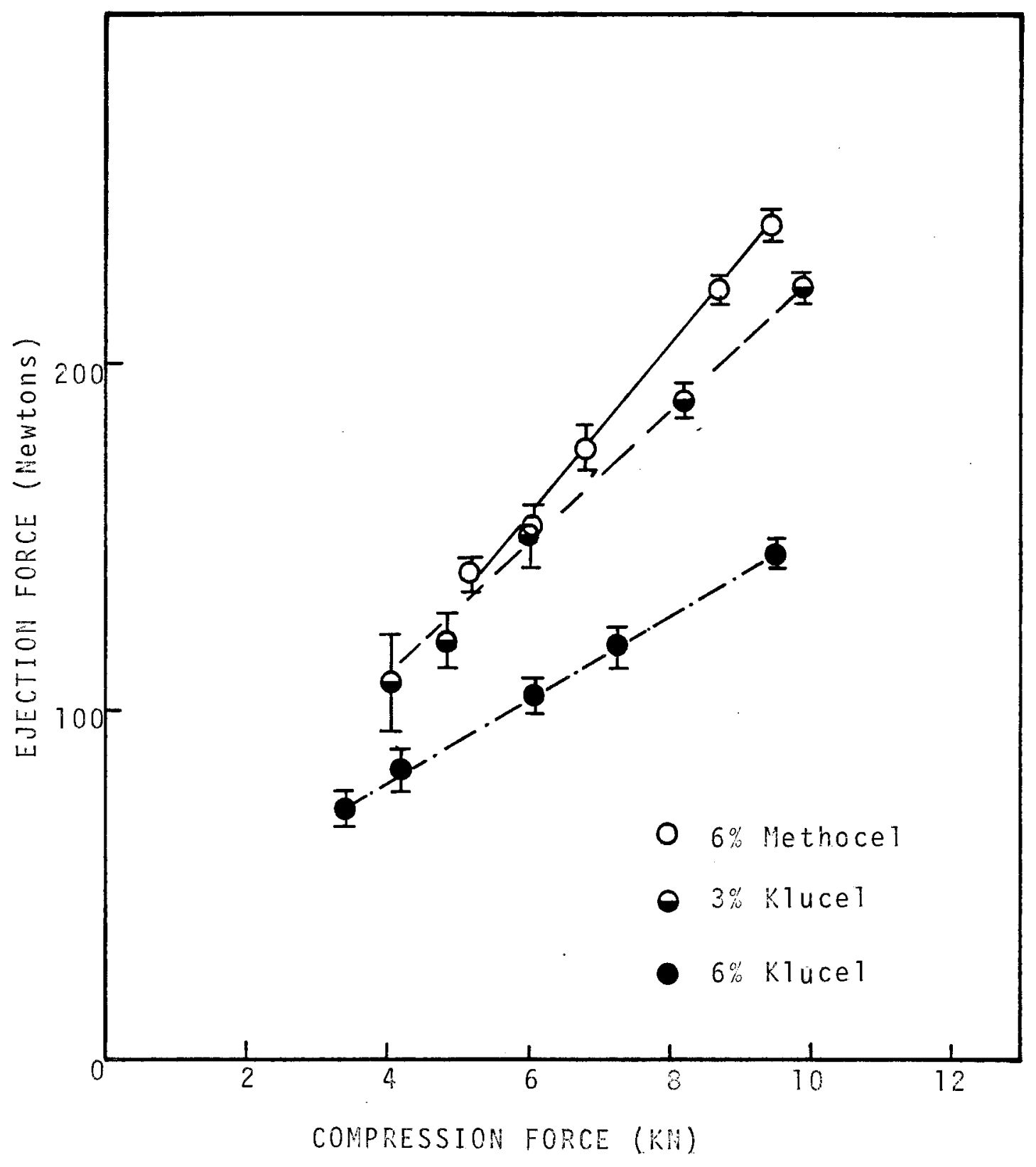




\section{FIGURE 69}

Experimental design I: Ejection profile:

Isopropanol / Povidione

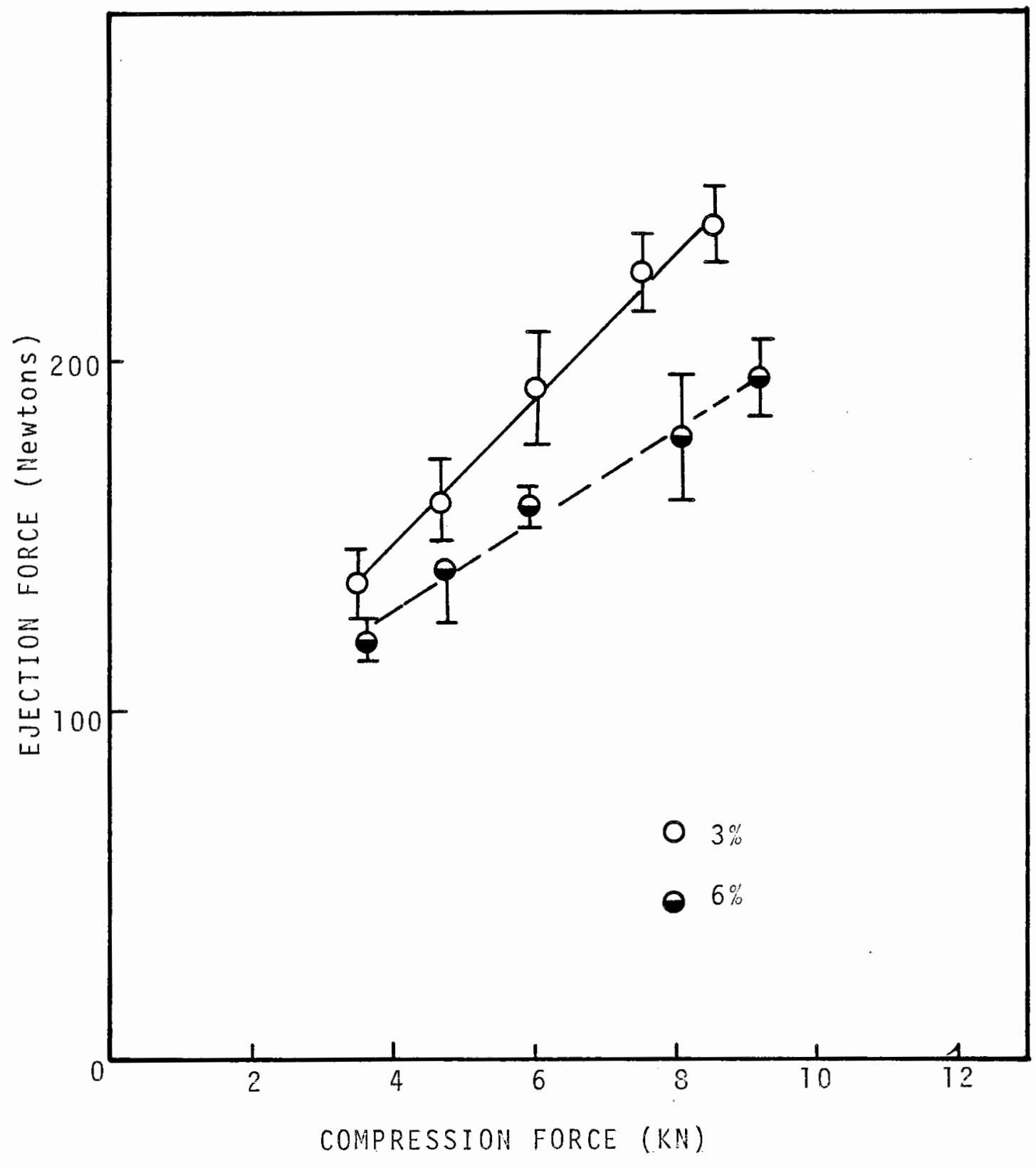


FIGURE 70

Experimental design I: Ejection profile:

Isopropanol / K1ucel

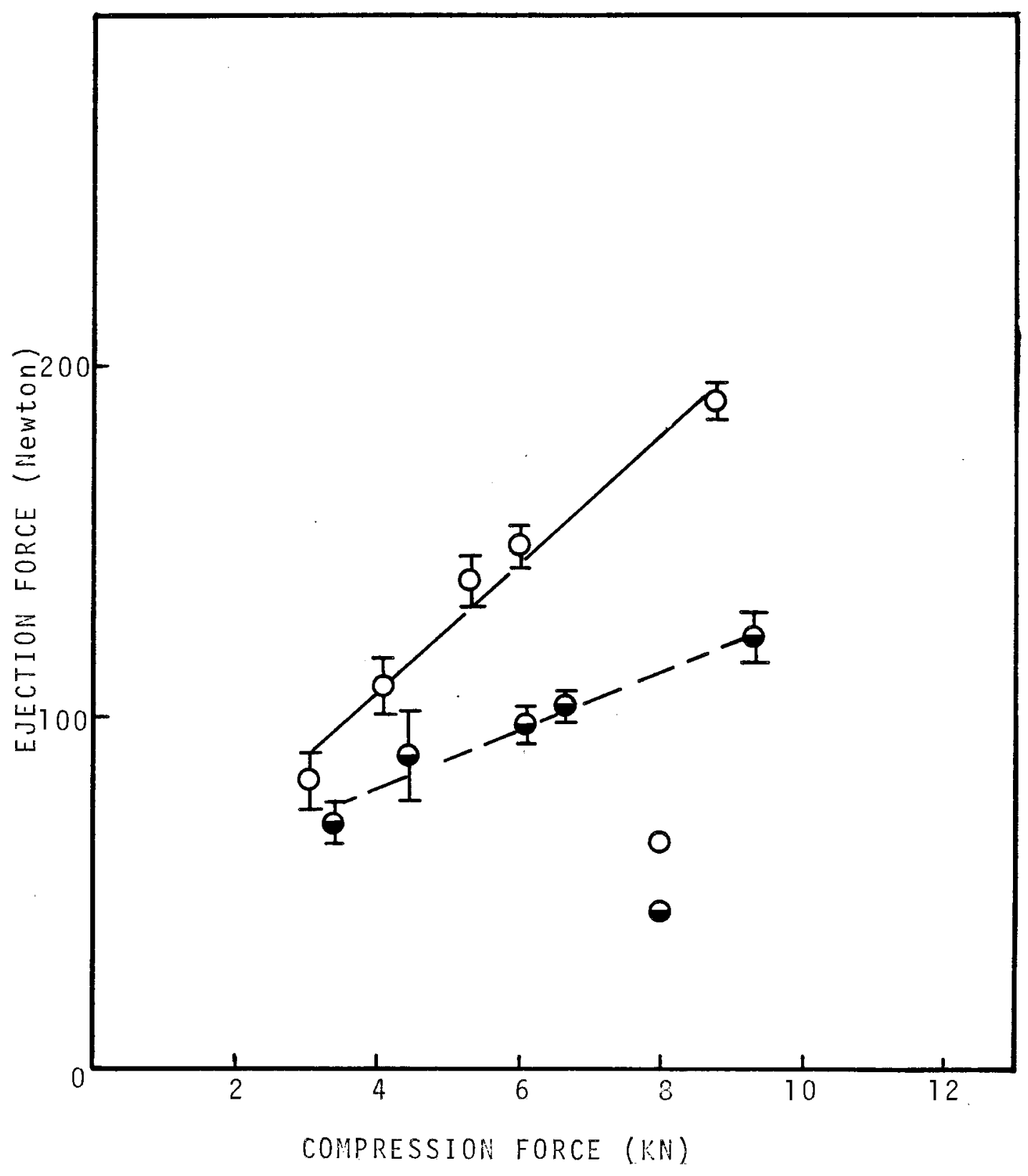


TABLE XL

Experimental Design I : Granulations Flow Rate (g/sec) $\bar{X}$ (S.D)

\begin{tabular}{|c|c|c|c|c|c|c|}
\hline & \multicolumn{2}{|c|}{ Povidone } & \multicolumn{2}{|c|}{ Methocel } & \multicolumn{2}{|c|}{ Klucel } \\
\hline & $3 \%$ & $6 \%$ & $3 \%$ & $6 \%$ & $3 \%$ & $6 \%$ \\
\hline Water & $\begin{array}{l}179.9(4.6) \\
205.6(6.8)\end{array}$ & $271.7(0.1)$ & $161.9(5.4)$ & $225.2(0.1)$ & $\begin{array}{l}225.6(7.7) \\
219.5(4.9)\end{array}$ & $254.9(6.6)$ \\
\hline $3 A$ ethanol & $203.8(8.7)$ & $217.5(4.7)$ & $B^{*}$ & $79.2(28.1)$ & $226.4(5.8)$ & $245.7(3.6)$ \\
\hline Isopropanol & $209.5(2.6)$ & $\begin{array}{l}266.8(10.9) \\
249.6(8.7)\end{array}$ & $B^{*}$ & $B^{*}$ & $141.5(2.0)$ & $\begin{array}{l}181.0 \\
185.2(3.3)\end{array}$ \\
\hline
\end{tabular}

$B^{*}=$ Blocked. 
TABLE XLI

Experimental Design I : Granulations Bulk Density: $\underset{\text { Tapped }}{\text { Loose }}\left(\mathrm{g} / \mathrm{cm}^{3}\right)$

\begin{tabular}{|c|c|c|c|c|c|c|}
\hline & \multicolumn{2}{|c|}{ Povidone } & \multicolumn{2}{|c|}{ Methocel } & \multicolumn{2}{|c|}{ Kluce 1} \\
\hline & $3 \%$ & $6 \%$ & $3 \%$ & $6 \%$ & $3 \%$ & $6 \%$ \\
\hline \multirow[t]{2}{*}{ water } & $\begin{array}{l}0.910 \\
1.094\end{array}$ & $\begin{array}{l}0.897 \\
1.096\end{array}$ & $\begin{array}{l}0.878 \\
1.066\end{array}$ & $\begin{array}{l}0.764 \\
0.928\end{array}$ & $\begin{array}{l}0.916 \\
1.082\end{array}$ & $\begin{array}{l}0.828 \\
0.991\end{array}$ \\
\hline & $\begin{array}{l}0.899 \\
1.099\end{array}$ & & & & $\begin{array}{l}0.910 \\
1.085\end{array}$ & \\
\hline $3 \mathrm{~A}$ ethanol & $\begin{array}{l}0.886 \\
1.057\end{array}$ & $\begin{array}{l}0.937 \\
1.108\end{array}$ & $\begin{array}{l}0.879 \\
1.326\end{array}$ & $\begin{array}{l}0.769 \\
1.066\end{array}$ & $\begin{array}{l}0.857 \\
1.040\end{array}$ & $\begin{array}{l}0.819 \\
0.962\end{array}$ \\
\hline \multirow[t]{2}{*}{ Isopropanol } & $\begin{array}{l}0.833 \\
0.979\end{array}$ & $\begin{array}{l}0.896 \\
1.038\end{array}$ & $\begin{array}{l}0.822 \\
1.173\end{array}$ & $\begin{array}{l}0.807 \\
1.146\end{array}$ & $\begin{array}{l}0.923 \\
1.126\end{array}$ & $\begin{array}{l}0.896 \\
1.068\end{array}$ \\
\hline & & $\begin{array}{l}0.898 \\
1.040\end{array}$ & & & & $\begin{array}{l}0.902 \\
1.071\end{array}$ \\
\hline
\end{tabular}


TABLE XLII

Experimental Design I: Percentage Compressibility of Granulations

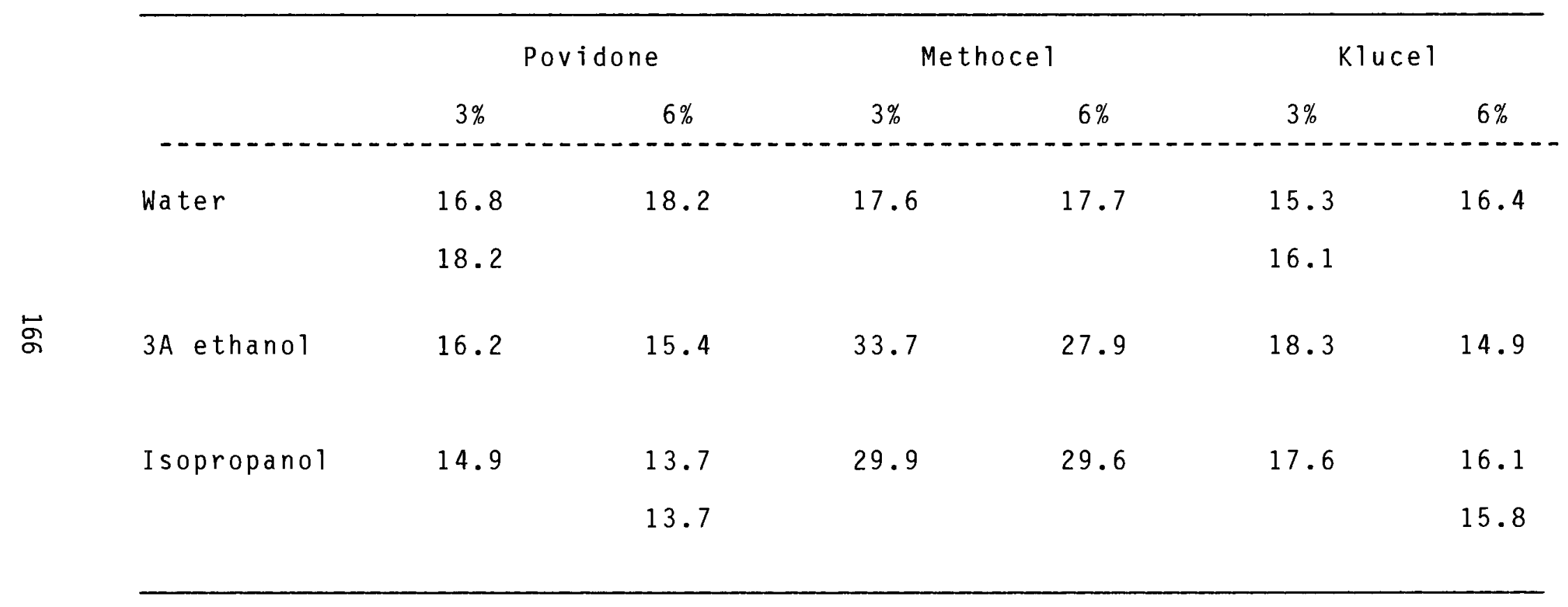


TABLE XLIII

Experimental Design I : Compression Force (Newtons) $\bar{X}$ (S.D)

\begin{tabular}{lllllll}
\hline & \multicolumn{2}{c}{ Povidone } & \multicolumn{2}{c}{ Methocel } & \multicolumn{2}{c}{ K1 ucel } \\
& $3 \%$ & $6 \%$ & $3 \%$ & $6 \%$ & $3 \%$ & $6 \%$ \\
Water & 6034 & 6059 & 6012 & 6092 & 6087 & 5963 \\
& $(171)$ & $(219)$ & $(249)$ & $(235)$ & $(213)$ & $(185)$ \\
3 3A ethanol & 6083 & 6029 & - & 6033 & 5950 & 6065 \\
& $(160)$ & $(279)$ & - & $(259)$ & $(332)$ & $(319)$ \\
& & & & & & \\
Isopropanol & 6052 & 5950 & - & - & 6006 & 6035 \\
& $(511)$ & $(423)$ & - & - & $(249)$ & $(579)$ \\
& & & & & & \\
\hline
\end{tabular}


TABLE XLIV

Experimental Design I : Ejection Force (Newtons) $\bar{X}$ (S.D)

\begin{tabular}{lcccccc}
\hline & \multicolumn{2}{c}{ Povidone } & \multicolumn{2}{c}{ Methocel } & \multicolumn{2}{c}{ K1 ucel } \\
& $3 \%$ & $6 \%$ & $3 \%$ & $6 \%$ & $3 \%$ & $6 \%$ \\
Water & 185 & 162 & 184 & 146 & 164 & 108 \\
& $(6)$ & $(4)$ & $(8)$ & $(5)$ & $(5)$ & $(5)$ \\
3A ethanol & 206 & 183 & - & 153 & 149 & 104 \\
& $(4)$ & $(6)$ & - & $(7)$ & $(9)$ & $(5)$ \\
Isopropanol & 192 & 158 & - & - & 149 & 104 \\
* Compression & $(17)$ & $(6)$ & - & - & $(6)$ & $(3)$ \\
\end{tabular}


TABLE XLV

Experimental Design I : Tablet Hardness (kg) $\bar{X}$ (S.D)

\begin{tabular}{|c|c|c|c|c|c|c|}
\hline & \multicolumn{2}{|c|}{ Povidone } & \multicolumn{2}{|c|}{ Methoce 1} & \multicolumn{2}{|c|}{ Klucel } \\
\hline & $3 \%$ & $6 \%$ & $3 \%$ & $6 \%$ & $3 \%$ & $6 \%$ \\
\hline Water & $\begin{array}{l}5.50 \\
(0.38)\end{array}$ & $\begin{array}{l}8.50 \\
(0.55)\end{array}$ & $\begin{array}{l}6.50 \\
(0.72)\end{array}$ & $\begin{array}{l}7.00 \\
(1.13)\end{array}$ & $\begin{array}{l}5.00 \\
(0.33)\end{array}$ & $\begin{array}{l}7.70 \\
(0.43)\end{array}$ \\
\hline $3 A$ ethanol & $\begin{array}{c}6.00 \\
(0.43)\end{array}$ & $\begin{array}{l}10.03 \\
(1.02)\end{array}$ & - & $\begin{array}{l}5.37 \\
(0.45)\end{array}$ & $\begin{array}{l}5.32 \\
(0.31)\end{array}$ & $\begin{array}{l}10.50 \\
(0.95)\end{array}$ \\
\hline I sopropanol & $\begin{array}{c}7.01 \\
(0.55)\end{array}$ & $\begin{array}{c}9.12 \\
(0.31)\end{array}$ & - & - & $\begin{array}{c}5.68 \\
(0.56)\end{array}$ & $\begin{array}{l}10.40 \\
(0.81)\end{array}$ \\
\hline
\end{tabular}


TABLE XLVI

Experimental Design I : Tablet Friability (\% Loss)

\begin{tabular}{|c|c|c|c|c|c|c|}
\hline & \multicolumn{2}{|c|}{ Povidone } & \multicolumn{2}{|c|}{ Methocel } & \multicolumn{2}{|c|}{ Klucel } \\
\hline & $3 \%$ & $6 \%$ & $3 \%$ & $6 \%$ & $3 \%$ & $6 \%$ \\
\hline Water & 0.08 & 0.10 & 0.08 & 0.10 & 0.13 & 0.10 \\
\hline $3 \mathrm{~A}$ ethanol & 0.08 & 0.07 & - & 0.22 & 0.00 & 0.05 \\
\hline Isopropanol & 0.05 & 0.05 & - & - & 0.08 & 0.05 \\
\hline
\end{tabular}


TABLE XLVII

Experimental Design $I$ : Tablet Disintegration (Minutes) $\bar{X}$ (S.D)

\begin{tabular}{|c|c|c|c|c|c|c|}
\hline & \multicolumn{2}{|c|}{ Povidone } & \multicolumn{2}{|c|}{ Methocel } & \multicolumn{2}{|c|}{ K1uce 1} \\
\hline & $3 \%$ & $6 \%$ & $3 \%$ & $6 \%$ & $3 \%$ & $6 \%$ \\
\hline Water & $\begin{array}{l}2.38 \\
(0.14)\end{array}$ & $\begin{array}{l}16.92 \\
(0.49)\end{array}$ & $\begin{array}{c}6.08 \\
(0.13)\end{array}$ & $\begin{array}{l}17.08 \\
(0.67)\end{array}$ & $\begin{array}{l}1.00 \\
(0.00)\end{array}$ & $\begin{array}{c}9.42 \\
(0.43)\end{array}$ \\
\hline $3 \mathrm{~A}$ ethanol & $\begin{array}{l}1.00 \\
(0.00)\end{array}$ & $\begin{array}{l}13.42 \\
(1.02)\end{array}$ & - & $\begin{array}{c}0.53 \\
(0.03)\end{array}$ & $\begin{array}{l}0.88 \\
(0.20)\end{array}$ & $\begin{array}{l}25.50 \\
(1.41)\end{array}$ \\
\hline Isopropanol & $\begin{array}{l}3.33 \\
(0.44)\end{array}$ & $\begin{array}{l}19.92 \\
(1.74)\end{array}$ & - & - & $\begin{array}{c}3.02 \\
(0.28)\end{array}$ & $\begin{array}{l}18.63 \\
(1.51)\end{array}$ \\
\hline
\end{tabular}


TABLE XLVIII

Experimental Design I

Tablet Dissolution - Percent Drug Dissolved at 15 Minutes. $\bar{x}$ (S.D)

\begin{tabular}{lllcccc}
\hline & \multicolumn{2}{c}{ Povidone } & \multicolumn{2}{c}{ Methocel } & \multicolumn{2}{c}{ K1ucel } \\
& $3 \%$ & $6 \%$ & $3 \%$ & $6 \%$ & $3 \%$ & $6 \%$ \\
Water & 96.97 & 83.49 & 83.68 & 78.31 & 96.51 & 95.75 \\
& $(0.64)$ & $(3.15)$ & $(0.22)$ & $(2.57)$ & $(0.77)$ & $(1.77)$ \\
3A ethano1 & 96.66 & 93.67 & - & 93.47 & 97.99 & 94.43 \\
& $(0.89)$ & $(1.75)$ & & $(1.24)$ & $(1.37)$ & $(1.67)$ \\
Isopropanol & 95.59 & 80.62 & - & - & 98.03 & 97.52 \\
& $(1.49)$ & $(3.91)$ & & & $(2.00)$ & $(0.90)$ \\
& & & & & & \\
\hline
\end{tabular}


TABLE XLIX

Experimental Design I

Tablet Dissolution - Percent Drug Dissolved at 30 Minutes. $\bar{x}$ (S.D)

\begin{tabular}{|c|c|c|c|c|c|c|}
\hline & \multicolumn{2}{|c|}{ Povidone } & \multicolumn{2}{|c|}{ Methoce 1} & \multicolumn{2}{|c|}{ Klucel } \\
\hline & $3 \%$ & $6 \%$ & $3 \%$ & $6 \%$ & $3 \%$ & $6 \%$ \\
\hline Water & $\begin{array}{l}98.60 \\
(0.56)\end{array}$ & $\begin{array}{l}97.50 \\
(1.02)\end{array}$ & $\begin{array}{l}93.11 \\
(0.33)\end{array}$ & $\begin{array}{l}92.00 \\
(1.04)\end{array}$ & $\begin{array}{l}99.50 \\
(0.45)\end{array}$ & $\begin{array}{l}99.78 \\
(0.81)\end{array}$ \\
\hline $3 A$ ethanol & $\begin{array}{l}98.27 \\
(1.01)\end{array}$ & $\begin{array}{l}96.62 \\
(0.53)\end{array}$ & - & $\begin{array}{l}95.40 \\
(0.95)\end{array}$ & $\begin{array}{l}99.57 \\
(0.97)\end{array}$ & $\begin{array}{l}97.14 \\
(0.76)\end{array}$ \\
\hline Isopropanol & $\begin{array}{l}99.23 \\
(0.53)\end{array}$ & $\begin{array}{l}95.61 \\
(0.89)\end{array}$ & - & - & $\begin{array}{l}99.36 \\
(0.71)\end{array}$ & $\begin{array}{l}99.91 \\
(0.47)\end{array}$ \\
\hline
\end{tabular}


TABLE L

\section{Experimental Design I}

Tablet Dissolution - Percent Drug Dissolved at 45 Minutes. $\bar{X}$ (S.D)

\begin{tabular}{|c|c|c|c|c|c|c|}
\hline & \multicolumn{2}{|c|}{ Povidone } & \multicolumn{2}{|c|}{ Methocel } & \multicolumn{2}{|c|}{ KTuce 1} \\
\hline & $3 \%$ & $6 \%$ & $3 \%$ & $6 \%$ & $3 \%$ & $6 \%$ \\
\hline Water & $\begin{array}{l}99.87 \\
(0.15)\end{array}$ & $\begin{array}{l}98.33 \\
(0.89)\end{array}$ & $\begin{array}{l}95.97 \\
(0.84)\end{array}$ & $\begin{array}{l}96.40 \\
(0.81)\end{array}$ & $\begin{array}{l}99.85 \\
(0.24)\end{array}$ & $\begin{array}{r}100.90 \\
(1.21)\end{array}$ \\
\hline $3 A$ ethanol & $\begin{array}{l}99.10 \\
(0.74)\end{array}$ & $\begin{array}{l}97.23 \\
(0.49)\end{array}$ & - & $\begin{array}{l}96.74 \\
(0.40)\end{array}$ & $\begin{array}{l}99.90 \\
(0.20)\end{array}$ & $\begin{array}{l}99.90 \\
(0.17)\end{array}$ \\
\hline Isopropanol & $\begin{array}{l}99.40 \\
(0.56)\end{array}$ & $\begin{array}{l}97.28 \\
(0.87)\end{array}$ & - & - & $\begin{array}{l}99.40 \\
(0.72)\end{array}$ & $\begin{array}{l}99.92 \\
(0.17)\end{array}$ \\
\hline
\end{tabular}


specification (USP) for these tablets requires that eighty percent of label drug has to be dissolved within 30 minutes.

A factorial design to study the effect of type of disintegrant, concentration of disintegrant and the location of disintegrant in the granules on the wet granulation process is shown in Tables XI thru XIII. Granulations flow rate are recorded in Table LI. Intragranular disintegrants (up to $2.0 \%$ ) in the formulation improved flow properties of granulations. However, in the case of four percent Ac-Di-Sol in the granulation, the flow of granulation was adversely affected. Explotab and crospovidone showed no effect at this level.

Bulk density of granules decreased with the increased concentration of disintegrant in the formulation (Table LII). These disintegrants did not have any effect on tablet weight variation, ejection force, hardness and friability of the tablet (Tables LIV-LIX). Thickness of tablets containing disintegrants was increased slightly. All the factors exerted statistically significant effects $(P<0.05)$ on disintegration time, dissolution at fifteen minutes and at thirty minutes. A General Linear Model was used to analyze the data. Tablet disintegration and dissolution results are recorded in Tables $L X$ thru LXII. Intergranular disintegrant on dissolution rate is significantly better than intragranular disintegrant, irrespective of the disintegrants (Fig's. 71-76). Intragranular crospovidone and Starch 1500 in this system seem to be missing part of their disintegration action due to the wet granulation process (Fig's. 72-76). These results indicate that $50 \%$ intra- plus $50 \%$ intergranular disintegrant on dissolution of tablet at fifteen minutes is better than $100 \%$ 
TABLE LI

Experimental Design II : Granulation Flow Rate (Grams / Second) $\bar{X}$ (S.D)

\begin{tabular}{|c|c|c|c|c|}
\hline $\begin{array}{l}\text { Total \% } \\
\text { Disintegrant }\end{array}$ & $A C-D i-S o l$ & Explotab & $\begin{array}{l}\text { Cros- } \\
\text { povidone }\end{array}$ & Starch 1500 \\
\hline 0.00 & $\begin{array}{c}227.46 \\
(9.19)\end{array}$ & $\begin{array}{l}204.56 \\
(14.83)\end{array}$ & $\begin{array}{l}215.65 \\
(10.53)\end{array}$ & - \\
\hline 0.25 & $\begin{array}{r}253.82 \\
(3.72)\end{array}$ & $\begin{array}{r}247.80 \\
(6.25)\end{array}$ & $\begin{array}{r}265.60 \\
(7.80)\end{array}$ & - \\
\hline 0.50 & $\begin{array}{r}254.11 \\
(7.58)\end{array}$ & $\begin{array}{c}260.69 \\
(3.77)\end{array}$ & $\begin{array}{c}256.38 \\
(6.53)\end{array}$ & - \\
\hline 1.00 & $\begin{array}{c}204.12 \\
(7.34)\end{array}$ & $\begin{array}{c}267.98 \\
(4.04)\end{array}$ & $\begin{array}{c}246.02 \\
(3.54)\end{array}$ & $\begin{array}{r}246.81 \\
(3.51)\end{array}$ \\
\hline 2.00 & $\begin{array}{r}215.90 \\
(2.66)\end{array}$ & $\begin{array}{l}265.98 \\
(10.92)\end{array}$ & $\begin{array}{r}252.17 \\
(3.67)\end{array}$ & $\begin{array}{r}225.59 \\
(5.91)\end{array}$ \\
\hline 4.00 & $\begin{array}{c}182.76 \\
(0.04)\end{array}$ & $\begin{array}{r}228.94 \\
(3.05)\end{array}$ & $\begin{array}{r}212.38 \\
(3.99)\end{array}$ & $\begin{array}{r}252.38 \\
(7.22)\end{array}$ \\
\hline 8.00 & - & - & - & $\begin{array}{c}236.23 \\
(6.50)\end{array}$ \\
\hline 16.0 & - & - & - & $\begin{array}{r}205.57 \\
(4.31)\end{array}$ \\
\hline
\end{tabular}


TABLE LII

Experimental Design II : Granulations Bulk Density: $\underset{\text { Tapped }}{\operatorname{Loose}}\left(\mathrm{g} / \mathrm{cm}^{3}\right)$

\begin{tabular}{|c|c|c|c|c|}
\hline $\begin{array}{l}\text { Total \% } \\
\text { Disintegrant }\end{array}$ & $A C-D i-S 01$ & Explotab & $\begin{array}{l}\text { Cros- } \\
\text { povidone }\end{array}$ & Starch 1500 \\
\hline 0.00 & $\begin{array}{l}1.122 \\
1.350\end{array}$ & $\begin{array}{l}1.123 \\
1.361\end{array}$ & $\begin{array}{l}1.129 \\
1.386\end{array}$ & - \\
\hline 0.25 & $\begin{array}{l}0.945 \\
1.098\end{array}$ & $\begin{array}{l}0.988 \\
1.155\end{array}$ & $\begin{array}{l}1.011 \\
1.162\end{array}$ & - \\
\hline 0.50 & $\begin{array}{l}0.913 \\
1.070\end{array}$ & $\begin{array}{l}1.040 \\
1.201\end{array}$ & $\begin{array}{l}1.060 \\
1.216\end{array}$ & - \\
\hline 1.00 & $\begin{array}{l}0.888 \\
1.060\end{array}$ & $\begin{array}{l}0.980 \\
1.149\end{array}$ & $\begin{array}{l}0.988 \\
1.174\end{array}$ & $\begin{array}{l}0.945 \\
1.089\end{array}$ \\
\hline 2.00 & $\begin{array}{l}0.857 \\
1.011\end{array}$ & $\begin{array}{l}0.946 \\
1.077\end{array}$ & $\begin{array}{l}0.908 \\
1.061\end{array}$ & $\begin{array}{l}0.916 \\
1.062\end{array}$ \\
\hline 4.00 & $\begin{array}{l}0.754 \\
0.912\end{array}$ & $\begin{array}{l}0.832 \\
0.968\end{array}$ & $\begin{array}{l}0.771 \\
0.892\end{array}$ & $\begin{array}{l}0.856 \\
0.980\end{array}$ \\
\hline 8.00 & - & - & - & $\begin{array}{l}0.804 \\
0.927\end{array}$ \\
\hline 16.0 & - & - & - & $\begin{array}{l}0.741 \\
0.867\end{array}$ \\
\hline
\end{tabular}




\section{TABLE LIII}

Experimental Design II : Percent Compressibility of Granulations

\begin{tabular}{|c|c|c|c|c|}
\hline $\begin{array}{l}\text { Total } \% \\
\text { Disintegrant }\end{array}$ & $A C-D i-S o 1$ & Explotab & $\begin{array}{l}\text { Cros- } \\
\text { povidone }\end{array}$ & Starch 1500 \\
\hline 0.00 & 17.6 & & & \\
\hline 0.25 & 13.9 & 14.5 & 13.0 & - \\
\hline 0.50 & 14.7 & 13.4 & 12.8 & - \\
\hline 1.00 & 16.2 & 14.7 & 15.8 & 13.2 \\
\hline 2.00 & 15.2 & 12.2 & 14.4 & 13.7 \\
\hline 4.00 & 17.3 & 14.0 & 13.6 & 12.7 \\
\hline 8.00 & - & - & - & 13.3 \\
\hline 16.0 & - & - & - & 14.5 \\
\hline
\end{tabular}


TABLE LIV

Experimental Design II : Compression Force (Newtons) $\bar{X}$ (S.D)

\begin{tabular}{lrllll}
\hline $\begin{array}{l}\text { Total } \% \\
\text { Disintegrant }\end{array}$ & $\%$ Intra & Ac-Di-Sol & Explotab & $\begin{array}{l}\text { Cros- } \\
\text { povidone }\end{array}$ & Starch 1500 \\
& & & & & \\
Control & 0 & $3532(138)$ & & & \\
0.25 & 0 & $3555(93)$ & $3550(90)$ & $3711(163)$ & - \\
0.25 & 100 & $3553(214)$ & $3344(149)$ & $3454(128)$ & - \\
0.50 & 0 & $3590(121)$ & $3561(124)$ & $3540(265)$ & $3589(158)$ \\
0.50 & 50 & $3365(121)$ & $3567(161)$ & $3373(157)$ & - \\
0.50 & 100 & $3437(145)$ & $3411(131)$ & $3550(77)$ & - \\
1.00 & 0 & $3314(92)$ & $3513(90)$ & $3563(71)$ & $3586(144)$ \\
1.00 & 50 & $3564(361)$ & $3612(135)$ & $3666(88)$ & $3322(154)$ \\
1.00 & 100 & $3559(206)$ & $3528(191)$ & $3541(88)$ & $3577(178)$ \\
\hline
\end{tabular}


TABLE LIV ---Continued

\begin{tabular}{|c|c|c|c|c|c|}
\hline $\begin{array}{l}\text { Total \% } \\
\text { Disintegrant }\end{array}$ & $\%$ Intra & $A C-D i-S_{0} 1$ & Explotab & $\begin{array}{l}\text { Cros- } \\
\text { povidone }\end{array}$ & Starch 1500 \\
\hline$-\ldots-\ldots-\ldots$ & $---\ldots$ & $----\ldots$ & ----- & ----- & --------- \\
\hline 2.00 & 0 & $3495(123)$ & - & - & $3556(130)$ \\
\hline 2.00 & 50 & $3571(119)$ & - & - & $3407(145)$ \\
\hline 2.00 & 100 & $3371(69)$ & - & - & $3518(121)$ \\
\hline 4.00 & 0 & $3400(153)$ & - & - & $3699(153)$ \\
\hline 4.00 & 50 & $3344(117)$ & - & - & $3482(150)$ \\
\hline 4.00 & 100 & $3559(104)$ & - & - & $3692(167)$ \\
\hline
\end{tabular}


TABLE LV

Experimental Design II : Ejection Force (Newtons) $\bar{X}$ (S.D)

\begin{tabular}{|c|c|c|c|c|c|}
\hline $\begin{array}{l}\text { Total \% } \\
\text { Disintegrant }\end{array}$ & $\%$ Intra & $A C-D i-S_{0} 1$ & Explotab & $\begin{array}{l}\text { Cros- } \\
\text { povidone }\end{array}$ & Starch 1500 \\
\hline Control & 0 & $118(7)$ & & & \\
\hline 0.25 & 0 & $126(5)$ & $129(6)$ & 139 (5) & - \\
\hline 0.25 & 100 & $132(9)$ & $127(8)$ & $128(7)$ & - \\
\hline 0.50 & 0 & $121(7)$ & $124(5)$ & $124(12)$ & $131(6)$ \\
\hline 0.50 & 50 & $133(9)$ & $121(8)$ & $123(4)$ & - \\
\hline 0.50 & 100 & $126(8)$ & $125(5)$ & $123(4)$ & - \\
\hline 1.00 & 0 & $112(8)$ & $120(5)$ & $125(5)$ & $121(7)$ \\
\hline 1.00 & 50 & $131(14)$ & $116(6)$ & $132(6)$ & $123(6)$ \\
\hline 1.00 & 100 & $127(7)$ & $125(4)$ & $126 \quad(3)$ & $124(10)$ \\
\hline
\end{tabular}


TABLE LV -.--Continued.

\begin{tabular}{lccccc}
\hline $\begin{array}{l}\text { Total } \% \\
\text { Disintegrant }\end{array}$ & Intra & Ac-Di-Sol & Explotab & $\begin{array}{l}\text { Cros- } \\
\text { povidone }\end{array}$ & Starch 1500 \\
\hline 2.00 & 0 & $108(5)$ & - & - & $113(6)$ \\
2.00 & 50 & $127(7)$ & - & - & $112(5)$ \\
2.00 & 100 & $110(4)$ & - & - & $120(6)$ \\
4.00 & 0 & $106(5)$ & - & - & $110(7)$ \\
4.00 & 50 & $110(5)$ & - & - & $114(4)$ \\
4.00 & 100 & $117(4)$ & - & - & $115(6)$ \\
\hline
\end{tabular}


TABLE LVI

Experimental Design II : Tablet Weight (mg) $\bar{X}$ (S.D)

\begin{tabular}{|c|c|c|c|c|c|}
\hline $\begin{array}{l}\text { Total } \% \\
\text { Disintegrant }\end{array}$ & $\%$ Intra & $A C-D i-S O I$ & Explotab & $\begin{array}{l}\text { Cros- } \\
\text { povidone }\end{array}$ & Starch 1500 \\
\hline Control & 0 & $201.2(2.64)$ & - & - & - \\
\hline 0.25 & 0 & $200.7(1.86)$ & $202.2(1.83)$ & $202.5(1.38)$ & - \\
\hline 0.25 & 100 & $198.2(3.37)$ & $196.2(1.83)$ & $198.8(1.83)$ & - \\
\hline 0.50 & 0 & $201.2(2.14)$ & $197.5(1.97)$ & $201.5(1.64)$ & $200.7(1.75)$ \\
\hline 0.50 & 50 & $202.5(1.22)$ & $196.8(2.04)$ & $200.5(2.66)$ & - \\
\hline 0.50 & 100 & $201.3(2.66)$ & $199.7(3.01)$ & $200.2(1.60)$ & - \\
\hline 1.00 & 0 & $200.2(1.17)$ & $202.3(2.80)$ & $198.2(0.75)$ & $200.2(0.75)$ \\
\hline 1.00 & 50 & $200.2(2.08)$ & $197.0(1.67)$ & $204.2(0.84)$ & $201.3(1.86)$ \\
\hline 1.00 & 100 & $203.5(2.59)$ & $199.6(0.92)$ & $199.0(0.84)$ & $201.3(2.07)$ \\
\hline
\end{tabular}




\begin{tabular}{|c|c|c|c|c|c|}
\hline $\begin{array}{l}\text { Total } \% \\
\text { Disintegran }\end{array}$ & $n t^{\%}$ Intra & $A C-D i-S o l$ & Explotab & $\begin{array}{l}\text { Cros- } \\
\text { povidone }\end{array}$ & Starch 1500 \\
\hline \multicolumn{6}{|c|}{ 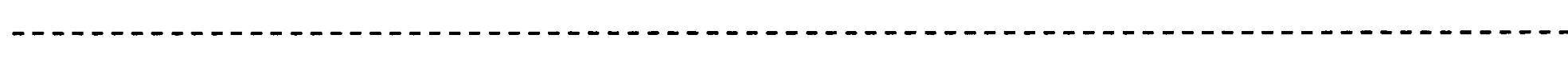 } \\
\hline 2.00 & 0 & $198.2(1.72)$ & - & - & $200.3(1.10)$ \\
\hline 2.00 & 50 & $200.3(2.50)$ & - & - & $201.2(1.23)$ \\
\hline 2.00 & 100 & $197.8(1.83)$ & - & - & $201.5(1.38)$ \\
\hline 4.00 & 0 & $196.7(1.69)$ & - & - & $203.5(0.84)$ \\
\hline 4.00 & 50 & $195.8(1.72)$ & - & - & $202.5(1.64)$ \\
\hline 4.00 & 100 & $201.5(1.05)$ & - & - & $205.0(0.75)$ \\
\hline
\end{tabular}




\section{TABLE LVII}

Experimental Design II : Tablet Hardness (kg) $\bar{X}$ (S.D)

\begin{tabular}{|c|c|c|c|c|c|}
\hline $\begin{array}{l}\text { Total \% } \\
\text { Disintegrant }\end{array}$ & $\%$ Intra & $A C-D i-S 01$ & Explotab & $\begin{array}{l}\text { Cros- } \\
\text { povidone }\end{array}$ & Starch 1500 \\
\hline Control & 0 & $3.88(0.42)$ & & & \\
\hline 0.25 & 0 & $4.33(0.51)$ & $4.93(0.40)$ & $4.77(0.55)$ & - \\
\hline 0.25 & 100 & $3.65(0.21)$ & $4.10(0.58)$ & $4.13(0.51)$ & - \\
\hline 0.50 & 0 & $6.12(0.69)$ & $3.70(0.28)$ & $4.60(0.36)$ & $4.23(0.27)$ \\
\hline 0.50 & 50 & $6.60(0.93)$ & $3.12(0.13)$ & $3.67(0.31)$ & - \\
\hline 0.50 & 100 & $5.48 \quad(0.37)$ & $4.55 \quad(0.53)$ & $3.62(0.24)$ & - \\
\hline 1.00 & 0 & $4.38(0.38)$ & $4.03(0.37)$ & $3.63(0.15)$ & $4.18(1.06)$ \\
\hline 1.00 & 50 & $5.00(0.52)$ & $3.57(0.12)$ & $3.83(0.21)$ & $3.98(0.21)$ \\
\hline 1.00 & 100 & $5.53(0.49)$ & $4.65 \quad(0.48)$ & $4.13(0.88)$ & $4.63(0.58)$ \\
\hline
\end{tabular}


TABLE LVII ---Continued

\begin{tabular}{|c|c|c|c|c|c|}
\hline $\begin{array}{l}\text { Total } \% \\
\text { Disintegrant }\end{array}$ & $\%$ Intra & $A C-D i-S 01$ & Explotab & $\begin{array}{l}\text { Cros- } \\
\text { povidone }\end{array}$ & Starch 1500 \\
\hline 2.00 & 0 & $4.60(0.23)$ & - & - & $3.72(0.28)$ \\
\hline 2.00 & 50 & $5.90 \quad(0.51)$ & - & - & $5.03(0.67)$ \\
\hline 2.00 & 100 & $6.20(0.76)$ & - & - & $4.35(0.52)$ \\
\hline 4.00 & 0 & $4.22(0.25)$ & - & - & $3.92(0.46)$ \\
\hline 4.00 & 50 & $5.42(0.25)$ & - & - & $5.57(0.35)$ \\
\hline 4.00 & 100 & $7.45(0.30)$ & - & - & $6.21(0.58)$ \\
\hline
\end{tabular}


TABLE LVIII

Experimenta] Design II : Tablet Thickness (inches)

\begin{tabular}{|c|c|c|c|c|c|}
\hline $\begin{array}{l}\text { Total \% } \\
\text { Disintegrant }\end{array}$ & $\%$ Intra & $A C-D i-S o l$ & Explotab & $\begin{array}{l}\text { Cros- } \\
\text { povidone }\end{array}$ & Starch 1500 \\
\hline Control & 0 & 0.149 & & & \\
\hline 0.25 & 0 & 0.152 & 0.151 & 0.152 & - \\
\hline 0.25 & 100 & 0.152 & 0.151 & 0.151 & - \\
\hline 0.50 & 0 & 0.150 & 0.149 & 0.152 & 0.152 \\
\hline 0.50 & 50 & 0.153 & 0.149 & 0.152 & - \\
\hline 0.50 & 100 & 0.153 & 0.150 & 0.152 & - \\
\hline 1.00 & 0 & 0.152 & 0.152 & 0.153 & 0.152 \\
\hline 1.00 & 50 & 0.152 & 0.150 & 0.153 & 0.152 \\
\hline 1.00 & 100 & 0.153 & 0.150 & 0.152 & 0.153 \\
\hline 2.00 & 0 & 0.152 & - & - & 0.153 \\
\hline 2.00 & 50 & 0.153 & - & - & 0.153 \\
\hline 2.00 & 100 & 0.153 & - & - & 0.153 \\
\hline 4.00 & 0 & 0.153 & - & - & 0.158 \\
\hline 4.00 & 50 & 0.154 & - & - & 0.157 \\
\hline 4.00 & 100 & 0.156 & - & - & 0.158 \\
\hline
\end{tabular}


TABLE LIX

Experimental Design II : Tablet Friability (\% Loss)

\begin{tabular}{lrlllc}
\hline $\begin{array}{l}\text { Total \% } \\
\text { Disintegrant }\end{array}$ & \% Intra & Ac-Di-Sol & Explotab & $\begin{array}{l}\text { Cros- } \\
\text { povidone }\end{array}$ & Starch 1500 \\
\hdashline Control & 0 & 0.15 & & & \\
0.25 & 0 & 0.15 & 0.12 & 0.10 & - \\
0.25 & 100 & 0.13 & 0.15 & 0.18 & - \\
0.50 & 0 & 0.08 & 0.18 & 0.15 & 0.12 \\
0.50 & 50 & 0.07 & 0.21 & 0.23 & - \\
0.50 & 100 & 0.15 & 0.18 & 0.23 & - \\
1.00 & 0 & 0.15 & 0.15 & 0.15 & 0.15 \\
1.00 & 50 & 0.15 & 0.23 & 0.15 & 0.10 \\
1.00 & 100 & 0.15 & 0.15 & 0.26 & 0.05 \\
2.00 & 0 & 0.18 & - & - & 0.17 \\
2.00 & 50 & 0.15 & - & - & 0.20 \\
2.00 & 100 & 0.13 & - & - & 0.15 \\
4.00 & 0 & 0.33 & - & - & 0.22 \\
4.00 & 50 & 0.10 & - & - & 0.30 \\
4.00 & 100 & 0.10 & - & - & 0.10 \\
\hline & & & & & - \\
\hline
\end{tabular}




\section{TABLE LX}

Experimental Design II : Tablet Disintegration Time (minutes) $\bar{X}$ (S.D)

\begin{tabular}{|c|c|c|c|c|c|}
\hline $\begin{array}{l}\text { Total \% } \\
\text { Disintegrant }\end{array}$ & $t^{\%}$ Intra & $A C-D i-S 01$ & Explotab & $\begin{array}{l}\text { Cros- } \\
\text { povidone }\end{array}$ & Starch 1500 \\
\hline Control & 0 & $>30.00$ & & & \\
\hline 0.25 & 0 & $4.38 \quad(0.57)$ & $14.98 \quad(2.34)$ & $9.83(1.54)$ & - \\
\hline 0.25 & 100 & $14.92(4.20)$ & $20.95(1.31)$ & $>30.00$ & - \\
\hline 0.50 & 0 & $4.30(0.97)$ & $4.01 \quad(0.35)$ & $4.54(0.75)$ & $23.67(3.72)$ \\
\hline 0.50 & 50 & $12.95(1.46)$ & $8.10(0.74)$ & $25.83(0.61)$ & - \\
\hline 0.50 & 100 & $13.85 \quad(1.37)$ & $14.76(0.24)$ & $>30.00$ & - \\
\hline 1.00 & 0 & $2.68(0.69)$ & $3.58(0.09)$ & $2.50(0.22)$ & $7.30(1.49)$ \\
\hline 1.00 & 50 & $9.30(0.63)$ & $4.75(0.27)$ & $9.83(1.36)$ & $22.67(5.12)$ \\
\hline 1.00 & 100 & $9.21(1.10)$ & $9.25(1.64)$ & $24.63(2.54)$ & $>30.00$ \\
\hline
\end{tabular}


TABLE LX ----Continued

\begin{tabular}{lrrrrr}
\hline $\begin{array}{l}\text { Total \% } \\
\text { Disintegrant }\end{array}$ & Intra & \multicolumn{1}{c}{ Ac-Di-Sol } & Explotab & $\begin{array}{l}\text { Cros- } \\
\text { povidone }\end{array}$ & Starch 1500 \\
\hline 2.00 & 0 & $2.05(0.26)$ & - & - & $7.71(1.54)$ \\
2.00 & 50 & $5.93(0.32)$ & - & - & $21.75(4.35)$ \\
2.00 & 100 & $6.15(0.44)$ & - & - & $>30.00$ \\
4.00 & 0 & $1.91(0.46)$ & - & - & $3.63(0.35)$ \\
4.00 & 50 & $4.30(0.10)$ & - & - & $20.75(3.31)$ \\
4.00 & 100 & $5.08(0.07)$ & - & & \\
\hline 8
\end{tabular}


TABLE LXI

Experimental Design II

Tablet Dissolution - Percent Drug Dissolved at 15 minutes. $\bar{X}$ (S.D)

\begin{tabular}{|c|c|c|c|c|c|}
\hline $\begin{array}{l}\text { Total } \% \\
\text { Disintegrant }\end{array}$ & $\%$ Intra & $A C-D i-S 01$ & Explotab & $\begin{array}{l}\text { Cros- } \\
\text { povidone }\end{array}$ & Starch 1500 \\
\hline Control & 0 & $21.83(3.24)$ & & & \\
\hline 0.25 & 0 & $92.43(1.04)$ & $78.12(7.05)$ & $95.22(0.82)$ & - \\
\hline 0.25 & 100 & $76.00(10.44)$ & $53.65(11.92)$ & $30.91 \quad(3.36)$ & - \\
\hline 0.50 & 0 & $92.05(3.53)$ & $96.60(1.73)$ & $96.79(1.26)$ & $90.61(2.76)$ \\
\hline 0.50 & 50 & $60.03(4.98)$ & $85.92(1.76)$ & $84.87(3.68)$ & - \\
\hline 0.50 & 100 & $89.14(3.25)$ & $49.97(10.93)$ & $55.38 \quad(6.20)$ & - \\
\hline 1.00 & 0 & $95.29(1.52)$ & - & - & $96.41(1.16)$ \\
\hline 1.00 & 50 & $90.68 \quad(0.70)$ & - & - & $89.90(2.76)$ \\
\hline 1.00 & 100 & $90.47 \quad(1.92)$ & $72.52(1.96)$ & $91.76(1.95)$ & $27.41(8.86)$ \\
\hline 2.00 & 100 & - & - & - & $41.72(5.81)$ \\
\hline 4.00 & 100 & - & - & - & $70.06(3.71)$ \\
\hline
\end{tabular}




\section{TABLE LXII}

Experimental Design II

Tablet Dissolution - Percent Drug Dissolved at 30 Minutes. $\bar{X}$ (S.D)

\begin{tabular}{|c|c|c|c|c|c|}
\hline $\begin{array}{l}\text { Total \% } \\
\text { Disintegrant }\end{array}$ & $\%$ Intra & $A C-D i-S o l$ & Explotab & $\begin{array}{l}\text { Cros- } \\
\text { povidone }\end{array}$ & Starch 1500 \\
\hline Control & 0 & $36.18 \quad(5.27)$ & & & \\
\hline 0.25 & 0 & $99.58(0.87)$ & $97.84(0.79)$ & $99.18(1.12)$ & - \\
\hline 0.25 & 100 & $98.07(1.62)$ & $93.96(3.44)$ & $67.91(7.60)$ & - \\
\hline 0.50 & 0 & $97.00 \quad(1.58)$ & $99.16(1.22)$ & $99.68(0.68)$ & $98.94(1.32)$ \\
\hline 0.50 & 50 & $92.50(1.74)$ & $92.94(0.81)$ & $98.72(1.30)$ & - \\
\hline 0.50 & 100 & $96.07(1.12)$ & $91.52(3.33)$ & $96.30(0.97)$ & - \\
\hline 1.00 & 0 & $97.14(1.14)$ & - & - & $98.96(0.74)$ \\
\hline 1.00 & 50 & $95.19(0.45)$ & - & - & $98.62(1.95)$ \\
\hline 1.00 & 100 & $94.10(1.23)$ & $98.08 \quad(0.62)$ & $99.20(0.80)$ & $54.56(16.00)$ \\
\hline 2.00 & 100 & - & - & - & $94.50(2.65)$ \\
\hline 4.00 & 100 & - & - & - & $100.00(0.43)$ \\
\hline
\end{tabular}




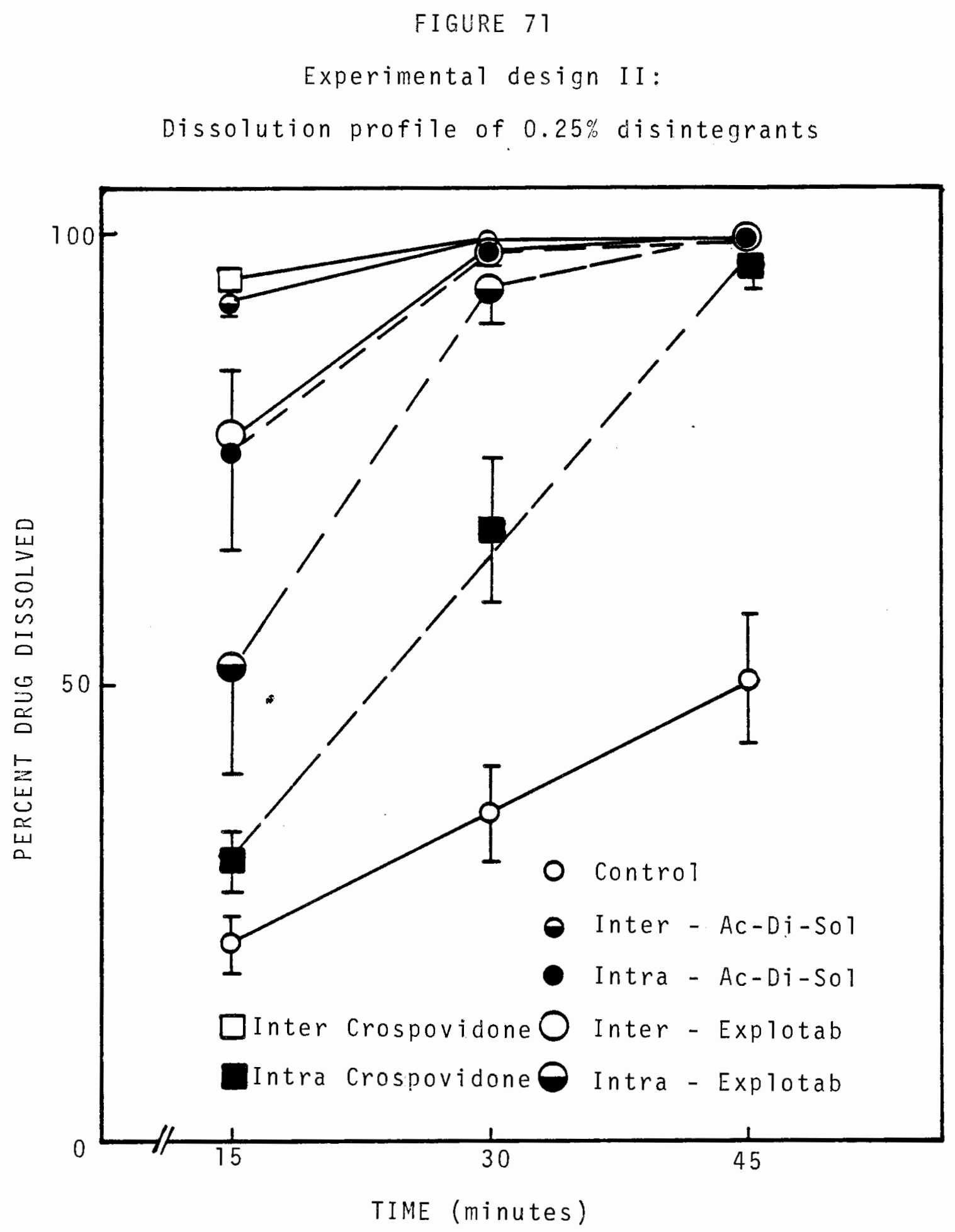




\section{FIGURE 72}

Experimental design II:

Dissolution profile of $0.5 \%$ intragranular disintegrants

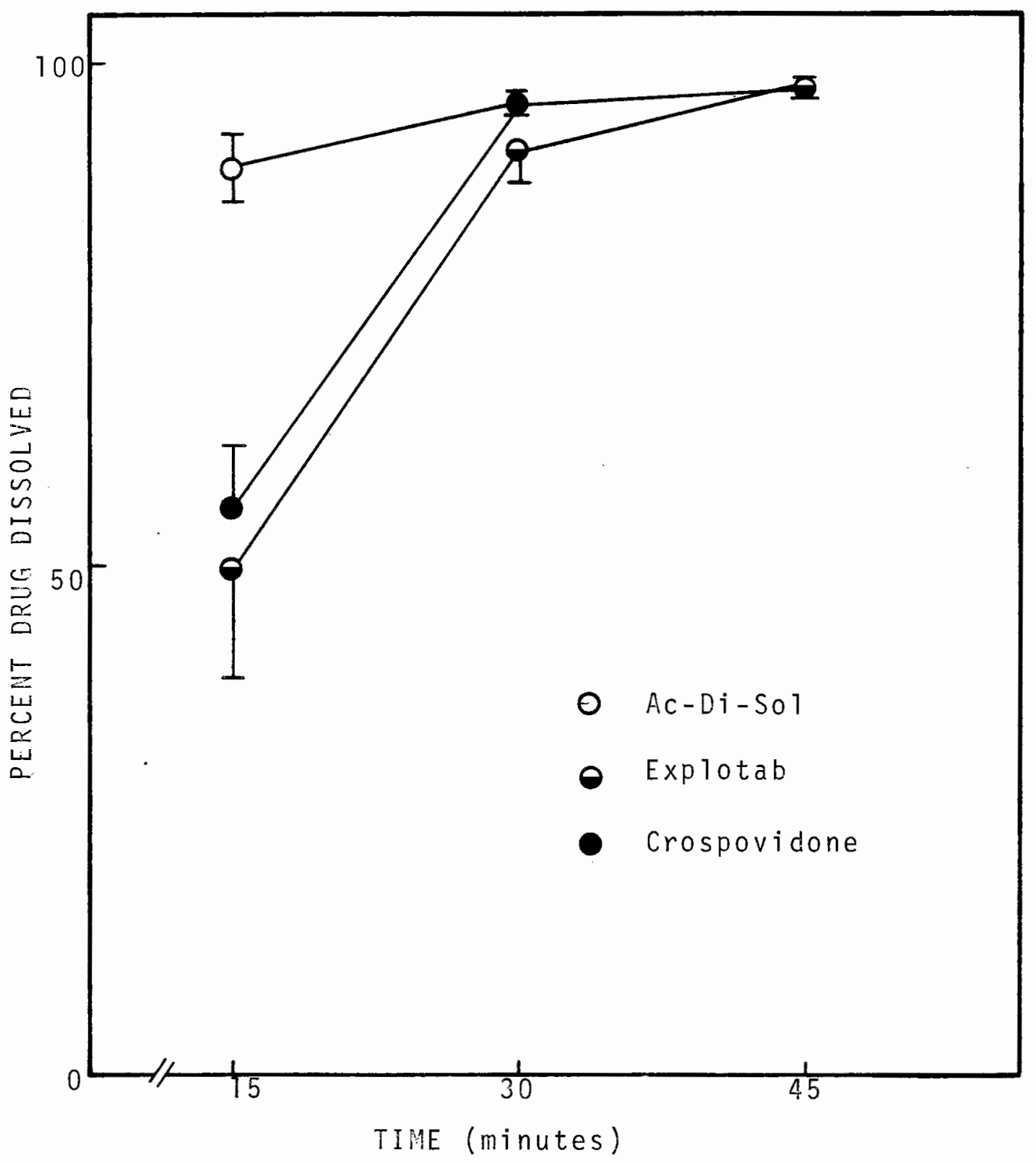




\section{FIGURE 73}

\section{Experimental design II:}

Dissolution profile of $1.0 \%$ intragranular disintegrants

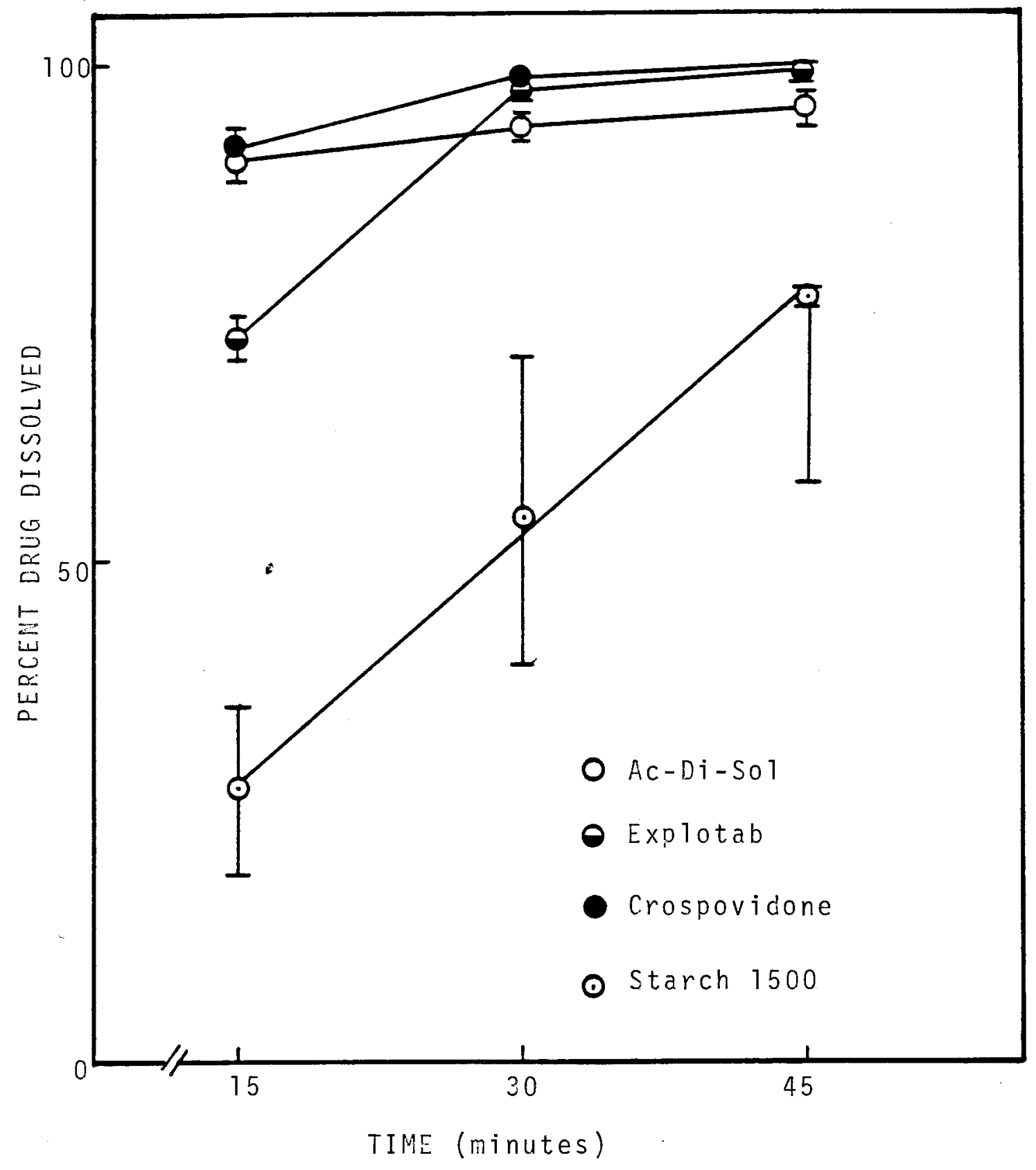




\section{FIGURE 74}

\section{Experimental design II:}

Dissolution profile of formulations w/ Explotab

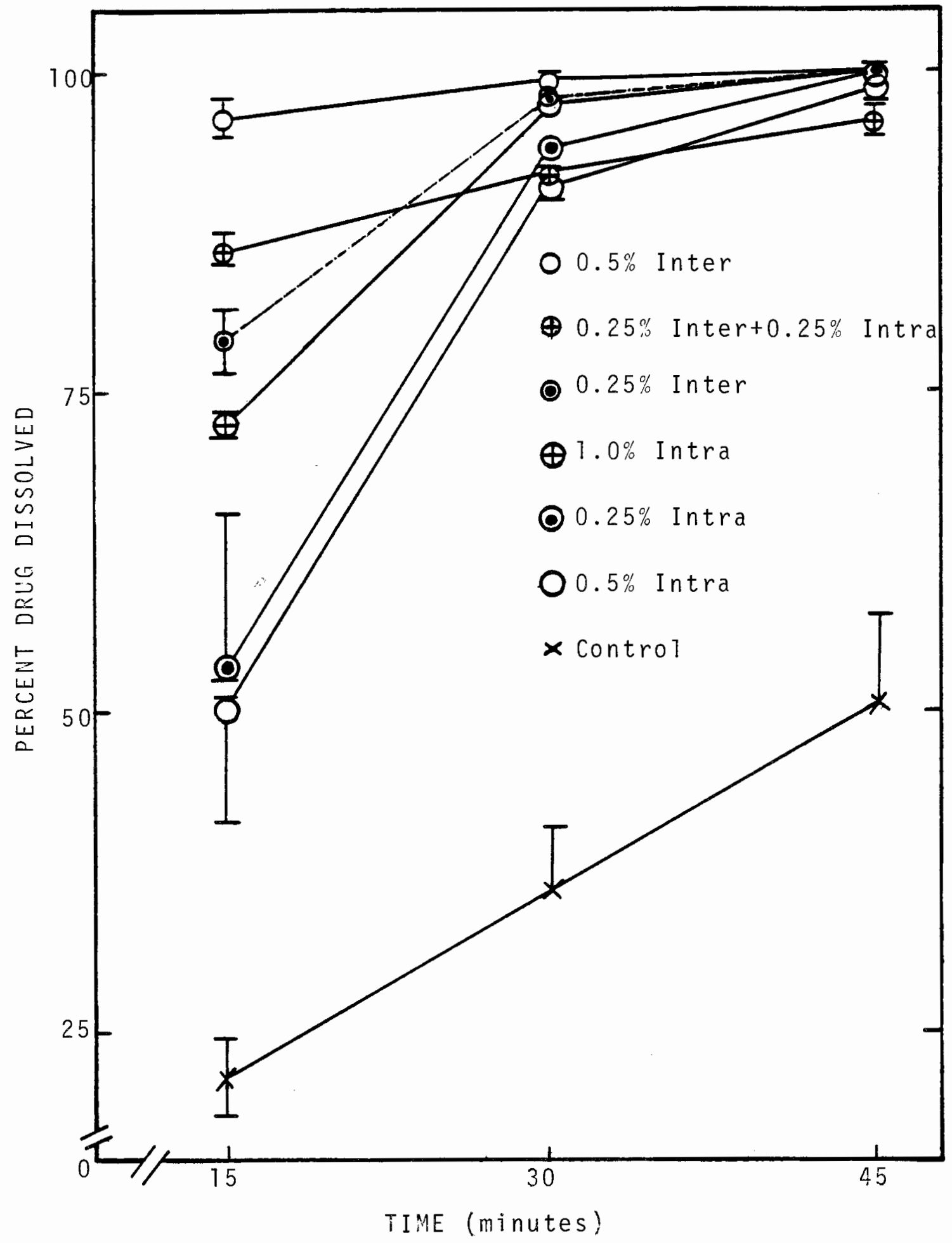




\section{FIGURE 75}

Experimental design II:

Dissolution profile of formulations with crospovidone

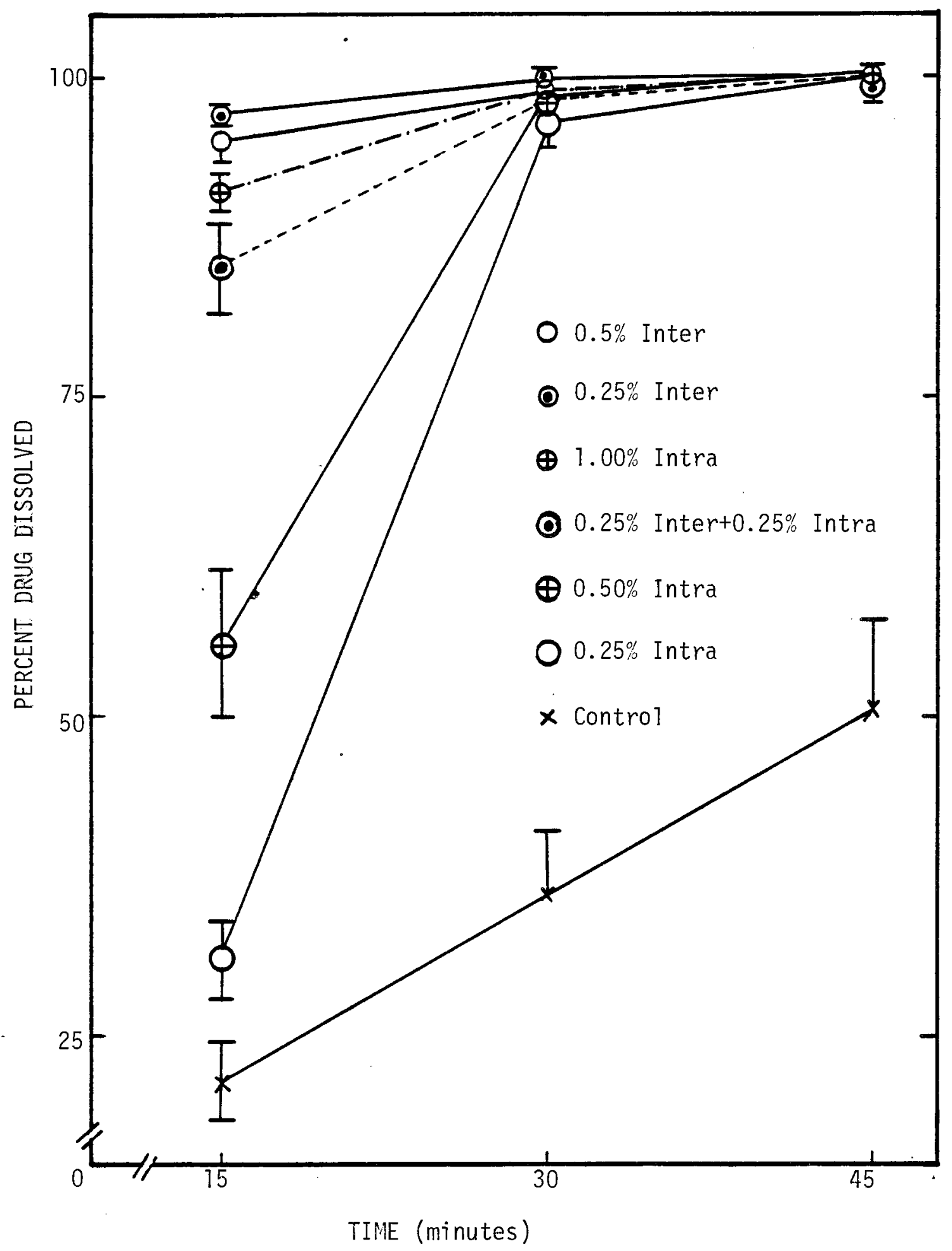


FIGURE 76

Experimental deisgn II:

Dissolution profile of formulations with Starch 1500

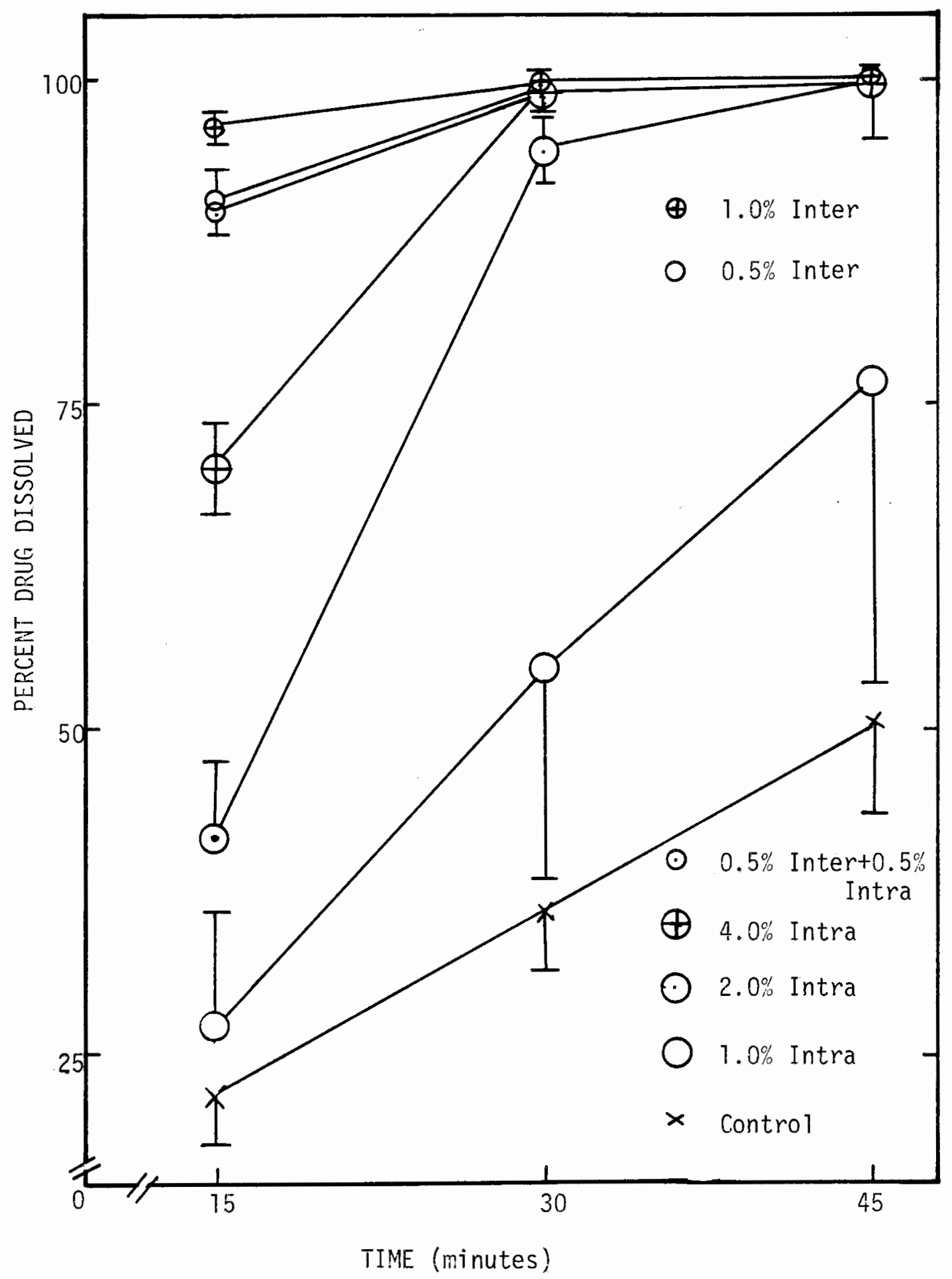


intragranular disintegrant but worse than $100 \%$ intergranular disintegrant.

Figure 77 shows the effect of different grades of lactose (Table XIV) on the torque profile of the wet granulation process. The lactose hydrous (finer grade) produced all five distinct phases reported earlier (with 30 percent $w / w$ water). The lactose anhydrous (coarse grade) showed condensation of phase I, II and III. This material was not overwet with 30 percent granulation fluid. Furher, phase $V$ was not apparent in the torque profile. This instrumentation is sensitive to changes in the particle size of raw materials. This behaviour with coarse size lactose can be related to the total surface area of the powder; with particle size increase, the surface area decreases, so the quantity of liquid needed to create bonds between particles is also less. The quantity of liquid required for granulation is a straight line function of the inverse of the particle size (97).

Figure 78 shows the effect of different levels of sucrose (soluble material) in the formulation on the torque profiles. The results show that the higher the level of soluble material in the formulation, the lower the amount of granulating fluid required for optimum granulation process. The granulation fluid required for agglomeration seems to be a function of log concentration of the soluble material in the formulation. Obviously, we need much more data and this should be a subject of future research. Hardesty reported $(33,34)$, that the moisture requirement for agglomeration decreases linearly with increasing proportion of salt in the granulation fluid. 


\section{FIGLRE 77}

Formulations 14 and 15:

Effect of different grades of lactose on the torque profile

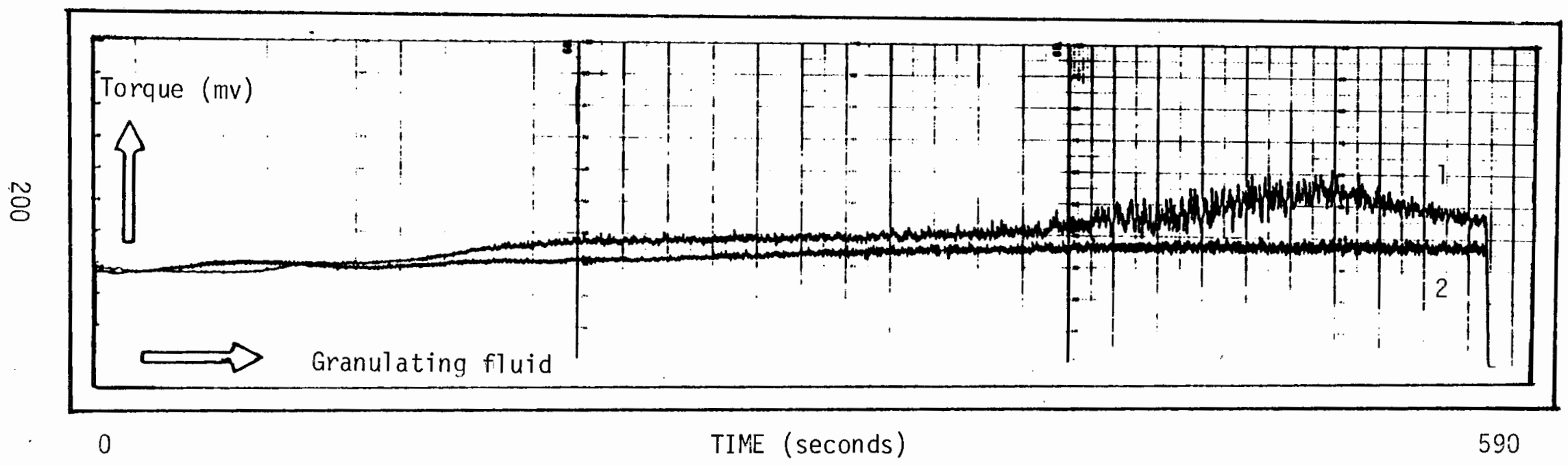

1. Formulation 14

2. Formulation 15 
FIGURE 78

Formulations $16-19$ :

Effect of different levels of Sucrose on the torque profile

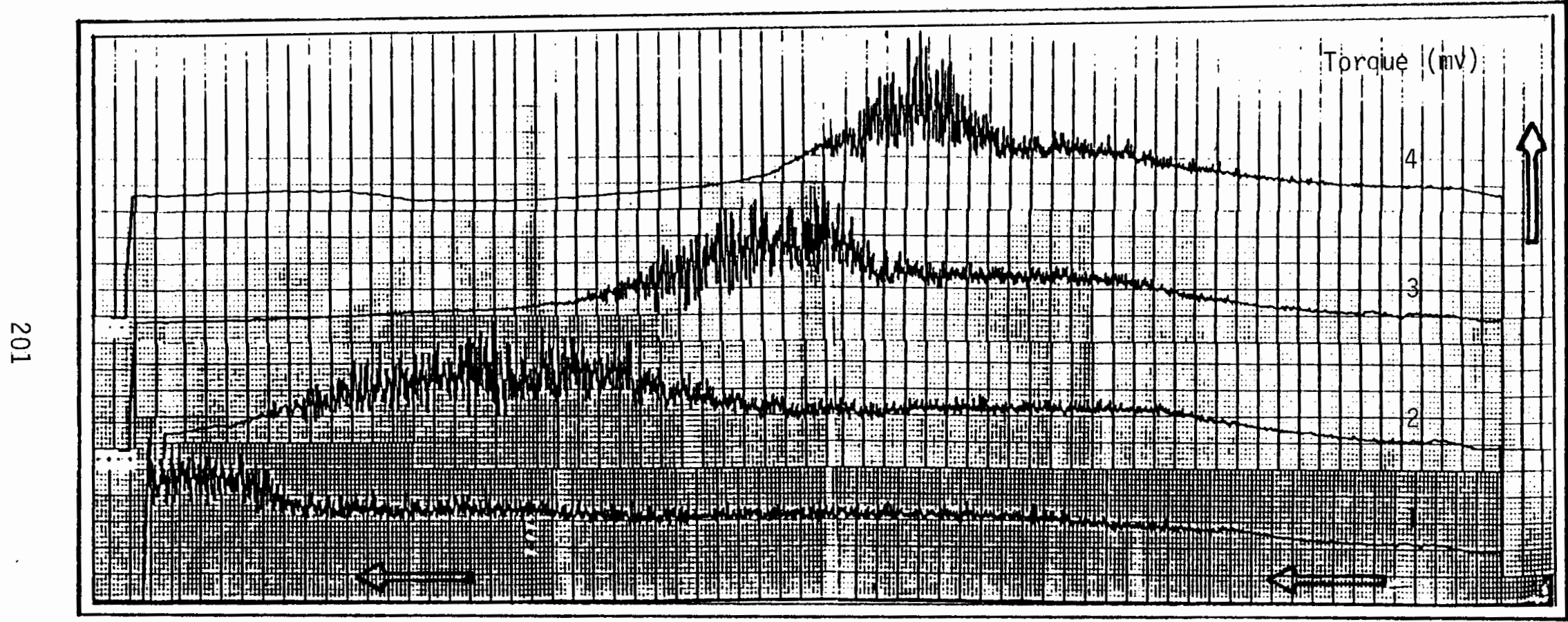

600

TIME (seconds)

1. Formulation 16 (0\% sucrose)

3. Formulation 18 (10\% sucrose)

2. Formulation 17 ( $5 \%$ sucrose)

4. Formulation 19 (20\%-ucrose) 
Figure 79 shows the effect of different levels of Avicel PH 101 in the lactose formulation on the torque profiles. These torque profiles indicate that the increase in Avicel PH 101 in the formulation, results in an increase in the volume of granulating fluid needed for optimum granulation. This phenomenon may be due to the rapid diffusion of granulating fluid into the inner pores so that the amount of liquid available on the surface of the powder for agglomeration decreases. Different levels of microcrystalline cellulose in highly soluble matrix formulations are of interest for future work.

Figure 80 shows the effect of rate of mixing of the lactose formulation on the torque profiles. These curves indicate that the increase in rate of mixing caused the decrease in the amount of granulating fluid required for optimum granulation. A probable explanation is that the higher paddle speed causes faster densification of granules, squeezes the intragranular liquid out, and that results in excess surface moisture. The excess of free surface liquid provided rapidly results in agglomeration of nuclei into large agglomerates and the process goes into phase IV faster than the process which has slow mixing.

The granule size needed in the pharmaceutical industry is much smaller than in the fertilizer industry. Important contributions were made in the field of granule growth mechanism in the fertilizer industry by Newitt and Conway Jones, Kapur and Fuerstenau, Capes and Danckwerts, Rumpf, and Sastry. All the researchers studied granule growth mechanism in a wet pelletising dish or rotary drum. Three different mechanisms of granule growth were agreed to by most workers (i.e., coalescence, 
FIGURE 79

Formulations $20-22$ :

Effect of different levels of Avicel PHlol on the torque profile

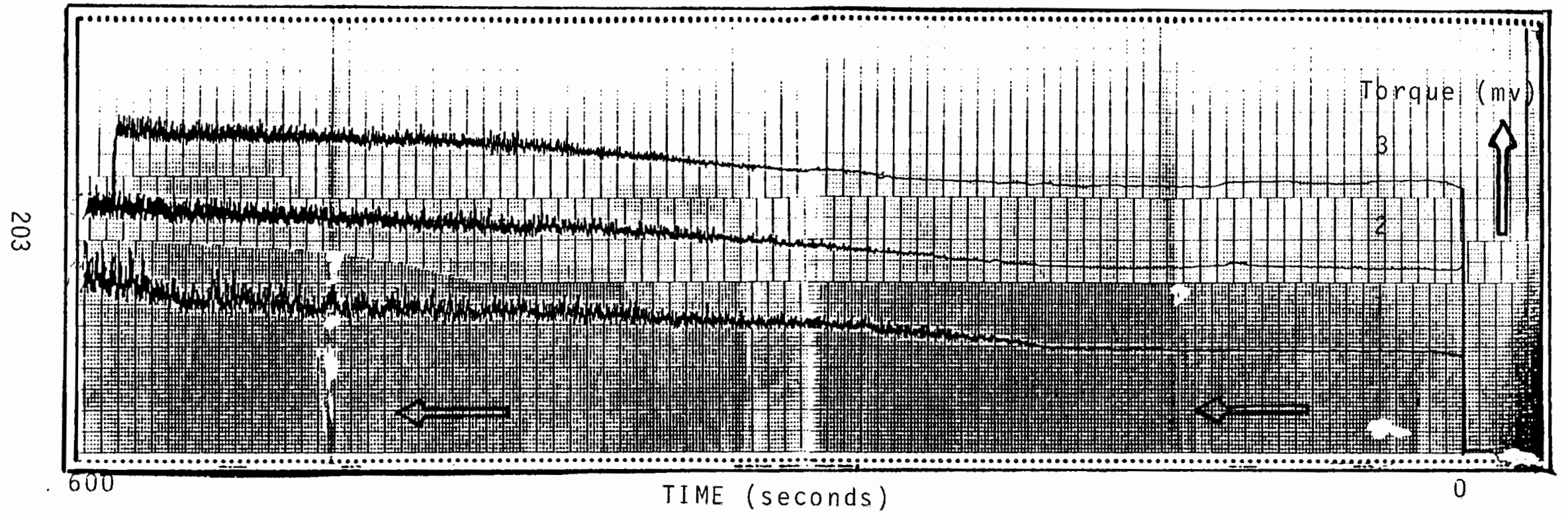

1. Formulation 20 ( $5 \%$ Avicel)

2. Formulation $22(20 \%$ Avicel)

2. Formulation 21 (10\% Avicel) 


\section{FIGURE 30}

Formulation 23:

Effect of different rates of mixing on the torque profile

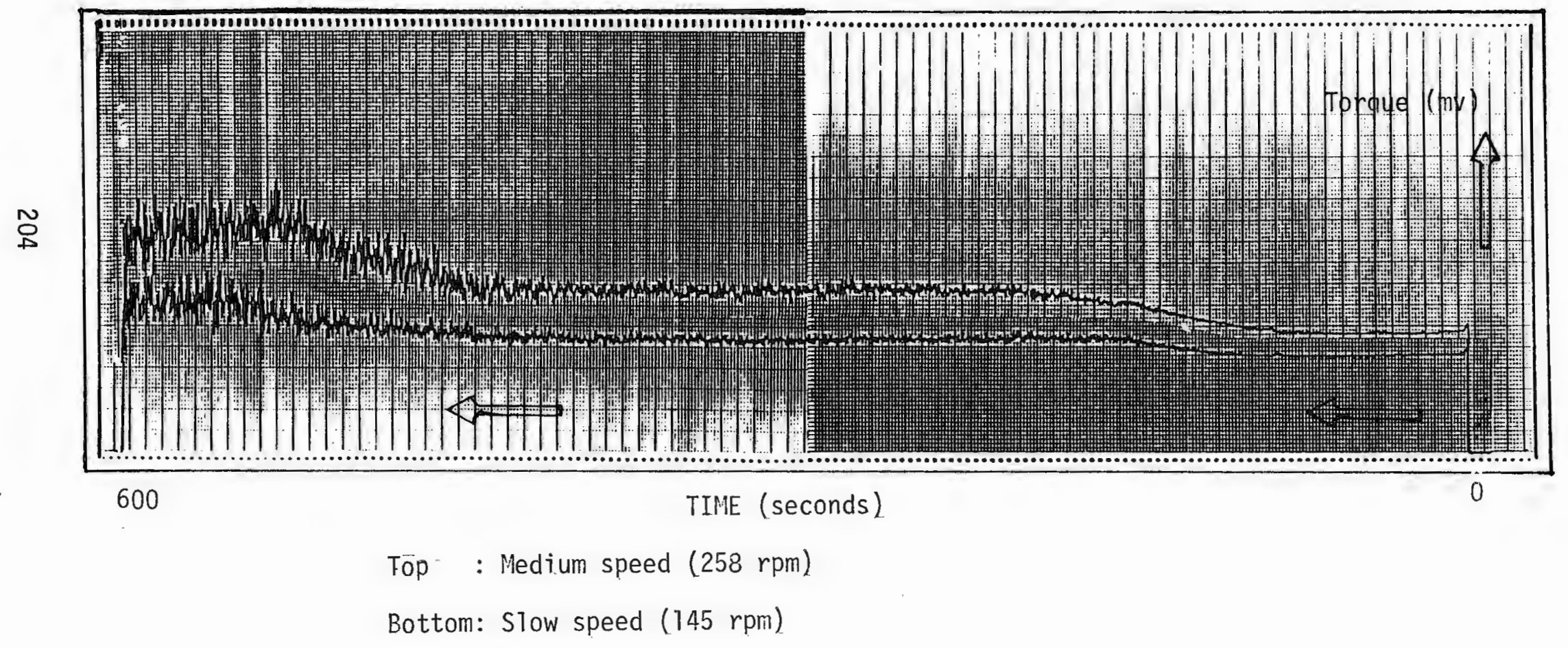


layering, and nucleation by coalescence and granule growth by layering). In the present study, scanning electron micrographs of the granulations suggest that the granule growth is due to a coalescence mechanism. These photographs also indicate that nucleation of granulation is in progress from phase I of the process. The actual granule growth was observed visually in phase III of the process. At the end of phase III, all the granules were wet and shiny. This observation suggests that the capillary state (23) is reached (all the pore spaces in the granules are completely filled). Due to the shear and compaction forces in the planetary mixer, these granules grow uncontrollably and form a pasty mass in phase IV of the process. If we stop adding the granulating fluid at the end of phase III and roll the granulations in a rolling drum we may cause further granule growth without forming a pasty mass. In the pharmaceutical field, we are not interested in agglomerates of a size greater than $2 \mathrm{~mm}$. The author of this thesis strongly feels that the moisture available on the surface of the solid material is the only liquid available for agglomeration. This can be achieved by adding granulation fluid at a slow rate or atomizing the granulation fluid and mixing the solid material for uniform dispersion of liquid. There may be a relationship between the liquid addition rate and time of mixing to achieve uniform wetting of the solid surface.

The use of torque measuring devices with the large scale equipment is possible without radical modification of the equipment. There are many different torque measuring instruments available commercially. It is a matter of finding a suitable location on the equipment at which to install appropriate instruments. If the equipment is operated by a 
syncronous motor, the power consumption of the motor is a direct function of torque applied on the mixing paddle. Leuenberger (39) has shown that the power consumption method allows an effective monitoring of the granulation process scaleup. He demonstrated linearity of the measurements (granulation fluid needed for different phases) in charges ranged from $3.75 \mathrm{~kg}$ up to $60 \mathrm{~kg}$ using different types of equipment. The ratio of batch size to rate of addition was kept constant. This author investigated only one formulation. Although one can keep the ratio of batch size to granulating fluid addition constant, there are many other variables that can affect the process.

Process validation is a systematic approach aimed at identifying, measuring, evaluating, documenting and reevaluating a series of critical steps in the manufacturing process that require control if a reproducible final product is to be obtained. The wet granulation process is one of the critical steps in the tableting manufacture. This study supports the simple theory that the quality of the tablets manufactured is often very largely dependent upon the quality of the granulations used. The amount of granulating fluid, mixing time, drying time, and sizing of the dried granules are the critical variables involved in the granulation process. The instrumentation described in this thesis is a valuable tool in quantifying the amount of granulating fluid needed for optimum granulation irrespective of the type of matrix, drug, drug concentration, particle size, rate of addition of granulating fluid, type of granulating fluid and rate of mixing. 
In recent years (post 1982), other techniques for monitoring the granulation process have been investigated. Measurement of power consumption of a planetary mixer has been used to study wet massing in the granulation process and correlations have been made between the power consumption curve and the various phases of the wet massing process $(39,97$ and 98$)$. The torque profile of the formulation 1 showed a close similarity with the power consumption curve reported in the literature (39) of a very similar formulation. It is very difficult to compare the results of the present study with the literature data because of insufficient information in the literature such as equipment size, mixing rate, granulation fluid addition rate and amplification of signals. In general, it seems if all the variables are kept constant, the power consumption curve could be comparable to the torque profile. Leuenberger (39) suggested the following equation to make a theoreticle estimate of the quantity of granulation liquid required in the granulation process.

$$
W=\left\{\gamma \varepsilon \rho_{\ell} / \rho_{\ell} \varepsilon+(1-\varepsilon) \rho_{S}\right\}+\delta_{H}
$$

$W=$ weight fraction of granulating liquid needed for optimum agglomeration

$\bar{\gamma}=0.213$ (mean percent pore space between cubic and rhombohedral particle packing)

$\varepsilon=$ porosity obtained by tamped density measurements

$\rho_{s}=$ true density of particles

$\rho_{\ell}=$ density of granulating liquid 


$$
\begin{aligned}
\delta_{\mathrm{H}}= & \text { equlibrium moisture uptake of the solid materials when } \\
& \text { exposed to } 100 \% \text { relative humidity }
\end{aligned}
$$

This equation does not take into account of the solubility of the solid material in the granulation fluid, and also the $\delta_{H}$ term does not take into account that the solid which picks up moisture may also be soluble in the same moisture. For example this $\delta_{H}$ term predicts more moisture requirement for the formulation containing higher level of povidone. Povidone is highly hygroscopic material. The study in this thesis showed that as the povidone level in the formulation was increased, the granulation fluid required for optimum granulation was decreased. This finding is in agreement with the observation made by the present author that the higher the soluble material in the formulation, the lower the amount of granulating fluid needed for optimum granulation.

Paris et al. (97 and 98) studied the effect of other variables on wet granulation. These authors, however, passed the wet granulation through a screen which made their study is of limited value. They concluded that some mixers are not convenient to produce a good power consumption recording, but for a given type of mixer, rate of mixing or batch size do not affect the optimal liquid quantity requirement for wet granulation. These authors showed that reduction in the particle size of lactose used for granulation caused an increase in the amount of granulation fluid needed for optimum granulation. Torque measuring equipment used in the present study showed that the mixing speed can affect the optimum quantity of liquid needed for wet granulation. The present study is in agreement with the later finding of the above authors. 
Alleva et al. (99) have studied the rheological properties of granulations using the resistance to movement of instrumented deflection beams through a shallow bed of granulation. Static measurements are of limited value in quantifying the wet granulation process. This test requires stopping the process and sampling the granulation for testing the reological properties of the wet mass.

Fry et al. (100) have been used the moisture analyzer interfaced with a computer to study the granulation process. This instrumentation seems to be a more valuable tool to check the distribution of moisture in the powder bed rather than to quantitate the wet granulation process. Holm et al. (101-104) studied the granulation of lactose and dicalcium phosphate in a high speed mixer (Fielder). These authors subjectively selected ten and fifteen percent of granulation fluid and studied the effects of process variables on the granulation process. These authors showed the increase in impeller speed causes a decrease in the volume of granulating fluid needed for wet granulation. This finding agrees with the observation reported in this thesis. They also concluded that the dicalcium phosphate granule growth is very sensitive to the amount of liquid added, whereas in case of lactose, the granule growth is more gradual. The dicalcium phosphate requires liquid saturation of about $90 \%$ for significant granule growth and lactose needs liquid saturation less than $50 \%$ for granule growth. The author of this thesis has noticed a similar effect with dicalcium phosphate and lactose in a planetary mixer. 


\section{CONCLUSIONS AND SUGGESTIONS FOR FUTURE WORK}

The following are believed to be the major points of this work as reported and discussed in the previous section.

1. The instrumentation described in this study can be assembled using commercially available equipment. It is cheap and convenient. The data generated by this instrumentation are reproducible.

2. This instrumentation is sensitive to all formulation and processing variables.

3. Formulations containing widely used lactose, dicalcium phosphate or mannitol matrices produce torque profiles with five distinct phases. The study of these phases of the wet granulation process showed that the optimum flowable and compressible granulations can be obtained only from phase III of the process irrespective of the drug, drug concentration and matrix.

4. Scanning electron micrographs of granulations suggest that the mechanism of granule growth is due to a coalescence mechanism.

5. Finer starting materials require more granulating fluid for optimum granulation compared to the coarser starting materials.

6. Increase in soluble material in the formulation causes a decrease in the amount of granulating fluid necessary for optimum granulation. 7. As the concentration of drug or soluble material in the formulation is increased, the granulation process becomes more sensitive to process variables. 
8. Binder, binder level and granulating fluid exert statistically significant effects on flow rate, tablet hardness, and disolution at fifteen and 30 minutes.

9. Disintegrant, disintegrant level and percent intragranular disintegrant exert statistically significant effects on disintegration and dissolution at fifteen and 30 minutes.

10. Low viscosity binders (Methocel LV15) do not produce satisfactory granules due to their poor bonding strength.

11. Some tablet properties are more sensitive (hardness, and disintegration) to process variables than others (dissolution and friability) in the granulation process.

12. This instrumentation is a valuable tool for optimization and validation of wet granulation process.

Suggestions for future research

1. There is a need for an equation which can estimate the amount of granulating fluid needed for optimum granulation process. The following variables have to be given some attention in developing the equation. Particle size (or surface area), shape, porosity, density, solubility in the granulating fluid (or rate of dissolution of the material in the granulating fluid), moisture sorption, granulation liquid density, surface tension, and rate of mixing.

2. Electronic equipment should be developed to automate the granulation process using the torque measurements. 
3. Granulation fluid requirement may be a function of $10 \mathrm{~g}$ concentration of the soluble material in the formulation. This observation should be explored.

4. Formulations containing different concentrations of microcrystalline cellulose with highly soluble solids should be investigated. Microcrystalline cellulose may control the moisture available on the surface of the solids in the granulation process, and the granule growth may be uniform.

There is thus an immense amount of further research required before our knowledge of the granulation process can even be described as adequate. The field does not lack challenge, interest or opportunity. The big question, however, remains as always: is there ever likely to be sufficient motivation and skill for the very demanding experimental and theoretical work required? 


\section{REFERENCES}

1. "The United States Pharmacopoeia ", 20th ed., United States Pharmacopoeial Convention, Inc., Rockville, Maryland (1980).

2. King, R.E., in "Remington Pharmaceutical Sciences ", vol.16, Mack publishing company, Eaton, PA (1980) p. 1553 - 1584.

3. Banker, G.S., Peck, G.E., and Baley, G., in "Pharmaceutical Dosage Forms: Tablets ", vol.1 eds. Lieberman, H.A., and Lachman, L., Marcel Dekker, Inc., New York (1980) p.61.

4. Cooper, J., in Bean, H.S., et al.,eds: "Advances in Pharmaceutical Sciences ", vol. 3, Acadamic, New York, (1971).

5. Cooper, J., and Rees, J.E., J. Pharm.Sci. 61, 1511, (1972).

6. Evans, A.J., and Train, D., in "Bibliography of the Tableting of Medicinal Substances "1st suppl, Pharmaceutical Press, London, (1963).

7. Gunce1, W.C., Swartz, C.J., and Kanig, J.L., in "The Theory and Practice of Indusrial Pharmacy "eds. Lachman, L., Lieberman, H.A., and Kanig, J.L., Lea \& Febiger, Philadelphia, PA (1970).

8. Sheth, B.B., Bandelin, F.J., and Shangraw, R.F., in "Pharmaceutical Dosage Forms: Tablets ", vol.1 eds. Lieberman, H.A., and Lachman, L., Marcel Dekker, Inc., New York (1980).

9. Mendes, R.W., and Roy, S.B., Pharm. Tech., 2 (Sept):61, (1978).

10. Sherrington, P.J., and Oliver, R., "Granulation ", Heydon \& Son, Ltd. , London (1981) p.1.

11. Finholt, P., in "Dissolution Technology ", Leeson, L., and Carstensen, J.T., A.Ph.A. Academy of Pharmaceutical Sciences, Washington, D.C. (1974).

12. Capes, C.E., " Proceedings of Powtech 71 ", Hargate, England, Powder Advisory Center, London (1972) p.149.

13. Mehta, A., Adams, K., Zoglio, M.A., and Carstensen, J.T., J. Pharm. Sci., 66, 1462 (1977).

14. Sastry, K.V.S., and Fuerstenau, D.W., Powder Technology 7, 97-105 (1973).

15. Linkson, P.B., Glastonbury, J.R., and Duffy, G.J., Trans. Inst. Chem. Eng., 51, 251 (1973). 


\section{REFERENCES (continued)}

16. Rumpf, H., Chem. Ing. Tech., 30, 144 (1958) through ${ }^{*}$ The Eng. Index p.528 (1958).

17. Ibid., 46, 1 (1974).

18. Hardesty, J.0., Chem. Eng. Progr. Symp. Ser., 60 (48), 46-52 (1964).

19. Rumpf, H., Chap. The strength of granules and agglomerates, in "Agglomeration ", ed. Knepper, W.A., Wiley - Interscience, New York (1962).

20. Fisher, R.A., J. Agr. Sci., 16, 492 (1926).

21. Ibid., 18,406 (1928).

22. Haines, W.B., J. Agr. Sci., 20, 97 (1930).

23. Newitt, D.M., and Conway-Jones, J.M., Trans. Inst. Chem. Engr., 36, 422-442 (1958).

24. Pietsch, W., Trans. ASME B 91 (2), 435 (1969).

25. Pietsch, W., and Rumpf, H., Chem. Ing. Tech., 38 (3), 371 (1966).

26. Pietsch, W., Can. J. Chem. Eng., 47, 403 (1969).

27. Capes, C.E., and Danckwerts, P.V., Trans. Inst. Chem. Eng., 43, T 116 (1965).

28. Kapur, P.C., and Fuerstenau, D.W., Trans. AIME 229, 348 (1964) through The Eng. Index p.1152 (1965).

29. Kapur, P.C., and Fuerstenau, D.W., Ind. Eng. Chem. Process Des. Dev., 5 (1), 5 (1966).

30. Sherrington, P.J., Chem. Eng., 220, 201 (1968).

31. Kapur, P.C., Chem. Eng. Sci., 27, 1863 (1972).

32. Kapur, P.C., Arora, S.C.D., and Subbarao, S.V.B., Chem. Eng. Sci., $28,1535(1973)$.

33. Hardesty, J.0., Chem. Eng. Prog., 51, 291 (1955).

34. Hardesty, J.0., Szabo, A., and Cummings, J.G., J. Agric. Food Chem., 4, 60 (1956).

35. Capes, C.E., Germain, R.J., and Coleman, R.D., Ind. Eng. Chem. Process Des. Dev., 16, 517 (1977). 
REFERENCES (continued)

36. Leuenberger, H., Bier, H.P., and Sucker, H., Pharm. Tech. Int., 2 (3), 35-42, (1979).

37. Ibid., Pharm. Tech., 3, 61-68 (June 1979).

38. Bier, H.P., Leuenberger, H., and Sucker, H., Pharm. Ind., 41, 375-80 (1979).

39. Leuenberger, H., Pharm. Acta. Helv., 57, 72 (1982).

40. Toyoshima, S., Watanabe, S., Matsuo, K., and Kasai, M., Yakugaku Zasshi 91, 1088 (1971).

41. Hunter, B.M., and Ganderton, D., J. Pharm. Pharmac., 25, supp1., $71 p-78 p(1973)$.

42. Lindberg, N.-0., Leander, L., Wenngren, L., Helgesen, H., and Reenstierna, B., Acta Pharm. Sueciaca 11, 603-620 (1974).

43. Travers, D.N., Rogerson, A.G., and Jones, T.M., J. Pharm. Pharmac., $27,3 p(1975)$.

44. Lindberg, N.-0., Leander, L., Nilsson, P.G., and Reenstierna, B., Acta Pharm. Suecica 14, 191-196 (1977).

45. Lindberg, N.-0., Leander, L., and Lamm, C.J., Acta Pharm. Suecica 18,102 (1981).

46. Lindberg, N.-0., Leander, L., and Reenstierna, B., Drug Dev. and Ind. Pharmacy $8(5), 775-782$ (1982).

47. Spring, M.S., Drug Dev. and Ind. Pharmacy 9 (8), 1507-1512 (1983).

48. Hutchins, H.H., Cacosa, A.G., Hart, E.G., and Stienberg, W.H., J. Pharm. Sci., 54, 776 (1965).

49. Flesch, C.J., Pharm. Ind., 40, 758 (1978).

50. Kay, D., and Record, P.C., Mfg. Chemist and Aer. News 49 (9), 45 (1978).

51. Record, P.C., Ibid., (11), 65 (1979).

52. Tainsh, D.A., and Summers, M.P., J. Pharm. Pharmac., 34, supp1, 47p (1982).

53. Andersson, J., and Lindberg, N.-0., Drug Dev. and Ind. Pharmacy 9 (8), 1495-1505 (1983). 
REFERENCES (continued)

54. Titley, P.C., J. Pharm. Pharmac., 35, supp1. 111p (1983).

55. Arumbolo, A.S., Drug Dev. and Ind. Pharmacy 5, 523 (1979).

56. Federal Register, vol, 43-No 190 9/29/70 pages 45013-45089 U.S printing office, Washington, D.C.

57. Byers, T.E., "Validation: A systematic Approach to quality Assuarance". Pharm. Tech. Conference, New York, NY (Sep., 1981).

58. Loftus, B.E., "Validation Protocol: The Bottom line, proprietary Association" Manufacturing control seminar, Cherry Hill, NJ (0ct. 9, 1980).

59. Byers, T.E., "Role of Product and Process Design in Assuring Quality", Good Manufacturing Practice Conference, Cherry Hill, NJ (Feb., 1977).

60. Von Doehran, P.J., "An Approach to the characterization of Sol id Dosage Forms", Pharm. Tech. Conference, New York, NY (Sep.,1981).

61. Harpaz, D., "Process Evaluation / Validation of Solid Dosage Forms", Pharm. Tech. Conference, New York, NY (Sep.,1981).

62. Samyn, J.C., "New product validation Begins in R \& D", Pharmaceutical Manufacturers Association seminar on validation, Atlanta, Georgia, (May, 1980).

63. Berry, I.R., "Process validation of raw materials", Pharmaceutical Technology 2, 38-39 (1981).

64. Kumkumian, C., "0.K, your Candidate Drug has Activity. Now what?" Chem. Tech., 3, 178-180 (1980).

65. Rippie, E.G., chap. Mixing in "Theory and practice of Industrial Pharmacy", eds. Lackman, L., Lieberman, H., and Kanig, J., 2d.ed. Lea \& Febiger, Philadelphia, PA (1976).

66. Rudolph, J.S., chap. Validation of Solid Dosage Forms in "Pharmaceutical Process Validation", ed. Loftus, B.T., and Nash, R.A., Marcel Dekker, Inc., New York, NY (1984).

67. Butler, Q.A., and Ramsey, J.C., Drug Std., 20, 217 (1952).

68. Carr, R.L., Chem. Eng., 72, 163 (January 1965).

69. Jordan, R.P., and Rhodes, C.T., Drug Dev. and Ind. Pharmacy 5 (2), 151-167 (1979). 


\section{REFERENCES (continued)}

70. Hegde, R.P., and Rhodes, C.T., Pharm. Acta. Helv. 60 (20), 53 (1985).

71. Fonner Jr., D.E., Banker, G.S., and Swarbrick, J., J. Pharm. Sci., 55 (2), 181 (1966).

72. Hunter, B.M., and Ganderton, D., J. Pharm. Pharmac., 24, Suppl., 47P-56P (1974).

73. Nagykaldi, A., and Gyarmati, L., Pharm. Ind., 42, 526 (1980).

74. Carstensen, J.T., Lai, T., Flickner, D.W., Huber, H.E., and Zoglio, M.A., J. Pharm. Sci., 65, 992 (1976).

75. Ganderton, D., and Hunter, B.M., J. Pharm. Pharmac., 23, Supp1., 1s-10s (1971).

76. Zoglio, M.A., Huber, H.E., Koehne, G., Chan, P.I., and Carstensen, J.T., J. Pharm. Sci., 65, 1205 (1976).

77. Zoglio, M.A., and Carstensen, J.T., Drug Dev. and Ind. Pharmacy 9 (8), 1417 (1983).

78. Chalmers, A.A., and Elworthy, P.H., J. Pharm. Pharmac., 28, 228-233 (1976).

79. Ibid., 28, 234-238 (1976).

80. Chowhan, Z.T., and Yang, I.C., J. Pharm. Sci., 72(9), 983, (1983).

81. Shotton, E., and Leonord, G.S., J. Pharm. Sci., 65(8), 1173 (1976).

82. Ganderton, D., and Selkirk, A,B., J. Pharm. Pharmac., 24, Suppl., 17P-24P (1972).

83. Steiner, G., Patel, M., and Carstensen, J.T., J. Pharm. Sci., 63(9), 1397 (1974).

84. Esezobo, S., and Pilpel, N., J. Pharm. Pharmac., 26, Suppl., 47P-56P (1974).

85. Ridgeway, K., and Rubenstein, M.H., J. Pharm. Pharmac., 23, Supp1., $11 \mathrm{~s}-17 \mathrm{~s}(1971)$.

86. Carstensen, J.T., and Zoglio, M.A., J. Pharm. Sci., 71(1), 35 (1982).

87. Chowhan, Z.T., J. Pharm. Sci., 69(1), 1 (1980). 


\section{REFERENCES (continued)}

88. Opankunle, W.0., and Spring, M.S., J. Pharm. Pharmac., 28, 508-511 (1976).

89. Ibid., 28, 806-809 (1979).

90. Jaiyeoba, K.T., and Spring, M.S., J. Pharm. Pharmac., 31, 197-200 (1979).

91. Schildcrout, S.A., J. Pharm. Pharmac., 36, 502-505 (1984).

92. Lebow Products Catalog No: 250 C, Eaton Corporation, Troy, MI

93. Paruta, A.N., Sciarrone, B.J., and Lordi, N.G., J. Pharm. Sci., 54, $6(1965)$.

94. Schwartz, P.A., Rhodes, C.T., Cooper, J.W. Jr., J. Pharm. Sci., 66 994 (1977).

95. Paruta, A.N., Irani, Shapur A., J. Pharm. Sci., 54, 9 (1965).

96. " SAS Users Guide, " 1984 ed., SAS Institute, Cary, NC

97. Paris, L., and Stamm, A., Drug Dev. and Ind. Pharmacy 11 (2\&3), 361-386 (1985).

98. Stamm, A., and Paris, L., Drug Dev. and Ind. Pharmacy 11 (2\&3), 333-360 (1985).

99. Alleva, D.S.,Schwartz, J.B., and Schnarre, R.L., "Granulation Rheology 11: Granule Formation as a function of Liquid Level and Mixing Time," Academy of Pharmaceutical Sciences Meeting, April 1983.

100. Fry, W.C., Stagner, W.C., and Wichman, K.C., J. Pharm. Sci., $73(3), 420-421(1984)$.

101. Holm, P., Jungersen, 0., Schaefer, T., and Kristensen, H.G., Pharm. Ind. $45(8), 806(1983)$.

102. Ibid., 46 (1), 97 (1984).

103. Jaegerskou, A., Holm, P., Schaefer, T., and Kristensen, H.G., Pharm. Ind., 46 (3), 310 (1984).

104. Kristensen, H.G., Holm, P., Jaegerskou, A., and Schaefer, T., Pharm. Ind., 46 (7), 763 (1984).

* The word through refers, abstract was read through a secondary source. 
VI. APPENDICES 


\section{APPENDIX 1}

\section{Program to calculate tablet dissolution:}

The following Basic program for Apple PC calculates tablet dissolution using: volume of dissolution medium, individual tablet weight, sampling volume, dilution factor, absorbance (reference) values as a function of concentration, and the absorbance (test) values as a function of time. The output displays the values of slope, intercept, coefficient of determination of Beer's plot, mean percent drug dissolved, and amount of drug dissolved in dissolution medium as a function of time. In addition, it also calculates mean $T_{50}, T_{75}, T_{90}$ and standard deviation. 


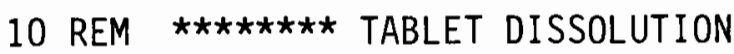

20 PRINT " TABLET DISSOLUTION PROGRAM. WRITTEN BY S.R. GHANTA "

30 PRINT

40 PRINT

50 PRINT " IF MISSING A SAMPLE ENTER INVERSE TIME AND 0 FOR ABSORBANCE "

60 PRINT

70 PRINT

80 INPUT " PRODUCT NAME ";N\$

90 PRINT

100 INPUT " LOT \# ";M\$

110 PRINT " ENTER TOTAL VOLUME IN ML OF DISSOLUTION MEDiA "; A

120 PRINT

130 INPUT " ENTER AMOUNT IN ML OF SAMPLE WITHDRAWN ";C

140 PRINT

150 INPUT " DILUTION FACTOR "; DF

160 PRINT

165 INPUT " ENTER PERCENT ACTIVE IN THE TABLET "; PA

170 FOR $I=1$ TO $D$

$180 F(I)=0: E(I)=0: E=0$

190 NEXT I

200 INPUT " ENTER TABLET WEIGHT "; W

$205 \mathrm{~L}=W * P A$

210 PRINT

220 INPUT " ENTER \# OF SAMPLES ";D

230 PRINT

$240 D \$=" M G / M L "$ 
250 PRINT

260 PRINT " ENTER SAMPLE ABSORBANCE, COMMA, AND TIME "

270 FOR I $=1$ TO $D$

280 INPUT A (I), B (I)

290 NEXT I

300 IF $R=1$ THEN 320

310 GOSUB 730

$3200 \$=" M G / 900 \mathrm{ML} "$

330 PRINT

340 PRINT " TIME ", $0 \$, \quad$ \% LABEL"

350 PRINT

$360 F(1)=((A(1)-B 2) / B 1) * A * D F$

$370 Q(1)=(\operatorname{INT}((F(1) / L) * 10000) / 10000) * 100$

$380 \operatorname{IF~} A(1)=0$ THEN $V(1)=V(1)+1: Q(1)=0: F(1)=0$

390 PRINT B (1), INT $(F(1) * 1000) / 1000, Q(1)$

400 IF $D=1$ THEN 500

410 REM $\star \star \star \star \star *$ ERROR ROUTINE

420 FOR I $=2$ TO D

$430 E(I)=F(I-1) / A * C$

$440 E=E+E(I)$

$450 F(I)=(((A(I)-B 2) / B 1) * A * D F)+E$

$460 Q(I)=(\operatorname{INT}((F(I) / L) * 10000) / 10000) * 100$

$470 \operatorname{IF~} A(I)=0$ THEN $V(I)=V(I)+1: Q(I)=0: F(I)=0$

480 PRINT B (I), INT (F (I) * 1000) / 1000 , Q (I)

490 NEXT I

500 FOR I $=1$ TO D 
$510 \mathrm{C}(\mathrm{I})=(\mathrm{F}(\mathrm{I}) / \mathrm{L}) * 100$

520 NEXT I

$530 \mathrm{P} 1=50:$ GOSUB $600:$ GOSUB 960

$540 P 1=75:$ GOSUB $600:$ GOSUB 980

$550 \mathrm{P1}=90:$ GOSUB $600:$ GOSUB 1000

560 PRINT

570 PRINT " TYPE 1 FOR MORE SAMPLES OR 0 TO END '

580 INPUT $G$

590 IF $G=1$ THEN $R=1$ : GOSUB $1140:$ GOSUB 1020 : GOSUB 1210

$600 \mathrm{FOR} I=1 \mathrm{TO} D$

$610 A 9=P 1-C(I)$

620 IF A9 $\therefore=0$ THEN GOSUB 650

630 NEXT I

640 RETURN

$650 Y_{2}=C(I): Y_{1}=C(I-1): X 2=B(I): X 1=B(I-1)$

$660 X 3=X 1+(P 1-Y 1) *(X 2-X 1) /(Y 2-Y 1): I=D$

670 PRINT

680 PRINT " LINEAR INTEWRPOLATION "

$690 D \$=\operatorname{STR} \$(P 1): E \$=" T ": G \$="="$

$700 F \$=E \$+D \$+G \$$

710 PRINT F\$, X3

720 RETURN

730 INPUT "ENTER \# OF CALIBRATION POINTS "; N

740 PRINT

750 PRINT "INVERSE ENTER "; D\$;"INVERSE COMMA AND ABSORB. FOR THAT CONC." 
770 FOR I $=1$ TO N

780 INPUT $X, Y$

$790 \mathrm{~S} 1=\mathrm{S} 1+\mathrm{X}$

$800 \mathrm{~S} 2=\mathrm{S} 2+\mathrm{Y}$

$810 \mathrm{~S} 3=\mathrm{S} 3+\mathrm{x} \wedge 2$

$820 S 4=S 4+Y \wedge 2$

$830 S 5=S 5+X * Y$

840 NEXT I

$850 \mathrm{~B} 1=(\mathrm{N} * \mathrm{~S} 5-\mathrm{S} 2 * \mathrm{~S} 1) /(\mathrm{N} * \mathrm{~S} 3-\mathrm{S} 1 \wedge 2)$

$860 \mathrm{~B} 2=(\mathrm{S} 2-\mathrm{B} 1 * \mathrm{~S} 1) / \mathrm{N}$

870 PRINT

880 PRINT " SLOPE $=" ; B 1$

890 PRINT " INTERCEPT $=$ ";B2

$900 \mathrm{~S} 1=\mathrm{B} 1 *(\mathrm{~S} 5-\mathrm{S} 1 * \mathrm{~S} 2 / \mathrm{N})$

$910 \mathrm{~S} 4=\mathrm{S} 4-\mathrm{S} 2 \hat{\imath} 2 / \mathrm{N}$

$920 \mathrm{~S} 5=\mathrm{S} 1 / \mathrm{S} 4$

$930 \mathrm{~S} 6=\mathrm{S} 5 \wedge 2$

940 PRINT " CORRELATION DETERMINATION = ";S6

950 RETURN

$960 X 4=X 4+X 3: Y 5=Y_{5}+X 3 * X 3: Z 7=Z 7+1$

970 RETURN

$980 X 5=X 5+X 3: Y 6=Y 6+X 3 * X 3$

990 RETURN

$1000 X 6=X 6+X 3: Y 7=Y 7+X 3 * X 3$

1010 RETURN 
1020 IF $Z 7=1$ THEN 1300

$1030 M 4=X 4 / Z 7: M 5=\operatorname{SQR}((Y 5-(X 4) \wedge 2 / Z 7) /(Z 7-1))$

1040 PRINT " MEAN T50 ",M4

1050 PRINT " STD. DEV. T50 ", M5

$1060 M 6=X 5 / Z 7: M 7=\operatorname{SQR}((Y 6-(X 5) \wedge 2 / Z 7) /(Z 7-1))$

1070 PRINT " MEAN T75 ",M6

1080 PRINT " STD. DEV. T75 ",M7

$1090 M 8=X 6 / Z 7: M 9=\operatorname{SQR}((Y 7-(X 6) \wedge 2 / Z 7) /(Z 7-1))$

1100 PRINT " MEAN T90 ",M8

1110 PRINT " STD. DEV. T90 ",M9

1120 PRINT " TOTAL NUMBER OF TABLET RUNS = ",Z7

1130 RETURN

1140 FOR I $=1$ TO D

$1150 \times(\mathrm{I})=\mathrm{B}(\mathrm{I})$

$1160 S(I)=S(I)+Q(I) * Q(I)$

$1170 T(I)=T(I)+Q(I)$

1180 NEXT I

1200 RETURN

1210 PRint " Time ", "MeAn \% LABeL", "StD. DeV."

1220 FOR $I=1$ TO D

$1230 Y(\mathrm{I})=\mathrm{T}(\mathrm{I}) /(27-\mathrm{V}(\mathrm{I}))$

1240 PRINT X (I), (INT $(Y(I) * 1000)) / 1000$

1250 PRINT SQR ((S (I) - (T (I)^2)/(Z7 - V (I))) / ((Z7 - V (I)) -

1))

1260 IF $(Z 7-V(I))<=2$ THEN PRINT "STD. DEV. SAMPLE "; I;" NOT VALID" 1270 NEXT I 
1280 PRINT

1290 PRINT " DO YOU WANT TO RUN ANOTHER SET ? IF YES TYPE RUN" 1300 END 


\section{APPENDIX II}

A sample program to analyze data from unbalanced factorial design

General Linear Model - SAS Program 
$10 / /$ LKP101B J0B (LKP101), 'S.R.GHANTA', MSGCLASS=W,TIME $=(0,30)$

$20 / *$ JOBPARM LINES $=2$

$30 / /$ EXEC SAS

$40 / /$ GO.FT11FO01 DD SYSOUT =A,HOLD $=$ YES

$50 / /$ GO. FT12F001 DD SYSOUT $=A, H O L D=Y E S$

$60 / /$ GO.SYSIN DD *

70 TITLE EFFECT OF BINDER BINDER-CONCENTRATION AND GRANULATING FLUID;

80 DATA BINDERS;

90 INPUT ID BINDER B_C GF FLOW REP;

100 CARDS;

DATA SET

800 PROC PRINT;

810 TITLE2 LISTING OF THE DATA;

820 PROC GLM;

830 CLASSES BINDER B_C GF REP;

840 MODEL FLOW=BINDER B_C GF BINDER*B_C BINDER*GF B_C*GF BINDER*B_C*GF;

$850 /$ *

$860 / /$

A sample output can be found in SAS manual (96). 
APPENDIX III

Beer - Lambert's law plots of theophylline, phenylpropanolamine, hydrochlorothiazide, phenytoin, and acetaminophen. 
FIGURE 81

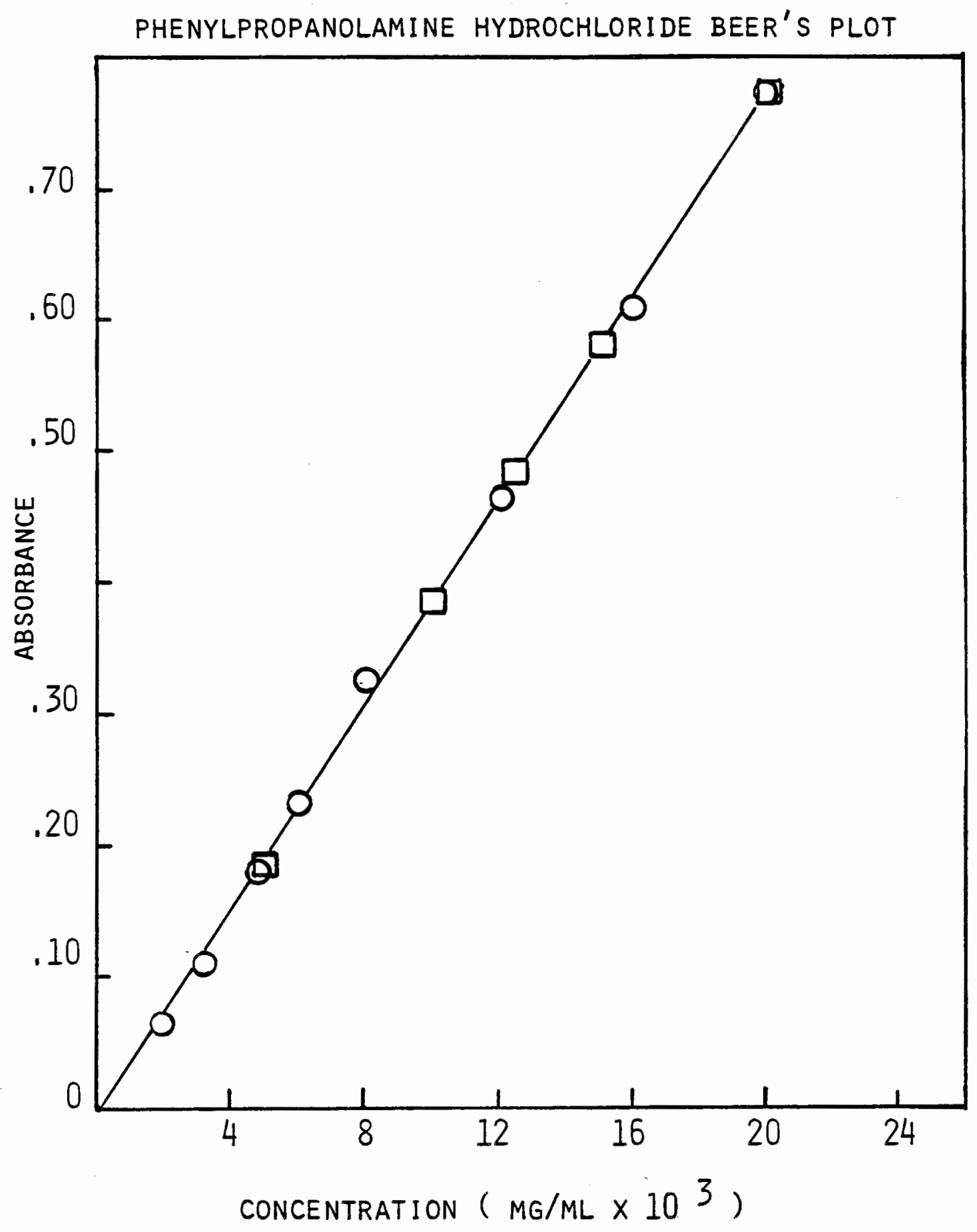


FIGURE 82

THEOPHYLLINE BEER'S PLOT

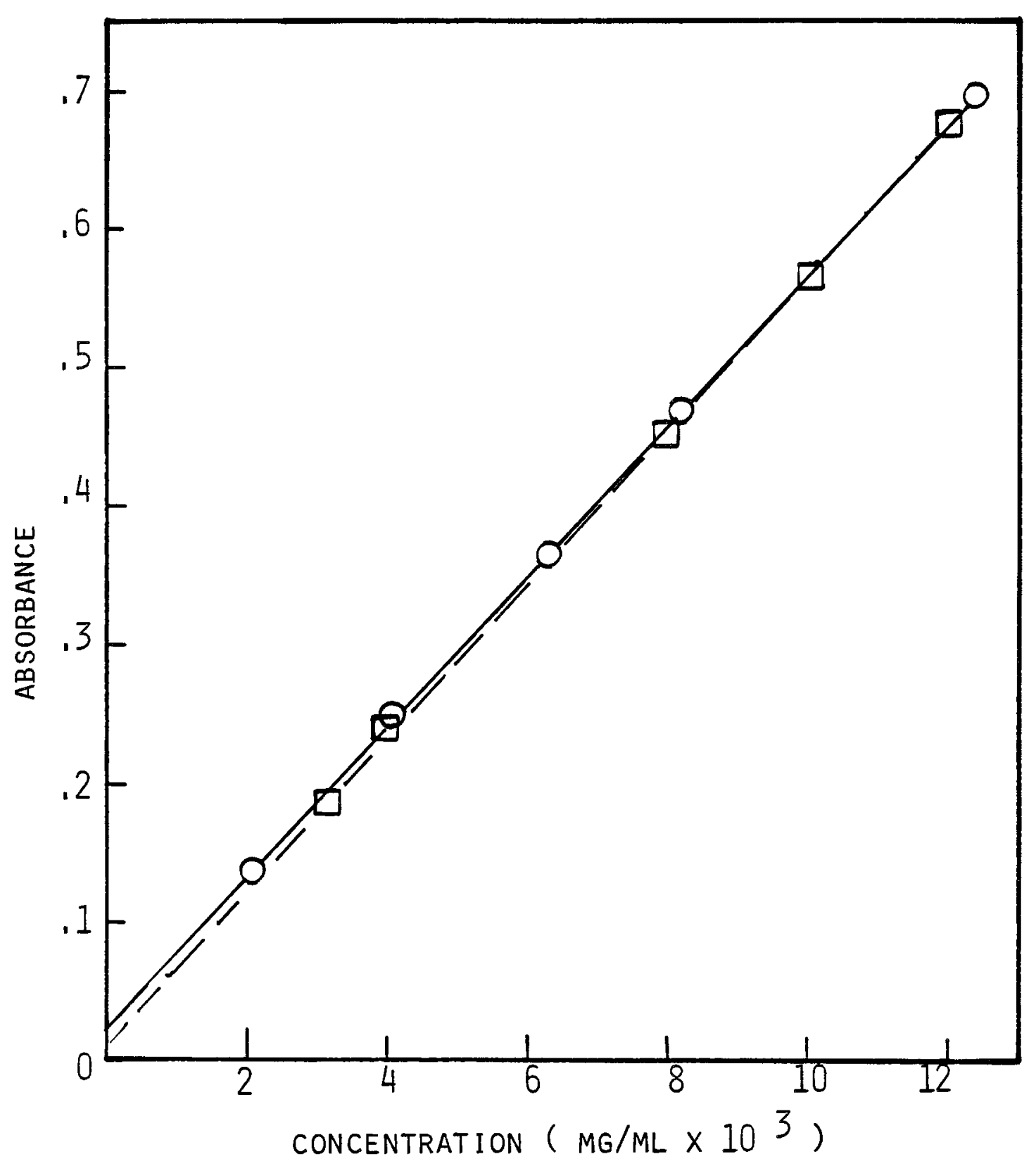




\section{FIGURE 83}

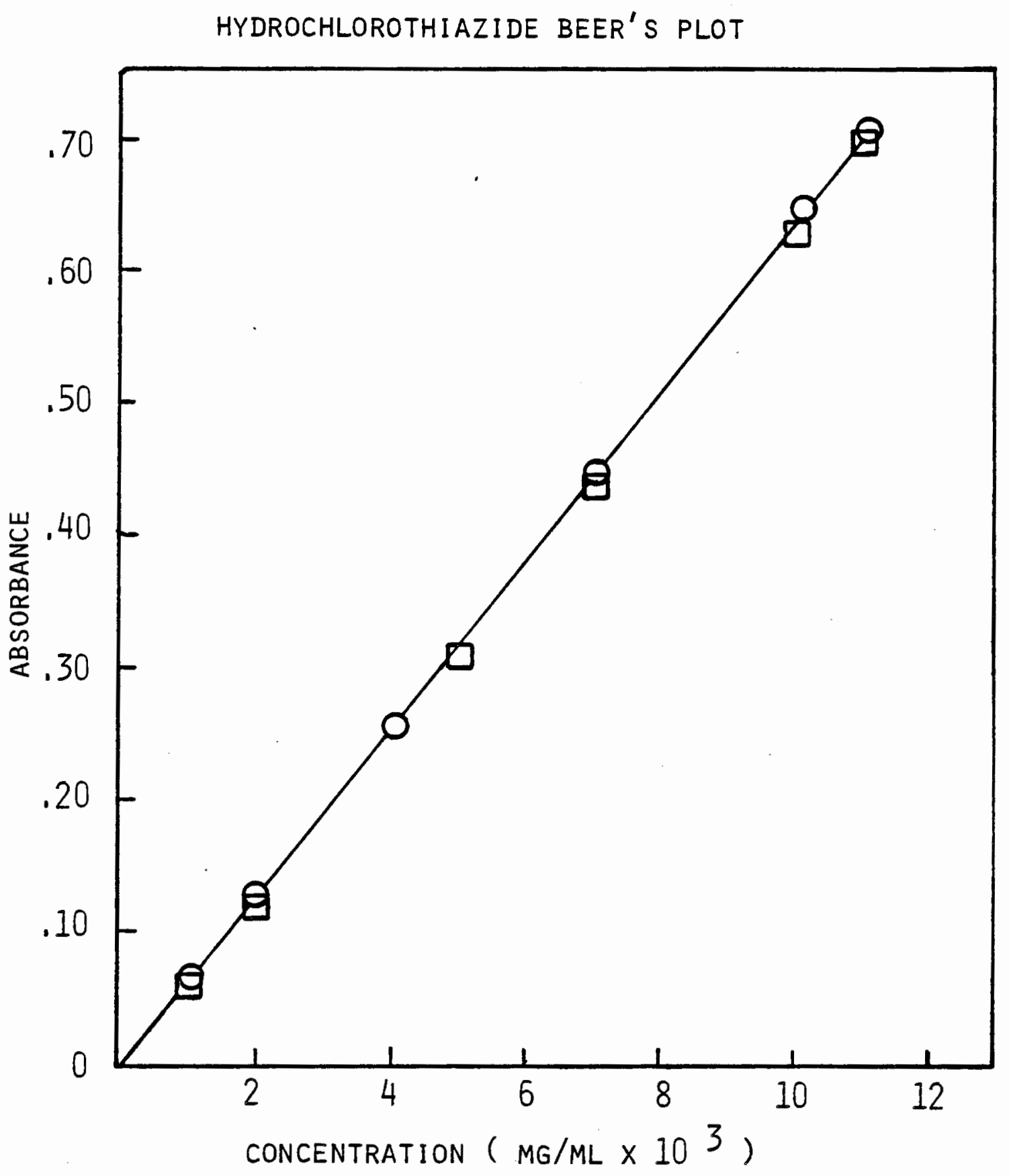


FIGURE 34

PHENYTOIN BEER'S PLOT

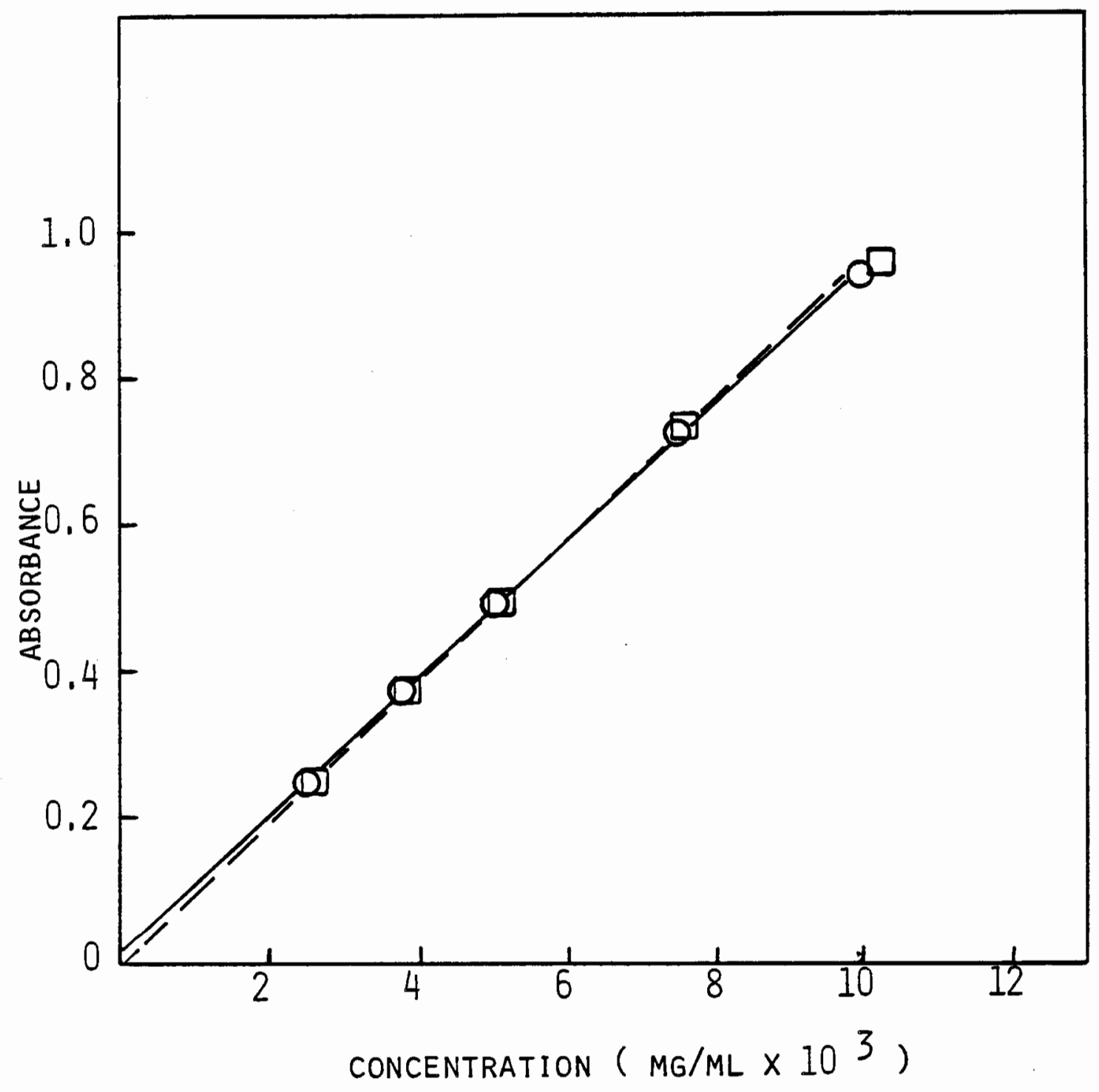




\section{FIGURE 85}

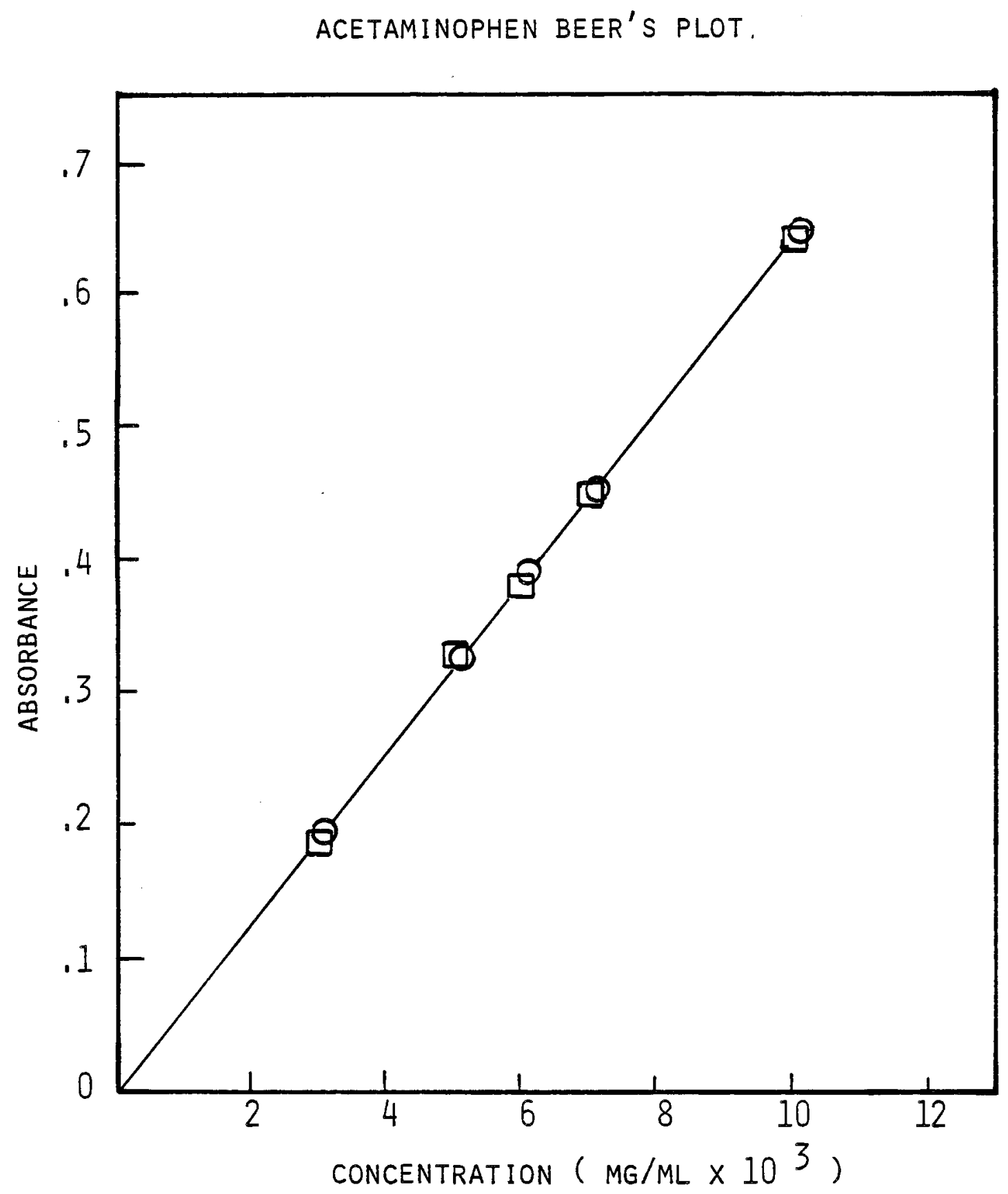




\section{BIBLIOGRAPHY}

Alleva, D.S.,Schwartz, J.B., and Schnarre, R.L., "Granulation Rheology II: Granule Formation as a function of Liquid Level and Mixing Time," Academy of Pharmaceutical Sciences Meeting, April (1983).

Andersson, J., and Lindberg, N.-0., Drug Dev. and Ind. Pharmacy 9 (8), 1495-1505 (1983).

Arumbolo, A.S., Drug Dev. and Ind. Pharmacy 5, 523 (1979).

Banker, G.S., Peck, G.E., and Baley, G., in "Pharmaceutical Dosage Forms: Tablets ", vol.1 eds. Lieberman, H.A., and Lachman, L., Marcel Dekker, Inc., New York (1980) p.61.

Berry, I.R., "Process validation of Raw materials", Pharmaceutical Technology 2, 38-39 (1981).

Bier, H.P., Leuenberger, H., and Sucker, H., Pharm. Ind., 41, 375-80 (1979).

Butler, Q.A., and Ramsey, J.C., Drug Std., 20, 217 (1952).

Byers, T.E., "Role of Product and Process Design in Assuring Quality", Good Manufacturing Practice Conference, Cherry Hill, NJ (Feb., 1977).

Byers, T.E., "Validation: A systematic Approach to quality Assuarance". Pharm. Tech. Conference, New York, NY (Sep., 1981).

Capes, C.E., " Proceedings of Powtech 71 ", Hargate, England, Powder Advisory Center, London (1972) p.149.

Capes, C.E., and Danckwerts, P.V., Trans. Inst. Chem. Eng., 43, T 116 (1965).

Capes, C.E., Germain, R.J., and Coleman, R.D., Ind. Eng. Chem. Process Des. Dev., 16, 517 (1977).

Carr, R.L., Chem. Eng., 72, 163 (January 1965).

Carstensen, J.T., Lai, T., Flickner, D.W., Huber, H.E., and Zoglio, M.A., J. Pharm. Sci., 65, 992 (1976).

Carstensen, J.T., and Zoglio, M.A., J. Pharm. Sci., 71(1), 35 (1982).

Chalmers, A.A., and Elworthy, P.H., J. Pharm. Pharmac., 28, 228-233 (1976).

Ibid., 28, 234-238 (1976). 


\section{BIBLIOGRAPHY (continued)}

Chowhan, Z.T., J. Pharm. Sci., 69(1), 1 (1980).

Chowhan, Z.T., and Yang, I.C., J. Pharm. Sci., 72(9), 983, (1983).

Cooper, J., in Bean, H.S., et al.,eds: "Advances in Pharmaceutical

Sciences ", vol. 3, Acadamic, New York, (1971).

Cooper, J., and Rees, J.E., J. Pharm.Sci., 61, 1511, (1972).

Esezobo, S., and Pilpe1, N., J. Pharm. Pharmac., 26, Suppl., 47P-56P (1974).

Evans, A.J., and Train, D., in "Bibliography of the Tableting of Medicinal Substances "1st suppl, Pharmaceutical Press, London (1963).

Federal Register, vol, 43-No 190 9/29/70 pages 45013-45089 U.S Printing Office, Washington, D.C.

Finholt, P., in " Dissolution Technology ", Leeson, L., and Carstensen, J.T., A.Ph.A. Academy of Pharmaceutical Sciences, Washington, D.C. (1974).

Fisher, R.A., J. Agr. Sci., 16, 492 (1926).

Ibid., 18, 406 (1928).

Flesch, C.J., Pharm. Ind., 40, 758 (1978).

Fonner Jr., D.E., Banker, G.S., and Swarbrick, J., J. Pharm. Sci., 55 (2), 181 (1966).

Fry, W.C., Stagner, W.C., and Wichman, K.C., J. Pharm. Sci., $73(3), 420-421$ (1984).

Ganderton, D., and Hunter, B.M., J. Pharm. Pharmac., 23, Suppl., 1s-10s (1971).

Ganderton, D., and Selkirk, A,B., J. Pharm. Pharmac., 24, Suppl., 17P-24P (1972).

Guncel, W.C., Swartz, C.J., and Kanig, J.L., in " The Theory and Practice of Industrial Pharmacy " eds. Lachman, L., Lieberman, H.A., and Kanig, J.L., Lea \& Febiger, Philadelphia, PA (1970).

Haines, W.B., J. Agr. Sci., 20, 97 (1930).

Hardesty, J.0., Chem. Eng. Prog., 51, 291 (1955). 
BIBLIOGRAPHY (continued)

Hardesty, J.0., Szabo, A., and Cummings, J.G., J. Agric. Food Chem., 4, 60 (1956).

Hardesty, J.0., Chem. Eng. Progr. Symp. Ser., 60 (48), 46-52 (1964).

Harpaz, D., "Process Evaluation / Validation of Solid Dosage Forms", Pharm. Tech. Conference, New York, NY (Sep., 1981).

Hegde, R.P., and Rhodes, C.T., Pharm. Acta. Helv. 60 (2), 53 (1985).

Holm, P., Jungersen, 0., Schaefer, T., and Kristensen, H.G., Pharm. Ind. 45 (8), 806 (1983).

Ibid., 46 (1), 97 (1984).

Hunter, B.M., and Ganderton, D., J. Pharm. Pharmac., 25, suppl., 71p-78p (1973).

Hunter, B.M., and Ganderton, D., J. Pharm. Pharmac., 24, Suppl., 47P-56P (1974).

Hutchins, H.H., Cacosa, A.G., Hart, E.G., and Stienberg, W.H., J. Pharm. Sci., 54, 776 (1965).

Jaegerskou, A., Holm, P., Schaefer, T., and Kristensen, H.G., Pharm. Ind., 46 (3), 310 (1984).

Jaiyeoba, K.T., and Spring, M.S., J. Pharm. Pharmac., 31, 197-200 (1979).

Jordan, R.P., and Rhodes, C.T., Drug Dev. and Ind. Pharmacy 5 (2), 151-167 (1979).

Kapur, P.C., Chem. Eng. Sci., 27, 1863 (1972).

Kapur, P.C., Arora, S.C.D., and Subbarao, S.V.B., Chem. Eng. Sci., 28, 1535 (1973).

Kapur, P.C., and Fuerstenau, D.W., Trans. AIME 229, 348 (1964)

through The Eng. Index p.1152 (1965).

Kapur, P.C., and Fuerstenau, D.W., Ind. Eng. Chem. Process Des. Dev., 5 (1), 5 (1966).

Kay, D., and Record, P.C., Mfg. Chemist and Aer. News 49 (9), 45 (1978).

King, R.E., in "Remington Pharmaceutical Sciences ", vol.16, Mack

Publishing Company, Eaton, PA (1980) p. 1553 - 1584. 


\section{BIBL IOGRAPHY (cont inued)}

Kristensen, H.G., Holm, P., Jaegerskou, A., and Schaefer, T., Pharm. Ind., 46 (7), 763 (1984).

Kumkumian, C., "0.K, your Candidate Drug has Activity. Now what?" Chem. Tech., 3, 178-180 (1980).

Lebow Products Catalog No: 250 C, Eaton Corporation, Troy, MI

Leuenberger, H., Pharm. Acta. Helv., 57, 72 (1982).

Leuenberger, H., Bier, H.P., and Sucker, H., Pharm. Tech. Int., 2 (3), 35-42, (1979).

Lindberg, N.-0., Leander, L., Nilsson, P.G., and Reenstierna, B., Acta Pharm. Suecica 14, 191-196 (1977).

Lindberg, N.-0., Leander, L., and Lamm, C.J., Acta Pharm. Suecica 18,102 (1981).

Lindberg, N.-0., Leander, L., and Reenstierna, B., Drug Dev. and Ind. Pharmacy $8(5), 775-782$ (1982).

Lindberg, N.-0., Leander, L., Wenngren, L., Helgesen, H., and Reenstierna, B., Acta Pharm. Sueciaca 11, 603-620 (1974).

Linkson, P.B., Glastonbury, J.R., and Duffy, G.J., Trans. Inst.Chem. Eng., 51, 251 (1973).

Loftus, B.E., "Validation Protocol: The Bottom line, Proprietary Association" Manufacturing control seminar, Cherry Hill, NJ (Oct.9, 1980).

Mehta, A., Adams, K., Zoglio, M.A., and Carstensen, J.T., J. Pharm. Sci., 66, 1462 (1977).

Mendes, R.W., and Roy, S.B., Pharm. Tech., 2 (Sept):61, (1978).

Nagykaldi, A., and Gyarmati, L., Pharm. Ind., 42, 526 (1980).

Newitt, D.M., and Conway-Jones, J.M., Trans. Inst. Chem. Engr., 36, 422-442 (1958).

Opankunle, W.0., and Spring, M.S., J. Pharm. Pharmac., 28, 508-511 (1976).

Ibid., 28, 806-809 (1979).

Paris, L., and Stamm, A., Drug Dev. and Ind. Pharmacy 11 (2\&3), 361-386 (1985). 
BIBL IOGRAPHY (continued)

Paruta, A.N., Irani, Shapur A., J. Pharm. Sci., 54, 9 (1965).

Paruta, A.N., Sciarrone, B.J., and Lordi, N.G., J. Pharm. Sci., 54, 6 (1965).

Pietsch, W., Trans. ASME B 91 (2), 435 (1969).

Pietsch, W., and Rumpf, H., Chem. Ing. Tech., 38 (3), 371 (1966).

Pietsch, W., Can. J. Chem. Eng., 47, 403 (1969).

Record, P.C., Ibid., (11), 65 (1979).

Ridgeway, K., and Rubenstein, M.H., J. Pharm. Pharmac., 23, Suppl., $11 s-17 s(1971)$.

Rippie, E.G., chap. Mixing in " Theory and Practice of Industrial Pharmacy", eds. Lackman, L., Lieberman, H., and Kanig, J., 2d.ed. Lea \& Febiger, Philadelphia, PA (1976).

Rudolph, J.S., chap. Validation of Solid Dosage Forms in "Pharmaceutical Process Validation", ed. Loftus, B.T., and Nash, R.A., Marcel Dekker, Inc., New York, NY (1984).

Rumpf, H., Chem. Ing. Tech., 30, 144 (1958) through The Eng. Index p.528 (1958).

Ibid., 46, 1 (1974).

Rumpf, H., Chap. The strength of granules and agglomerates, in

"Agglomeration ", ed. Knepper, W.A., Wiley - Interscience, New York (1962).

Samyn, J.C., "New Product Validation Begins in R \& D", Pharmaceutical Manufacturers Association seminar on validation, Atlanta, Georgia, (May, 1980).

" SAS Users Guide, " 1984 ed., SAS Institute, Cary, NC

Sastry, K.V.S., and Fuerstenau, D.W., Powder Technology 7, 97-105 (1973).

Schildcrout, S.A., J. Pharm. Pharmac., 36, 502-505 (1984).

Schwartz, P.A., Rhodes, C.T., Cooper, J.W. Jr., J. Pharm. Sci., 66, 994 (1977). 


\section{BIBL IOGRAPHY (continued)}

Sherrington, P.J., Chem. Eng., 220, 201 (1968).

Ibid., Pharm. Tech., 3, 61-68 (June 1979).

Sherrington, P.J., and 01 iver, R., "Granulation ", Heydon \& Son, Ltd., London (1981) p.1.

Sheth, B.B., Bandelin, F.J., and Shangraw, R.F., in "Pharmaceutical Dosage Forms: Tablets ", vol.1 eds. Lieberman, H.A., and Lachman, L., Marcel Dekker, Inc., New York (1980).

Shotton, E., and Leonord, G.S., J. Pharm. Sci., 65(8), 1173 (1976). Spring, M.S., Drug Dev. and Ind. Pharmacy 9 (8), 1507-1512 (1983). Stamm, A., and Paris, L., Drug Dev. and Ind. Pharmacy 11 (2\&3) 333-360 $(1985)$.

Steiner, G., Patel, M., and Carstensen, J.T., J. Pharm. Sci., 63(9), 1397 (1974).

Tainsh, D.A., and Summers, M.P., J. Pharm. Pharmac., 34, supp1, 47p (1982).

"The United States Pharmacopoeia ", 20th ed., United States Pharmacopoeial Convention, Inc., Rockville, Maryland (1980).

Titley, P.C., J. Pharm. Pharmac., 35, supp1. 111p (1983).

Toyoshima, S., Watanabe, S., Matsuo, K., and Kasai, M., Yakugaku Zasshi 91, 1088 (1971).

Travers, D.N., Rogerson, A.G., and Jones, T.M., J. Pharm. Pharmac., 27, $3 p(1975)$.

Von Doehran, P.J., "An Approach to the characterization of Solid Dosage Forms", Pharm. Tech. Conference, New York, NY (Sep.,1981).

Zoglio, M.A., and Carstensen, J.T., Drug Dev. and Ind. Pharmacy 9 (8), 1417, (1983).

Zoglio, M.A., Huber, H.E., Koehne, G., Chan, P.I., and Carstensen, J.T., J. Pharm. Sci., 65, 1205 (1976).

\footnotetext{
* The word through refers, abstract was read through a secondary source.
} 